SERVIÇO DE PÓS-GRADUAÇÃO DO ICMCUSP

Data de Depósito:

Assinatura:

\title{
Simulação e modelamento da retina sensorial
}

\author{
Leandro Paganotti Brazil
}

Orientador: Prof. Dr. Odemir Martinez Bruno

Dissertação apresentada ao Instituto de Ciências Matemáticas e de Computação - ICMC-USP, como parte dos requisitos para obtenção do título de Mestre em Ciências - Ciências de Computação e Matemática Computacional.

USP - São Carlos

Agosto 2009 

Simulação e modelamento da retina sensorial

Leandro Paganotti Brazil 

Aos meus pais, Evanilda e Leovaldo e minhas irmãs, Kellen e Fabiana. 



\section{Agradecimentos}

A Deus, por tudo e sempre.

Aos meus pais, Evanilda e Leovaldo, que me proporcionaram uma dedicada e carinhosa educação e me transformaram na pessoa que sou. Sem dúvida, são os grandes responsáveis na realização de mais uma importante etapa da minha vida.

Às minhas irmãs, Kellen e Fabiana, por todo o amor, carinho, compreensão e respeito.

Ao meu orientador, Professor Doutor Odemir Martinez Bruno, que me ajudou a solucionar os problemas e a encontrar o caminho para finalização deste trabalho. Agradeço também pelo conhecimento transferido e por sua amizade.

Agradeço a Professora Doutora Rosane Minghim pela convivência, pelas conversas de apoio e pela confiança deposita. Minha admiração e respeito.

Agradeço às pessoas que estiveram presentes em minha vida e que contribuíram de forma direta ou indireta com o desenvolvimento deste trabalho. Aos amigos que sempre dividimos as alegrias, as tristezas e as fúrias. Obrigado a todos e todas!

E à FAPESP, o apoio financeiro foi indispensável para conclusão deste trabalho. 



\section{Resumo}

A visão é o sentido humano mais complexo e importante para os processos de cognição e de interação de um indivíduo com o mundo. Neurofisiologistas buscam identificar e compreender como funcionam os mecanismos celulares envolvidos neste processo. O sistema visual recebe os sinais de imagens captadas pelos olhos e, por meio de transformações e processamento diversos, integra esses sinais em representações de objetos internos perceptuais. O projeto Olho Virtual consegue reconstruir, em três dimensões, modelos de olhos utilizando córneas reais ou simuladas em computador, reproduzindo suas propriedades ópticas captando imagens de maneira satisfatória. Este trabalho introduz, no projeto Olho Virtual, um modelo computacional de retina baseado no modelo biológico, capaz de reproduzir as propriedades das células cones e bastonetes em suas distribuições radiais e também em suas funcionalidades em particular. Além dessa, é apresentado uma modelagem para reprodução dos campos receptivos das células ganglionares presentes na retina, gerando sinais de saída nos sistemas parvo e magno. Por fim, são feitas simulações de experimentos psicofísicos com propósito de verificar a validade da modelagem proposta. 



\section{Abstract}

The vision is the human sense more complex and important in cognitive processes and the interaction of an individual with the world. Neurophysiologists seek to identify and understand how the cellular mechanisms involved in this process work. The visual system receives the image signals captured by the eyes and, through several transformations and processing, integrate those signals into internal representations of perceptual objects. The project Virtual Eye can reconstruct three-dimensional models of eye corneas using real or simulated on the computer, playing their optical properties capturing images satisfactorily. This work introduces the Virtual Eye project, a computational model of retina-based biological model, able to reproduce the properties of rod and cone cells in their radial distributions and also in its functionality in particular. Besides this, a model is presented for reproduction of the receptive fields of ganglion cells present in the retina, generating output signals in the parvo and magno systems. Finally, simulations are made with psychophysical experiments in order to verify the accuracy of the proposed model. 



\section{Sumário}

Sumário

vii

Lista de Figuras

xi

Lista de Tabelas

xix

Lista de Algoritmos

$\mathrm{xxi}$

1 Introdução 1

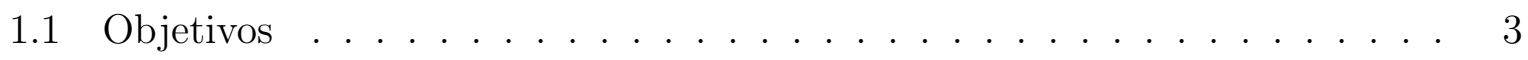

1.2 Organização do texto . . . . . . . . . . . . . . . . . . 3

2 Conceitos básicos da visão e óptica 5

2.1 Sistema visual humano . . . . . . . . . . . . . . . . . . . 5

2.1 .1 O Olho Humano . . . . . . . . . . . . . . . . . . . . 6

2.1.2 Funções dos olhos . . . . . . . . . . . . . . . . . . . . . 8

2.1 .3 Formação da imagem . . . . . . . . . . . . . . . . . . . 9 9

2.2 Óptica geométrica . . . . . . . . . . . . . . . . . . . . 9

2.2.1 Formação de imagens em um sistema óptico . . . . . . . . . . . . . 11

2.2.2 Sistemas ópticos complexos formados por lentes espessas . . . . . . 13

2.3 Óptica do olho . . . . . . . . . . . . . . . . . . 14

2.3.1 Eixos do olho . . . . . . . . . . . . . . . . . 15 
2.3.2 Modelos esquemáticos de olhos . . . . . . . . . . . . . . 16

3 Retina: anatomia geral e fisiologia $\quad 19$

3.1 Camadas da retina . . . . . . . . . . . . . . . . . . . . 19

3.2 Conexões sinápticas entre as camadas da retina . . . . . . . . . . . . 20

3.3 Dois caminhos paralelos . . . . . . . . . . . . . . . . . . 22

3.4 Fotorreceptores . . . . . . . . . . . . . . . . . . 22

3.5 Visão central versus visão periférica . . . . . . . . . . . . . . . . . 23

3.5.1 Distribuição dos receptores . . . . . . . . . . . . . . . . . . . . . . 24

3.6 Patologias da retina . . . . . . . . . . . . . . . . . . 25

3.7 Sinais de saída da retina . . . . . . . . . . . . . . . . . . . . 27

3.7.1 Campos receptivos . . . . . . . . . . . . . . . . 27

3.7 .2 Detecção de bordas . . . . . . . . . . . . . . . . . . . . . . 31

4 Trabalhos relacionados $\quad 33$

4.1 Transformação Log-Polar . . . . . . . . . . . . . . . . . . . . . . 33

4.2 Filtro bioinspirado . . . . . . . . . . . . . . . . . 35

4.3 Retina artificial com campos receptivos $D o G \ldots \ldots$. . . . . . 36

4.4 Simulação de visão na retina biológica . . . . . . . . . . . . . . . . 37

4.5 Campos Receptivos de Marr-Hildreth . . . . . . . . . . . . . . . . . . 38

5 Olho virtual $\quad 41$

5.1 Modelagem ............................ 41

5.1.1 Modelagem por quádricas . . . . . . . . . . . . . . . . . . 42

5.1 .2 Modelagem por malhas . . . . . . . . . . . . . . . 43

5.1 .3 Modelagem in-vivo . . . . . . . . . . . . . . . . . 45

5.2 Simulação . . . . . . . . . . . . . . . . . . . . . 46

5.2 .1 Traçado de raios . . . . . . . . . . . . . . . 46

5.2 .2 Projeção de cones . . . . . . . . . . . . . . . . . . . . 49

5.2 .3 Cálculo das propriedades paraxiais . . . . . . . . . . . . . 51

5.3 Visualização . . . . . . . . . . . . . . . . . . . . . . . 51

5.4 Óptica e Simulações no Olho Virtual . . . . . . . . . . . . . . . . 52 
5.4 .1 Propriedades gaussianas . . . . . . . . . . . . . . 52

5.4 Diagrama de pontos ................... 54

6 Simulação de ametropias no Olho Virtual $\quad 57$

6.1 As ametropias . . . . . . . . . . . . . . . . . . . 58

6.2 Induzindo erros de refração no Olho Virtual . . . . . . . . . . . . . . . . . 60

6.3 Lente divergente da miopia . . . . . . . . . . . . . . . . . . 62

6.4 Lente convergente da hipermetropia . . . . . . . . . . . . . . . . . 62

7 Modelagem da retina no Olho Virtual $\quad 67$

7.1 Visão geral . . . . . . . . . . . . . . . . . . . . . . . 68

7.2 Projeção e mapeamento . . . . . . . . . . . . . . . . . . 70

7.3 Anéis concêntricos . . . . . . . . . . . . . . . . . 73

7.4 Receptores . . . . . . . . . . . . . . . . . 74

7.4.1 Relação de aspecto de um setor $(\gamma) \ldots$. . . . . . . . . 78

7.4.2 Funcionalidades das células receptoras . . . . . . . . . . . . . . 79

7.5 Mapeamento de patologias . . . . . . . . . . . . . . . 80

7.5.1 Mapeando as degenerações . . . . . . . . . . . . . . . . . . . 80

7.5.2 Mapeamento da patologia no VEye . . . . . . . . . . . 82

7.6 Campos receptivos . . . . . . . . . . . . . . . 83

8 Simulações e resultados $\quad 85$

8.1 Simulação das ametropias . . . . . . . . . . . . . . . . 85

8.2 Fóvea versus periferia . . . . . . . . . . . . . . . . . . 88

8.3 Cone versus bastonetes . . . . . . . . . . . . . . . . . . 96

8.4 Patologias da retina . . . . . . . . . . . . . . . . . . . . 99

8.5 Campos receptivos . . . . . . . . . . . . . . . . . 101

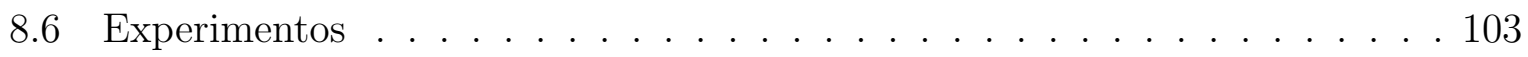

8.6.1 Acuidade Visual . . . . . . . . . . . . . . . . . 103

8.6 .2 Hermann Grid . . . . . . . . . . . . . . . . . 106

8.6 .3 Mach Bands . . . . . . . . . . . . . . . . . . . . . . . 109

8.6.4 Contraste simultâneo . . . . . . . . . . . . . . . . . . . . 113 
9 Conclusão e perspectivas futuras

Referências Bibliográficas 


\section{Lista de Figuras}

2.1 Diagrama esquemático do olho humano. Extraído de (AS00) . . . . . . . 6

2.2 Representação óptica do olho focalizando uma árvore. Ponto C é o centro óptico do cristalino. Extraído de $(\mathrm{GW} 92)$. . . . . . . . . . . . . . . 10

2.3 Ilustração dos raios incidente, refletido e de refração sobre uma superfície. Extraído de (Yun04). . . . . . . . . . . . . . . . . . . . 10

2.4 Formação de imagem por um sistema óptico. Extraído de (PP98). . . . . . 12

2.5 Ilustração dos pontos cardinais.(a) e (b) ilustração dos pontos focais e pontos principais. (c) ilustração dos pontos nodais. . . . . . . . . . . . . . . . 14

2.6 Ilustração dos eixos no olho humano. Estraído de (AS00) . . . . . . . . . . 16

3.1 Relações entre as células da retina. Extraído de (Gol02) . . . . . . . . . . . 21

3.2 Distribuição das células receptoras na retina, produzido por Osterberg (1935) e adaptado por Lindsay e Norman (1977). Extraído de (Gol02). . 25

3.3 Organização das celulas na retina no disco óptico.Extraído de (Gol02) . . . 25

3.4 Foto tirada de uma retina (a) normal e (b) uma retina diabética. Extraído de $(\operatorname{Hos} 08) \ldots \ldots \ldots \ldots \ldots \ldots$

3.5 Resposta de um campo receptivo sob estímulo em diferentes regiões. (a) Fora do campo receptivo (área A). (b) Dentro da área excitatória do campo receptivo (área B). (c) Dentro da área inibitória do campo receptivo (área

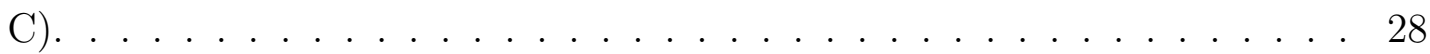


3.6 Resposta dos campos receptivos ON e OFF com arquitetura center-surround. Extraído de (EK00)

3.7 Gráfico mostrando como o tamanho do campo receptivo aumenta em relação a distância da fóvea. Extraído de $(\mathrm{SB} 90)$. . . . . . . . . . . . . 30

3.8 Detecção de bordas via arquitetura center-surround. A: Campos receptivos center-surround em diferentes locais. B: Correspondentes taxas de respostas das atividades das células $\mathrm{ON}$ e OFF ao longo de uma linha unidimensional perpendicular a borda. . . . . . . . . . . . . . . . . 32

4.1 Lado esquerdo Plano de coordenadas cartesianas e Lado direito plano de coordenadas log-polar.. . . . . . . . . . . . . . . . . 34

4.2 (a) Imagem original. (b) Inverso da distribuição log polar. . . . . . . . . . 35

4.3 Distribuição dos pontos em função da excentricidade. . . . . . . . . . . . 36

4.4 (a) Imagem original. (b) Resultado da aplicação do filtro. . . . . . . . . . . 36

4.5 (a) Imagem original. (b) Distribuição celular. (c) Capos receptivos DoG. . 37

4.6 Matrizes de células da retina. . . . . . . . . . . . . . . . . . . . . 38

4.7 (a) Imagem original. (b) Atividade das células ganglionares na retina. . . . 39

4.8 Representação do filtro de Marr-Hildreth. . . . . . . . . . . . . . . . . . . . 39

5.1 Posição do Olho Virtual no sistema de coordenadas cartesianas. O eixo $x$ está saindo do papel. A origem do sistema de coordenadas é o vértice da córnea. . . . . . . . . . . . . . . . . . . . . . . . 4 42

5.2 Malha inicial $\mathbf{M}$ composta pelos cinco vértices iniciais. O prisma delimita a malha.

5.3 Malha inicial com (a) duas camadas e (b) quatro camadas. . . . . . . . . 44

5.4 Esquema de refinamento da malha. o triângulo $t=\Delta v_{i} v_{i+1} v_{i+2}$ é removido e os demais triângulos $t_{1}=\Delta v_{i} v_{k+1} v_{k}, t_{2}=\Delta v_{k+1} v_{i+1} v_{k+2}, t_{3}=$ $\Delta v_{k} v_{k+2} v_{i+2}$ e $t_{4}=\Delta v_{k} v_{k+1} v_{k+2}$ são adicionados à malha. . . . . . . . . . 44

5.5 Duas camadas com número de refinamentos diferentes. . . . . . . . . . 45

5.6 Modelo de uma retina com quatro camadas. . . . . . . . . . . . . . 46

5.7 Malhas geradas por (a) dados simulados (b) dados reais. . . . . . . . . 47

5.8 Princípio de "Door in-Door out". . . . . . . . . . . . . . . . . 49 
5.9 Projeção de cones e o conjuntos de pontos $\mathbf{W}$ formado na retina. . . . . . . 50

5.10 Tra,cado de raio paraxial em uma superfície de refração $S_{j}$. r é o raio de curvatura de $S_{j}$ e $C$ é o centro de curvatura. O raio incidente $l$ intercepta $S_{j}$ em $B$ com normal $N$. O raio refratado $l^{\prime}$ é propagado até a próxima superfície $S_{j}+1$. $\phi$ e $\phi^{\prime}$ são os ângulos de incidência e refração respectivamente. ......................... 52

5.11 Diagrama de pontos do modelo de Le Grand não acomodado e o padrão airy disc. (a) $R=1 \mathrm{~mm}, R M S=0.0019 \mathrm{~mm}, \rho^{\prime}=0.0053 \mathrm{~mm}$ e $D_{a}=$ $0.0037 \mathrm{~mm}$; (b) $R=2.0 \mathrm{~mm}, R M S=0.0250 \mathrm{~mm}, \rho^{\prime}=0.0680 \mathrm{~mm}$ e $D_{a}=$ $0.0019 \mathrm{~mm}$ e (c) $R=1,0 \mathrm{~mm}, \alpha=5^{\circ}, R M S=0.0023 \mathrm{~mm}, \rho^{\prime}=0.0010 \mathrm{~mm}$ e $D_{a}=0.0037 \mathrm{~mm} \ldots \ldots \ldots \ldots \ldots \ldots \ldots$

5.12 Diagrama de pontos do modelo de Le Grand acomodado e o padrão airy disc. (a) $R=1 \mathrm{~mm}, R M S=0.0048 \mathrm{~mm}, \rho^{\prime}=0.0110 \mathrm{~mm}$ e $D_{a}=0.0066 \mathrm{~mm}$; (b) $R=2.0 \mathrm{~mm}, R M S=0.0373 \mathrm{~mm}, \rho^{\prime}=0.0943 \mathrm{~mm}$ e $D_{a}=0.0033 \mathrm{~mm}$ e (c) $R=1.0 \mathrm{~mm}, \alpha=5^{\circ}, R M S=0.0058 \mathrm{~mm}, \rho^{\prime}=0,0200 \mathrm{~mm} \mathrm{e}$ $D_{a}=0.0066 \mathrm{~mm}$.

6.1 Um olho míope sem correção e uma lente corretiva divergente. Extraído de (Yun04).

6.2 Um olho hipermetrope sem correção e uma lente corretiva convergente. Extraído de (Yun04).

6.3 As imagens de linhas verticais se formam em planos diferentes das linhas horizontais para este olho com astigmatismo. Extraído de (Yun04). . . . . 60

6.4 O desvio $d$ da retina é positivo na miopia e negativo na hipermetropia. $\quad$. 60

6.5 Lente divergente e o raio refratado. . . . . . . . . . . . . . 63

6.6 Lente convergente e o raio refratado. . . . . . . . . . . . . . . . . . 64

7.1 Conjuntos de pontos $\Omega$ gerados para constituir a imagem e plano de projeção

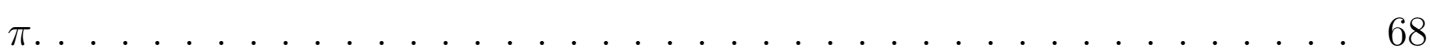

7.2 Diagrama com o fluxo de execução do software. . . . . . . . . . . . . . . 69 
7.3 (a) Projeção perspectiva, onde os pontos a serem projetados são os pontos da esfera (retina) e a superfície de projeção é o plano $(\pi)$. (b) Projeção paralela, onde os pontos a serem projetados são os pontos do plano $(\pi)$ e a superfície de projeção é a esfera $($ retina $) \ldots$. . . . . . . . . . . . . . 71

7.4 (a) Anéis concêntricos na superfície da retina. (b) Anéis concêntricos na no plano de projeção imagem $\mathrm{PGM}(\mathrm{mxn}) . \quad$. . . . . . . . . . . . . . . . . 73

7.5 Densidade das células receptoras nas excentricidade da retina. . . . . . . . 75

7.6 (a) Anel com densidade máxima, toda a luz incidente neste anel será detectada. (b) Anel com densidade baixa, grande parte da luz incidente nesse anel é perdida, pois não há receptores para detectá-la. . . . . . . . . . . . . 76

7.7 Resolução de um anel em $(\rho, \theta))$. . . . . . . . . . . . . . . . . 77

7.8 (a) Distribuição das células cones. (b) Distribuição das células bastonetes. 79

7.9 Relação de aspecto de um setor. . . . . . . . . . . . . . . . . . . . 80

7.10 Um exemplo da execução do software e suas ferramentas. . . . . . . . . . . 82

7.11 Mapeamento da imagem de retina degenerada com a retina no VEye . . . 83

7.12 Mapeamento de células degeneradas na distribuição das células cones . . . 83

8.1 Imagens geradas pela simulação de olhos míopes no modelo de $l g r_{u} . \mathrm{m} .=$ miopia, m.l.d $=$ miopia e lente divergente. . . . . . . . . . . . . 86

8.2 Imagens geradas pela simulação de olhos hipermétropes no modelo de $l g r_{a}$. h. $=$ hipermetropia, h.l.c $=$ hipermetropia e lente convergente. . . . . . . 87

8.3 (a)Círculo de confusão em olhos míopes com e sem o uso de lentes divergentes. (b) Círculo de confusão em olhos hipermétropes com e sem o uso de lentes convergentes. . . . . . . . . . . . . . . . . . 87

8.4 (a) Espaço reservado a imagem original. (b) Distribuição $D_{1}$ dos cones para imagens formadas somente na fóvea. (c) $D_{2}$ Distribuição dos cones para imagens formadas nas regiões da fóvea e periferia com excentricidades de $0^{\circ}$ a $16^{\circ}$. (d) $D_{3}$ Distribuição dos cones para imagens formadas nas regiões da fóvea e periferia com excentricidades de $0^{\circ}$ a $50^{\circ} \ldots \ldots$. . . . . . . 89 
8.5 Resultado das simulações de formação de imagem pelas células cones. (a) Imagem original. (b) Imagem formada na fóvea $\left(D_{1}\right)$. (c) Imagem formada na fóvea e periferia $\left(D_{2}\right)$. (d) Imagem formada na fóvea e periferia $\left(D_{3}\right) . \quad$. 90

8.6 Ampliação feita na imagem formada nas regiões de fóvea e periferia. . . . . 91

8.7 Densidade de cones em $D_{3}$. (a) Área dada em $\mathrm{mm}^{2}$. (b) Área dada em quantidade de pixels. . . . . . . . . . . . . . . . . . . . . 91

8.8 Resultado das simulações de formação de imagem pelas células cones. (a) Imagem original. (b) Imagem formada na fóvea $\left(D_{1}\right)$. (c) Imagem formada na fóvea e periferia $\left(D_{2}\right)$. (d) Imagem formada na fóvea e periferia $\left(D_{3}\right)$. . 92

8.9 Resultado das simulações de formação de imagem pelas células cones. (a) Imagem original. (b) Imagem formada na fóvea $\left(D_{1}\right)$. (c) Imagem formada na fóvea e periferia $\left(D_{2}\right)$. (d) Imagem formada na fóvea e periferia $\left(D_{3}\right)$. . 93

8.10 Resultado das simulações de formação de imagem pelas células cones. (a) Imagem original. (b) Imagem formada na fóvea $\left(D_{1}\right)$. (c) Imagem formada na fóvea e periferia $\left(D_{2}\right)$. (d) Imagem formada na fóvea e periferia $\left(D_{3}\right)$. $\quad 94$

8.11 Resultado das simulações de formação de imagem pelas células cones. (a) Imagem original. (b) Imagem formada na fóvea $\left(D_{1}\right)$. (c) Imagem formada na fóvea e periferia $\left(D_{2}\right)$. (d) Imagem formada na fóvea e periferia $\left(D_{3}\right)$. $\quad 95$

8.12 (a) Imagem experimental com alto contraste. (b) Imagem experimental com baixo contraste. . . . . . . . . . . . . . . . . 96

8.13 (a) Imagem da Figura 8.12(a) formada pela atuação das células cones. (b) Imagem da Figura 8.12(b) formada pela atuação das células cones. . . . . . 97

8.14 Imagem da Figura 8.12(b) formada pela atuação das células bastonetes. 97

8.15 (a) Imagem original com interruptor no foco. (b) Resposta das células cones para imagem (a). (c) Resposta das células bastonetes para imagem (a). (d) Imagem original com interruptor fora do foco. (e) Resposta das células cones para imagem (d). (f) Resposta das células bastonetes para imagem $(\mathrm{d}) \ldots \ldots \ldots \ldots$

8.16 (a) e (c) Imagens originais das retinas com as degenerações. (b) e (d) Mapeamentos feitos no programa de Degenerações. . . . . . . . . . . . . . 99 
8.17 Resultados de simulações de mapeamento de patologias na retina. . . . . . 100

8.18 (a) Campos receptivos On-Center Off-Surround. (b) Campos receptivos Off-Center On-Surround. (c) Campos receptivos como detector de bordas. 101

8.19 (a) Campos receptivos On-Center Off-Surround. (b) Campos receptivos Off-Center On-Surround. (c) Campos receptivos como detector de bordas. 102

8.20 (a) Campos receptivos On-Center Off-Surround. (b) Campos receptivos Off-Center On-Surround. (c) Campos receptivos como detector de bordas. 102

8.21 Demonstração da acuidade visual. Experimento extraído de (Gol02). . . 103

8.22 Resultado da simulação de acuidade visual na retina do Olho Virtual gerado como resposta das células cones. . . . . . . . . . . . . . . . . . . . . . . . 104

8.23 Anéis de Landolt, usado em testes de acuidade visual. Experimento extraído de (Gol02). . . . . . . . . . . . . . . . . . . . . . . . 104

8.24 Simulação dos anéis de Landolt na retina do VEye. (a) Distribuição dos cones utilizada. (b) Respostas das células cones diante da imagem dos anéis de Landolt. . . . . . . . . . . . . . . . . . . . . . . . . 105

8.25 Demonstração de Stuart Anstis. Todas as letras neste quadrado devem ser legíveis quando o ponto central é focalizado. Experimento extraído de (SB90).

8.26 Simulação dos anéis de Landolt na retina do Olho Virtual. (a) Distribuição dos cones utilizada. (b) Respostas das células cones diante da imagem de Stuart. . . . . . . . . . . . . . . . . 107

8.27 Ilusão de Hermann Grid. Manchas escuras aparecem nas intersecções das barras brancas e desaparecem quando se olha fixamente para elas. Experimento extraído de (SB90) . . . . . . . . . . . . . . . . 108

8.28 Possível explicação para Hermann Grid. . . . . . . . . . . . . . . . . . 108

8.29 Possível explicação para Hermann Grid no ponto de fixação. ....... 109

8.30 Simulação dos campos receptivos para ilusão de Hermann Grid. (a) Região periférica. (b) Ponto de fixação. . . . . . . . . . . . . . . . . . . . . . 109

8.31 Simulação dos campos receptivos para ilusão de Hermann Grid no ponto de fixação e nas regiões periféricas. 
8.32 A intensidade de luz varia no padrão, mas é constante dentro de cada faixa. Experimento extraído de (SB90). . . . . . . . . . . . . . . . 111

8.33 Possivel explicação para Mach Bands com campos receptivos On-Center Off-Surround. . . . . . . . . . . . . . . . . . 111

8.34 Resultado gerado pela simulação dos campos receptivos On-Center OffSurround dos gânglios parvos para imagem de Mach Bands. . . . . . . . . 112

8.35 Taxa de resposta dos campos receptivos ao longo do padrão Mach Bands. . 112

8.36 Contraste Simultâneo. Os dois quadrados centrais refletem a mesma quantidade de luz, mas parecem diferentes. Experimento extraído de (Gol02). 113

8.37 Possível explicação para contraste simultâneo usando campos receptivos On-Center Off-Surround. . . . . . . . . . . . . . . 113 



\section{Lista de Tabelas}

2.1 Modelo Le Grand não acomodado. . . . . . . . . . . . . . . . . . . . . . 17

2.2 Modelo Le Grand acomodado A=7.053D . . . . . . . . . . . . . . . . . . 17

2.3 Modelo Liou-Brennan não acomodado. . . . . . . . . . . . . . . . . . . . . 17

2.4 Constantes da Equação 2.5 que descreve a distribuição do índice de refração na porção anterior $n_{A}$ e posterior $n_{P}$ do cristalino. . . . . . . . . . . . 18

3.1 Comparações de cones e bastonetes. . . . . . . . . . . . . . . . . 23

5.1 Propriedades Gaussianas de Le Grand $\operatorname{lgr}_{a} A=6.96 \mathrm{D}$. . . . . . . . . . . 53

5.2 Propriedades Gaussianas de Le Grand não acomodado $\operatorname{lgr}_{u}$. . . . . . . . . 53

5.3 propriedades Gaussianas de Liou-Brennan $l b r_{u}$. . . . . . . . . . . . . . . . 54 



\section{Lista de Algoritmos}

6.3 .1 Lente Divergente da Miopia $\left(R, V_{l}, z_{0}\right) \ldots \ldots \ldots$

6.4.1 Lente Convergente da Hipermetropia $\left(R, V_{l}, z_{0}\right) \ldots \ldots \ldots$

7.2 .1 Go2Plane $(P) \quad \ldots \ldots \ldots$. . . . . . . . . . . . . . . . . . 72

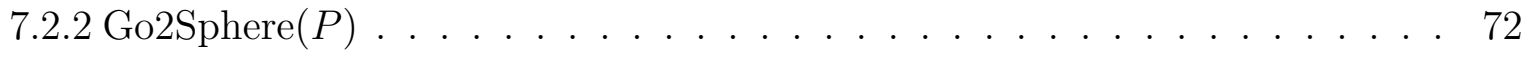

$7.2 .3 \operatorname{Mapping}\left(P, P_{0}, P_{1}, I M G, m, n\right) \quad \ldots \ldots \ldots \ldots \ldots \ldots$

7.3 .1 MakeRings $(\Delta \alpha, A) \ldots \ldots \ldots \ldots \ldots$. . . . . . . . . . . . . . . . . .

7.4.1 MakeCells $(A$, Densidade $I M G) \ldots \ldots \ldots$. . . . . . . . 76

$7.4 .2 \operatorname{Select}(N, A, I M G) \ldots \ldots \ldots \ldots \ldots \ldots$ 


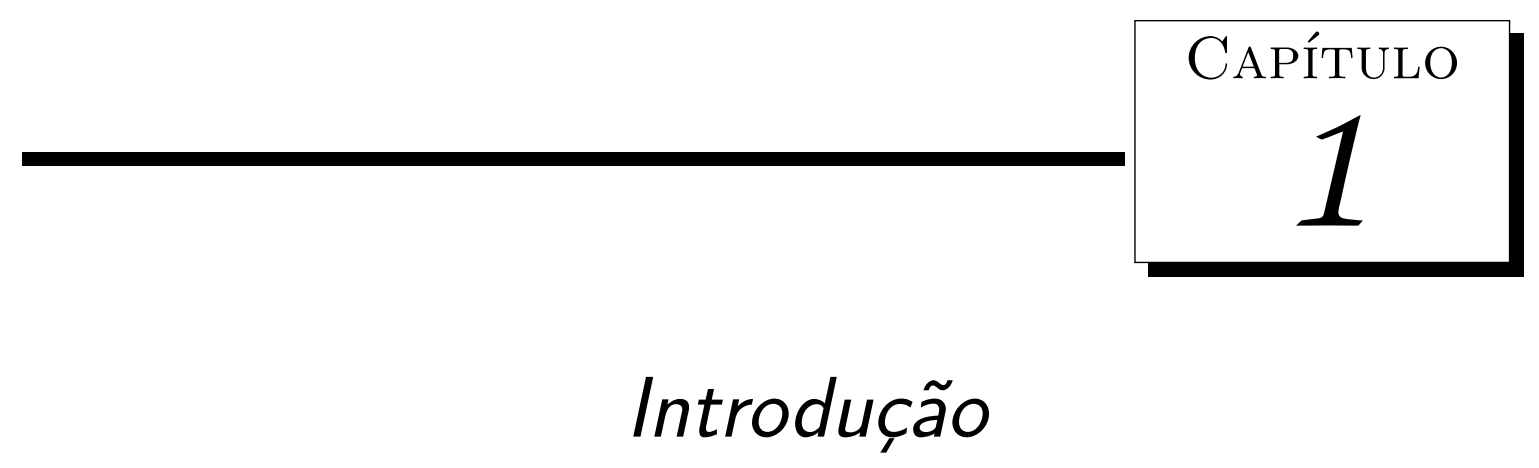

A simulação de objetos e comportamentos em ambientes virtuais vem sendo amplamente explorada em diversos campos científicos. O principal problema encontrado nesse contexto está em descobrir maneiras de gerar simulações que imitem com certo grau de precisão o comportamento natural.

Com o aperfeiçoamento das técnicas de computação gráfica e ao constante avanço da tecnologia presente nos computadores modernos, cresce a cada dia a ambição de reproduzir com alto grau de realismo o sentido mais complexo e importante do ser humano: a visão.

Várias modelagens de simulação de visão humana têm sido propostas na comunidade científica com o objetivo de reproduzir o comportamento óptico envolvido neste processo. Essas modelagens buscam auxilar no desenvolvimento de aparelhos ópticos como também no processo de compreensão do funcionamento do olho humano entre estudantes e médicos da área.

Na USP, campus de São Carlos, foi desenvolvido o projeto Olho Virtual. Trata-se de um arcabouço computacional composto de técnicas matemáticas, físicas e de computação gráfica que permite modelar o olho humano e simular os fenômenos ópticos e fisiológicos como acomodação e aberração (Fer08) (Dur05).

Embora muitos trabalhos têm sido propostos para reunir esforços em simular a visão 


\section{Introdução}

humana, muitos deles possuem como o último estágio a formação de imagens sobre a retina que, neste caso, é tratada como uma simples "tela de projeção" sem levar em consideração a atuação de suas células no processo de percepção visual.

Neurofisiologistas buscam identificar e compreender como funcionam os mecanismos celulares envolvidos neste processo. O sistema visual recebe os sinais de imagens captadas pelos olhos e, por meio de transformações e processamento diversos, integra esses sinais em representações de objetos internos perceptuais (Car06).

A retina desempenha um dos papeis mais importantes na visão humana, pois é nela que se formam as imagens de cenas e objetos presentes no mundo. É composta por células sensíveis à luz, os cones e os bastonetes. Essas células transformam a energia luminosa das imagens em sinais nervosos que são transmitidos ao cérebro pelo nervo óptico.

Neste contexto, também se destacam alguns modelos computacionais motivados a reprodução do comportamento da retina humana. Adrien Wohrer (Woh08) propôs um modelo com controle de contraste que transforma uma sequência de vídeo em um conjunto de sinais que são emitidos pelas células ganglionares da retina.

Outro modelo de retina artificial encontrado na literatura é o de Hui Wei (WG08), que consiste em uma representação baseada na anatomia celular da retina biológica, com o propósito de simular a distribuição dos receptores e os campos receptivos das células ganglionares.

No entanto, notam-se nos modelos atuais que as imagens de entrada utilizadas para o processamento são basicamente imagens em formato PGM, JPEG, BMP e etc. Tais trabalhos, não levam em consideração todo o processo do sistema visual e a habilidade de captação de imagens do mundo real, desempenhadas pelas componentes ópticas do olho.

Neste trabalho, a simulação do sistema visual humano consiste em unir o processamento realizado na captação de imagens pelas componentes ópticas do olho humano no projeto Olho Virtual e a simulação do comportamento das células da retina direcionada aos fenômenos pertinentes ao processo de percepção humana. 


\section{Introdução}

\subsection{Objetivos}

O objetivo geral deste projeto é introduzir um modelo de retina sensorial no Olho Virtual, baseado no modelo biológico, para que seja possível a simulação de alguns processos que ocorrem neste sistema, tais como a distribuição de fotorreceptores, a diferença de resolução entre as imagens formadas em diferentes posições da retina, as projeções das imagens captadas pelos sistemas parvo e magno, fenômenos psicofísicos, campos receptivos e, até mesmo, observar o campo visual mapeado em pessoas portadoras de anomalias na retina. No decorrer deste trabalho, serão explicados em detalhes todos esses processos que compõem o sistema visual humano.

Com o desenvolvimento deste trabalho, muitos dos fenômenos citados acima poderão ser melhor entendidos. Estudantes de oftalmologia poderão expandir seus conhecimentos de maneira mais didática e experimental. Estes fatores podem desencadear em um conveniente avanço na cura de doenças da visão ou possibilitar o desenvolvimento de aparelhos eficientes utilizados em tratamentos.

\subsection{Organização do texto}

O restante do texto está organizado da seguinte forma:

No Capítulo 2 são apresentados os conceitos básicos da fisiologia do olho humano e da óptica envolvida nele que serviram como base teórica para o desenvolvimento do projeto Olho Virtual.

No Capítulo 3 é feita uma revisão teórica nos conceitos referentes a anatomia e funcionalidade da retina e suas células. É com base nessa teoria que o modelo artificial de retina proposto nesse trabalho é desenvolvido.

No Capítulo 4 são apresentadas algumas modelagens encontradas na literatura usadas para simular a retina e as células que a constitui.

No Capítulo 5 é feito um levantamento do estado atual do arcabouço computacional VEye.

No Capítulo 6 é proposta uma modelagem de simulações de ametropias como miopia e hipermetropia usando a superfície da retina para induzir a anomalia.

No Capítulo 7 é mostrado como foi modelado a retina no VEye. São listados os 


\section{Introdução}

principais algoritmos desenvolvidos.

No Capítulo 8 são apresentados algumas simulações e resultados acerca da modelagem desenvolvida no Capítulo 7, que averiguam a veracidade da metodologia adota. Juntamente com os resultados são apresentadas a discussão sobre os mesmo.

E por fim, no Capítulo 9 são apresentadas uma breve discussão e conclusão dos resultados alcançados, alem de uma sugestão para trabalho futuros. 


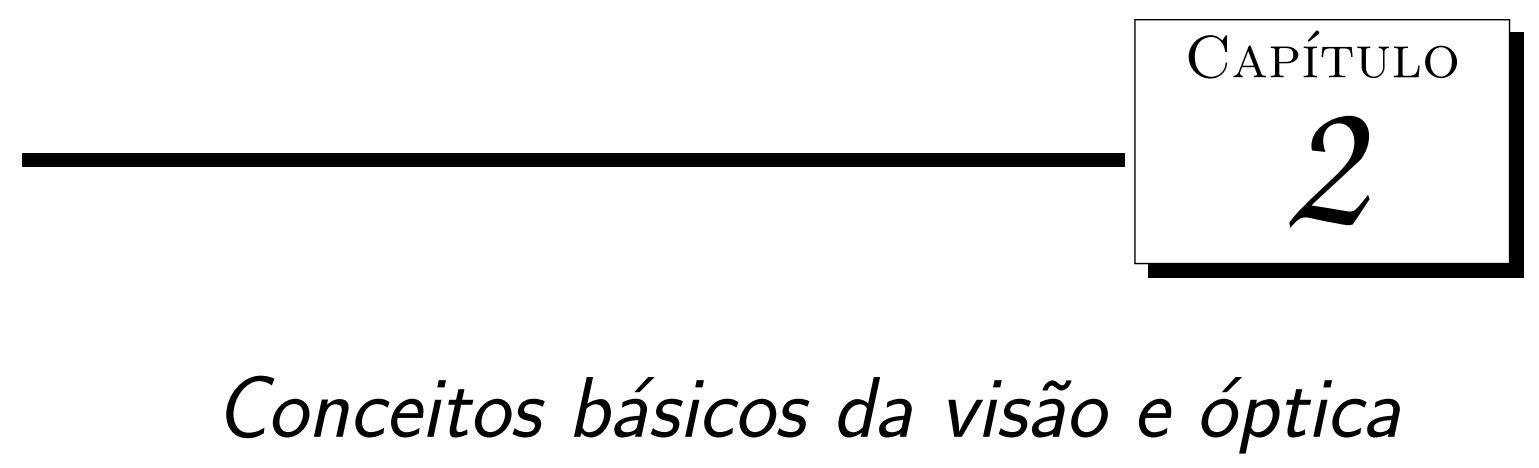

Para simular o sistema visual humano em um computador, torna-se necessário o estudo biológico do seu funcionamento. Com base nesse sistema natural é possível desenvolver sistemas artificiais capazes de detectar, localizar e reconhecer objetos e cenas.

Além dos conceitos biológicos, é necessário também, compreender os conceitos físicos envolvidos no sistema visual humano, tais como as propriedades ópticas da córnea, cristalino e demais estruturas que compõem o olho. Trata-se do comportamento da luz desde o momento em que esta deixa o ponto de origem no meio externo, passando pelos componentes do sistema até chegar na retina.

O objetivo deste capítulo é introduzir alguns conceitos do sistema visual biológico e a óptica do olho para a compreensão dos modelos desenvolvidos no projeto Olho Virtual.

\subsection{Sistema visual humano}

O olho é o órgão responsável pela captação das imagens que serão enviadas ao sistema neurológico. A luz incidente no olho é primeiramente refratada pela córnea e em seguida pelo cristalino, que focaliza e cria a imagem na retina. A imagem formada é então transformada em impulsos neurais pelos fotorreceptores, elementos sensíveis à luz do olho. Por fim, a informação é levada pelo nervo óptico até o sistema neurológico, onde 


\section{Conceitos básicos da visão e óptica}

o cérebro interpreta essas imagens produzindo a percepção de tudo que é captado pelo olho.

\subsubsection{O Olho Humano}

O olho humano é uma estrutura que pode ser descrita como um globo de forma quase esférica com $24 \mathrm{~mm}$ de diâmetro em média. A camada exterior do olho é dividida em duas partes: a córnea e a esclera. A córnea é transparente e possui a forma aproximada de uma esfera com o raio de curvatura de aproximadamente $8 \mathrm{~mm}$. A esclera é um tecido fibroso denso, branco e opaco que possui função principal de proteger o olho e forma aproximada de uma esfera com raio de curvatura de $12 \mathrm{~mm}$, Os centros de curvaturas da esclera e da córnea são separado por cerca de $5 \mathrm{~mm}$. A camada interna do olho é a retina, que é uma extensão do sistema nervoso central e é conectado ao cérebro pelo nervo óptico (AS00).

A luz entra no olho através da córnea, um tecido transparente que cobre a íris, passando pelo humor aquoso, penetrando no globo ocular pela pupila, atingindo o cristalino que funciona como uma lente de focalização, convergindo então os raios luminosos para um ponto focal sobre a retina, onde os sinais luminosos são transformados em sinais neurais e conduzidos para o cérebro pelo nervo óptico (Rig08). A estrutura do olho humano é ilustrada na Figura 2.1.

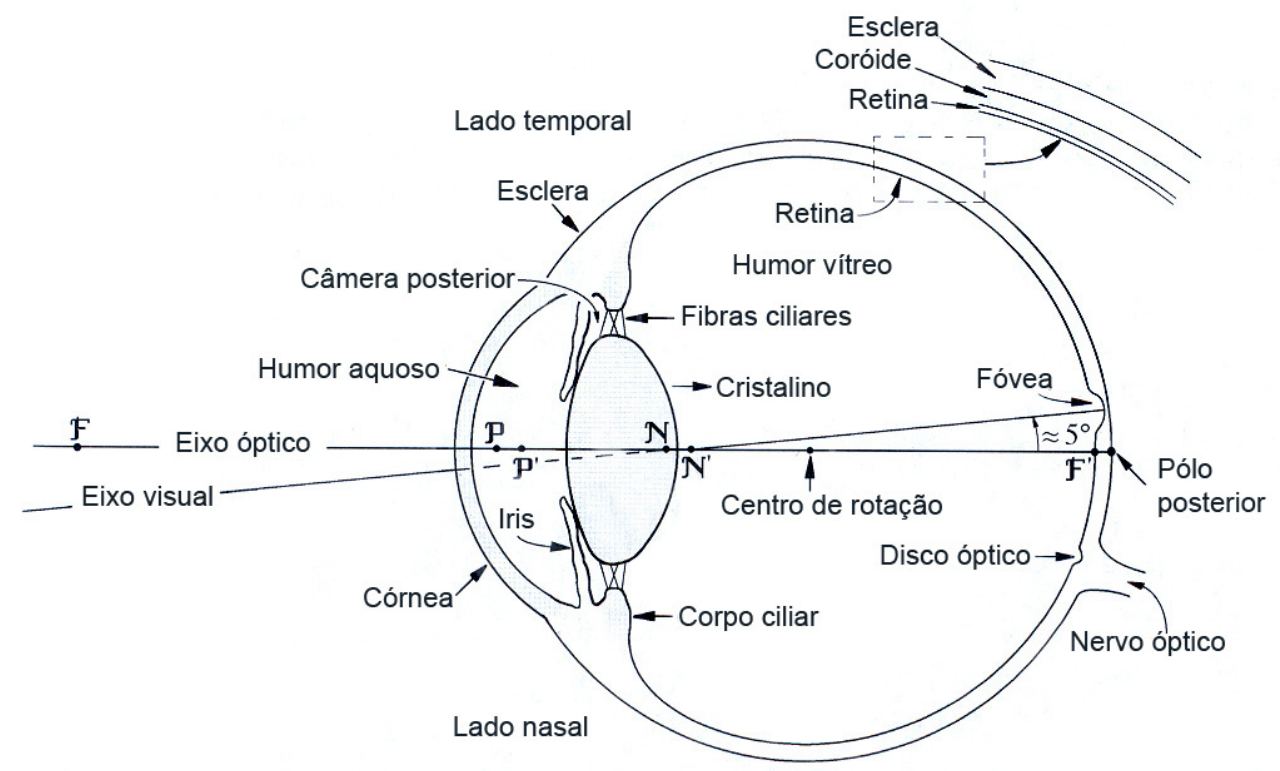

Figura 2.1: Diagrama esquemático do olho humano. Extraído de (AS00). 


\section{Conceitos básicos da visão e óptica}

Na retina há uma região no centro, chamada fóvea, responsável pela visão mais aguçada, proporcionando uma visão nítida nessa região. Na periferia, no entanto, a baixa luminosidade é mais bem percebida com pouca definição e alta percepção de movimentos.

As principais estruturas do olho são:

- Córnea: parte anterior do globo ocular, transparente e protetora do olho. É o principal meio que faz com que os raios paralelos, provenientes do infinito, se convirjam alcançando juntos à fóvea central. O índice de refração da córnea é de aproximadamente de 1,376 ;

- Pupila: porta de entrada e que admite e regula o fluxo de luz para a retina. Seu diâmetro pode ser alterado para regular a intensidade incidente na lente Cristalino;

- Retina: camada que envolve internamente grande parte do globo ocular, onde as imagens são projetadas. Retém as imagens e as traduz para o cérebro através de impulsos neurais enviados pelo nervo óptico (Rig08).

- Nervo Óptico: tem função sensitiva e transporta as sensações visuais do olho para o cérebro formando-se por convergência de células ganglionares na retina do olho (Bas06);

- Íris: controla a quantidade de luz que entra no olho contraindo a pupila em caso de muita luz ou a dilata, caso contrário (Rig08);

- Cristalino: é uma lente complexa constituída por camadas com índice de refração que varia de camada a camada. É constituído por células organizadas longitudinalmente, como uma casca de cebola. Tem de 7 a $9 \mathrm{~mm}$ de comprimento no seu maior eixo e 2 a $4 \mathrm{~mm}$ de espessura, com formato parecido com uma lentilha. O cristalino cresce continuamente durante a vida do indivíduo; Um estudo detalhado do cristalino e sua funcionalidade pode ser encontrado em (Fer08).

- Humor Aquoso: líquido incolor, constituído por água (98\%) e sais dissolvidos (2\%) que preenche as câmaras oculares, cavidade do olho entre a córnea e o cristalino. Possui índice de refração igual a 1,336; 
- Humor Vítreo: substância gelatinosa e viscosa, formada por substância amorfa semilíquida, fibras e células. Localizada na parte posterior do Cristalino e possui índice de refração de 1,336;

- Fóvea: região na retina onde se encontra a maior concentração de células fotorreceptoras, portanto a imagem que nela se forma tem grande precisão. Localiza-se no eixo ótico (Zek93).

\subsubsection{Funções dos olhos}

Para operar como um eficiente sistema óptico, o olho deve formar uma imagem de um objeto ou cena, estando distante ou nas proximidades do olho, sobre a retina. A fim de obter essa operação com eficiência, o olho desenvolve algumas funções especiais, tais como acomodação, adaptação, acuidade visual e visão estereoscópica. Nesta seção é apresentado um breve resumo de tais funções, um estudo mais detalhado pode ser encontrado em (PP98).

Dependendo da distância dos objetos, o cristalino é tensionado ou relaxado pelos músculos ciliares, alterando a dioptria da lente. A esse processo dá-se o nome de acomodação. Para um objeto distante os músculos ciliares anexados no cristalino são relaxados, aumentando o seu raio de curvatura e consequentemente a distância focal. Conforme o objeto aproxima-se do olho, os músculos ciliares são tensionados alongando a lente e diminuindo seu raio de curvatura e a distância focal. Com o passar dos anos, a focalização desses objetos torna-se cada vez mais difícil para o olho focalizar objetos próximos, sendo inevitável o problema de Presbiopia (OMB08). Um estudo mais aprofundado do processo de acomodação do olho é encontrado em (Fer08).

A capacidade de responder a sinais luminosos com diferentes intensidades é denominada de adaptação. Essa função é primeiramente exercida pela íris, que controla a quantidade de luz incidente no olho variando o diâmetro de sua abertura de $2 \mathrm{~mm}$ a 8 $m m$. Em seguida a luz é controlada pelas células fotorreceptores presentes na retina.

A acuidade visual é, basicamente, a capacidade de ver claramente, isto é, distinguir detalhes de objetos bem próximos, que depende de diversos fatores, em especial do espaçamento dos fotorreceptores na retina e da precisão da refração do olho. 
visão estereoscópica é habilidade de detectar profundidade de tudo que enxergamos. A diferença entre as imagens geradas pelo olho direito e pelo olho esquerdo é processada pelo cérebro dando uma noção de profundidade, percebendo um ambiente com objetos com diferentes distâncias (AR06).

\subsubsection{Formação da imagem}

O princípio da formação de imagens pelo olho é o mesmo do sistema ótico de lentes em câmeras criadas pelo homem. A luz entra no olho através da córnea e é refratada por ela até o cristalino para ser focalizada na retina, formando nela uma imagem invertida. Destes dois elementos refratores, a córnea possui um grande e constante poder de refração, enquanto o cristalino pode alterar o poder da lente quando o olho precisa focalizar objetos em diferentes distâncias.

A forma do cristalino é controlado pela tensão das fibras do corpo ciliar, Figura 2.1. Segundo Helmholtz (HEL09), para focalizar um objeto distante, os músculos ciliares são relaxados, aumentando o seu raio de curvatura e consequentemente a distancia focal. Para um objeto mais próximo do olho, os músculos ciliares são tencionados alongando a lente e diminuindo seu raio de curvatura e a distancia focal.

A distância entre o centro focal do cristalino e a retina varia aproximadamente de 17 $m m$ à $14 \mathrm{~mm}$ de acordo com a necessidade do poder de refração. Quando o olho focaliza um objeto com mais de $3 m$ de distância, o cristalino atua com seu menor poder e, quando o olho focaliza um objeto próximo, atua com seu mais alto poder de refração.

O tamanho da imagem formada na retina pode ser calculado facilmente. Na Figura 2.2, por exemplo, o observador está olhando para uma árvore de $15 \mathrm{~m}$ de altura e a $100 m$ de distância do olho. Se $x$ é o tamanho em milímetros da imagem retinal, então $15 / 100=x / 17$ e $x=2.55 \mathrm{~mm}$. Essa imagem formada na retina é então, decodificada em impulsos elétricos e enviados para o cérebro.

\section{2 Óptica geométrica}

Para entender as imagens e como elas são formadas, é preciso entender o modelo da descrição da luz por meio de raios, as leis da reflexão e da refração e um pouco de geometria e trigonometria. O papel desempenhado pela geometria é o principal motivo pelo qual o 


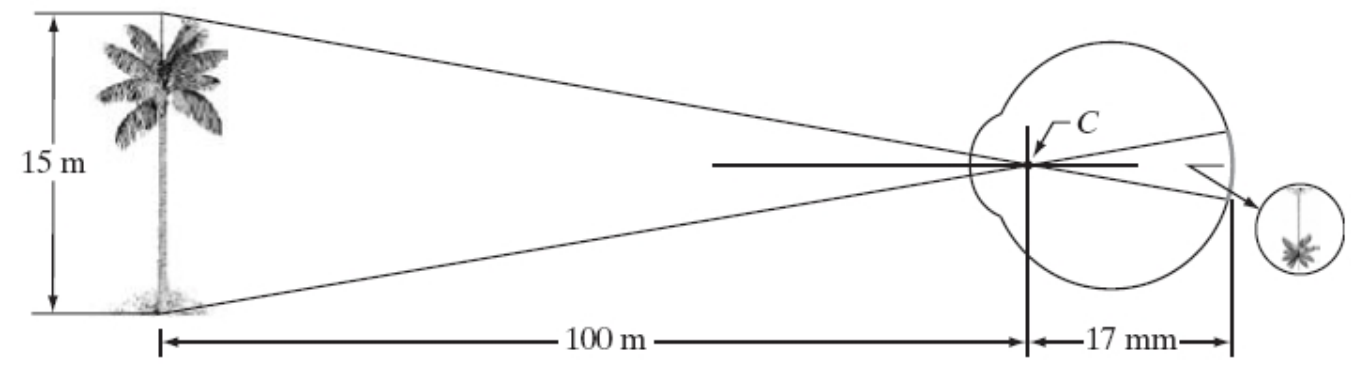

Figura 2.2: Representação óptica do olho focalizando uma árvore. Ponto C é o centro óptico do cristalino. Extraído de (GW92)

nome óptica geométrica é usado para designar o estudo da formação de imagens.

Quando uma onda de luz atinge uma superfície lisa separando dois meios transparentes, tal como o ar e o vidro, em geral a onda parcialmente é refletida e parcialmente refratada para o outro material, como indicado na Figura 2.3. Nesta figura são descritos as direções dos raios incidentes, refletidos, refratados, na interface lisa separando dois meios transparentes em relação aos ângulos que esses raios formam com a normal à superfície no ponto de incidência.

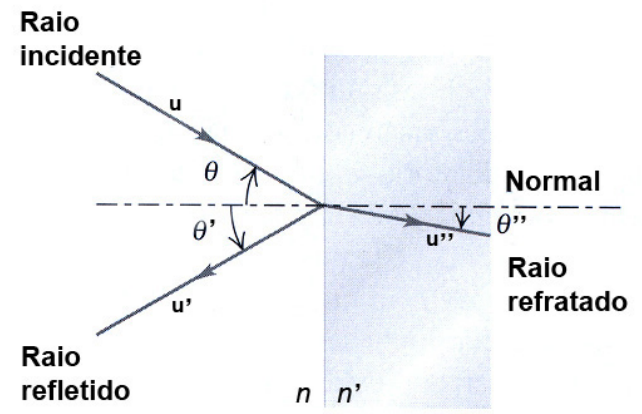

Figura 2.3: Ilustração dos raios incidente, refletido e de refração sobre uma superfície. Extraído de (Yun04).

O índice de refração de um material, designado pela letra $n$, define a razão entre a velocidade da luz $c$ no vácuo e a velocidade da luz $v$ no material:

$$
n=\frac{c}{v}
$$

A seguir são definidas duas definições básicas na geometria óptica: 
Conceitos básicos da visão e óptica

Definição 2.1 (Raio) Linha imaginária ao longo da direção de propagação da onda.

Definição 2.2 (Plano de incidência) Plano que contém o raio incidente e a normal à interface no ponto de incidência do raio de luz na Figura 2.3.

Definição 2.3 (Lei de reflexão) $O$ raio incidente, o raio refletido, o raio refratado $e$ a normal à superfície pertencem a um mesmo plano e o ângulo de reflexão $\theta^{\prime}$ é igual ao ângulo de incidência $\theta$ para todos os comprimentos de onda e para qualquer par de materiais, Figura 2.3.

$$
\theta=\theta^{\prime}
$$

Definição 2.4 (Lei de refração ou Lei de Snell) O raio incidente, o raio refletido, o raio refratado e a normal à superfície pertencem a um mesmo plano, que divide dois meios de índices de refração $n$ e $n^{\prime}$. A razão entre o seno do ângulo $\theta$ e o seno do ângulo $\theta^{\prime \prime}$, onde esses ângulos são medidos a partir da normal à superfície, é igual ao inverso da razão entre os dois indices de refração $n$ e $n^{\prime}$, Figura 2.3.

$$
\frac{\operatorname{sen}(\theta)}{\operatorname{sen}\left(\theta^{\prime \prime}\right)}=\frac{n^{\prime}}{n}
$$

A formulação vetorial da lei de Snell, Equação 2.4, é computacionalmente conveniente para os desenvolvimento do Projeto Olho Virtual e é dado da seguinte forma:

$$
u^{\prime}=n^{\prime \prime} u+\left(n^{\prime \prime} \cos (\theta)-\cos \left(\theta^{\prime}\right)\right) N
$$

Onde $\theta$ e $\theta^{\prime \prime}$ são os ângulos de incidência e o de refração, $n$ e $n^{\prime}$ são os índices de refração dos meios, $N$ é a normal na superfície e $n^{\prime \prime}$ é a razão $n / n^{\prime}$ (Figura 2.3).

\subsubsection{Formação de imagens em um sistema óptico}

Um Sistema óptico centrado é caracterizado como sendo um conjunto de superfícies refletoras e/ou refratoras separando vários meios homogêneos e isotrópicos, cada qual com um determinado índice de refração e curvatura, e estão alinhadas sob um mesmo 
eixo óptico. A Figura 2.4 ilustra esquematicamente um sistema óptico. São estabelecidas três regiões importantes:

- Espaço objeto: local onde se encontram os objetos. Nesta região, os raios não atingiram nenhuma superfície do sistema. No espaço objeto os raios são divergentes e as frentes de ondas estão se expandindo.

- Sistema óptico: local onde se encontram as superfícies refletoras e/ou refratoras.

- Espaço imagem: local que contém os raios de luz que formam a imagem após a última superfície do sistema óptico. Lugar onde são formadas as imagens. Nesta região os raios de luz provenientes de um ponto que atravessaram o sistema e as frentes de ondas estão convergindo.
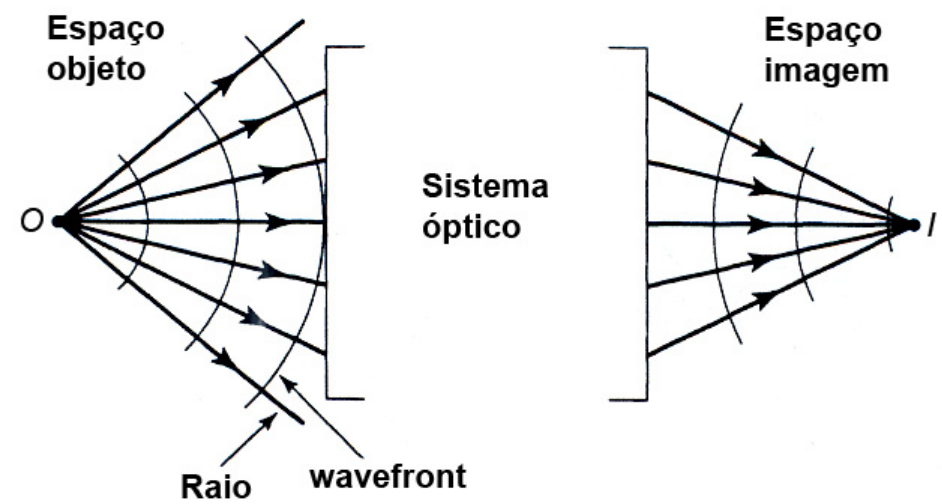

Figura 2.4: Formação de imagem por um sistema óptico. Extraído de (PP98).

Deste modo, raios de luz são lançados radialmente em todas as direções a partir do ponto $O$, como mostrado no espaço objeto. O sistema óptico redireciona estes raios de modo que ao deixarem o sistema e adentrarem no espaço objeto, as frentes de ondas são contraídas e passam a convergirem para um ponto comum denominado ponto imagem $I$.

Teoricamente, e baseado no Princípio de Fermat, pode-se dizer que todo raio que parte do ponto $O$ termina em $I$, e necessita o mesmo tempo de transição para realizar este percurso. Estes raios são chamados de isócronos e, pelo princípio da reversibilidade, se $I$ é o ponto objeto, cada raio inverte sua direção, mas mantém seu caminho no sistema 
óptico, sendo $O$ o ponto imagem correspondente. Os pontos $O$ e $I$ são chamados de pontos conjugados. Num sistema óptico ideal, todo raio que parte de $O$, intercepta o sistema e passa através do ponto $I$. Em (PP98) pode ser encontrado um estudo mais aprofundado de formação de imagens em sistemas ópticos.

\subsubsection{Sistemas ópticos complexos formados por lentes espessas}

Nesta seção serão abordadas algumas características de um sistema óptico centrado mais complexo. Trata-se de um sistema, cuja espessura da lente ao longo do eixo óptico não pode ser ignorada. Este fato conduz a graves erros em análise, sendo necessário analisá-la como se fosse composta por unidades refratoras e superfícies separadas (PP98).

A imagem de um determinado objeto, formada pela refração na primeira superfície, torna-se objeto de refração no segundo pavimento. A distância do objeto na segunda superfície leva em conta a espessura da lente. A imagem formada pela segunda superfície é então a imagem final devido à ação da composição das lentes.

Assim como as lentes delgadas, um sistema composto por lentes espessas também define regras para determinação das imagens dos objetos correspondentes. Um sistema óptico complexo, formado por várias componentes refletoras e/ou refratoras, é caracterizado por um conjunto de pontos cardinais: os pontos focais, denotado por $F$ e $F^{\prime}$, os pontos principais $P$ e $P^{\prime}$ e os pontos nodais $N$ e $N^{\prime}$.

Um raio que entra no sistema passando pelo ponto focal $F$, emerge no espaço imagem paralelo ao eixo, Figura 2.5(a), e um raio paralelo ao eixo entra na lente e é refratado fazendo com que ele atravesse o segundo ponto focal $F^{\prime}$, Figura 2.5(b). Em cada caso, a extensão do raio incidente e o refratado interceptam, por definição, no plano principal, e as intersecções destes planos com o eixo definem os pontos principais $P$ e $P^{\prime}$. Se essas lentes fossem lentes delgadas os dois planos principais coincidiriam em uma linha vertical que é usualmente desenhada para representar o sistema. Por fim, um raio que entra na lente na direção do primeiro ponto nodal $N$ emerge no espaço imagem paralelo ao raio incidente, mas é deslocado fazendo com que ele passe pelo segundo ponto nodal $N^{\prime}$, Figura $2.5(\mathrm{c})$.

A imagem do ponto $F^{\prime}$ no espaço imagem é formada no infinito no espaço objeto. De maneira análoga, a imagem do ponto $F$ no espaço objeto é formada no infinito no espaço 


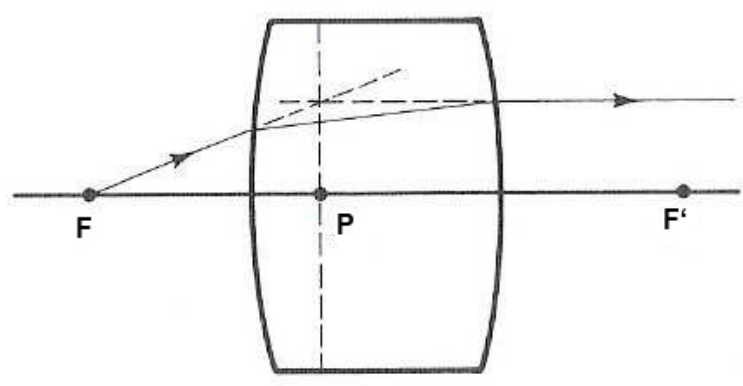

(a)

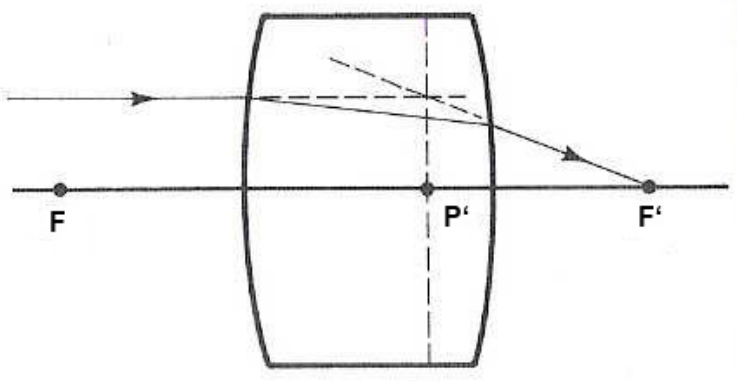

(b)

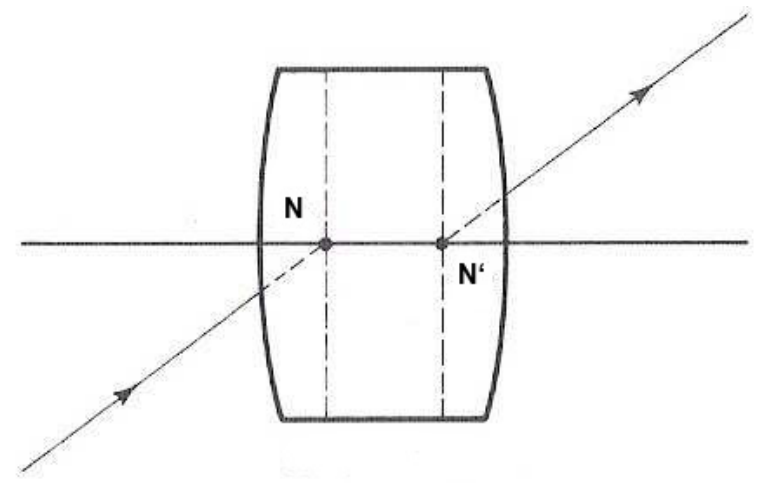

(c)

Figura 2.5: Ilustração dos pontos cardinais.(a) e (b) ilustração dos pontos focais e pontos principais. (c) ilustração dos pontos nodais.

imagem. A imagem de um objeto em $P$ é formada em $P^{\prime}$ do mesmo tamanho.

\section{3 Óptica do olho}

O comportamento óptico do olho é semelhante ao de um sistema óptico composto por lentes espessas. As partes essenciais do olho humano foram mencionados na Seção 2.1 e os pontos cardinais são ilustrados na Figura 2.1. A forma do olho é quase esférica, com aproximadamente $2,5 \mathrm{~cm}$ de diâmetro. A parte frontal é ligeiramente mais encurvada e é recoberta pela córnea. A região atrás da córnea contém o humor aquoso e a seguir o cristalino, uma lente em forma de cápsula com uma gelatina fibrosa dura no centro e progressivamente mais macia à medida que se aproxima da sua periferia. O índice de refração do cristalino é de aproximadamente 1,437. Atrás do cristalino, o olho contém o humor vítreo, de índice de refração aproximadamente 1,336, o mesmo valor do índice do humo aquoso. 


\section{Conceitos básicos da visão e óptica}

As refrações na córnea e nas superfícies da lente produzem uma imagem real do objeto que está sendo observado e a imagem é formada na retina. A íris se localiza na parte frontal do cristalino. Ela contém a abertura (stop) com diâmetro variável chamado pupila que se abre ou fecha para adaptar a entrada da luz no olho.

\subsubsection{Eixos do olho}

Em um sistema óptico centrado, os centros de curvaturas de todas as superfícies refletoras e/ou refratoras estão sobre uma linha denominada eixo óptico. Porém, em se tratando das propriedades ópticas do olho humano, torna-se necessário introduzir alguns conceitos sobre outros eixos. Isto ocorre devido à falta de simetria do olho e ao fato de que o ponto de fixação e a fóvea não estão sobre um eixo bem definido de simetria. $\mathrm{O}$ ponto de fixação é o ponto $T$ de interesse para o qual o olho humano aponta, sendo $T^{\prime}$ o seu conjugado na fóvea, Figura 2.6.

O olho não é sistema centrado e não contém um eixo óptico verdadeiro. Sendo assim, é definido para ele, como sendo eixo óptico, a linha que melhor se ajusta aos centros de curvaturas de todas as superfícies.

A linha que passa através de ponto de fixação e o centro de rotação do olho é chamada de eixo de fixação. Este eixo é referência para medição dos movimentos do olho.

O eixo visual é a linha que une o ponto de fixação e a imagem na fóvea por meio dos pontos nodais. Como os pontos nodais no olho não coincidem, não é propriamente uma linha ou eixo. Trata-se dos segmentos de linhas $T N$ e $N^{\prime} T^{\prime}$ mostrado na Figura 2.6. O ângulo formado pelo eixo visual e o eixo óptico é denominado por muitos autores como ângulo $\alpha$.

O eixo pupilar é uma linha que passa através do centro da entrada da pupila e que é normal à córnea. Se o olho fosse um sistema centrado e a pupila também fosse centrada, o eixo pupilar estaria ao longo do eixo óptico. No entanto, a pupila não é centrada em relação à córnea, que, por sua vez, pode não possuir uma forma regular. Em geral, o eixo pupilar não passa pelo ponto de fixação $T$ como mostrado na Figura 2.6. A linha que passa neste local é denominada linha de vista. 


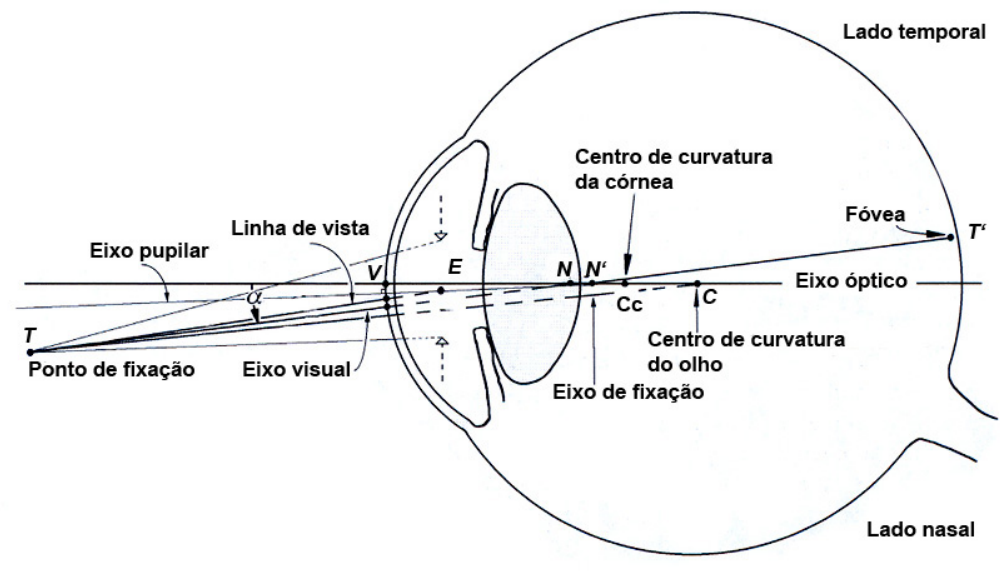

Figura 2.6: Ilustração dos eixos no olho humano. Estraído de (AS00).

\subsubsection{Modelos esquemáticos de olhos}

Modelos esquemáticos do olho humano podem ser construídos utilizando valores médios de parâmetros óticos relevantes. Alguns modelos são muito simples e servem somente para fins educacionais, como o modelo Emsley (EMS52). Outros modelos simples modelam as superfícies da córnea, cristalino e retina como superfícies esféricas. Tais modelos são classificados na literatura como modelos esquemáticos paraxiais e recebem este nome porque estes modelos são precisos em representar o olho humano na região paraxial. Gullstrand (Gul09) e Le Grand (YLG80) são exemplos deste modelo.

Outros modelos, mais sofisticados, consideram as superfícies como superfícies quádricas, modelando com mais precisão as aberrações do olho e também a qualidade da imagem formada na retina. Estes modelos são conhecidos como modelos esquemáticos finitos. Kooijman (KOO83), Navarro (RN83) e Liou e Brennan (LH97) são exemplos deste modelo.

Para as simulações deste trabalho serão usados somente os modelos de Le Grand e Liou-Brennan. A especificação dos demais modelos podem ser encontrados em (PP98) (AS00) e em (Fer08) a implementação dos mesmo.

O modelo de Le Grand é apresentado em seus estados não acomodado $\left(l g r_{u}\right)$ e acomodado $\left(l g r_{a}\right)$. Na Tabela 2.1 é especificado os valores de $\left(l g r_{u}\right)$ e na Tabela 2.2 os valores de $\left(\lg r_{a}\right)$. 
Tabela 2.1: Modelo Le Grand não acomodado.

\begin{tabular}{|c|c|c|c|c|c|c|}
\hline Medium & $\mathrm{n}$ & $\mathrm{R}$ & d & $\begin{array}{l}\text { Powers } \\
\text { Surface }\end{array}$ & Component & Eye \\
\hline Air & 1.000 & & & & & \\
\hline & & 7.8 & & 48.346 & & \\
\hline Cornea & 1.377 & 6.5 & 0.55 & -6.108 & 42.356 & \\
\hline Aqueous & 1.337 & & 3.05 & & & 59.940 \\
\hline Lens & 1.420 & $\begin{array}{l}10.2 \\
-6.0\end{array}$ & 4.0 & $\begin{array}{l}8.098 \\
14.000\end{array}$ & 21.779 & \\
\hline Vitreous & 1.336 & & 16.59 & & & \\
\hline
\end{tabular}

Tabela 2.2: Modelo Le Grand acomodado $A=7.053 D$ D

\begin{tabular}{|c|c|c|c|c|c|c|}
\hline Medium & $\mathrm{n}$ & $\mathrm{R}$ & d & $\begin{array}{l}\text { Powers } \\
\text { Surface }\end{array}$ & Component & Eye \\
\hline Air & 1.000 & & & & & \\
\hline & & 7.8 & & 48.346 & & \\
\hline Cornea & 1.377 & & 0.55 & & 42.356 & \\
\hline & & 6.5 & & -6.108 & & \\
\hline Aqueous & 1.337 & & 2.65 & & & 67.677 \\
\hline Lens & 1.427 & 6.0 & 4.5 & 14.933 & 30.700 & \\
\hline Vitreous & 1.336 & -5.5 & 16.49 & 16.545 & & \\
\hline
\end{tabular}

O modelo de Liou-Brennan, Tabela 2.3, é baseado em dados obtidos experimentalmente do olho humano. Este é o único modelo empregado que usa o índice de refração distribuído para cada parte do cristalino. Tanto a distribuiçãoo anterior $n_{A}$ como a posterior $n_{P}$ são dadas pela Equação 2.5.

$$
n\left(\rho^{\prime}, z^{\prime}\right)=n_{00}+n_{01} z^{\prime}+n_{02} z^{\prime 2}+n_{10} \rho^{\prime 2}
$$

onde $\rho^{\prime 2}=x^{\prime 2}+y^{\prime 2}$ e $\left(x^{\prime}, y^{\prime}, z^{\prime}\right)$ são um sistema de coordenadas centrado em $z_{0}$ no eixo óptico $z$ e $n_{00}, n_{01}, n_{02}$ e $n_{10}$ são constantes explicadas na Tabela 2.4 .

\begin{tabular}{|c|c|c|c|c|c|c|}
\hline Medium & $\mathrm{n}$ & $\mathrm{R}$ & $\mathrm{d}$ & $\begin{array}{l}\text { Powers } \\
\text { Surface }\end{array}$ & Component & Eye \\
\hline Air & 1.000 & & & & & \\
\hline Cornea & 1.376 & $\begin{array}{l}7.77 \\
6.40\end{array}$ & 0.55 & $\begin{array}{l}48.391 \\
-6.250\end{array}$ & 42.262 & \\
\hline Aqueous & 1.336 & 12.40 & 3.16 & 2.581 & & 60.314 \\
\hline Lens & $n_{A}$ & $\infty$ & 1.59 & 6.283 & 22.134 & \\
\hline Lens & $n_{P}$ & -8.10 & 2.43 & $\begin{array}{l}9.586 \\
3.950\end{array}$ & & \\
\hline Vitreous & 1.336 & & 16.23 & & & \\
\hline
\end{tabular}


Conceitos básicos da visão e óptica

Tabela 2.4: Constantes da Equação 2.5 que descreve a distribuição do índice de refração na porção anterior $n_{A}$ e posterior $n_{P}$ do cristalino.

\begin{tabular}{lcc}
\hline & $n_{A}$ & $n_{P}$ \\
\hline \hline$n_{00}$ & 1.368 & 1.407 \\
$n_{01}$ & 0.049057 & 0.000000 \\
$n_{02}$ & -0.015427 & -0.006605 \\
$n_{10}$ & -0.001978 & -0.001978 \\
$z_{0}$ & -3.71 & -5.30 \\
\hline
\end{tabular}




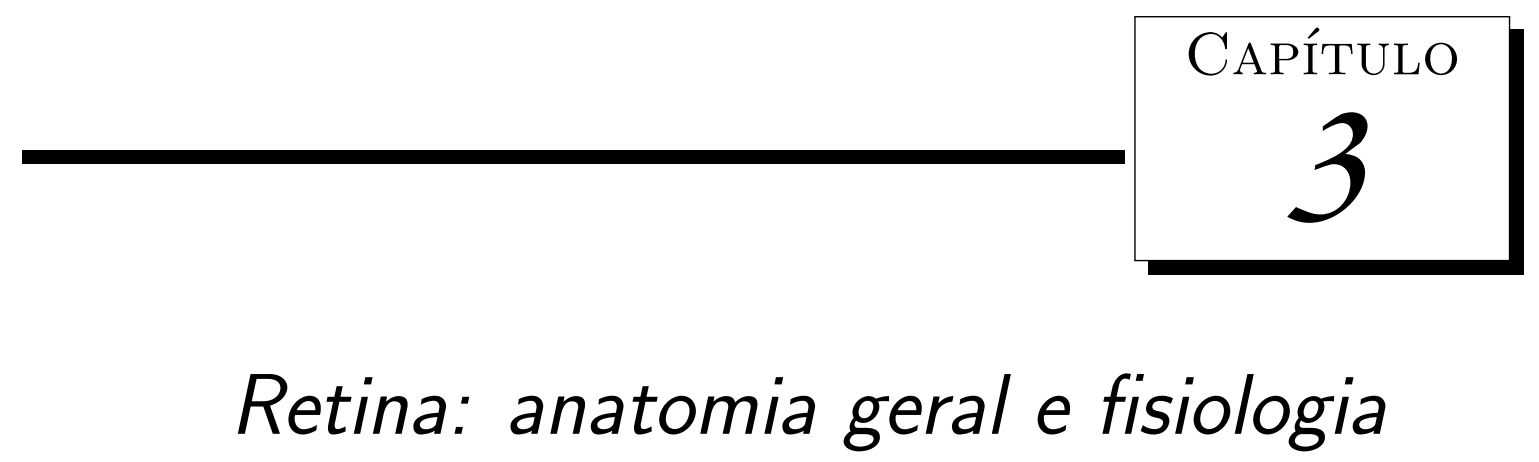

A retina é a entrada neural do sistema visual. Contém os primeiros neurônios visuais que convertem a luz incidente em sinais elétricos enviados para o cérebro.

Com aproximadamente $0.05 \mathrm{~mm}$ de espessura, a retina é uma camada que reveste internamente a cavidade ocular e possui uma alta concentração de terminações nervosas essenciais para a captação da luz, que são os fotorreceptores (bastonetes e cones), estudados com detalhes na Seção 3.4. É responsável, basicamente, pela formação de imagens funcionando como uma "tela de projeção" onde se projetam as imagens. Retém os raios luminosos que adentram no olho e os traduz para o cérebro através de impulsos elétricos enviados pelo nervo óptico.

Este capítulo é dedicado a fornecer a base teórica para o desenvolvimento do modelo artificial de retina proposto neste trabalho.

\subsection{Camadas da retina}

As células da retina são organizadas em uma arquitetura de camadas em sequência. Desde os receptores, responsáveis pela aquisição de luz recebida, até as células ganglionares, que enviam a informação visual para o cérebro em forma de sinais elétricos. Há cinco tipos diferentes de células presentes retina: 
Retina: anatomia geral e fisiologia

- Receptores de luz;

- Células Horizontais;

- Células Bipolares;

- Células Amácrinas;

- Células Ganglionares.

Tais células podem ser distribuídas em 5 camadas, sendo elas 3 camadas nucleares intercaladas de 2 camadas plexiformes, onde ocorrem as ligações sinápticas. No entanto, na fóvea, região onde possui a maior concentração de células fotorreceptoras, a retina é formada apenas pela camada composta de fotorreceptores cones.

A camada pigmentar da retina possui grandes quantidades de melanina, cuja função é absorver os raios luminosos que atravessam a retina, impedindo a reflexão da luz de volta para o olho. Dessa forma, os receptores ficam próximos a essa camada, no fundo da retina. A Figura 3.1 mostra a anatomia da retina, com suas diferentes camadas celulares. Os raios luminosos atingem primeiramente a camada das células ganglionares (parte de baixo da figura) e atravessam toda a sua espessura antes de atingir os bastonetes e os cones (parte superior da figura).

A luz chega primeiramente na camada de células ganglionares, e deve penetrar todas as demais camadas antes de chegar nos fotorreceptores. A próxima camada é a plexiforme interna, onde os prolongamentos das células bipolares, amácrinas e ganglionares fazem sinapses, passando em seguida pela camada nuclear interna, onde se encontram os corpos celulares das células bipolares, horizontais, amácrinas e das células ganglionares deslocadas. Em seguida a camada plexiforme externa, onde os prolongamentos de fotorreceptores, células bipolares e horizontais fazem conexões sinápticas e,por fim, a luz chega na última camada, a nuclear externa, onde se encontram os corpos celulares dos fotorreceptores (cones e bastonetes).

\subsection{Conexões sinápticas entre as camadas da retina}

Entre os neurônios presentes na retina, alguns são excitatórios, liberando neurotransmissores que tendem a despolarizar, ou excitar, suas ligações sinápticas. Outros são 


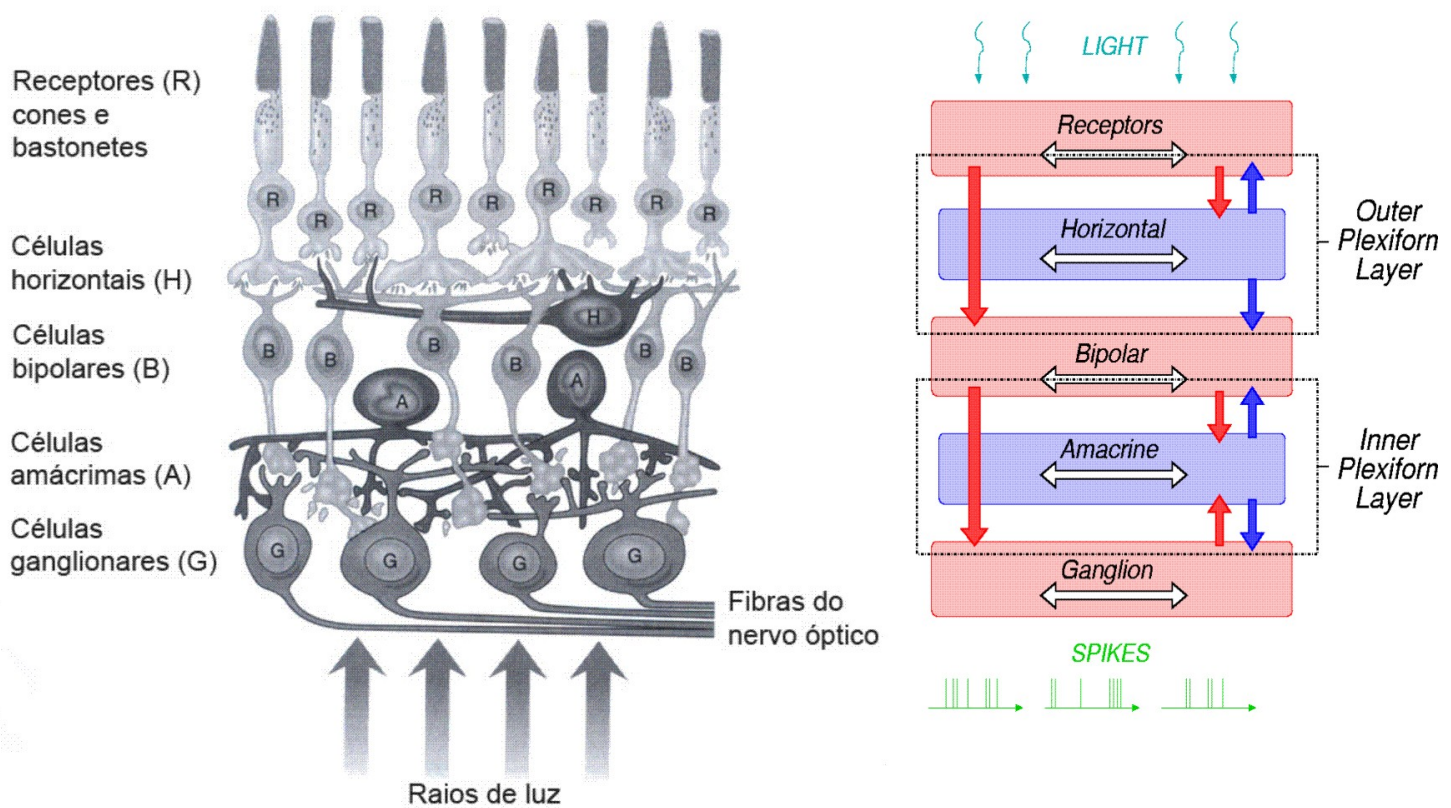

Figura 3.1: Relações entre as células da retina. Extraído de (Gol02)

inibitórios, liberando neurotransmissores que tendem a hiperpolarizar, ou inibir, a suas pós ligações sináptica.

- Via Excitatória: Os receptores, células bipolares e ganglionares são neurônios excitatórios. São representados em vermelho na Figura 3.1 e suas conexões sinápticas são definidas pelas setas vermelhas. O percurso sináptico definido pela transmissão receptores $\rightarrow$ bipolar $\rightarrow$ gânglios é considerado um percurso excitatório direto.

- Modulação Inibitória: Em oposição, a retina possui dois tipos de neurônios inibitórios: células horizontais e amácrinas. São representados em azul na Figura 3.1 e suas conexões sinápticas pelas setas azuis. Como visto na figura, esses neurônios são ligados por transmissões indiretas, conectando células horizontais em receptores e células amácrinas em células bipolares.

As células horizontais recebem sinais de diversos fotorreceptores, têm campos receptivos circulares simples, e produzem sinal inibitório. Células bipolares têm campos receptivos antagônicos entre centro e periferia, e combinam sinais de múltiplos fotorreceptores e células horizontais. Já as células amácrinas disparam por curto período logo após a mudança na incidência de luz, seja quando esta começa a ser percebida ou quando cessa. 


\subsection{Dois caminhos paralelos}

Há dois tipos de gânglios na retina, um para o processamento de informação espacial e outro para informação temporal: parvos (gânglios P) e magnos (gânglios M), constituindo os caminhos parvocelular e magnocelular respectivamente.

Os gânglios parvos são mais frequentes na fóvea e recebem sinais das células cones. Sua atuação é sobre informações espaciais, dando maior percepção de cores, e também possui campos receptivos centro-periferia, podendo sinalizar percepção de luz ou o término desta. Os gânglios magnos são mais frequentes na periferia da retina, recebem sinais de células bastonetes. São responsáveis pela percepção temporal, sensíveis a movimentação, luminosidade e também detectam direção e deslocamento.

Existem várias diferenças no modo como os neurônios no caminho parvocelular e magnocelular codificam informação, transportando diferentes tipos de informação para o cérebro. Sinais elétricos que saem da retina através das camadas parvocelulares, possuem tempo de condução maior do que os sinais que são enviados as camadas magnocelulares. Diante de diferentes padrões, os neurônios nestas duas vias respondem de maneiras diferente. Conforme o estímulo de contraste aumenta, a resposta dos neurônios no percurso magnocelular é efetivada mais rapidamente do que a resposta no percurso parvocelular. Assim, existe uma especialização no caminho magnocelular que melhora a capacidade de executar tarefas que exijam alta frequência temporal de informação. Dois exemplos de tais tarefas são detecção de movimentos e resolução de monitoramento. Por outro lado, o caminho parvocelular atua sobre informações espaciais, dando maior percepção de cores e de forma (SB90).

\subsection{Fotorreceptores}

Existem dois tipos de fotorreceptores no olho humano, um deles é chamado de bastonete, que permite a visão em preto e branco, constituindo o caminho magnocelular, e o outro de cone, que permitem a visão em cores, constituindo o caminho parvocelular. As principais diferenças entre cones e bastonetes são mostradas na Tabela 3.1 e pode ser mais bem estudadas em (MF97).

Bastonetes são sensíveis à luminância, sendo capazes de perceber baixa intensidade 


\begin{tabular}{|c|c|c|}
\hline Característica & Cones (cores) & Bastonetes (preto e branco) \\
\hline Forma & Ponta canônica & Ponta cilíndrica, alongada \\
\hline Quantidade & 5 milhões em cada olho & 100 milhões em cada olho \\
\hline Distribuição & $\begin{array}{l}\text { Em toda a retina, maior } \\
\text { densidade na fóvea }\end{array}$ & Ausente na fóvea \\
\hline $\begin{array}{l}\text { Iluminação para melhor } \\
\text { funcionamento }\end{array}$ & Bem iluminado & Pouco iluminado \\
\hline $\begin{array}{l}\text { Número de receptores } \\
\text { por gânglio }\end{array}$ & Poucos & Muitos \\
\hline Acuidade & Excelente & Pobre \\
\hline Sensitividade & Pobre & Excelente \\
\hline Fotopigmento & Três tipos (cores RGB) & Um tipo (tons de cinza) \\
\hline Adaptação ao escuro & Rápido, limite alto & Lento, limite baixo \\
\hline
\end{tabular}

Tabela 3.1: Comparações de cones e bastonetes.

luminosa, ocupando principalmente a periferia. São responsáveis pela visão noturna e visão periférica. Têm este nome devido à sua forma alongada e cilíndrica. Servem para um ambiente mais escuro, sendo mais sensível à luz que os cones, mas detectam apenas tons de cinza. Os bastonetes constituem o caminho magnocelular.

Cones são responsáveis pela acuidade visual e pela percepção de cores. São menores e mais espessos do que os bastonetes. Há três tipos de cones em seres humanos, cada um destinado à percepção de uma determinada cor, isto é, responde à luz de comprimentos de onda diferente: vermelho (ondas longas), verde (ondas médias), e azul (ondas curtas). São capazes de perceber detalhes espaciais mais finos e estão presentes principalmente na fóvea. Os cones constituem o caminho parvocelular.

\subsection{Visão central versus visão periférica}

Quando se quer visualizar um objeto com um alto grau de precisão é necessário mover os olhos de modo a ter o objeto alvo projetado no centro da retina. Isto acontece devido ao fato de que a retina apresenta uma determinada estrutura radial, com uma região central que apresenta uma maior densidade de células e, consequentemente, uma imagem muito mais nítida do que na periferia.

Em seres humanos essa região central é chamado de fóvea. Abrange cerca de $5^{\circ}$ de campo visual, localizada diretamente no eixo visual, a $5^{\circ}$ do eixo óptico Figura 2.1. É neste local que é projetado a imagem do objeto focalizado. A fóvea é a parte central da 
Retina: anatomia geral e fisiologia

mácula, região central com diâmetro de aproximadamente $5.5 \mathrm{~mm}$ (AS00).

No centro da fóvea, existe uma região ainda menor chamada foveola com cerca de $1^{\circ}$ de

campo visual. É composta por apenas cones, a imagem que nela se forma possui grande precisão, o que nos permite executar tarefas visuais muito precisas tal como leitura.

\subsubsection{Distribuição dos receptores}

Os cones e bastonetes não diferem apenas em seus formatos e funcionalidades, mas também no modo de como eles são distribuídos na retina.

Existem cerca de 5 milhões de cones em cada retina, mas a fóvea é tão pequena, de forma circular com aproximadamente $1.5 \mathrm{~mm}$ de diâmetro, que possui aproximadamente 50.000 cones, $1 \%$ do total do número de cones da retina (AS00). Os restantes dos cones estão localizados na periferia da retina, a área ao redor da fóvea que contém cones e bastonetes. No entanto, o proporção de bastonetes para cones é de 20 para 1, assim existem cerca de 120 milhões de bastonetes na retina, localizados todos na periferia.

A Figura 3.2 mostra as densidades de ambos os tipos de receptores da retina em seres humano, em função da excentricidade $\alpha$ (ângulo em relação a fóvea em graus). No centro $0^{\circ}$ é onde possui a maior concentração de cones. Sua densidade é decrementada rapidamente em $10^{\circ}$ em relação a fóvea, permanecendo baixa a partir de então. Isto explica a nossa decrescente habilidade em ver objetos projetados longe do centro da retina.

Os bastonetes, ao contrário dos cones, são praticamente ausentes na fóvea. A densidade de bastonetes atinge seu pico em torno de $20^{\circ}$ graus de excentricidade e depois diminui lentamente. O grande número de bastonetes permite que a retina detecte mudanças sutis de iluminação mesmo durante o dia quando eles estão, em sua maioria, saturados. O sinal dos bastonetes é uma boa base para detecção de movimentos, porém, apresenta uma perda na acuidade espacial. Por esta razão a fóvea não contém bastonetes, é dedicada a uma precisa, diurna, análise de formas baseada nos sinais dos cones.

Existe ainda, uma região na retina onde não se encontra nem cones nem bastonetes: blind spot, ou ponto cego, com cerca de $5^{\circ}$ de campo visual na horizontal e $7^{\circ}$ de campo visual na vertical e seu centro está aproximadamente a $15^{\circ}$ para o lado nasal e $1.5^{\circ}$ acima da fóvea . É a região de onde sai o nervo óptico em direção ao cérebro, Figura 3.3. Desprovida de células receptoras, qualquer imagem que se forma nesse local não será 

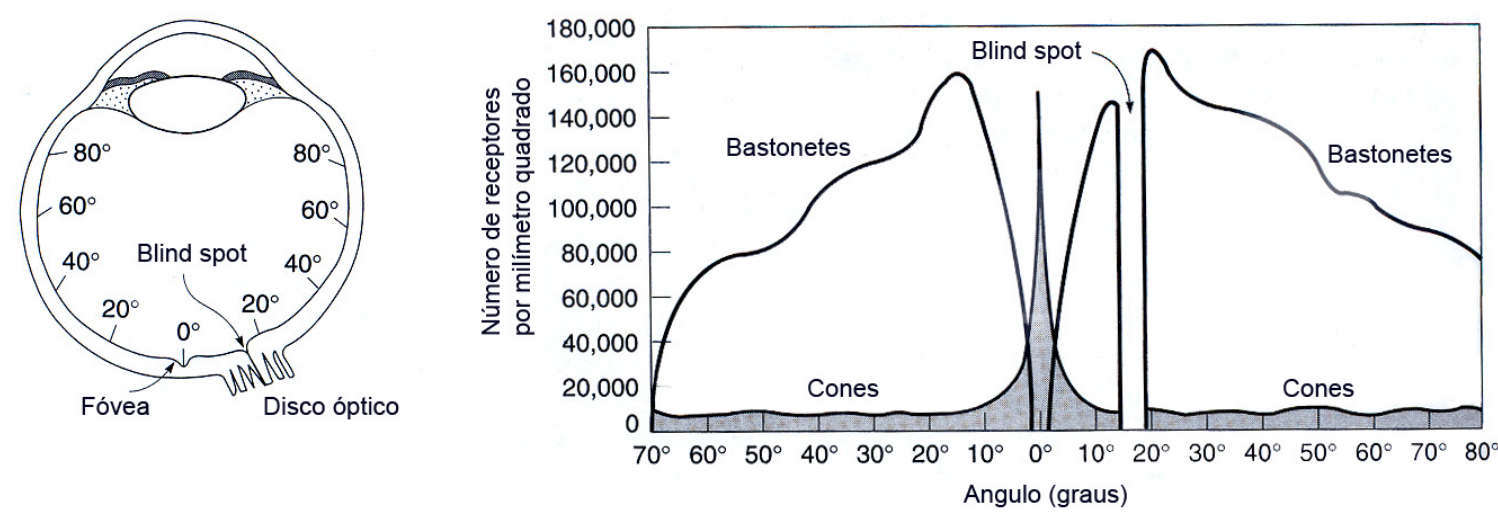

Figura 3.2: Distribuição das células receptoras na retina, produzido por Osterberg (1935) e adaptado por Lindsay e Norman (1977). Extraído de (Gol02).

vista.

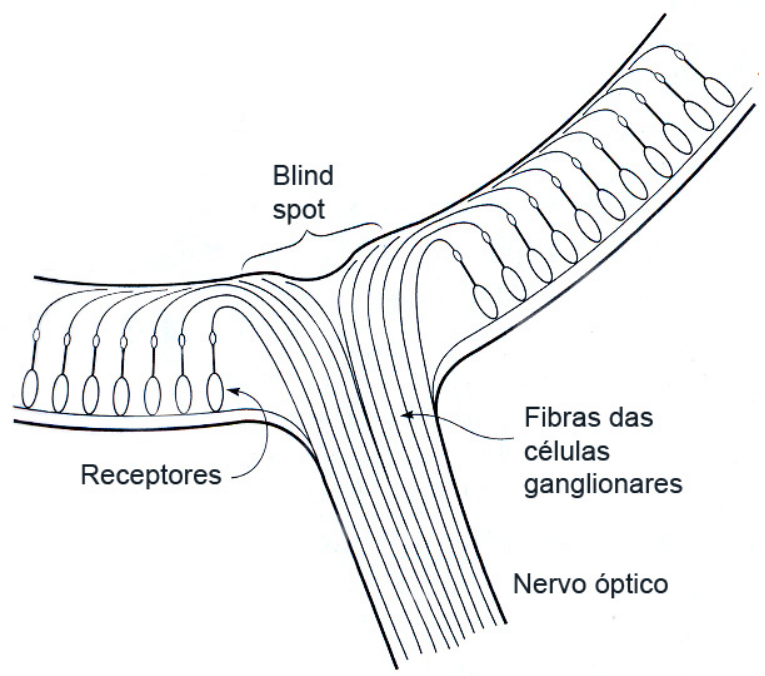

Figura 3.3: Organização das celulas na retina no disco óptico.Extraído de (Gol02)

O decremento da densidade com a excentricidade não é observado somente nos receptores, mas também para todas as células subsequentes da retina, incluindo células ganglionares.

\subsection{Patologias da retina}

As patologias que envolvem a retina podem causar alguns danos às suas células, provocando uma deficiência no sistema visual humano. Muitas delas dificultam a formação de imagens e até mesmo resultando na total perda da visão. A seguir são mostrados algumas 
Retina: anatomia geral e fisiologia

das mais conhecidas doenças envolvendo a retina.

Quando os raios ultravioletas (UV) interagem com o oxigênio, radicais livres (moléculas com pares desequilibrados de elétrons) são gerados. Estes radicais podem danificar as células da mácula nos olhos, causando a formação de toxinas e algumas vezes o crescimento de finos vasos sanguíneos sob a mácula, resultando no que se chama de degeneração macular relacionada à idade.

A retinopatia diabética, Figura 3.4 é o resultado dos efeitos do diabetes nos vasos sanguíneos da retina. O diabetes leva os vasos sanguíneos da retina a apresentar vazamento (soro e sangue) e crescimento anormal (Hos08).

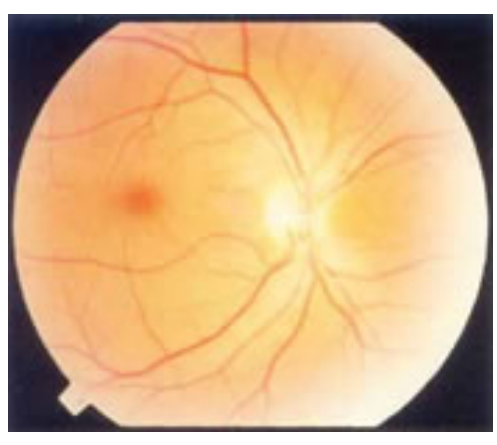

(a)

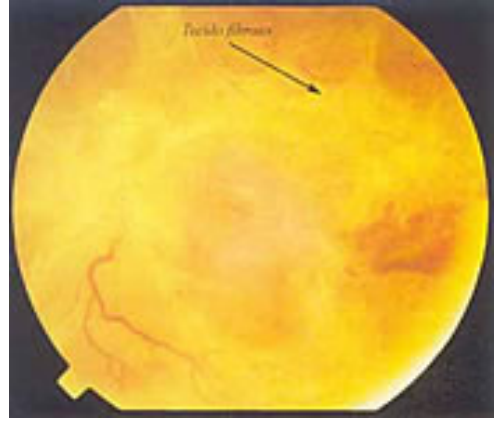

(b)

Figura 3.4: Foto tirada de uma retina (a) normal e (b) uma retina diabética. Extraído de (Hos08).

O descolamento de retina é a separação da retina da parede do fundo do olho. Quando há uma rotura de retina, o líquido do vítreo pode passar através desta rotura e descolar a retina (Hos08).

Glaucoma é o aumento da pressão intra-ocular que pode ocasionar lesão ao olho se não for tratado. A pressão intra-ocular aumentada pode comprimir os vasos sanguíneos que nutrem as sensíveis estruturas visuais do fundo do olho. Devido à falta de irrigação sanguínea, as células nervosas da retina e o nervo óptico vão morrendo provocando perda progressiva da visão e estreitamento do campo visual. Se o processo não for controlado pode levar à cegueira $(\operatorname{Hos} 08)$. 


\subsection{Sinais de saída da retina}

Quando a luz atinge a parte de trás do olho é absorvida pelas células receptoras (cones e bastonetes). Em seguida as camadas subsequentes transformam o sinal visual, definindo os sinais de saída da retina. Por fim, as células ganglionares enviam o sinal para o cérebro em forma de "trens de pulsos" (spike trains em inglês).

A informação conduzida ao cérebro é também subdividida em dois outros grupos formados por células ganglionares ON e OFF. A distinção que há entre tais células da retina é o seu comportamento em resposta à incidência de luz no seu campo receptivo. As células $\mathrm{ON}$ respondem fortemente ao incremento da luz, enquanto as células OFF respondem fortemente ao decremento da luz.

\subsubsection{Campos receptivos}

Como visto anteriormente, o sinal captado pelos receptores viaja através das células horizontais, bipolares e amácrinas para finalmente chegar aos gânglios e ir para o cérebro pelo nervo óptico. Uma importante propriedade desta rede de neurônios é que sinais provenientes de muitos receptores convergem em uma única célula ganglionar.

No domínio da visão, o campo receptivo de uma célula ganglionar $\mathbf{G}$ é definido como a área na retina que, quando estimulado pela luz, influencia na taxa de resposta do neurônio G, ou seja, a área correspondente na retina constituída pelos receptores que convergem para o gânglio $\mathbf{G}$.

A Figura 3.5 mostra um campo receptivo com diferentes áreas rotuladas como $\mathbf{A}, \mathbf{B}$ e C. No lado esquerdo da figura, são apresentadas as taxas de respostas do campo em três situações diferentes. Se qualquer região da área $\mathbf{A}$ for estimulada por feixes de luz, não haverá nenhuma alteração na atividade do neurônio, Figura 3.5(a). Caso a região estimulada for na área $\mathbf{B}$, haverá um incremento na taxa de resposta do neurônio, Figura 3.5(b). Esta área é marcada com um sinal + para indicar que a resposta para um estímulo nesta área é excitatória. Por outro lado, se o estímulo for sobre a área $\mathbf{C}$ haverá uma resposta inibitória causando um decremento na taxa de resposta do neurônio, Figura 3.5(c). Esta área é marcada com um sinal - para indicar que a resposta neste local é inibitória. Assim, as áreas $\mathbf{B}$ e $\mathbf{C}$ formam juntas um campo receptivo de um neurônio. 
Retina: anatomia geral e fisiologia

(a)

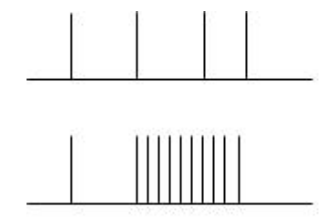

(c)
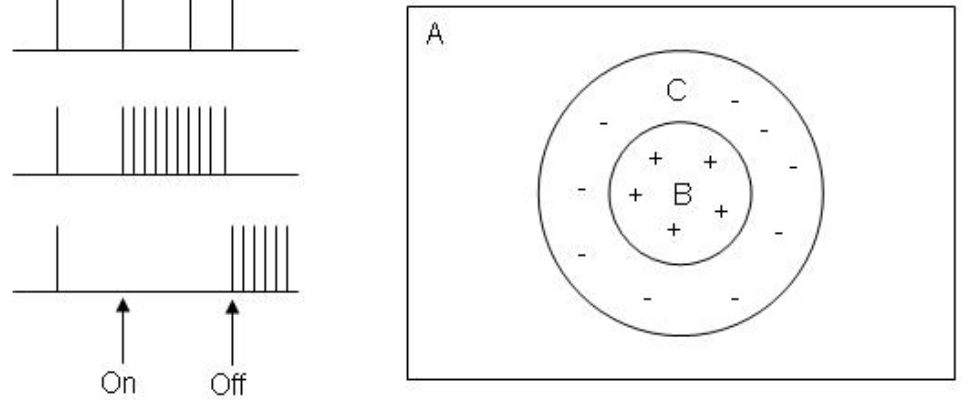

Figura 3.5: Resposta de um campo receptivo sob estímulo em diferentes regiões. (a) Fora do campo receptivo (área A). (b) Dentro da área excitatória do campo receptivo (área B). (c) Dentro da área inibitória do campo receptivo (área C).

Estes campos receptivos são antagônicos entre si, isto é, quando a porção central for ON, a porção periférica será OFF e vice-versa.

O campo receptivo da Figura 3.5 é chamado center-surround porque as áreas excitatórias e inibitórias são organizadas em uma área circular que responde de uma forma em sua região central e de maneira oposta na periferia. O campo receptivo neste caso é chamado de excitatory-center-inhibitory-surround ou simplemente ON-Center-OFFSurround, mas existem também campos receptivos inhibitory-center-excitatory-surround ou OFF-Center-ON-Surround. Na Figura 3.6 são mostradas as respostas em diferentes situações de estimulo de luz nos dois tipos de campos receptivos.

O número de campos receptivos ON-Center-OFF-Surround é aproximadamente igual ao número de campos receptivos OFF-Center-ON-Surround. Ambos os tipos possui maior taxa de resposta nas proximidades das bordas influenciando no processo de detecção de bordas que será visto na próxima seção.

\section{Tamanho do campos receptivos}

O tamanho de um campo receptivo varia sistematicamente de acordo com a excentricidade da retina. No centro, na região da mácula, seu tamanho é bem pequeno chegando a medir $0.01 \mathrm{~mm}$. As células deste local são responsáveis pelo monitoramento de pequenas áreas no campo visual. No entanto, a medida em que os campos receptivos se afastam da mácula e adentram na periferia da retina, o seu tamanho aumenta cada vez mais, chegando a medir cinquenta vezes em relação aos da fóvea. Neste local, as células coletam informações de áreas bem maiores. 
Retina: anatomia geral e fisiologia

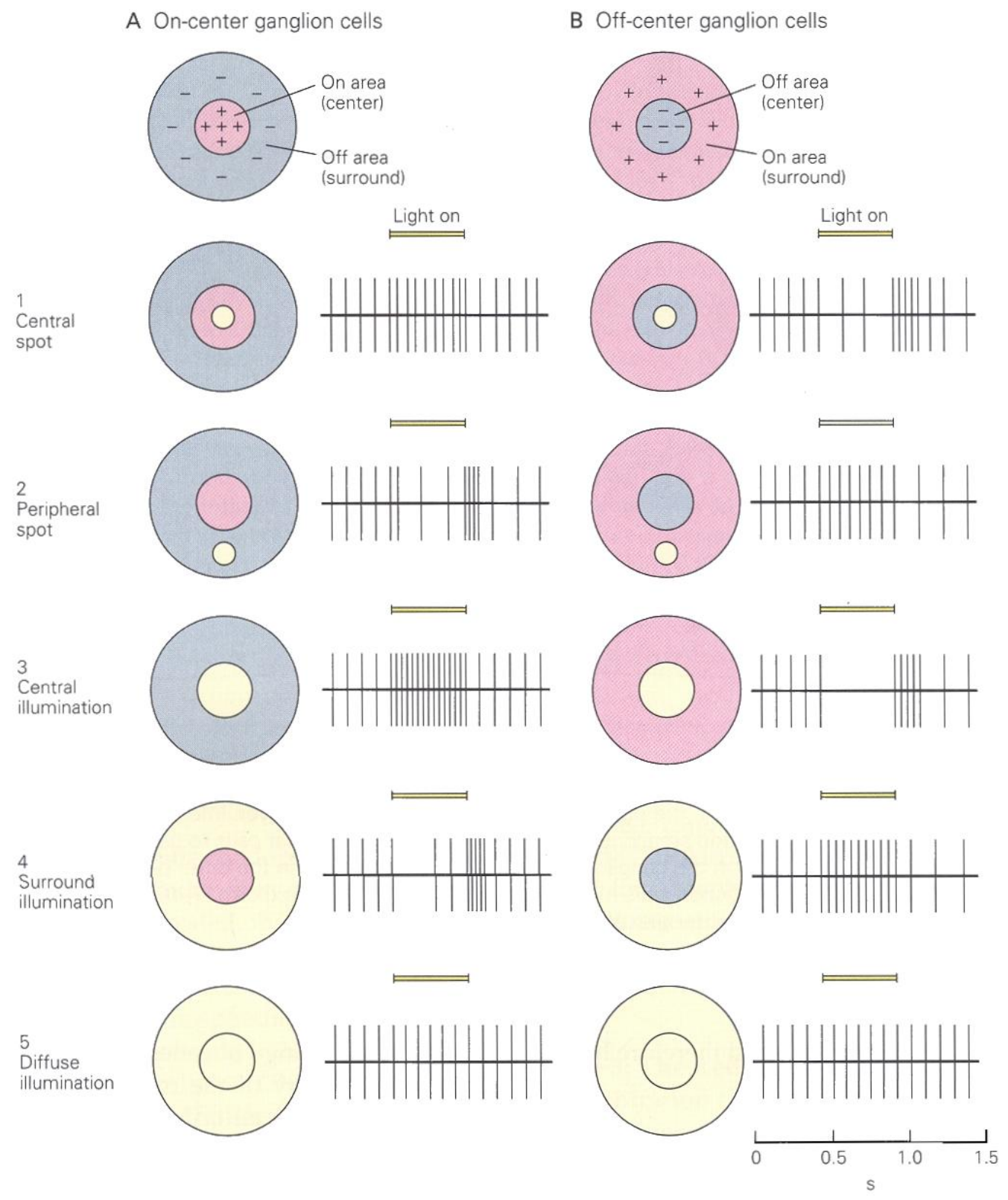

Figura 3.6: Resposta dos campos receptivos ON e OFF com arquitetura center-surround. Extraído de (EK00) 


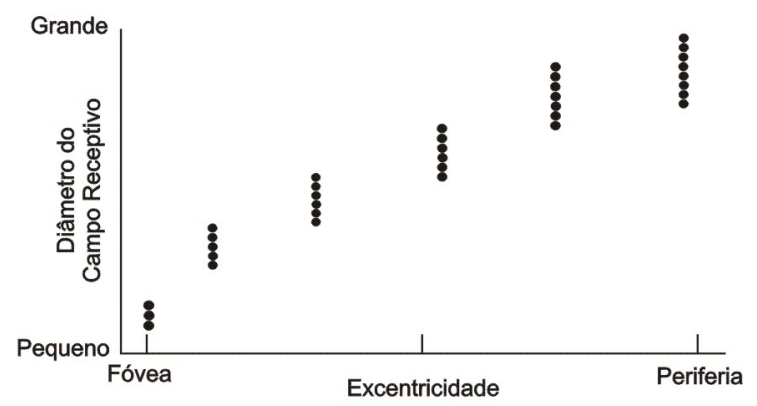

Figura 3.7: Gráfico mostrando como o tamanho do campo receptivo aumenta em relação a distância da fóvea. Extraído de (SB90)

O gráfico da Figura 3.7 mostra a relação entre o tamanho dos campos receptivos e suas posições ao longo da retina. O eixo horizontal apresenta o local da retina em que os campos receptivos estão posicionados e o eixo vertical apresenta o diâmetro dos mesmos. Assim, com o incremento da excentricidade - afastamento do centro da retina - o tamanho do diâmetro do campo receptivo tende a incrementar também.

O mesmo gráfico revela outra importante característica: em todas as excentricidades há campos receptivos com mais de um único tamanho, esse fenômeno é conhecido como "variação local".

\section{Tipos de campos receptivos}

Além dos tipos ON e OFF de células ganglionares, há também as informações separadas nos caminhos parvocelular (gânglios P) e magnocelular (gânglios M), descritos na Seção 3.3. Dentro deste contexto temos quatro tipos de campos receptivos: caminho parvovelular On-Center Off-Surround, caminho parvocelular Off-Center ON-Surround, caminho magnocelular On-Center Off-Surround e o caminho magnocelular Off-Center On-Surround. Além destes sinais, há também aqueles nos quais são gerados pela relação quase 1 à 1 (Figura 3.1) contendo informações originais tais como as cores e a intensidade da luz incidente.

As principais diferenças entre células ganglionares $\mathrm{P}$ e M em seres humanos são:

- Tamanho da célula: sob microscópio, os gânglios M são mais largos do que os gânglios $\mathrm{P}$, e a parte da célula que transporta a informação para fora da retina, o axônio, é mais espessa em células M. Isto significa que impulsos neurais viajam 
mais rapidamente para o cérebro através dos axônios das células $\mathrm{M}$, uma vez que a velocidade de condução de impulsos neurais aumenta com a espessura axônio.

- Número: gânglios P e M diferem altamente em número, com aproximadamente $80 \%$ dos gânglios pertencendo a classe P.

- Tamanho do campo receptivo: o tamanho do campo receptivo dos gânglios $\mathrm{P}$ são menores que o tamanho do campo receptivo dos gânglios M para qualquer excentricidade na retina. Isto significa que células $\mathrm{P}$ respondem melhor a menores objetos do que células M.

- Sensibilidade: células M respondem melhor a baixa diferença de luz do que células P. As células $\mathrm{P}$ necessitam de muito mais variação na luz para obter uma alta taxa de resposta. Esta distinção entre células $\mathrm{P}$ e M sugere que campos receptivos $\mathrm{M}$ sejam particularmente importantes para a percepção de objetos em baixo contraste, como letras escuras em um fundo cinza. Enquanto campos receptivos $\mathrm{P}$ sejam mais importantes para ver objetos em alto contraste, como letras escuras em um fundo branco.

- Cores: para células P, uma resposta excitatória é obtida somente quando o campo receptivo é estimulado por uma determinada cor, neste caso o campo é inibitório para as demais cores. Diferentes células P respondem a diferentes cores. No caso das células $\mathrm{M}$ as cores não fazem a menor diferença, pois estas respondem de forma igual para qualquer cor.

\subsubsection{Detecção de bordas}

A arquitetura center-surround dos campos receptivos proporciona uma importante funcionalidade às células ganglionares: sensibilidade ao contraste espacial atuando como um detector de bordas. O sinal periférico do campo receptivo estabelece uma média da iluminação, que pode ser comparado com o valor central da célula, aumentando assim, a sensibilidade da retina para pequenos detalhes.

Por exemplo, quando uma borda está presente em uma imagem, as respostas são mais fortes para as células localizadas próxima da borda, de tal forma que o centro do campo 
Retina: anatomia geral e fisiologia

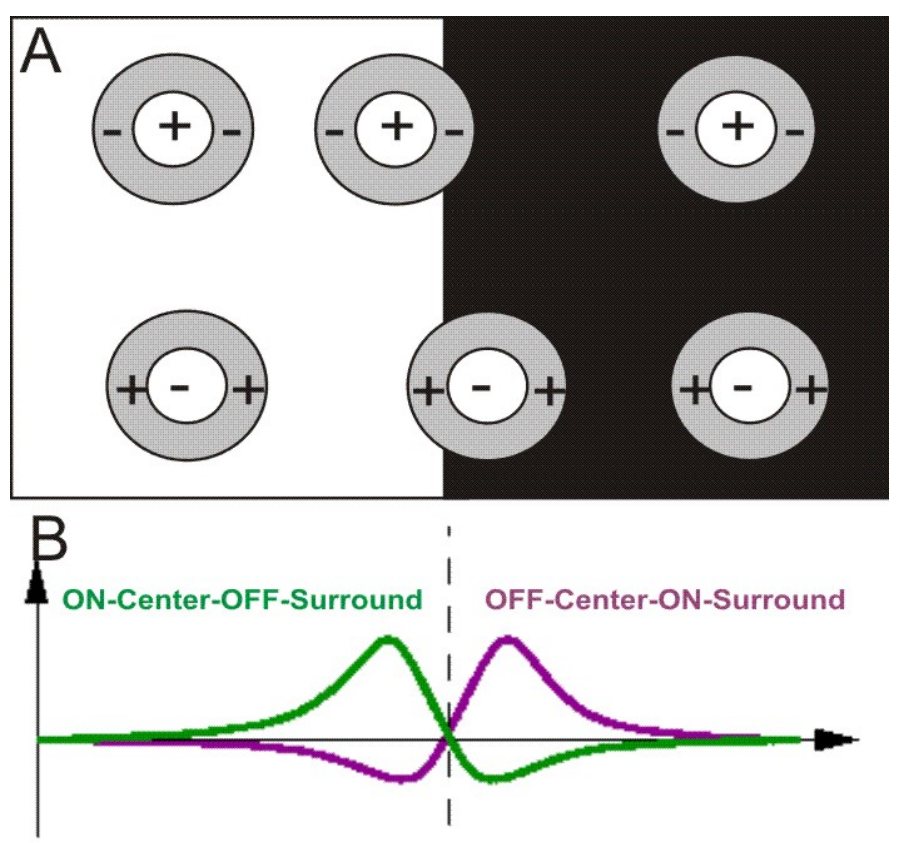

Figura 3.8: Detecção de bordas via arquitetura center-surround. A: Campos receptivos center-surround em diferentes locais. B: Correspondentes taxas de respostas das atividades das células ON e OFF ao longo de uma linha unidimensional perpendicular a borda.

receptivo fica em um único lado da borda, proporcionando um forte sinal excitatório para as células On-Center Off-Surround. Enquanto sua periferia fica parte em um lado da borda e outra parte de outro lado, provocando um pequeno sinal inibitório, resultando em uma alta taxa de resposta para a célula. Analogamente acontece para as células Off-Center On-Surround. Esta propriedade é esquematizada na Figura 3.8. 


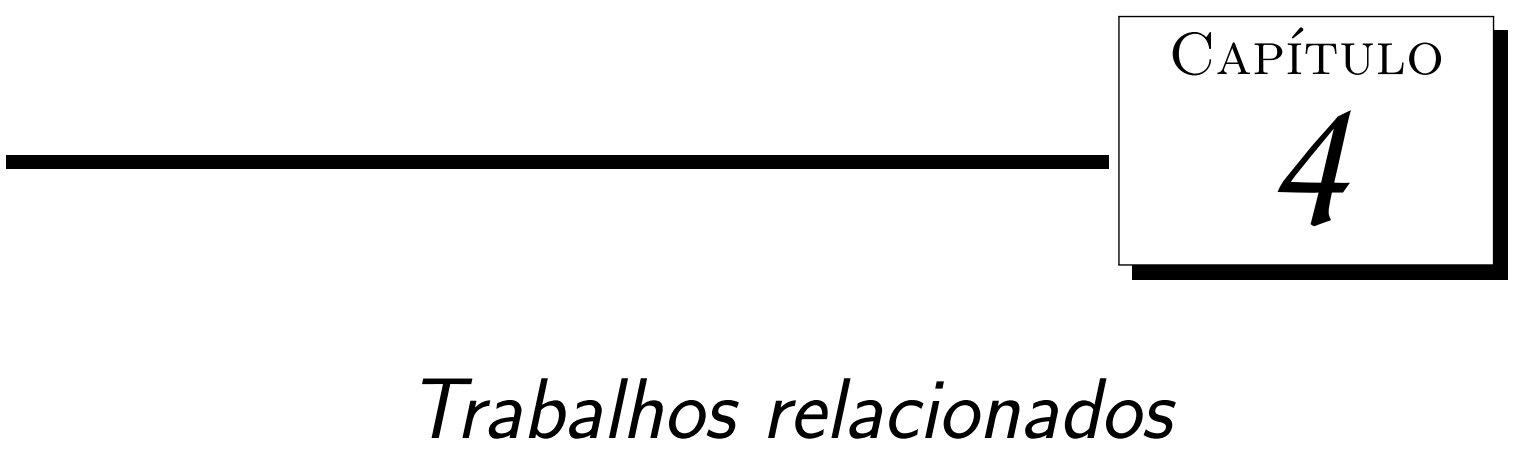

Neste Capítulo são mostradas resumidamente algumas abordagens matemáticas e computacionais encontradas na literatura com o objetivo de modelar e/ou simular a visão humana. Destacam-se modelos referentes à distribuição das células receptoras e suas funcionalidades, e também, às representação dos campos receptivos das células ganglionares presentes na retina humana.

\subsection{Transformação Log-Polar}

A transformação log-polar foi um dos primeiros métodos utilizados na representação de imagens com multirresolução bioinspirada. A geometria da imagem log-polar foi motivada por sua semelhança com a estrutura da retina de alguns sistemas biológicos de visão e por suas qualidades de compressão de dados. Quando comparado com as imagens cartesianas de costume, o log-polar imagens permitem maiores taxas de amostragem em sistemas de visão artificial, sem reduzir o tamanho do campo de visão e da resolução sobre a parte central da retina (fóvea) (Pet07), (VJT08) e (WQXz05).

O domínio da transformação é um conjunto de pontos de uma imagem bidimensional $I(x, y)$ indexado pelo Sistema de Coordenadas Cartesianas, e o conjunto imagem é dado por uma matriz $F(\eta, \xi)$. O algoritmo da transformação é dado em duas partes: a distância 
do pixel $(x, y)$ ao centro e o ângulo formado do raio do ponto $(x, y)$ com o centro (Figura $4.1)$.
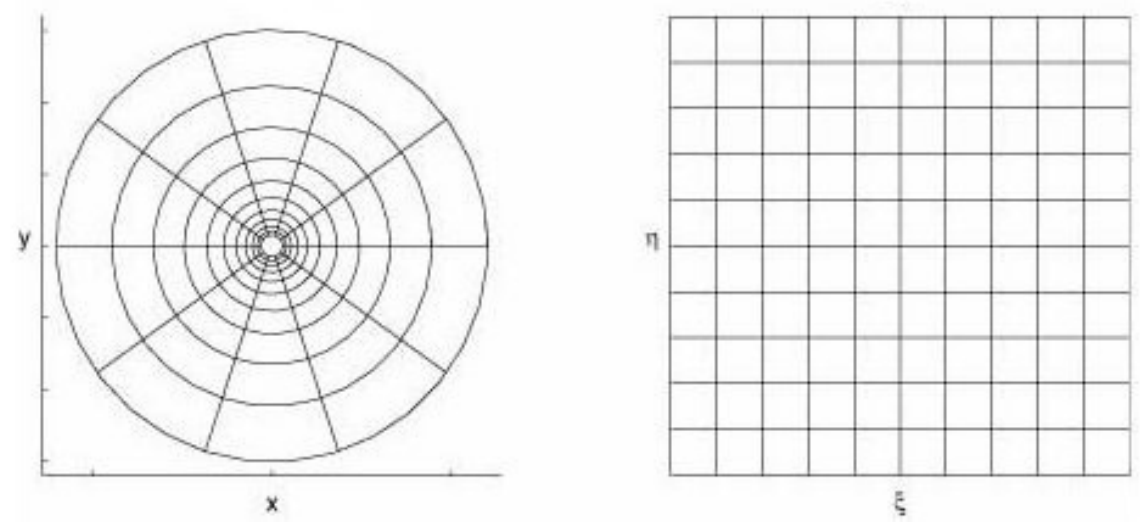

Figura 4.1: Lado esquerdo Plano de coordenadas cartesianas e Lado direito plano de coordenadas log-polar..

A transformação da distância é uma operação logarítmica:

$$
\begin{gathered}
\rho=\sqrt{\left(x-\text { Center }_{x}\right)^{2}+\left(y-\text { Center }_{y}\right)^{2}} \\
\eta=\log (\rho)
\end{gathered}
$$

Onde Center e Center $_{y}$ são as coordenadas cartesianas do foco da imagem. E para transformação do ângulo é usada uma operação arc-tangent:

$$
\xi=\operatorname{arctg}\left(\frac{y-\text { Center }_{y}}{x-\text { Center }_{x}}\right)
$$

O inverso da transformação resulta na imagem final com multirresolução bioinspirada. A inversa é dada por:

$$
\begin{gathered}
\rho=\exp (\eta) \\
\theta=\xi
\end{gathered}
$$

E as coordenadas cartesianas são dadas por: 
Trabalhos relacionados

$$
\begin{aligned}
& x=\rho \cdot \cos (\theta)+\text { Center }_{x} \\
& y=\rho \cdot \operatorname{sen}(\theta)+\text { Center }_{y}
\end{aligned}
$$

O resultado pode ser observado na Figura 4.2

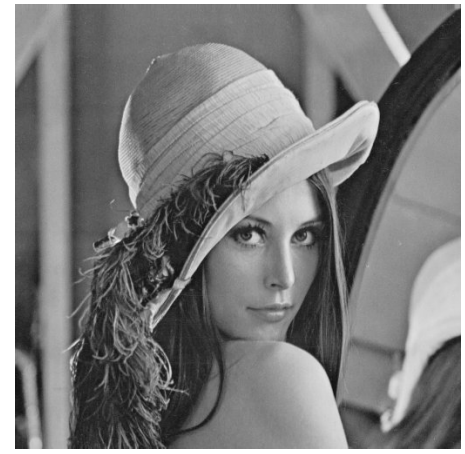

(a)

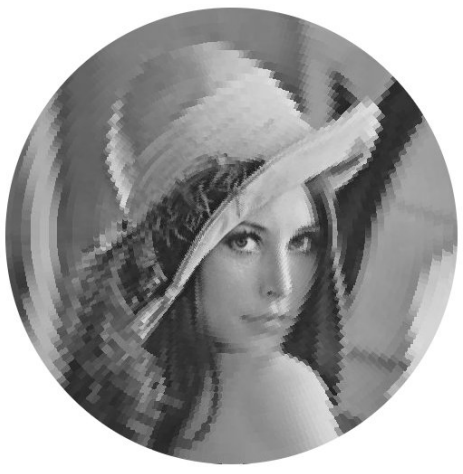

(b)

Figura 4.2: (a) Imagem original. (b) Inverso da distribuição log polar.

\subsection{Filtro bioinspirado}

Este é um trabalho desenvolvido por Frédérique Robert e Eric Dinet (FR97) na França que consiste em um filtro que usa a característica de mutirresolução da retina (fóvea e periferia). A abordagem é baseada na distribuição radial. Do ponto focal (centro da fóvea) para o limite da fóvea, a resolução não será alterada, enquanto fora da zona da fóvea, a resolução será decrementada em função linear da excentricidade.

Primeiro, algumas características são dadas para descrever a distribuição radial. Definese duas sequências de raios. A primeira são os raios de cada anel concêntrico no ponto de foco (fóvea) $\left(R_{n}\right)$ e a segunda sequência define os raios de atuação dos pontos definidos em cada anel $\left(r_{n}\right)$ (Fgura 4.3). São definidos dois fatores, o primeiro permite a seleção da distribuição em função do ângulo e o segundo em função do raio de cada anel.

As duas sequências de raios $R_{n}$ e $r_{n}$ são dadas pela seguinte fórmula:

$$
R_{n}=R_{0} \cdot\left(1+\frac{2 v_{r}\left(1-v_{\theta}\right)}{2-v_{r}\left(1-v_{\theta}\right)}\right)
$$

Onde $R_{0}$ é o raio da área da fóvea e $v_{r}$ e $v_{\theta}$ são os dois fatores definidos.

A Figura 4.4 mostra uma imagem gerada por essa filtragem. 


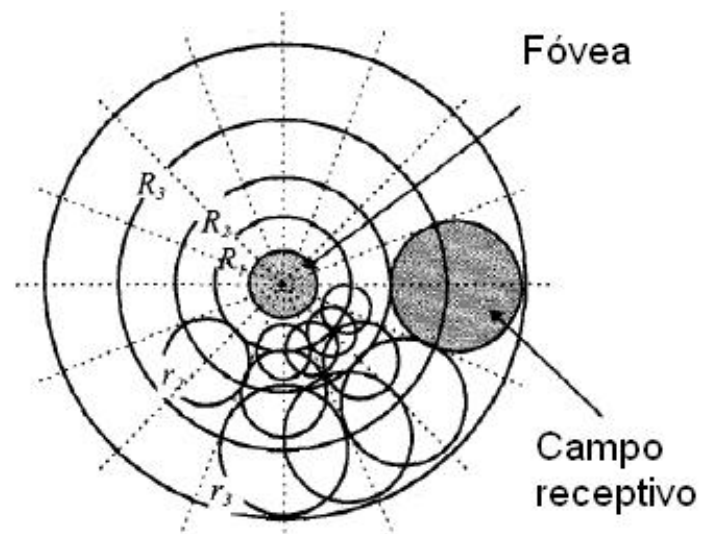

Figura 4.3: Distribuição dos pontos em função da excentricidade.

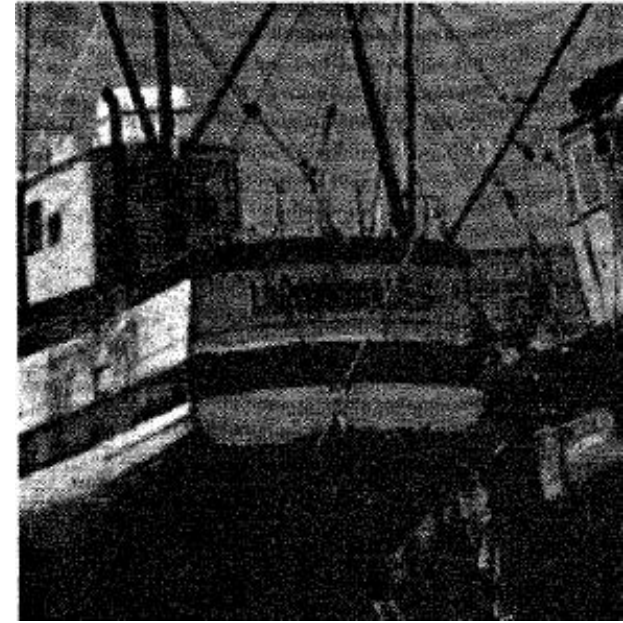

(a)

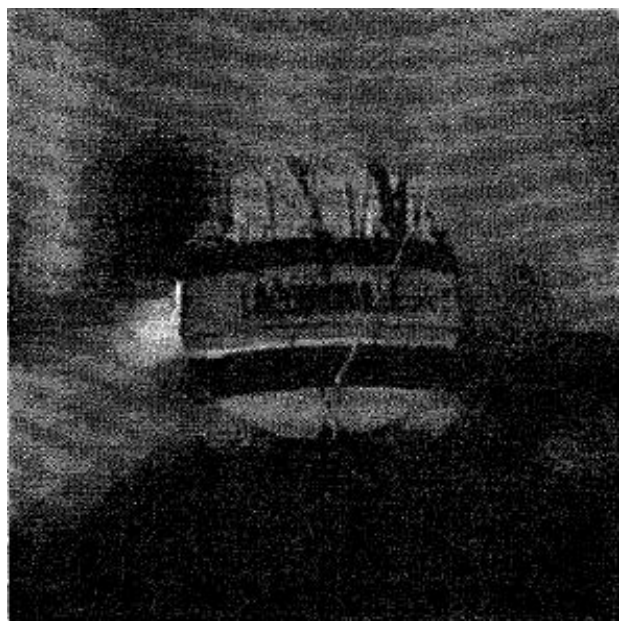

(b)

Figura 4.4: (a) Imagem original. (b) Resultado da aplicação do filtro.

\subsection{Retina artificial com campos receptivos DoG}

Neste trabalho, Basasuria e Siebert (BS05), apresentam um método para mapear os pontos das células na imagem usando a distribuição log polar. Se $z=x+j y$ é a localização de um campo receptivo na imagem, então o correspondente local na retina artificial é dado pelo $\log (z)$, onde:

$$
\log (z)=\log (|z|)+j \cdot \arg (z)=\log (\text { excentricidade })+j \cdot(\text { angulo })
$$

Os campos receptivos são colocados em cada ponto na distribuição e o tamanho do campo é calculado baseado na distancia com seu vizinho mais próximo e são modelados 
por Diferenças de Gaussianas (Difference of Gaussians-DoG):

$$
D o G=G_{\sigma 1}-G_{\sigma 2}=\frac{1}{\sqrt{2 \pi}}\left[\frac{1}{\sigma_{1}} e^{-\left(x^{2}+y^{2}\right) / 2 \sigma_{1}^{2}}-\frac{1}{\sigma_{2}} e^{-\left(x^{2}+y^{2}\right) / 2 \sigma_{2}^{2}}\right]
$$

Na Figura 4.5 é mostrada a reconstrução da imagem da Lena usando os campos receptivos $D o G$.

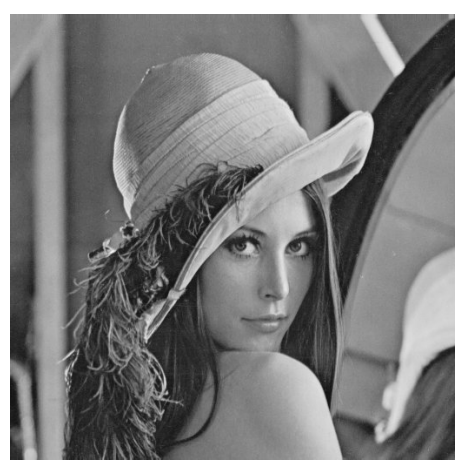

(a)

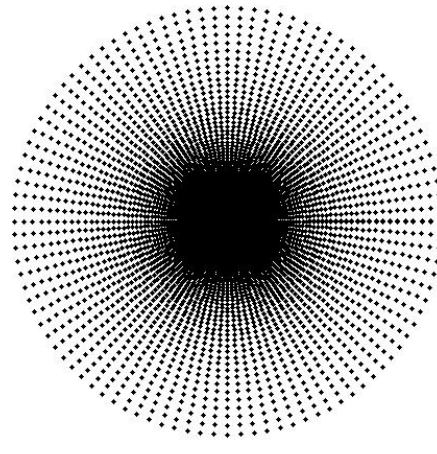

(b)

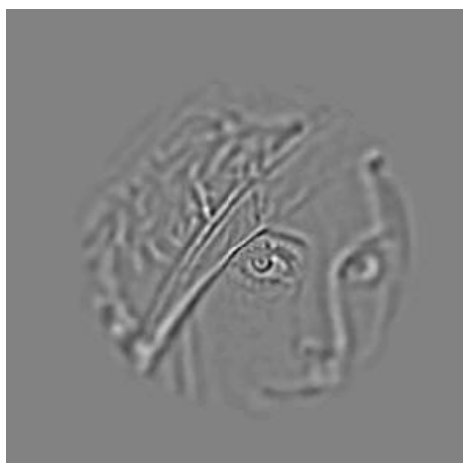

(c)

Figura 4.5: (a) Imagem original. (b) Distribuição celular. (c) Capos receptivos DoG.

\subsection{Simulação de visão na retina biológica}

Este é um trabalho desenvolvido por Hui Wei e XuDong na china, Universidade de Shanghai (WG08). Este modelo apresenta uma simulação para distribuição para células receptoras e o comportamento dos campos receptivos das células ganglionares presentes na retina humana.

O código seguinte descreve a geração das celulas receptoras da retina no primeiro quadrante (Figura 4.6).

1. Calcula o tamanho do lado do quadrado inscrito e circunscrito $L_{1}$ e $L_{2}$ respectivamente.

2. Defina quatro matrizes bi-dimensional $A_{m x n}, B_{m x m}, C_{n x m}$ e $A_{m x m}$ (Fogura 4.6), onde $m$ é o número de células na horizontal e $n$ na vertical e pode ser calculado por:

$$
\begin{aligned}
& m=\left(L_{2}-L_{1}\right) \cdot \sqrt{D} \\
& n=L_{1} \cdot \sqrt{D}
\end{aligned}
$$




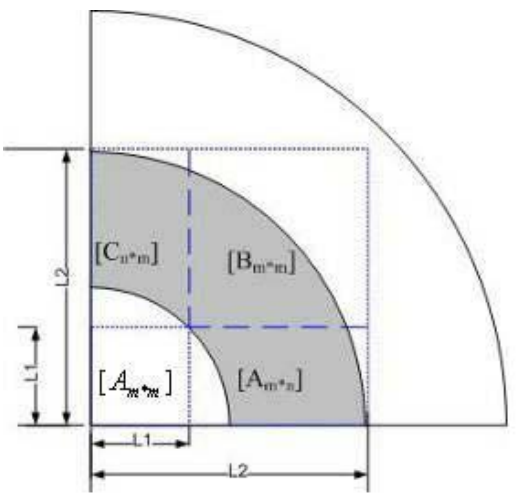

Figura 4.6: Matrizes de células da retina.

Onde $D$ é a densidade dada pelo gráfico da Figura 3.2.

3. A geração dos pontos de células para cada matriz é dada por:

$$
\begin{aligned}
& A_{m x n}(x, y)_{i, j}=\left(L_{1}+i \cdot 1 / \sqrt{D}, j \cdot 1 / \sqrt{D}\right) \\
& B_{m x m}(x, y)_{i, j}=\left(L_{1}+i \cdot 1 / \sqrt{D}, L_{1} j \cdot 1 / \sqrt{D}\right) \\
& C_{n x m}(x, y)_{i, j}=\left(i \cdot 1 / \sqrt{D}, L_{1}+j \cdot 1 / \sqrt{D}\right) \\
& i \in[0, m-1], j \in[0, n-1]
\end{aligned}
$$

Para melhorar a performance do programa, são calculados somente os pontos nas áreas cinzas da Figura 4.6.

As células ganglionares tem a estrutura center-surround antagônica dos campos receptivos. É usado o modelo 4.10 para gerar os sinais de saída dessas células.

$$
R_{g}(x, y)=R_{\text {center }}(x, y)-R_{\text {surround }}(x, y)
$$

Onde $R_{g}(x, y)$ é a saída do gânglio no ponto $x, y$ da imagem, $R_{c e n t e r}(x, y)$ é a saída da área central e $R_{\text {surround }}(x, y)$ é a saída da periferia.

A Figura 4.7(b) mostra as atividades das células ganglionares deste modelo. No canto inferior esquerdo está localizada a região da fóvea, apresentando maior resolução.

\subsection{Campos Receptivos de Marr-Hildreth}

O filtro de Marr-Hildreth (Mar96) é um dos detectores de borda mais populares em processamento de imagens. Uma das razões para isto é a sua forte base biológica, que 


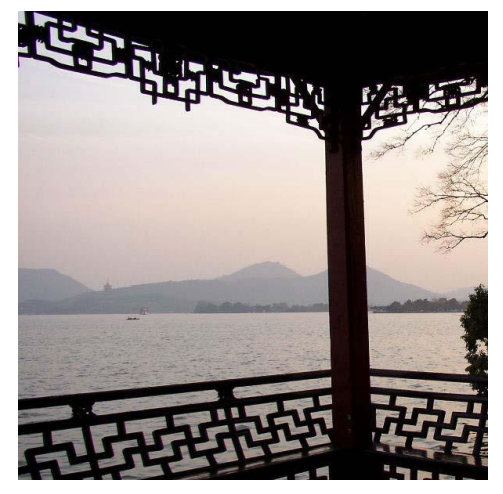

(a)

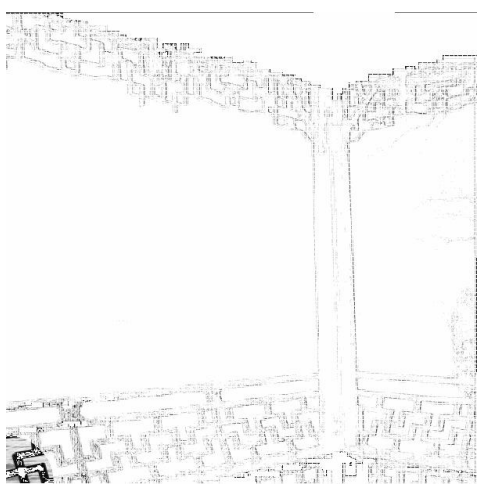

(b)

Figura 4.7: (a) Imagem original. (b) Atividade das células ganglionares na retina.

apresentam características semelhantes aos campos receptivos localizados na retina humana. O método é baseado na segunda derivada da gaussiana:

$$
\nabla^{2} G_{\sigma}=-\frac{1}{\sqrt{2 \pi \sigma_{3}}} \cdot\left(2-\frac{x^{2}+y^{2}}{\sigma_{2}}\right) e^{\frac{x^{2}+y^{2}}{2 \sigma^{2}}}
$$

Para determinar as bordas do sinal $I$, é realizada a convolução com o filtro de MarrHildreth $\left(I \otimes \nabla^{2} G_{\sigma}\right)$ e localizados os cruzamentos no eixo $x$ (cruzamentos por zero), que correspondem as bordas do sinal.

A Figura 4.8 é uma representação do filtro no espaço tridimensinal.

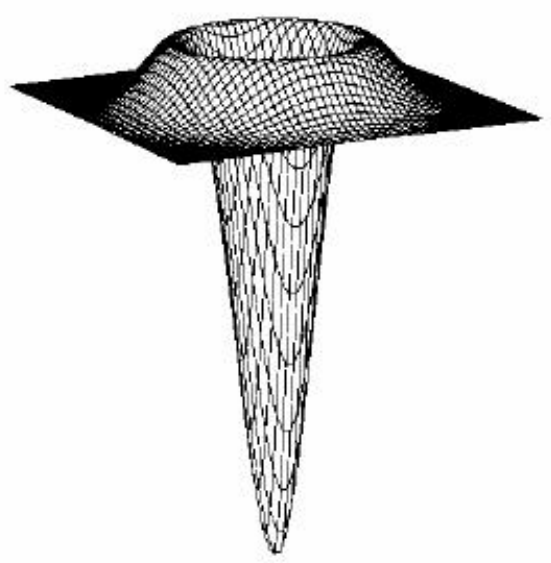

Figura 4.8: Representação do filtro de Marr-Hildreth. 
Trabalhos relacionados 


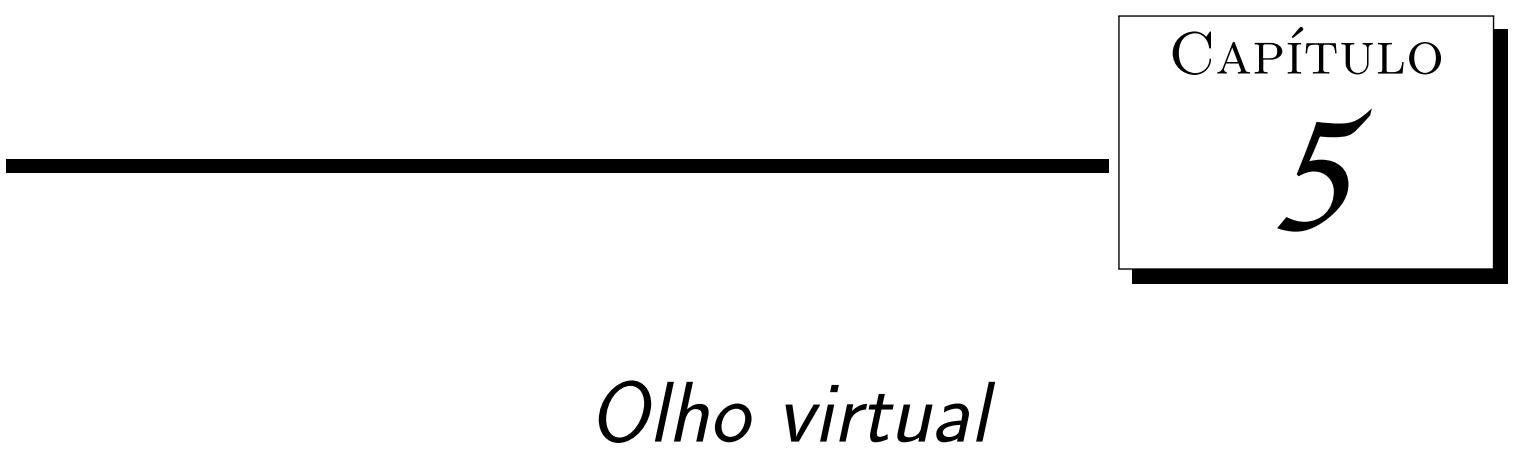

O Olho Virtual consiste em um modelo anatômico realístico de um olho humano em um ambiente virtual capaz de reproduzir, tridimensionalmente, suas estruturas com a finalidade de simular o processo de visão humana e as propriedades ópticas nele envolvidas. Trata-se de um sistema computacional desenvolvido com diversos algoritmos de computação gráfica, matemáticos e físicos, atuando sobre dados reais in-vivo, obtidos de um topógrafo de córnea, e/ou simulados em um computador.

O Olho Virtual é basicamente dividido em três módulos: modelagem, simulação ou traçado de raios e visualização. No módulo de modelagem são construídas as estruturas necessárias para formar os modelos esquemáticos do olho humano, bem como a córnea, pupila, cristalino e retina. Na simulação é implementada a parte óptica do sistema, onde é computado o ray tracing: lançamento de raios, cálculo de intersecções e raios refratados. E por último, na visualização, são gerados resultados gráficos para serem visualizados. A seguir é descrita a funcionalidade de cada módulo.

\subsection{Modelagem}

Este módulo é responsável pela modelagem dos principais componentes do olho humano: córnea, pupila, cristalino e retina. Foram criados modelos baseados em equações 
Olho virtual

quádricas e malhas geométricas triangulares superficiais para representar todos os componentes. A manipulação de malhas é feita com a estrutura de dados topológicos $S H E$ (Singular Handle-Edge) (NC02) (Dur05). Essa estrutura armazena diferentes entidades topológicas da modelagem, tais como células, bordas, vértices e etc. Permite realizar operações de intersecção, remoção e acesso a essas entidades de maneira simples e eficiente.

A Figura 5.1 mostra a posição do olho virtual no sistemas de coordenadas cartesiano. O centro da superfície anterior da córnea encontra-se na origem do sistema e as demais estruturas possuem valores negativos para o eixo $z$.

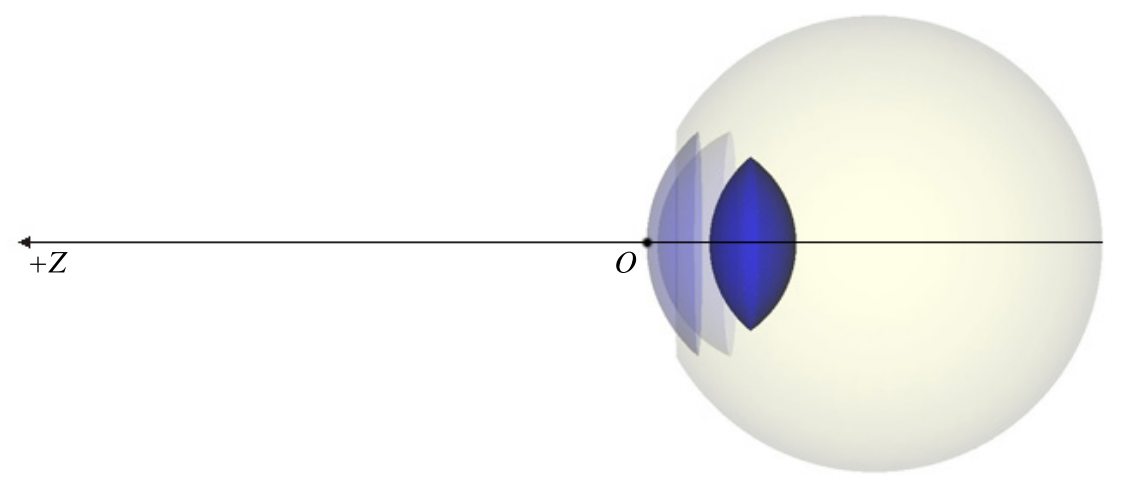

Figura 5.1: Posição do Olho Virtual no sistema de coordenadas cartesianas. O eixo $x$ está saindo do papel. A origem do sistema de coordenadas é o vértice da córnea.

\subsubsection{Modelagem por quádricas}

Em geral, os modelos esquemáticos (Seção 2.3.2) de olhos artificiais são construídos com superfícies quádricas. Cada superfície é gerada primeiramente na origem e depois transladada para a posição correta. A Equação 5.1 é usada para expressar tais superfícies (AS00).

$$
h^{2}+(1+Q) z^{2}-2 z r=0
$$

onde $z$ é o eixo óptico, $h^{2}=x^{2}+y^{2}, r$ é o raio de curvatura e $Q$ é a asfericidade da superfície:

- $Q<-1$ : a superfície é uma hiperbolóide; 
Olho virtual

- $Q=-1$ : a superfície é uma parabolóide;

- $-1<Q<0$ : a superfície é uma elipsóide, eixo maior $z$;

- $Q=0$ : a superfície é uma esfera;

- $Q>0$ : a superfície é uma elipsóide, eixo maior no plano $x y$.

\subsubsection{Modelagem por malhas}

A geração das malhas para modelar as superfícies é baseada na Equação 5.1. Córnea, cristalino e retina são criados com diferentes quádricas. Inicialmente, são definidos um número de camadas que sofrerão sucessivos processos de refinamento até que a malha atinja um nível satisfatório, resultando na superfície desejada.

São definidos cinco vértices iniciais: $v_{0}$, o vértice apex da superfície e $v_{1}, v_{2}, v_{3}, v_{4} \mathrm{e}$ $v_{5}$, que definem o plano limite da superfície. Esses vértices são arranjados na forma de um prisma $\mathbf{M}$ conforme mostrado na Figura 5.2, o vértice $v_{0}$ é o topo do prisma e a intersecção entre o eixo óptico e a superfície. Os últimos quatros vértices definem a base do prisma e o plano que limita a superfície.

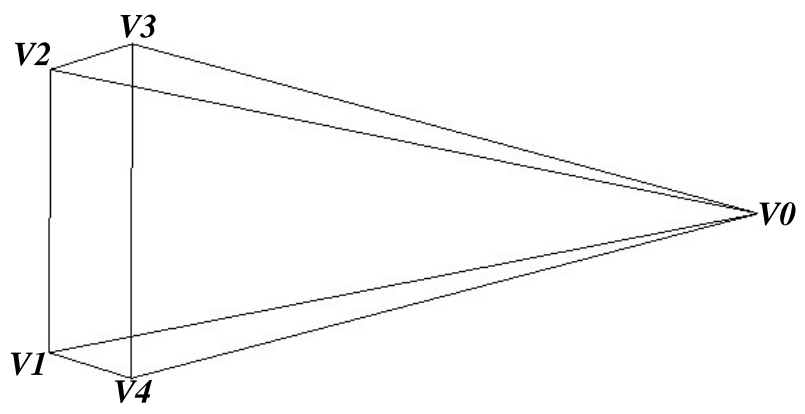

Figura 5.2: Malha inicial $\mathbf{M}$ composta pelos cinco vértices iniciais. O prisma delimita a malha.

Em seguida são adicionadas novas camadas no prisma. Se o modelo é composto por duas camadas, quatro novos vértices são adicionados, formando um plano que divide o prisma em duas áreas ou duas camadas. Se o desejado for três camadas, então oito novos vértices, formando dois planos, são acrescentados no modelo inicial dividindo o prisma da Figura 5.2 em três camadas, e assim sucessivamente para modelos com maiores números 


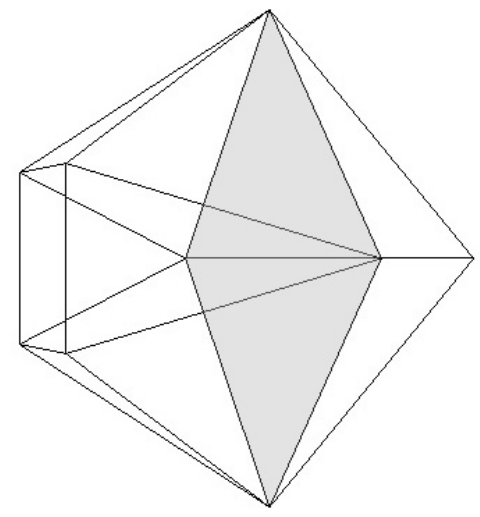

(a)

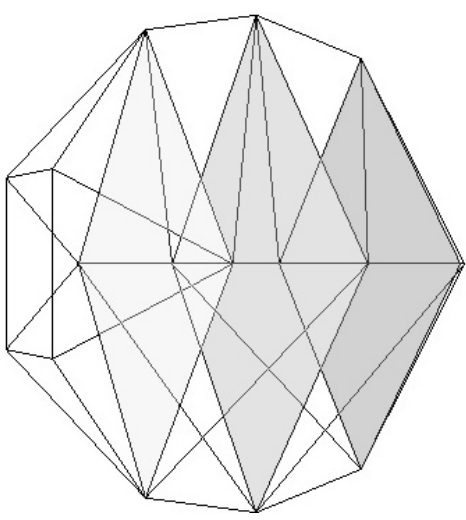

(b)

Figura 5.3: Malha inicial com (a) duas camadas e (b) quatro camadas.

de camadas. A Figura 5.3 ilustra as camadas inicias do processo de geração de malhas no VEye.

O próximo passo é o de refinamento. Os triângulos gerados na etapa de camadas são divididos em triângulos menores, formando uma superfície geométrica mais semelhante com a quádrica teórica. O refinamento é feito da seguinte forma: Seja $t$ um triângulo qualquer na malha $M$, onde $t=\Delta v_{i} v_{i+1} v_{i+2}$. Calcula-se o ponto médio das três arestas que compõem $t$, dando origem a três novos vértices $v_{k} v_{k+1} v_{k+2}$ que formam novos triângulos na malha, conforme mostrado na Figura 5.4. Estes novos triângulos são adicionados a $M$ e o triângulo original $t$ é removido.

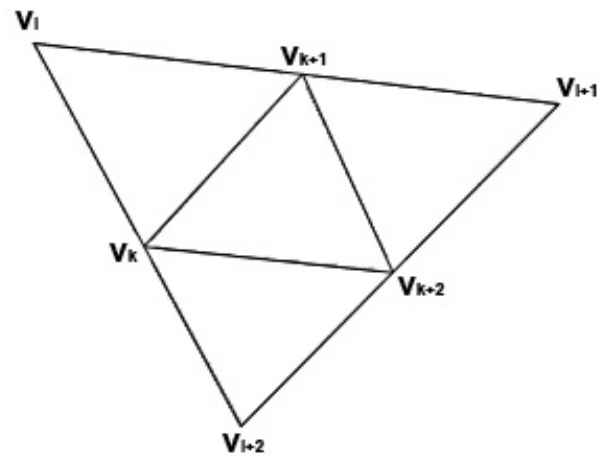

Figura 5.4: Esquema de refinamento da malha. o triângulo $t=\Delta v_{i} v_{i+1} v_{i+2}$ é removido e os demais triângulos $t_{1}=\Delta v_{i} v_{k+1} v_{k}, t_{2}=\Delta v_{k+1} v_{i+1} v_{k+2}, t_{3}=\Delta v_{k} v_{k+2} v_{i+2}$ e $t_{4}=$ $\Delta v_{k} v_{k+1} v_{k+2}$ são adicionados à malha.

Quando duas camadas adjacentes possuem números diferentes de refinamentos, surgem 
Olho virtual

em $M$ alguns buracos que prejudicam a qualidade da malha. Assim, para resolver este problema, novos triângulos são adicionados, porém, neste local a qualidade da malha diminui, pois geram triângulos com tamanho diferentes (Figura 5.5).

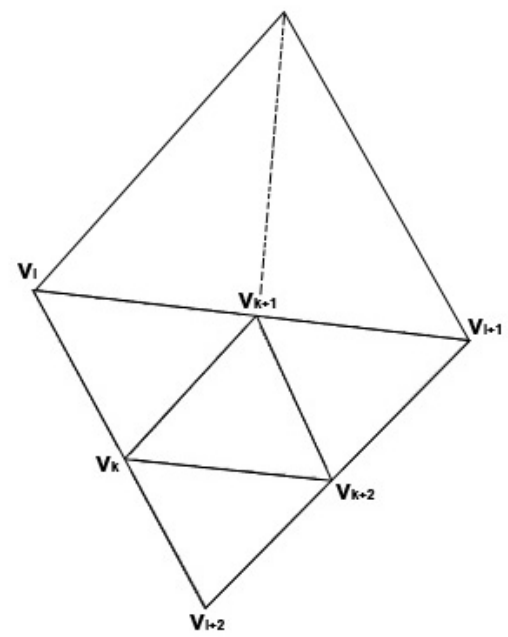

Figura 5.5: Duas camadas com número de refinamentos diferentes.

A Figura 5.6 mostra um modelo de malha para uma retina criada pelo Olho Virtual. Existe uma diferença de refinamento entre a última camada (camada mais a direita) e as demais, pois ali define o lugar onde se encontra a fóvea do olho com a maior concentração de células receptoras.

\subsubsection{Modelagem in-vivo}

Além das córneas teóricas geradas pelo computador, o Olho Virtual dispõe também de um conjunto de dados de córneas reais in-vivo, obtidos por um topógrafo de córneas do grupo de Óptica Oftalmológica do IFSC-USP São Carlos. O topógrafo mede as elevações relativas ao centro da córnea, origem $O$ do sistema de coordenadas e o ponto de elevação nula. Cada ponto é representado pela tripla $(r, \theta, h)$, onde $r$ é a distancia do ponto a origem $O, \theta$ é o ângulo medido a partir do eixo $x$ e $h$ é a elevação relativa ao plano ortogonal a $z$ tangente ao vértice da córnea. A leitura das elevações são feitas de um em um grau para diversas circunferências diferentes com o centro em $O$.

A superfície é aproximada à uma malha triangular superficial gerada através da triangulação do conjunto de pontos e suas elevações obtidos pelo topógrafo. O resultado pode 


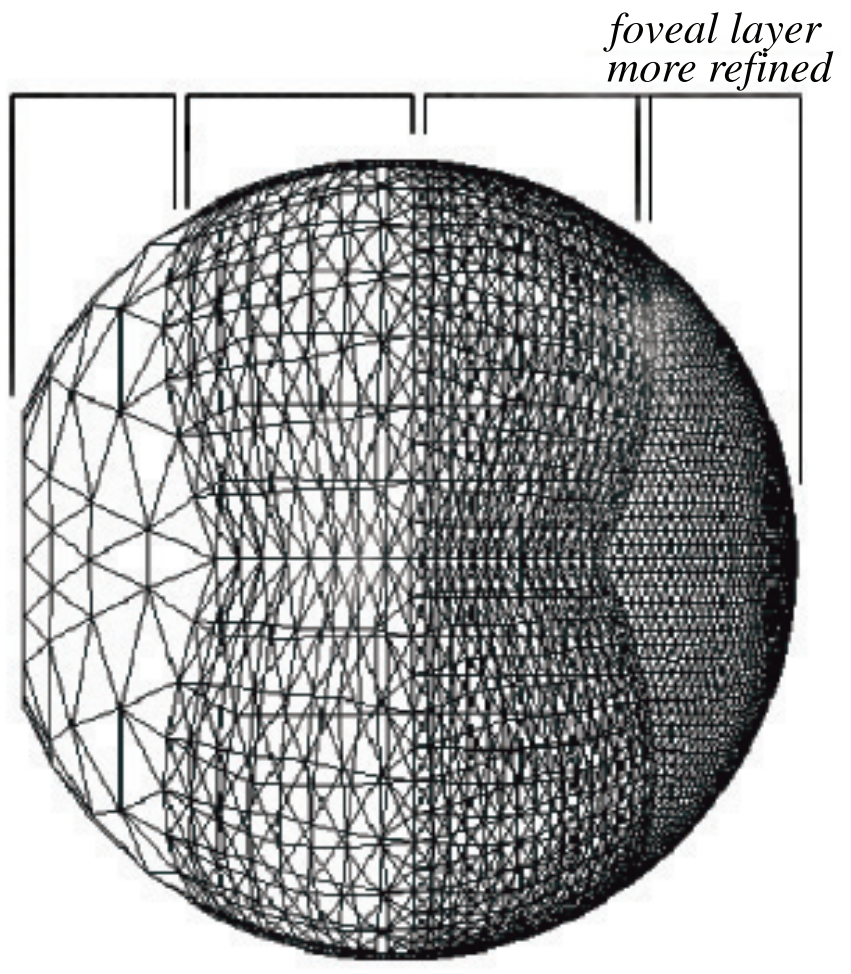

Figura 5.6: Modelo de uma retina com quatro camadas.

ser visualizado na Figura 5.7(b).

\subsection{Simulação}

A simulação trata-se de um ferramental disponibilizado pela área de pesquisa que permite a geração de ambientes, a partir dos quais pode-se orientar o processo de tomada de decisão, proceder análises e avaliações de sistemas e propor soluções para a melhoria de performance.

\subsubsection{Traçado de raios}

O traçado de raios é, basicamente, o que define a simulação do Olho Virtual. Consiste em lançar raios em direção ao olho calculando a intersecção com a primeira superfície refratora (córnea) e em seguida é calcular a normal da superfície no ponto. A direção do raio refratado é computado e o processo é feito para a próxima superfície até que a última (retina) seja atingida. Os cálculos de refração são calculados com base nas leis da física óptica estudadas no Capítulo 2.

O VEye implementa duas maneiras para calcular a intersecção do raio com a superfície 
Olho virtual

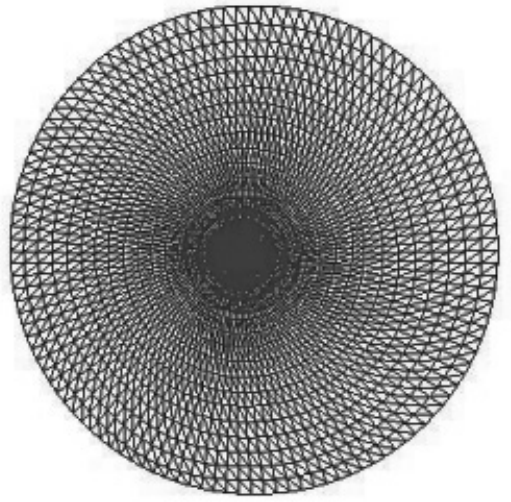

(a)

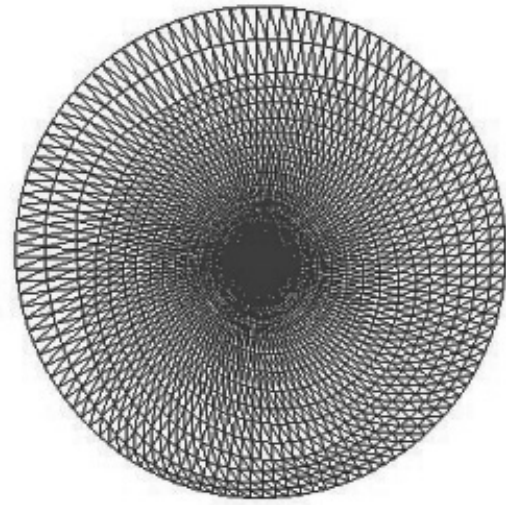

(b)

Figura 5.7: Malhas geradas por (a) dados simulados (b) dados reais.

e a normal neste ponto. A primeira é utilizada quando a superfície é baseada em dados sintéticos construídos pela Equação 5.1 e a segunda quando a superfície é baseada em dados in-vivo onde malhas tridimensionais superficiais são utilizadas.

Para o primeiro caso, a intersecção é obtida substituindo a Equação 5.2 na Equação 5.1, resolvendo o sistema do $2^{\circ}$ grau para $\alpha$ e escolhendo a raiz: $\alpha_{1}$ ou $\alpha_{2}$, apropriada, que resulte no menor valor positivo $\beta_{1}, \beta_{2}$ Equação 5.3, ver (ALS06).

$$
\begin{gathered}
R=R_{0}+\alpha L \\
\left.\beta_{i}=\operatorname{acos}\left[\frac{L *\left(R_{i}-R_{0}\right)}{\left\|R_{i}-R_{0}\right\|}\right]\right] \\
R_{i}=R_{0}+\alpha_{i} L
\end{gathered}
$$

A intersecção $W$ é dada por:

$$
W=R_{0}+\alpha_{k} L
$$

Onde $\alpha_{k}$ é a raiz escolhida. A normal em $W$ é calculada pelo operador gradiente:

$$
N_{w}=\nabla S(W)
$$




\section{Olho virtual}

Onde:

$$
\begin{gathered}
\nabla S(x, y, z)=\left[\begin{array}{c}
\frac{\partial S}{\partial x} \\
\frac{\partial S}{\partial y} \\
\frac{\partial S}{\partial z}
\end{array}\right] \\
\frac{\partial S}{\partial x}=2 x, \quad \frac{\partial S}{\partial y}=2 y \quad \text { e } \\
\frac{\partial S}{\partial z}=2[(1+Q) z-R]
\end{gathered}
$$

No segundo caso, para intersecção do raio com malhas, é usado o princípio de "Door-in Door-out" (LCE64), explicado a seguir.

Sejam $v_{1}, v_{2} v_{3}$ três vetores definindo um triângulo $t$ na malha. Suponha que um raio $l$ é lançado a partir do ponto $x$ em direção a $u$, Figura 5.8. O raio $l$ intersepta o plano definido por $t$ no ponto $w$, em termos matemáticos $w=x+\alpha u$. O ponto $w$ também pode ser escrito como $w=\lambda_{1} v_{1}+\lambda_{2} v_{2}+\lambda_{3} v_{3}$, onde $\lambda_{1}+\lambda_{2}+\lambda_{3}=1$. Estas duas expressões para $w$, definem o seguinte sistema linear:

$$
\left[\begin{array}{rrrr}
1 & 1 & 1 & 0 \\
v_{1} & v_{2} & v_{3} & u
\end{array}\right]\left[\begin{array}{c}
\lambda_{1} \\
\lambda_{2} \\
\lambda_{3} \\
\alpha
\end{array}\right]=\left[\begin{array}{l}
1 \\
x
\end{array}\right]
$$

O Sistema 5.9 calcula valores para $\lambda_{1}, \lambda_{2}, \lambda_{3}$ e $\alpha$. Se $\lambda_{i} \geq 0$ para todo $i=1,2,3$ então $w$ está dentro do triângulo $t$, caso contrário, pelo menos um $\lambda_{i}$ é negativo. Um $\lambda_{i}$ negativo indica que $w$ é oposto a $v_{i}$, por exemplo, na Figura 5.8, $w$ é oposto ao $v_{2} \mathrm{em}$ relação a aresta $v_{1} v_{3}$, então $v_{2}<0$. Note que o triângulo adjacente a $t$ oposto a $v_{i}$ está na direção de $w$ e partindo deste princípio é possível chegar no triângulo que contem $w$, onde $\lambda_{i} \geq 0, i=1,2,3$. Vale notar que o princípio de door in - door out não funciona se a malha possui grandes concavidades (curvaturas acentuadas), mas não é o caso deste contexto.

Além de permitir descobrir a intersecção dos pontos, os valores de $\lambda$ também podem ser usados para interpolação das normais na malha. Sendo $v_{1}, v_{2}$ e $v_{3}$ vértices do triângulo $t$ que contem $w$ e $n_{1}, n_{2}$ e $n_{3}$ as normais nestes vértices. Como $\lambda_{i} \geq 0, i=1,2,3$ no triângulo $t$, a normal $n_{w}$ em $w$ pode ser calculada pela Equação 5.10. 
Olho virtual

$$
n_{w}=\lambda_{1} n_{1}+\lambda_{2} n_{2}+\lambda_{3} n_{3}
$$

O raio de refração é calculado pelo Lei de Snell $n_{i} \operatorname{sen}(\theta)=n_{r} \operatorname{sen}\left(\theta_{r}\right)$, onde $n_{i}, \theta_{i}$ são os índices de refração e o ângulo de incidência do meio incidente e $n_{r}, \theta_{r}$ são os índices e o ângulo de refração do meio de refração.

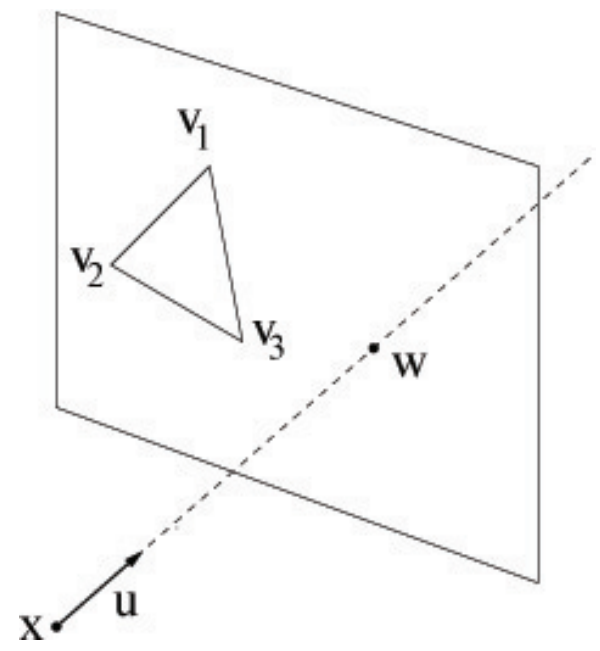

Figura 5.8: Princípio de "Door in - Door out".

\subsubsection{Projeção de cones}

Com o traçado de raios da Seção 5.2.1 o Olho Virtual é capaz de simular a formação de imagens na superfície da retina. Uma grande quantidade de raios partem de um ponto (pixel) de uma imagem $I$ em direção ao olho. No entanto, no mundo real, apenas uma parte dos raios adentram no olho formando um cone de luz como mostrado na Figura 5.9. Dessa forma, são lançados diversos cones de luz de cada pixel da imagem $I$, que passarão pela córnea, pupila, cristalino e, retina obtendo um conjunto de pontos $W$ das intersecções dos raios com a superfície (Traçado de raios).

Para fazer o lançamento dos cones de luz é necessário transformar cada pixel da imagem $I$ em coordenadas de mundo. A Equação 5.11 converte um pixel $(i, j)$ de $I$ em coordenadas reais $(x, y)$. 


\section{Olho virtual}

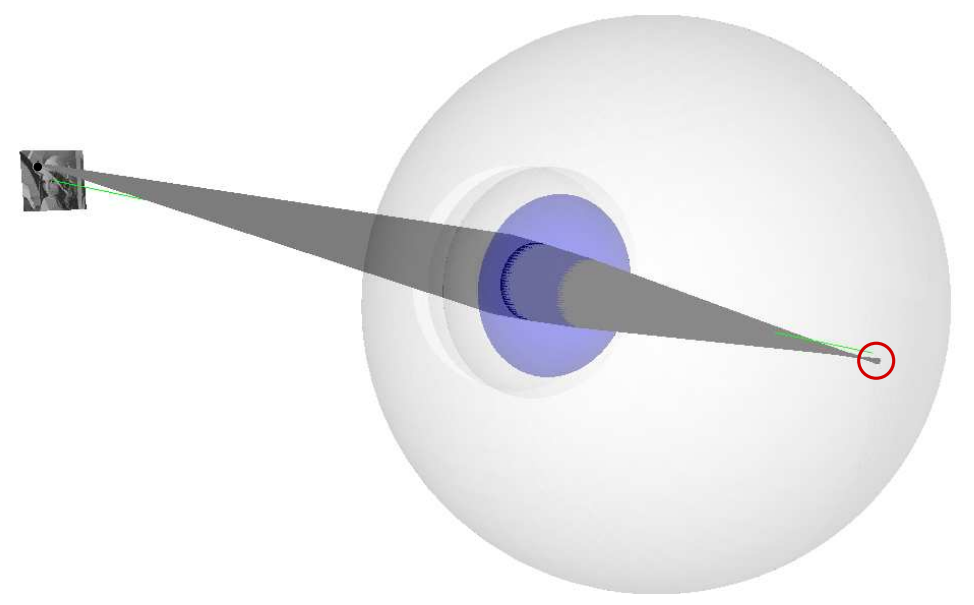

Figura 5.9: Projeção de cones e o conjuntos de pontos $\mathbf{W}$ formado na retina.

$$
\begin{array}{r}
x=x_{0}+i \Delta x \\
y=y_{0}+j \Delta y \\
\text { cor }=I[i, j]
\end{array}
$$

Com $i=0,1,2, \ldots, r_{x}-1$ e $j=0,1,2, \ldots, r_{y}-1$, onde $z_{0}$ é a posição no eixo óptico do plano objeto, $x_{0}$ e $y_{0}$ são a posição da imagem no plano objeto, $r_{x}$ e $r_{y}$ são as resoluções de $I$ e $\Delta x=h / r_{x}$ e $\Delta y=h / r_{y}$, onde $h$ é a altura e largura de $I$.

Para a construção da imagem final $I^{\prime}$ o processo é o inverso: a nuvem de pontos é convertida em coordenadas inteiras de imagem usando a Equação 5.12

$$
\begin{array}{r}
i^{\prime}=\operatorname{round}\left[\frac{h^{\prime}-y^{\prime}}{h^{\prime}}\right]\left(r_{y}^{\prime}-1\right) \\
j^{\prime}=\operatorname{round}\left[\frac{h^{\prime}-x^{\prime}}{h^{\prime}}\right]\left(r_{x}^{\prime}-1\right) \\
c o r=c o r
\end{array}
$$

Onde $h^{\prime}$ é a altura e largura de $I^{\prime}$ e $r_{x}^{\prime}$ e $r_{y}^{\prime}$ as resoluções. Depois disso é feito uma convolução de uma imagem $I_{K}$ (imagem formada com os deltas de Kronecker) com a gaussiana $G_{\sigma}$ e somado o resultado a $I^{\prime}$, Equação 5.13.

$$
I^{\prime}=I^{\prime}+I_{K} \otimes G_{\sigma}
$$

Onde $\otimes$ denota convolução e $G_{\sigma}$ é: 
Olho virtual

$$
G_{\sigma}\left(i^{\prime}, j^{\prime}\right)=\exp \left[-\frac{1}{2}\left(\frac{i^{\prime 2}+j^{\prime 2}}{\sigma^{2}}\right)\right]
$$

\subsubsection{Cálculo das propriedades paraxiais}

Para validar a acurácia dos algoritmos e modelos empregados no Olho Virtual, são calculadas as propriedades paraxiais da Seção 2.2.2 usando uma técnica chamada traçado de raios paraxiais (AS00), na qual consiste no lançamento de raios na região paraxial, próximos ao eixo óptico.

Os pontos focais $F$ e $F^{\prime}$ são computados lançando raios de luz paralelos ao eixo óptico $z$, e determina-se a intersecção entre o raio refratado e $z$. Os pontos principais $H$ e $H^{\prime}$ são $H=F+H F$ e o mesmo para $H^{\prime}=F^{\prime}+H^{\prime} F^{\prime}$. As medidas $H F=f$ e $H^{\prime} F^{\prime}=f^{\prime}$ são:

$$
f^{\prime}=-\frac{h}{\phi^{\prime}} \quad f=\frac{h}{\phi}
$$

onde $\phi^{\prime}$ é o ângulo formado pela intersecção entre o raio incidente e o eixo $z$ e $\phi$ o ângulo formado pela intersecção do raio refratado com o eixo $z$. $h$ é a distância entre o eixo óptico com a intersecção entre o raio incidente e a superfície. (Figura 5.10)

Os pontos nodais $N$ e $N^{\prime}$ são $N=H+H N$ e $N^{\prime}=H^{\prime}+H^{\prime} N^{\prime}$.

$$
H^{\prime} N^{\prime}=H N=\frac{\left(n^{\prime}-n\right)}{D}
$$

onde $n^{\prime}$ e $n$ são os índices de refração dos meios e $D$ é a dioptria da lente.

\subsection{Visualização}

O módulo de visualização compreende um conjunto de ferramentas gráficas desenvolvidas para visualizar os modelos das malhas e a saída da simulação do Olho Virtual. As ferramentas foram construídas com as bibliotecas $\boldsymbol{G L} \boldsymbol{U T}$ (Ope08a) implementação da OpenGL (Ope08b) nos sistemas Gnu/Linux. O aplicativo ParaView também pode ser usado para a visualização dos resultados.

As malhas geradas podem ser visualizadas em modo de wire-frame ou shading. Um exemplo de wire-frame pode ser visto na Figura 5.6. A Figura 5.9 mostra uma visão de 


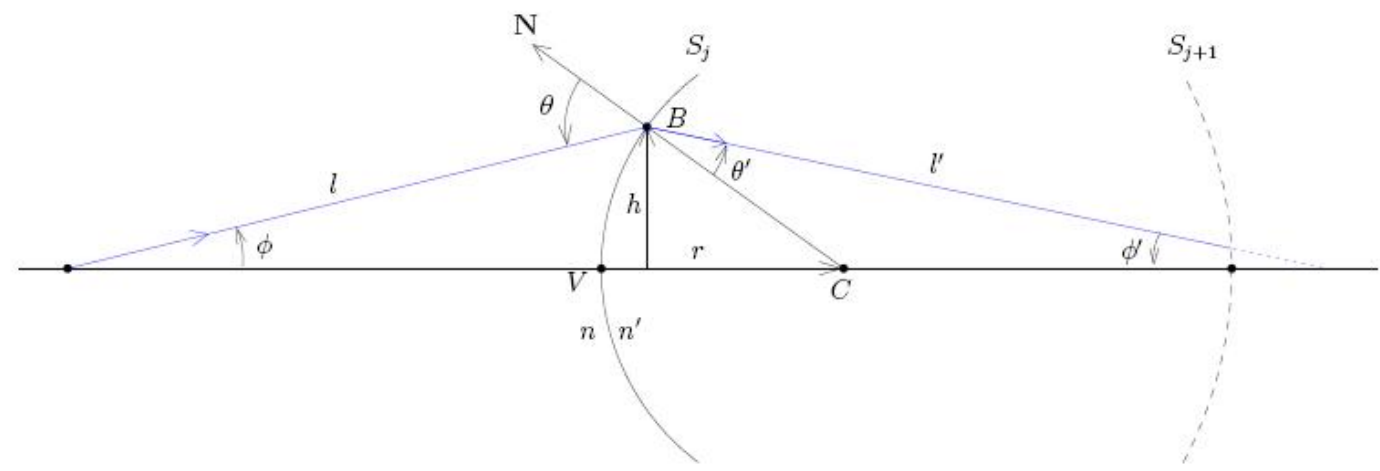

Figura 5.10: Tra,cado de raio paraxial em uma superfície de refração $S_{j}$. $r$ é o raio de curvatura de $S_{j}$ e $C$ é o centro de curvatura. O raio incidente $l$ intercepta $S_{j}$ em $B$ com normal $N$. O raio refratado $l^{\prime}$ é propagado até a próxima superfície $S_{j}+1$. $\phi$ e $\phi^{\prime}$ são os ângulos de incidência e refração respectivamente.

todos os componentes do olho em shading e também o traçado de raios.

Para apresentação da saída da simulação, pode ser usado tanto os vértices da malha ou exatamente a intersecção do raio com o ponto na retina. Na primeira alternativa cada intersecção do ponto é aproximada para ao vértice mais próximo na malha da retina. Esta opção é amplamente usada quando se quer obter o spot diagram (ME75), que empregado em analises de aberrações em instrumentos ópticos.

\section{4 Óptica e Simulações no Olho Virtual}

Para validar os algoritmos do modulo de modelagem e ray-tracing do Olho Virtual, Leandro Henrique, em seu trabalho de mestrado (Fer08), implementou uma série de simulações acerca das propriedades ópticas do olho. Alguns resultados são descritos a seguir.

\subsubsection{Propriedades gaussianas}

Foram calculadas as propriedades gaussianas dos modelos empregados: Le Grande não acomodado $\left(l g r_{u}\right)$, Le Grand acomodado $\left(l g r_{a}\right)$ e Liou-Brennan não acomodado $\left(l b r_{u}\right)$. Nas tabelas dessa seção as distâncias estao em $m m$ e dioptria $D$ e acomodação $A$ estão em D.Os modelos utilizados foram descritos na Seção 2.3.2.

A Tabela 5.1 mostra uma comparação das propriedades gaussianas entre os resultados obtidos pelo Olho Virtual e Smith em (AS00) para o modelo paraxial de Le Grand no 


\section{Olho virtual}

estado acomodado $\left(\lg r_{a}\right)$. Note que a dioptria no Olho Virtual é $D=67.1511 D$ quase o mesmo valor em Smith de $D=67,6780 D$ e não há muita diferença enter os demais valores da tabela.

Tabela 5.1: Propriedades Gaussianas de Le Grand $\operatorname{lgr}_{a} A=6.96 \mathrm{D}$.

\begin{tabular}{lccc}
\hline & VEye & Smith & Desvio \\
\hline \hline Power & 67.1511 & 67.678 & 0.5269 \\
VF & -12.8638 & -12.957 & 0.0932 \\
VF & 22.1482 & 21.932 & 0.2162 \\
VH & 1.9057 & 1.819 & 0.0867 \\
VH $^{\prime}$ & 2.2528 & 2.192 & 0.0608 \\
VN & 6.7947 & 6.784 & 0.0107 \\
VN $^{\prime}$ & 7.2564 & 7.156 & 0.1004 \\
$\mathbf{H}^{\prime} \mathbf{N}^{\prime}=\mathbf{H N}$ & 5.00364 & 4.965 & 0.03864 \\
$\mathbf{f}$ & 14.7694 & 14.776 & 0.0066 \\
$\mathbf{f}^{\prime}$ & 19.8954 & 19.741 & 0.15554 \\
\hline
\end{tabular}

A Tabela 5.2 mostra as propriedades gaussianas para o modelo de Le Grand não acomodado $\left(l g r_{u}\right)$. Note que a dioptria do modelo $l g r_{u}$ é de $D=59.941 D$, valor levemente inferior ao valor médio mais aceito $\langle D\rangle=60.00 D$ para adultos. Novamente pode-se notar que os valores não diferenciam muito entre os resultados obtido pelo Olho Virtual e na literatura de Smith.

Tabela 5.2: Propriedades Gaussianas de Le Grand não acomodado $l g r_{u}$.

\begin{tabular}{lccc}
\hline & VEye & Smith & Desvio \\
\hline \hline Power & 59.941 & 59.940 & 0.001 \\
VF & -15.0881 & -15.089 & 0.0009 \\
VF $^{\prime}$ & 24.197 & 24.197 & 0.0 \\
VH & 1.595 & 1.595 & 0.0 \\
VH & 1.908 & 1.908 & 0.0 \\
VN & 7.200 & 7.200 & 0.0 \\
VN $^{\prime}$ & 7.513 & 7.513 & 0.0 \\
$\mathbf{H}^{\prime} \mathbf{N}^{\prime}=\mathbf{H N}$ & 5.6055 & 5.606 & 0.0005 \\
$\mathbf{f}$ & 16.6832 & 16.683 & 0.0002 \\
$\mathbf{f}^{\prime}$ & 22.2887 & 22.289 & 0.0003 \\
\hline
\end{tabular}

O último modelo é baseado em dados in-vivo coletados da literatura e desenvolvido baseado na Seção 5.1.3. Os cálculos das propriedades gaussianas no modelo de LiouBrennan nao acomodado $l b r_{u}$ são feitos lancando-se raios a uma altura $h=0.01 \mathrm{~mm}$ do eixo óptico $z$. O modelo apresenta dioptria $D=60.3217 D$ valor acima de $\langle D\rangle$. 
Tabela 5.3: propriedades Gaussianas de Liou-Brennan $l b r_{u}$.

\begin{tabular}{lccc}
\hline & VEye & Smith & Desvio \\
\hline \hline Power & 60.3217 & 60.343 & 0.0213 \\
VF & -15.0352 & -15.040 & 0.0048 \\
VF & 23.9665 & 23.950 & 0.0165 \\
VH & 1.5436 & 1.532 & 0.0116 \\
$\mathbf{V H}^{\prime}$ & 1.8190 & 1.810 & 0.009 \\
$\mathbf{V N}^{\prime}$ & 7.1136 & 7.100 & 0.0136 \\
$\mathbf{V N}^{\prime}$ & 7.3890 & 7.378 & 0.011 \\
$\mathbf{H}^{\prime} \mathbf{N}^{\prime}=\mathbf{H N}$ & 5.570 & 5.568 & 0.002 \\
$\mathbf{f}$ & 16.5788 & 16.572 & 0.0068 \\
$\mathbf{f}^{\prime}$ & 22.140 & 22.140 & 0.0 \\
\hline
\end{tabular}

\subsubsection{Diagrama de pontos}

O diagrama de pontos DP (spot diagram) é uma coleção de intersecções $P_{i}^{\prime}=\left(x_{i}^{\prime}, y_{i}^{\prime}, z_{i}^{\prime}\right) \in$ $S$, com $i=1,2,3, \ldots, N$ entre os raios $l \in C$, onde $\mathrm{C}$ é o cone de luz lançado do ponto $P$ no espaço objeto, e a superfície $S \subset R^{3}$ representa a retina.

Quando a luz passa através de uma pequena abertura circular é formado um padrão de difração, denominado airy disc. Este padrão é constituído por um brilhante círculo central, ou simplesmente um "borrão", formado por anéis concêntricos com baixo contraste na periferia. Quando o olho focaliza um ponto objeto, é formado na retina uma imagem circular do tamanho do airy disc. Isto acorre mesmo para casos ideais em que há ausência de aberrações na lente, pois neste contexto, os efeitos de difração são mais influentes que as aberrações na formação de imagens. O diâmetro do airy disc é dado por:

$$
D_{a}=1,22 \lambda \frac{f}{d}
$$

onde $f$ é a distância focal e $d$ o diâmetro da pupila.

O valor RMS (root mean square), Equação 5.18, é uma medida quantitativa associado ao diagrama de pontos DP.

$$
R M S=\sum_{i} \frac{\sqrt{\left(x_{i}^{\prime}-x_{0}^{\prime}\right)^{2}+\left(y_{i}^{\prime}-y_{0}^{\prime}\right)^{2}}}{N}
$$

Outra medida comum é o raio do Círculo de Confusão ou raio geométrico $\rho^{\prime}$, Definição 5.1. 
Olho virtual

Definição 5.1 (Círculo de Confusão) Seja $C$ o conjunto dos raios de luz l no cone de luz lançado do ponto $P$. Seja $\Omega^{\prime} \subset S$ o conjunto de $n$ pontos $P_{k}^{\prime}=\left(x_{k}^{\prime}, y_{k}^{\prime}, z_{k}^{\prime}\right)$ em $S$ gerado pelas intersecções de l com $S$, onde $S \subset R^{3}$ é a superfície que representa a retina. O círculo de confusão ou raio geométrico $\rho^{\prime}$ é dado por:

$$
\begin{aligned}
& \rho_{k}^{\prime 2}=x_{k}^{\prime 2}+y_{k}^{\prime 2} \\
& \rho^{\prime}=\max \left\{\rho_{k}^{\prime}\right\}
\end{aligned}
$$

Consideramos os diagramas de pontos em duas situações. A primeira $C$ associado ao DP foi lançado de um ponto $P$ no eixo óptico dos modelos e na segunda $C$ foi lançado de um ponto $\mathrm{P}$ formando o ângulo visual $\alpha=5^{\circ}$ com o eixo óptico. As Figuras 5.11 e 5.12 exibem os diagramas de pontos juntamente com os respectivos airy disc para o modelo de Le Grand no estado não acomodado e acomodado respectivamente.

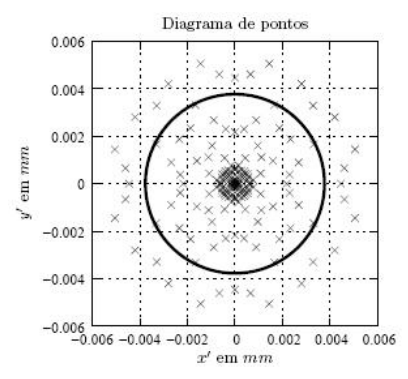

(a)

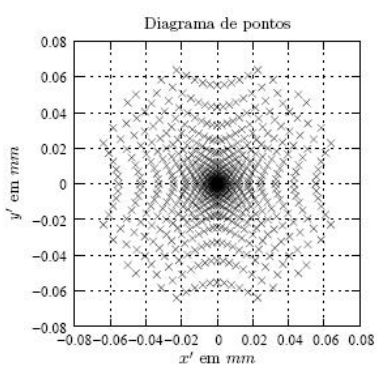

(b)

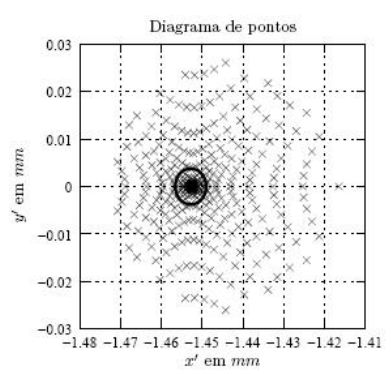

(c)

Figura 5.11: Diagrama de pontos do modelo de Le Grand não acomodado e o padrão airy disc. (a) $R=1 \mathrm{~mm}, R M S=0.0019 \mathrm{~mm}, \rho^{\prime}=0.0053 \mathrm{~mm}$ e $D_{a}=0.0037 \mathrm{~mm}$; (b) $R=2.0 \mathrm{~mm}, R M S=0.0250 \mathrm{~mm}, \rho^{\prime}=0.0680 \mathrm{~mm}$ e $D_{a}=0.0019 \mathrm{~mm}$ e (c) $R=1,0 \mathrm{~mm}$, $\alpha=5^{\circ}, R M S=0.0023 \mathrm{~mm}, \rho^{\prime}=0.0010 \mathrm{~mm}$ e $D_{a}=0.0037 \mathrm{~mm}$.

Pode-se observar que os diagramas de pontos diferem do diagrama ideal, que consiste de apenas um ponto em $S$. Note que nos dois níveis de acomodação, o airy disc é menor que o "borrão" produzido pelo aberração e reforça a idéia de que estes modelos não refletem as aberrações do olho humano. É possível verificar que o RMS e raio geométrico $\rho^{\prime}$ aumentam com o aumento do tamanho da pupila. 


\section{Olho virtual}

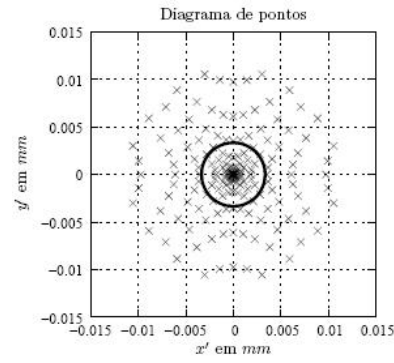

(a)

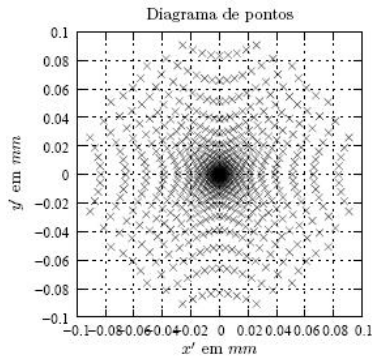

(b)

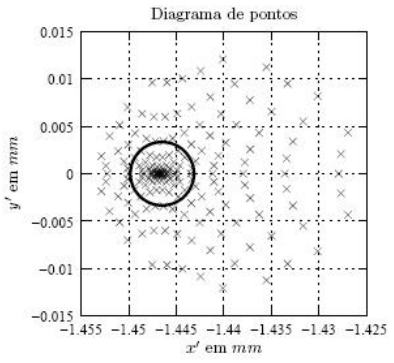

(c)

Figura 5.12: Diagrama de pontos do modelo de Le Grand acomodado e o padrão airy disc. (a) $R=1 \mathrm{~mm}, R M S=0.0048 \mathrm{~mm}, \rho^{\prime}=0.0110 \mathrm{~mm}$ e $D_{a}=0.0066 \mathrm{~mm}$; (b) $R=2.0 \mathrm{~mm}$, $R M S=0.0373 \mathrm{~mm}, \rho^{\prime}=0.0943 \mathrm{~mm}$ e $D_{a}=0.0033 \mathrm{~mm}$ e (c) $R=1.0 \mathrm{~mm}, \alpha=5^{\circ}$, $R M S=0.0058 \mathrm{~mm}, \rho^{\prime}=0,0200 \mathrm{~mm}$ e $D_{a}=0.0066 \mathrm{~mm}$. 


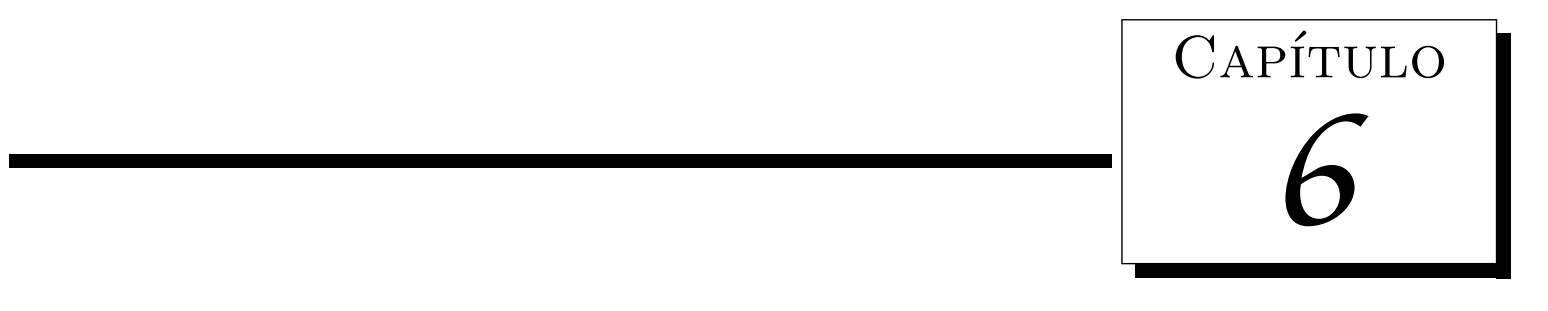

\section{Simulação de ametropias no Olho Virtual}

Como mostrado no Capítulo 5, o Olho Virtual realiza de maneira satisfatória a simulação de diversos fenômenos ocorrentes no processo de visão humana, bem como, formação de imagens na retina, o processo de acomodação do cristalino, aberrações esféricas, entre outros. Porém, os experimentos têm sido feitos a partir das simulações de olhos emétropes, então, o objetivo nesse capítulo é introduzir no Olho Virtual a simulação de ametropias, e assim, estudar o comportamento óptico do olho e também a formação de imagens sob tais condições.

Esse capítulo não só descreve a simulação de miopia e hipermetropia no Olho Virtual como também as suas respectivas correções. Basicamente é feita uma alteração na forma do globo ocular através de um alongamento ou achatamento da retina no eixo principal, ocasionando em erros de refração no sistema óptico resultando na formação de uma imagem desfocada. As correções para esses erros são feitas introduzindo no olho uma lente capaz de convergir ( para hipermetropia) ou divergir (para miopia) os raios lançados no olho. 


\subsection{As ametropias}

Idealmente, quando o olho fixa um objeto de interesse, a imagem é nitidamente formada sobre a fóvea. Em termos paraxiais, o objeto e a fóvea são pontos conjugados. No entanto, o objeto somente pode ser visto nitidamente se estiver dentro dos limites de acomodação do olho, caso contrário, o objeto de interesse não pode ser focalizado sobre a retina. Neste caso, a imagem na retina fica fora de foco, e a acuidade visual é reduzida.

Um olho com o ponto distante localizado no infinito é definido como olho emétrope, sendo considerado como normal. Possui um limite apropriado de acomodação, não necessitando de nenhuma compensação visual. Um erro de refração ocorre quando o ponto distante não está localizado no infinito, nesse caso o olho é definido como amétrope.

O intervalo de acomodação diminui à medida que a pessoa envelhece, pois o cristalino aumenta durante a vida e os músculos tornam-se menos capazes de se contrair. Assim, a distância do ponto próximo aumenta de acordo com a idade, fenômeno conhecido como presbiopia.

No olho com miopia, o globo ocular é muito alongado em comparação com o raio de curvatura da córnea e os raios dos objetos localizados no infinito são focalizados antes da retina, Figura 6.1. Isto significa que a maior distância que o olho pode focalizar uma imagem esta em um ponto mais próximo que um olho normal. Para ver nitidamente, é necessário o uso de lentes corretoras, neste caso é usada uma lente divergente que faz com que o objeto se desloque para uma distancia mais próxima do olho para que a imagem seja focalizada sobre a retina, Figura 6.1.

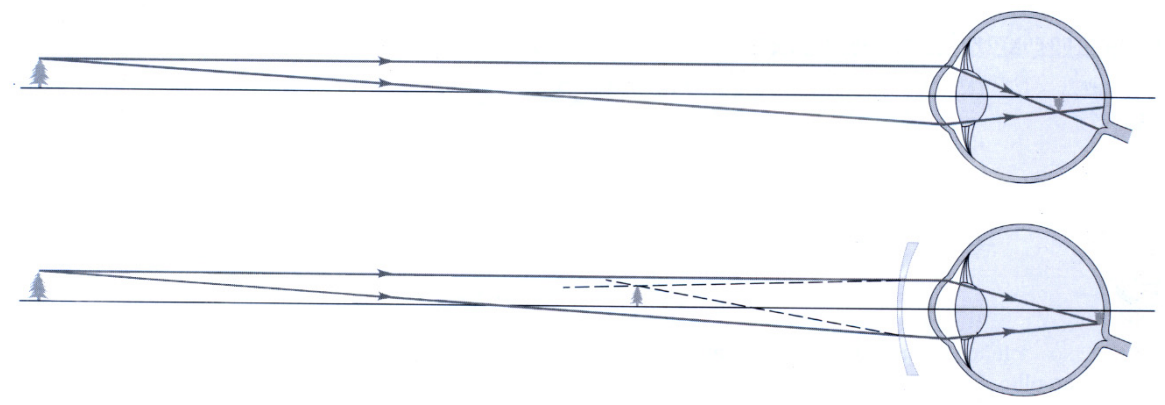

Figura 6.1: Um olho míope sem correção e uma lente corretiva divergente. Extraído de (Yun04). 


\section{Simulação de ametropias no Olho Virtual}

Na hipermétropia, o globo ocular é muito curto ou a córnea não é suficientemente encurvada, assim os raios de um objeto no infinito são focalizados atrás da retina (Figura 6.2). Outras causas incluem situações onde a córnea ou o cristalino apresentam alterações no seu formato que diminuem o seu poder refrativo. O grau do hipermétrope, geralmente diminui com o crescimento do olho, e é comum pessoas que necessitavam de óculos durante a infância, mas que deixaram de usá-los na idade adulta. Analogamente a miopia, a correção da hipermetropia é obtida usando-se uma lente convergente para fazer o objeto se deslocar para uma distância mais afastada do olho do que a distancia real do objeto.

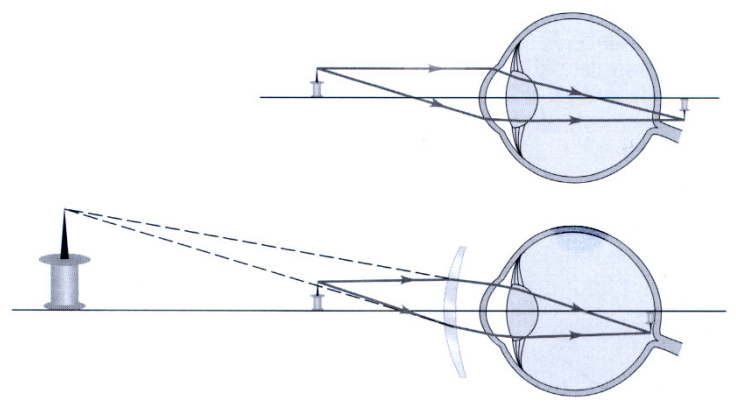

Figura 6.2: Um olho hipermetrope sem correção e uma lente corretiva convergente. Extraído de (Yun04).

No astigmatismo a superfície da córnea ou do cristalino não é esférica, sendo mais encurvada em um dado plano que em outro. Por causa disso, uma reta vertical pode formar uma imagem em um plano diferente de uma reta na horizontal, Figura 6.3. Este desajuste faz com que a luz se refrate por vários pontos da retina em vez de se focar em apenas um. Pessoas que sofrem de astigmatismo podem corrigir sua visão com o uso de uma lente oftálmica chamada tórica ou cilíndrica, que faz com que os raios de luz se concentrem em um plano único, em óculos ou lentes de contato.

As lentes corretivas são descritas em termos de potência, definida como o inverso da distância focal expressa em metros. A unidade de potência é a dioptria. Portanto, uma lente com $f=0,50 \mathrm{~m}$ possui uma potência igual a 2,0 dioptrias, $f=-0,25 \mathrm{~m}$ corresponde a uma potência igual a $-0,4$ dioptrias. 


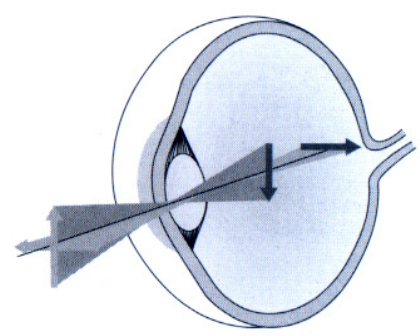

Figura 6.3: As imagens de linhas verticais se formam em planos diferentes das linhas horizontais para este olho com astigmatismo. Extraído de (Yun04).

\subsection{Induzindo erros de refração no Olho Virtual}

Para induzir um erro de refração no Olho Virtual foi preciso alterar as dimensões da superfície esférica do globo ocular. Isto é feito aumentado ou diminuindo o tamanho do raio da superfície da retina, resultando em um deslocamento $d$ da fóvea no eixo principal. Dessa forma, o objeto e a fóvea não são mais pontos conjugados e a imagem é formada fora de foco, Figura 6.4.

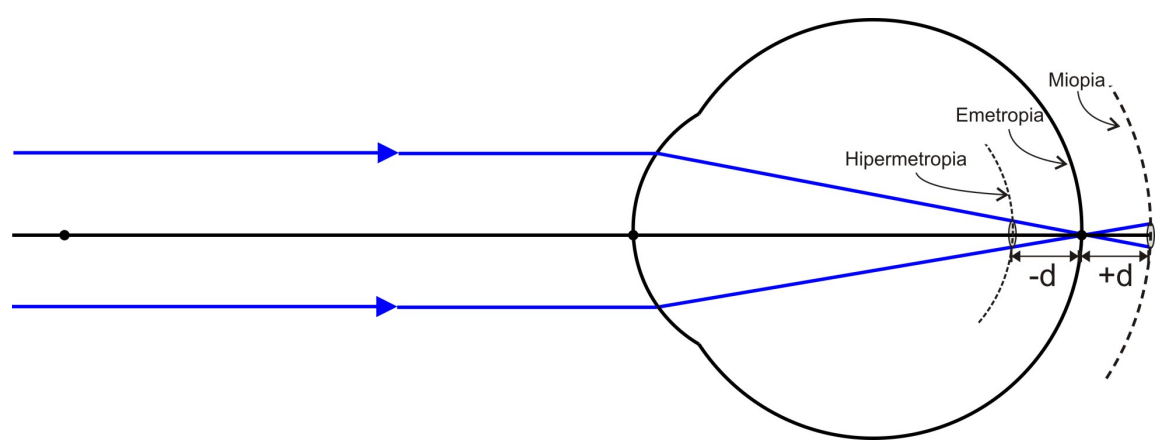

Figura 6.4: $\mathrm{O}$ desvio $d$ da retina é positivo na miopia e negativo na hipermetropia.

A Figura 6.4 mostra valores positivo e negativo para $d$. Se o valor de $d$ for negativo o erro de refração é hipermetropia. Nesse caso, a fóvea é deslocada para frente e os raios são focalizados atrás da retina, gerando uma imagem desfocada. Caso $d$ seja positivo, a fóvea é deslocada para trás e os raios são focalizados na frente da retina, resultando em um olho com miopia.

Um olho pode ser considerado como um sistema óptico simples formado por uma lente convergente com poder de dioptria de $V_{e}$. A dioptria de qualquer sistema óptico pode ser calculado pela Equação 6.1, conhecida na literatura como "Equação de conjugação" 
$(\operatorname{Gas} 00)$.

$$
V_{e}=\frac{1}{f}=\frac{1}{p}+\frac{1}{p^{\prime}}
$$

Onde $f$ é a distância focal, $p$ é a distância do objeto a lente e $p^{\prime}$ a distância da lente a imagem do objeto.

Para um olho emétrope o termo $p^{\prime}$ é a distância de lente até a "tela de projeção" onde a imagem é formada, ou seja, a retina. Porém, vamos assumir um olho míope em que objetos localizados no infinito $(p \rightarrow \infty)$, não podem ser vistos nitidamente. Dessa forma, existe uma distância máxima que o olho enxerga nitidamente, digamos que para este caso seja 222.222 $\mathrm{mm}$. Para que o olho possa ver corretamente é necessário o uso de uma lente corretiva para formar uma imagem virtual dos objetos, do infinito, a exatamente 222.222 $\mathrm{mm}$ à frente do olho (como na Figura 6.1). A dioptria desta lente pode ser calculada usando a Equação 6.1 onde $p=+\infty$ e $p^{\prime}=-0.222 m$ (negativo para imagens virtuais), então $V_{l}=\frac{1}{+\infty}+\frac{1}{-0.222} \cong 4.5 D$.

Se adicionarmos a lente corretiva ao sistema óptico do olho, o resultado será um único sistema óptico de dioptria $\left(V_{e}+V_{l}\right)$ que pode ser calculado pela seguinte equação:

$$
V_{e}+V_{l}=\frac{1}{p}+\frac{1}{p^{\prime \prime}}
$$

Onde $p^{\prime \prime}$ é a distância da lente à imagem do objeto. Note que antes o olho conjugava os raios à uma distância $p^{\prime}$ e depois, com uso da lente, à $p^{\prime \prime}$. Isso significa que a "tela de projeção" não estava posicionada em $p^{\prime}$ mas sim em $p^{\prime \prime}$, e por isso o olho é míope.

Finalmente, a diferença entre $p^{\prime \prime}$ e $p^{\prime}$ é exatamente o deslocamento $d$ da Figura 6.4 e pode ser calculado por $d=p^{\prime \prime}-p^{\prime}$, então, as Equações 6.1 e 6.2 definem $d$ da seguinte forma:

$$
d=\frac{1}{V_{e}+V_{l}-1 / p}-\frac{1}{V_{e}-1 / p}
$$

A Equação 6.3 nos permite encontrar o valor de $d$ necessário para gerar um olho ametrope com qualquer grau de miopia ou hipermetropia. Por exemplo, se usar o olho de Le Grand não acomodado da Seção 2.3.2, onde $V_{e}=59.940$ e atribuir $V_{l}=-2 D$ para 
resolver a Equação 6.3, o resultado será $d=0.000575884 m$, ou seja, para simular $-2 D$ de miopia no olho é preciso deslocar a fóvea da retina em $0.575884 \mathrm{~mm}$ da posição original.

Para gerar esse deslocamento da fóvea da retina do Olho Virtual basta aumentar (miopia) ou diminuir (hipermetropia) o raio da superfície esférica do modelo em $d / 2$.

\subsection{Lente divergente da miopia}

No olho míope, é usado um valor negativo para $V_{l}$ na Equação 6.3 e o resultado é um valor positivo para $d$. Aplicado o deslocamento na retina, o globo ocular fica muito alongado em comparação ao raio de curvatura da córnea e os raios dos objetos localizados no infinito são focalizados antes da retina. Para ver nitidamente, é necessário o uso de uma lente corretiva divergente que faz com que o objeto se desloque para uma distância mais próxima do olho, para que este possa focalizar corretamente a imagem na retina, veja Seção 6.1.

Para validar a Equação 6.3 neste caso, foi desenvolvido um programa para simular o comportamento de uma lente divergente. O programa recebe como parâmetro a vergência da lente, o mesmo valor aplicado a $V_{l}$ para achar o $d$. A lente é posta na frente do Olho Virtual, assim todo raio de luz quer for lançado no olho passará primeiro por ela, que por sua vez, calcula a nova direção do raio, com base na Definição 6.1, e o relança para o olho seguindo o percurso normal, atingindo a córnea até chegar na retina. O Algoritmo 6.3.1 e a Figura 6.5 explicam com maiores detalhes o processo.

Definição 6.1 (Raio refratado pela lente) Todo raio de luz que incide na lente se refrata passando pelo foco secundário. o foco secundário fica no plano focal do foco principal da lente e é calculado pela intersecção entre o raio que passa pela origem da lente paralelo ao raio incidente e o plano focal. As Figuras 6.5 e 6.6 ilustram esse processo para lentes divergente e convergente respectivamente.

\subsection{Lente convergente da hipermetropia}

Na hipermetropia, é usado um valor positivo para $V_{l}$ na Equação 6.3 e o resultado é um valor negativo para $d$. Assim, o globo ocular fica numa forma mais curta que a normal e os raios dos objetos localizados no infinito são focalizados depois da retina. 


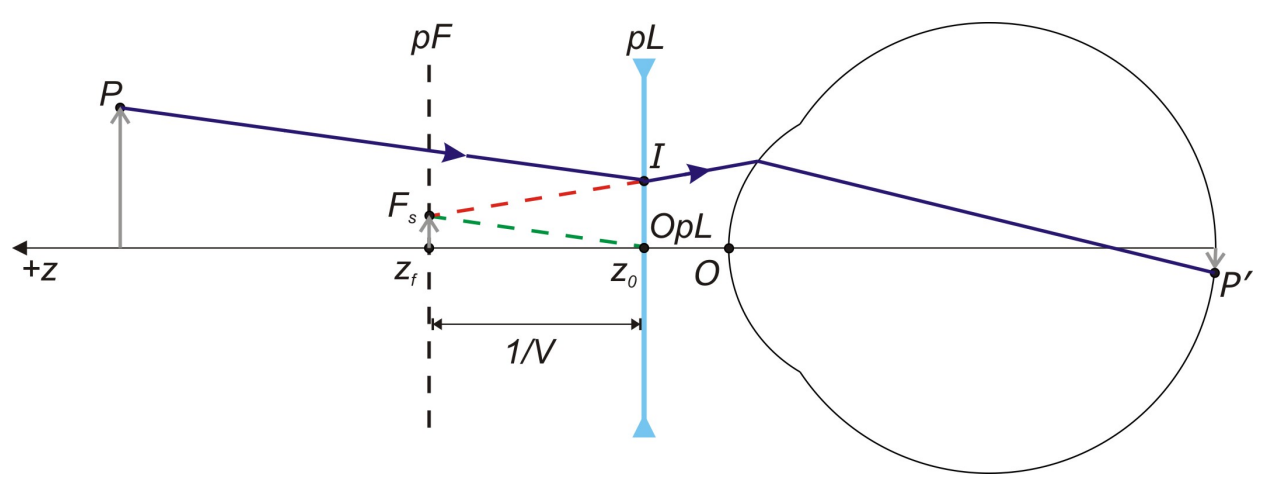

Figura 6.5: Lente divergente e o raio refratado.

\section{Algoritmo 6.3.1 Lente Divergente da Miopia $\left(R, V_{l}, z_{0}\right)$}

1. Seja $V_{l}$ a convergência da lente, $z_{0}$ sua posição no eixo $z$ e $R$ o raio lançado no olho

2. Define $p L$ o plano da lente tal que $p L$ é perpendicular ao eixo $z$ no ponto $z_{0}$ e a origem de $p L$ é dado pelo ponto $O p L\left(0,0, z_{0}\right)$

3. Define $p F$ o plano focal tal que $p F$ é perpendicular ao eixo $z$ no ponto $f$ onde $f=z_{0}+\frac{1}{V_{l}}$

4. $I=$ Intersecção do raio $R$ com plano $p L$

5. $F_{s}($ Foco Secundário $)=$ Intersecção do raio com origem em $O p L$ e com direção ao plano $p F$ paralelo ao raio $R$ (raio verde na Figura 6.5)

6. Define $d$ a nova direção do raio $R$ como sendo o vetor normalizado de $F_{s} I$ (raio vermelho na Figura 6.5)

7. R.o $=I$ (nova origem do raio)

8. $R . d=d$ (nova direção do raio)

9. Relança o raio $R$ com nova direção e origem 
Para ver nitidamente, é necessário o uso de uma lente corretiva convergente que faz com que o objeto se desloque para uma distancia mais afastada do olho, para que este possa focalizar corretamente a imagem na retina, veja Seção 6.1.

Para validar a Equação 6.3 neste caso, foi desenvolvido um programa para simular o comportamento de uma lente convergente. O programa recebe como parâmetro a vergência da lente, o mesmo valor aplicado a $V_{l}$ para achar o $d$. A lente é posta na frente do Olho Virtual, assim todo raio de luz que for lançado no olho passará primeiro por ela, que por sua vez, calcula a nova direção do raio, com base na Definição 6.1, e o relança para o olho seguindo o percurso normal, atingindo a córnea até chegar na retina. O Algoritmo 6.4.1 explica com maiores detalhes esse processo.

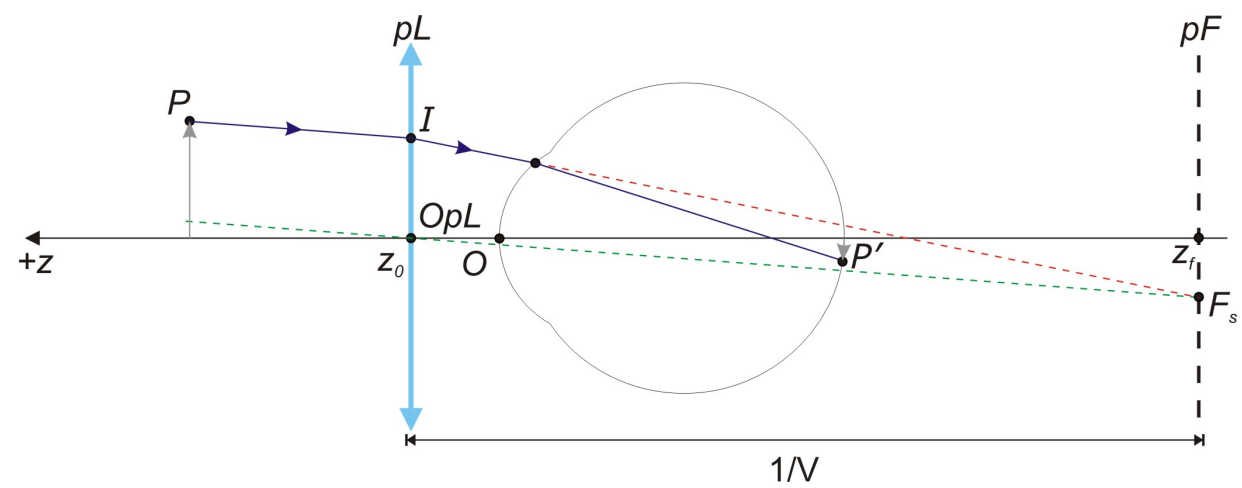

Figura 6.6: Lente convergente e o raio refratado. 


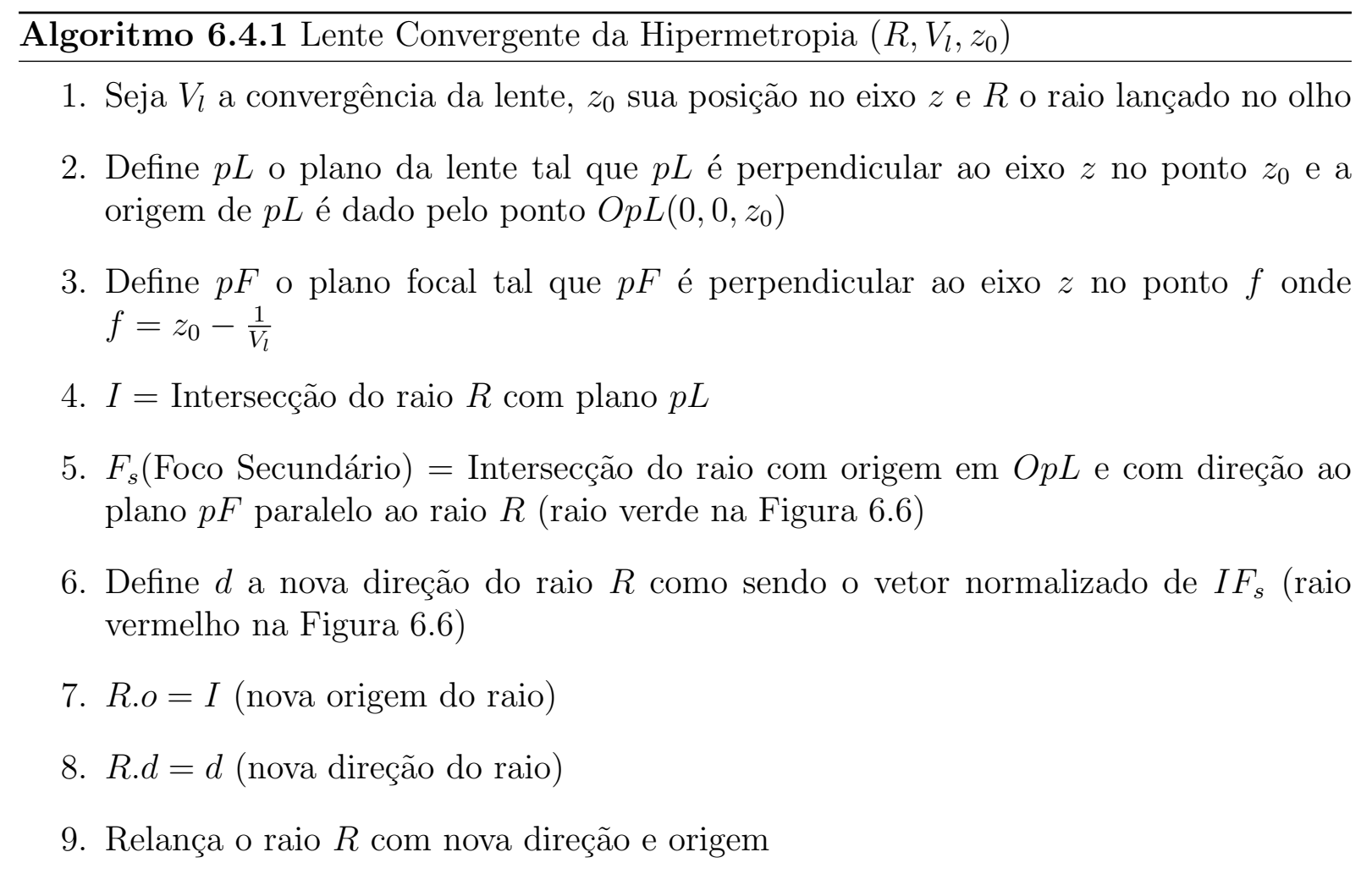


Simulação de ametropias no Olho Virtual 


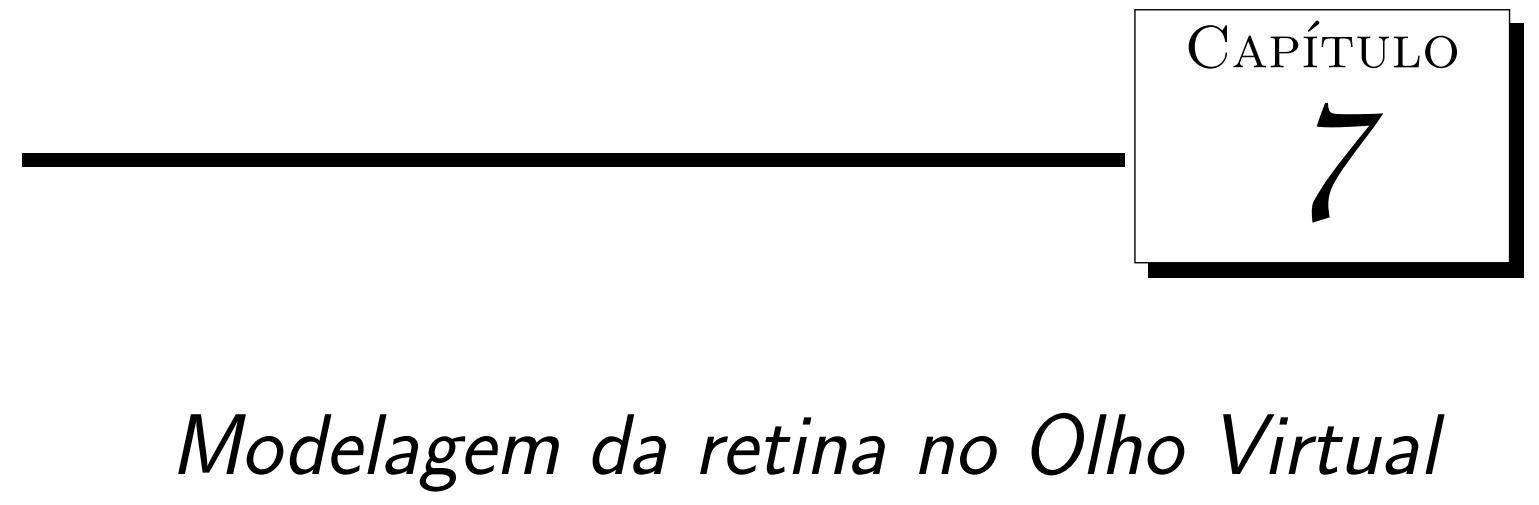

Neste capítulo é proposto um modelo de retina baseado no modelo biológico, levando em consideração a distribuição e as funcionalidades das celulas que a compõem.

Esse modelo é composto por duas componentes principais gerando dois níveis de respostas como saída da retina: em nível de receptores (cones e bastonetes) e em nível ganglionar (Campos receptivos parvos e magnos). A primeira componente permite comparar não só imagens formadas pelos dois tipos de receptores como também imagens formadas em diferentes excentricidades da retina, tais como fóvea e periferia. A segunda componente, gera respostas dos campos receptivos de gânglios parvos e magnos nas variações On-Center-Off-Surround e Off-Center-On-Surround, onde a combinação destes dois últimos auxiliam no processo de detecção de bordas nas imagens.

Existem também, outras componentes auxiliares que ajudam na formação das componentes principais: projeção, mapeamento, anéis concêntricos e degenerações. Nas próximas seções são mostrados a modelagem de todas as componentes e as descrições dos principais algoritmos desenvolvidos. 


\subsection{Visão geral}

Em uma simulação de formação de imagens do Olho Virtual é gerado como saída um conjunto de pontos $\Omega$ (coordenadas e cores) pertencente a quádrica do modelo(Figura 7.1). Estes são os pontos que constituem a imagem, definidos pela intersecção dos raios luminosos com a retina (Seção 5.2.2). A retina do Olho Virtual, por sua vez, faz uso desses pontos como dados de entrada para execução de suas tarefas. Outros dados de entrada que a retina necessita são os dados referentes a geometria do modelo de olho (Seção 2.3.2) no qual foi gerado o conjunto de pontos $\Omega$.

Após a leitura dos dados de entrada, é definido um plano de projeção $\pi$. Este é o plano onde os pontos de $\Omega$ são projetados (componente de projeção) e mapeados (componente de mapeamento) em uma imagem plana PGM (mxn). Neste plano serão definidos a distribuição das células receptoras e os campos receptivos das células ganglionares.

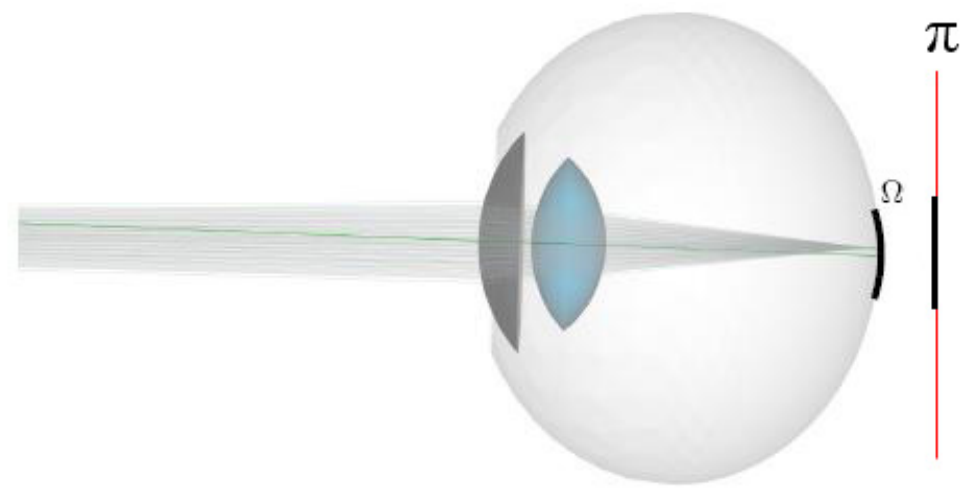

Figura 7.1: Conjuntos de pontos $\Omega$ gerados para constituir a imagem e plano de projeção $\pi$.

A distribuição dos receptores (componente de receptores) é baseada na curva do gráfico da Figura 3.2, onde a densidade de células varia de acordo com a excentricidade na retina dada em ângulo. Para isso, a retina é dividida em diversos anéis concêntricos (componente de anéis concêntricos) centrados na fóvea, onde cada anel representa um ângulo na excentricidade da retina. Após os anéis terem sido definidos, são projetados e mapeados no plano de projeção onde estão os pontos de $\Omega$, e a partir de daí é gerado a distribuição das células receptoras em cada anel. Os campos receptivos também são definidos no plano de projeção (componentes de campos receptivos). 


\section{Modelagem da retina no Olho Virtual}

O usuário também tem a possibilidade de passar como parâmetro de entrada uma imagem de uma retina sob ação de alguma patologia. Neste caso essas informações são interpretadas (componente de degenerações) e enviadas para a componente de receptores para identificar quais células não serão capazes de responder a estimulo de luz.

A Figura 7.2 mostra um diagrama com o fluxo de execução do software desenvolvido. As elipses amarelas são os dados de entrada, os blocos azuis são as componentes da retina, os blocos verdes são subcomponentes criados de outras componentes, os losangos roxos são processamentos realizados pela retina e os blocos vermelhos são imagens geradas como saída da retina. As ligações (- - ) indicam que uma componente faz uso da outra, sem fluxo de execução, e as ligações $(\rightarrow)$ indicam a direção do fluxo de execução.

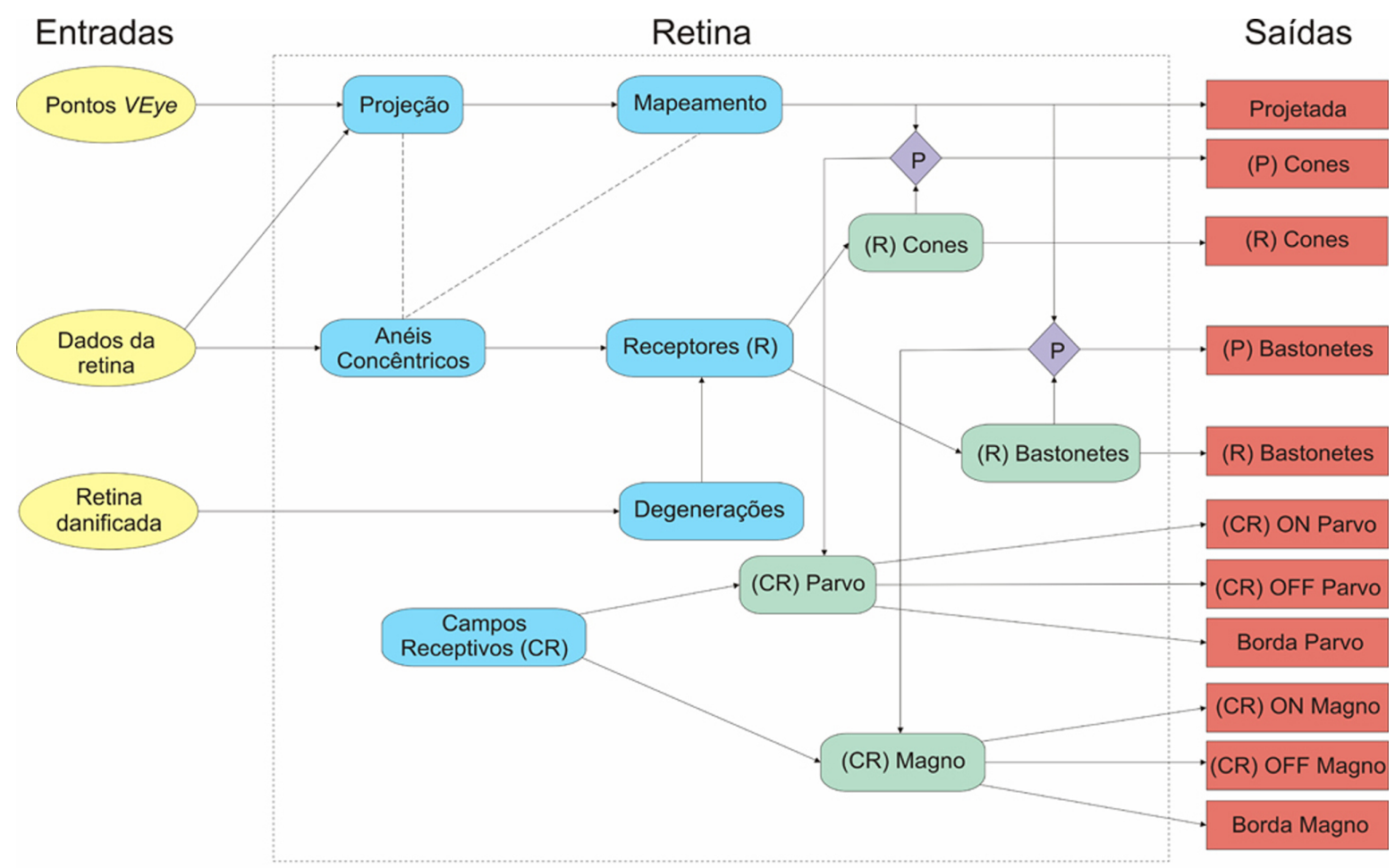

Figura 7.2: Diagrama com o fluxo de execução do software.

Imagens geradas pela retina:

- Projetada: imagem simples gerada apenas com a projeção e o mapeamento dos pontos de $\Omega$, sem respostas em nível de receptores ou campos receptivos.

- (P) Cones: imagem gerada pelo processamento dos receptores cones. 
Modelagem da retina no Olho Virtual

- (R) Cones: imagem gerada da distribuição das células receptoras cones.

- (P) Bastonetes: imagem gerada pelo processamento dos receptores bastonetes.

- (R) Bastonetes: imagem gerada da distribuição das células receptoras bastonetes.

- (CR) ON Parvo: imagem gerada pela resposta dos campos receptivos On-Center Off-Surround no caminho parvocelular.

- (CR) OFF Parvo: imagem gerada pela resposta dos campos receptivos Off-Center On-Surround no caminho parvocelular.

- (CR) Borda Parvo: deteç̧ão de bordas gerada pela combinação dos campos receptivos On-Center Off-Surround e Off-Center On-Surround do caminho parvocelular.

- (CR) ON Magno: imagem gerada pela resposta dos campos receptivos On-Center Off-Surround no caminho magnocelular.

- (CR) OFF Magno: imagem gerada pela resposta dos campos receptivos OffCenter On-Surround no caminho magnocelular.

- (CR) Borda Magno: deteç̧ão de bordas gerada pela combinação dos campos receptivos On-Center Off-Surround e Off-Center On-Surround do caminho magnocelular.

As demais seções deste capítulo são dedicadas a explicarem as componentes do diagrama acima.

\subsection{Projeção e mapeamento}

A componente de projeção é responsável em fazer as projeções necessárias na retina do Olho Virtual. Foi implementado um projetor que recebe um conjunto de pontos $\mathbf{P}$ e o projeta em uma determinada superfície, podendo ser um plano ou uma esfera.

O projetor é capaz de fazer dois tipos de projeções: perspectiva e paralela. As projeções perspectivas são obtidas através das intersecções entre retas, que passam pelos pontos de 


\section{Modelagem da retina no Olho Virtual}

$\mathbf{P}$ e por um ponto fixo (denominado ponto de vista), e a superfície de projeção. As projeções paralelas são definidas através das intersecções entre retas paralelas que passam pelos pontos de $\mathbf{P}$ e a superfície de projeção. As projeções são mostradas na Figura 7.3

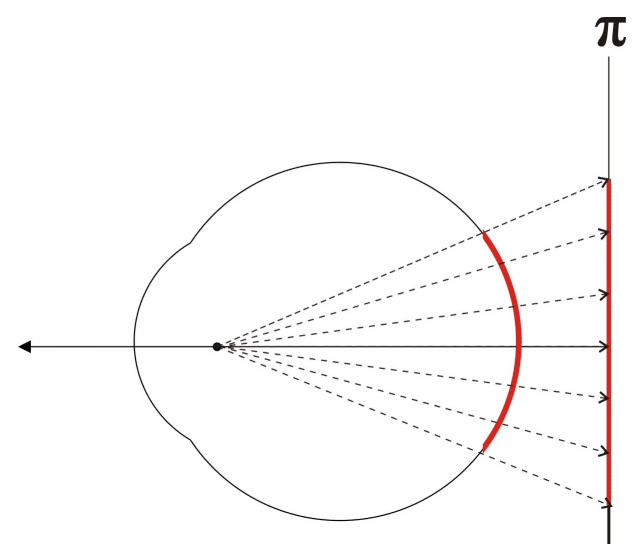

(a)

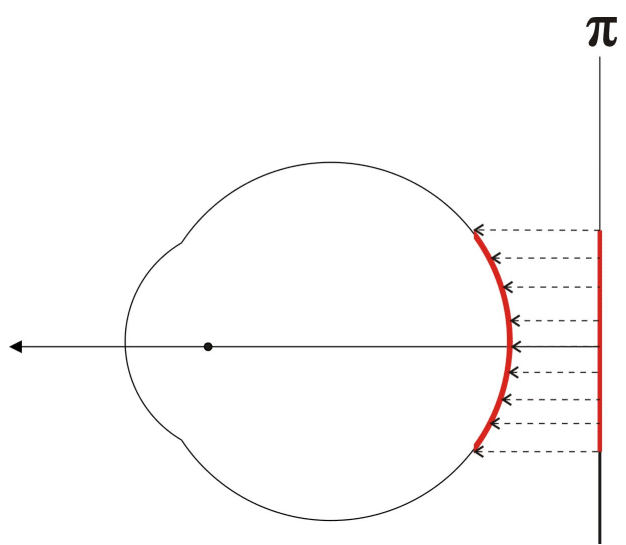

(b)

Figura 7.3: (a) Projeção perspectiva, onde os pontos a serem projetados são os pontos da esfera (retina) e a superfície de projeção é o plano $(\pi)$. (b) Projeção paralela, onde os pontos a serem projetados são os pontos do plano $(\pi)$ e a superfície de projeção é a esfera (retina).

O programa recebe como parâmetro o conjunto de pontos a serem projetados $(\mathbf{P})$, a superfície onde os pontos serão projetados (plano ou esfera) e o tipo de projeção (perspectiva ou paralela), caso perspectiva é definido o ponto de vista.

A principal projeção realizada na retina é a projeção dos pontos $\Omega$ mostrado na Figura 7.1. A projeção realizada nesse caso é a projeção perspectiva no plano como mostrado na Figura 7.3(a).

Os dois principais algoritmos que essa componente executa são Go2Plane (Algoritmo 7.2.1), projeta pontos em um plano, e Go2Sphere (Algoritmo 7.2.2), projeta pontos em uma esfera.

A componente de mapeamento é responsável em mapear os pontos $(x, y, z)$, depois de projetados no plano, em pontos $(i, j)$ para formar uma imagem de tamanho $(m x n)$. O programa recebe como parâmetro o conjunto de pontos a serem mapeados, os valores $m$ e $n$ e os pontos $P_{0}$ (Superior, esquerdo) e $P_{1}$ (inferior, direito) que definem o menor quadrado no plano tal que todos os pontos do conjunto estejam dentro deste quadrado. O Algoritmo 7.2.3 mostra com detalhes o processo de mapeamento. 

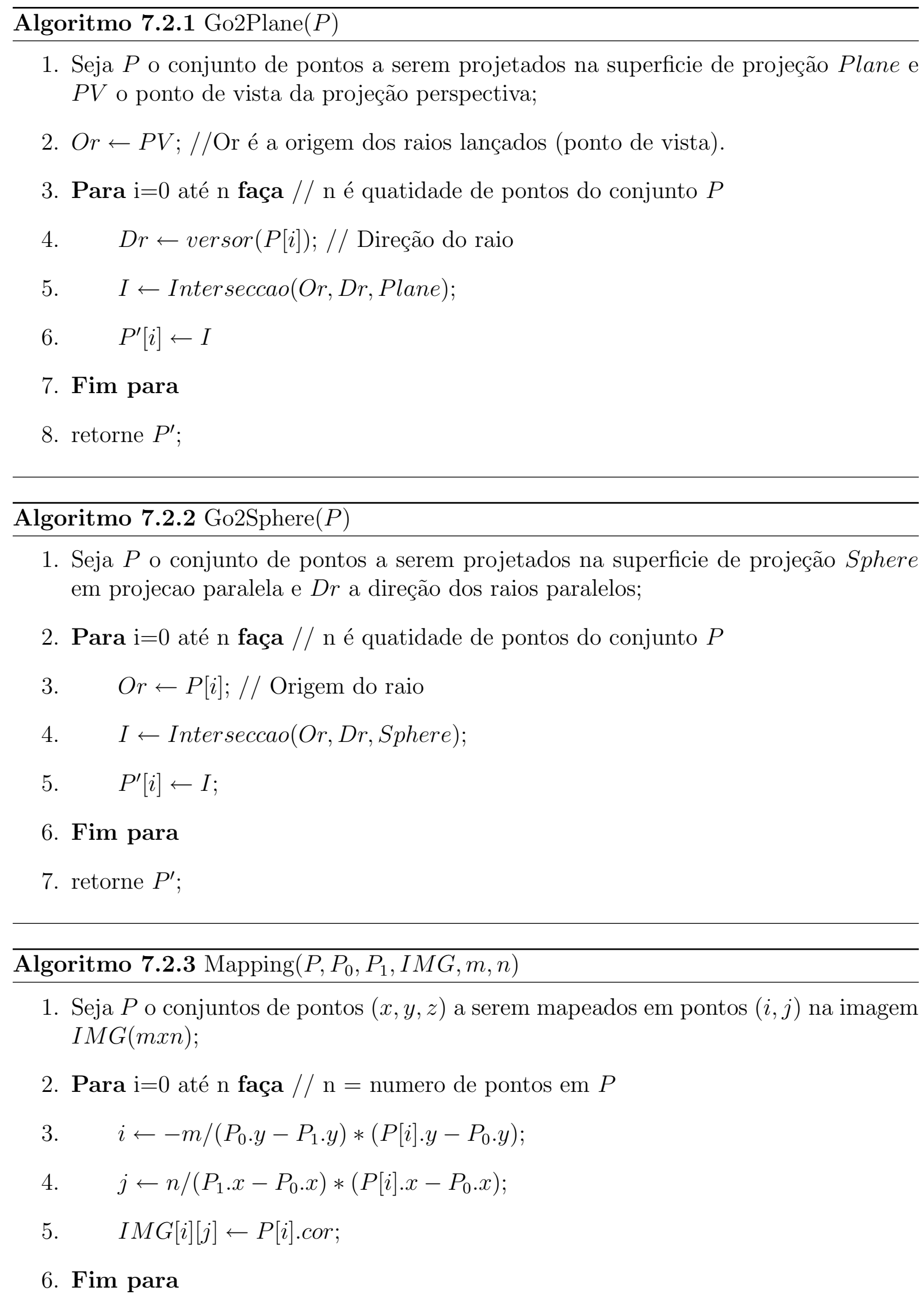


\subsection{Anéis concêntricos}

Como a distribuição das células receptoras é baseada na excentricidade da retina em ângulos relativos à fóvea, Figura 3.2, foi necessário dividir a retina em diversas subregiões denominadas anéis concêntricos. São anéis $A=A_{0}, A_{1}, A_{2}, \ldots, A_{n}$ definidos na superfície quádrica que possuem um $R$ (raio maior) e $r$ (raio menor) e formam um ângulo $\alpha$ em relação a fóvea, A Figura 7.4(a) mostra como são definidos os anéis.

O programa calcula o conjunto de pontos $S=\left\{S_{0}, S_{1}, S_{2}, \ldots, S_{n}\right\}$, onde $S_{i}$ é um ponto $(x, y, z)$ pertencente a circunferência que separa o anel $A_{i}$ e $A_{i+1}$. Em seguida, o conjunto $S$ é projetado e mapeado no plano de projeção (imagem $\operatorname{PGM}(\operatorname{mxn})$ ) tornando-se o conjunto $P=\left\{P_{0}, P_{1}, P_{2}, \ldots, P_{n}\right\}$, onde $P_{i}$ é um ponto $(i, j)$ pertencente a circunferência que separa o anel $A_{i}$ e $A_{i+1}$ na imagem PGM(mxn). Nesse estágio é armazenado o ângulo $\alpha$ de cada anel para o cálculo de densidade na componente de receptores. A Figura 7.4 ajuda a entender esse processo.

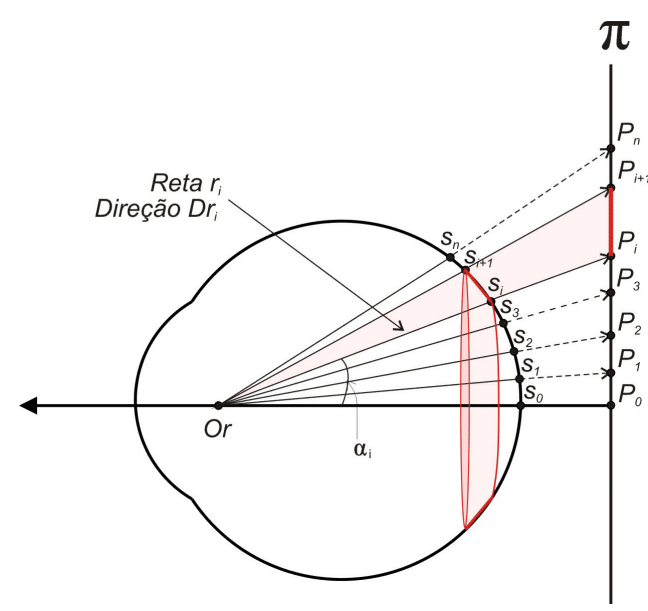

(a)

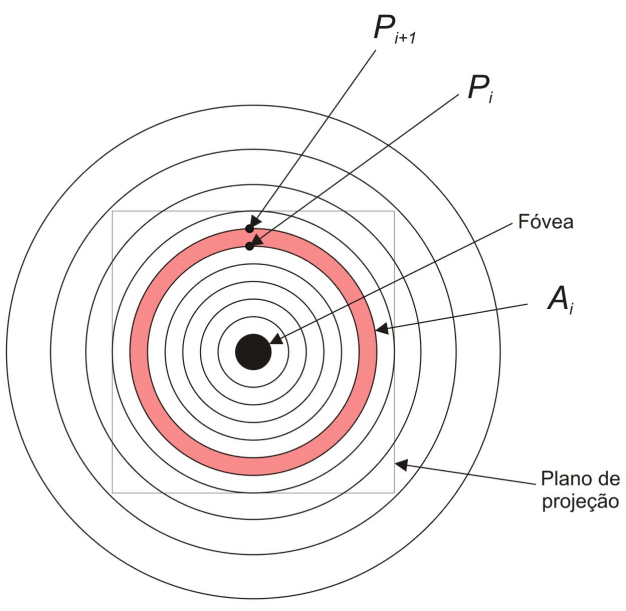

(b)

Figura 7.4: (a) Anéis concêntricos na superfície da retina. (b) Anéis concêntricos na no plano de projeção imagem $\mathrm{PGM}(\mathrm{mxn})$.

Os pontos do conjunto $S$ são obtidos pelas intersecções entre a superfície quádrica e os raios $r_{i}$ (Figura 7.4), que tem origem em $O r$ e direção $D r_{i}$ definida em relação ao ângulo $\alpha$, Equação 7.1. 


$$
D r_{i} \cdot x=\operatorname{sen}(\alpha) \quad D r_{i} . y=0.0 \quad D r_{i} . z=-\cos (\alpha)
$$

Os detalhes do programa são descritos no Algoritmo 7.3.1.

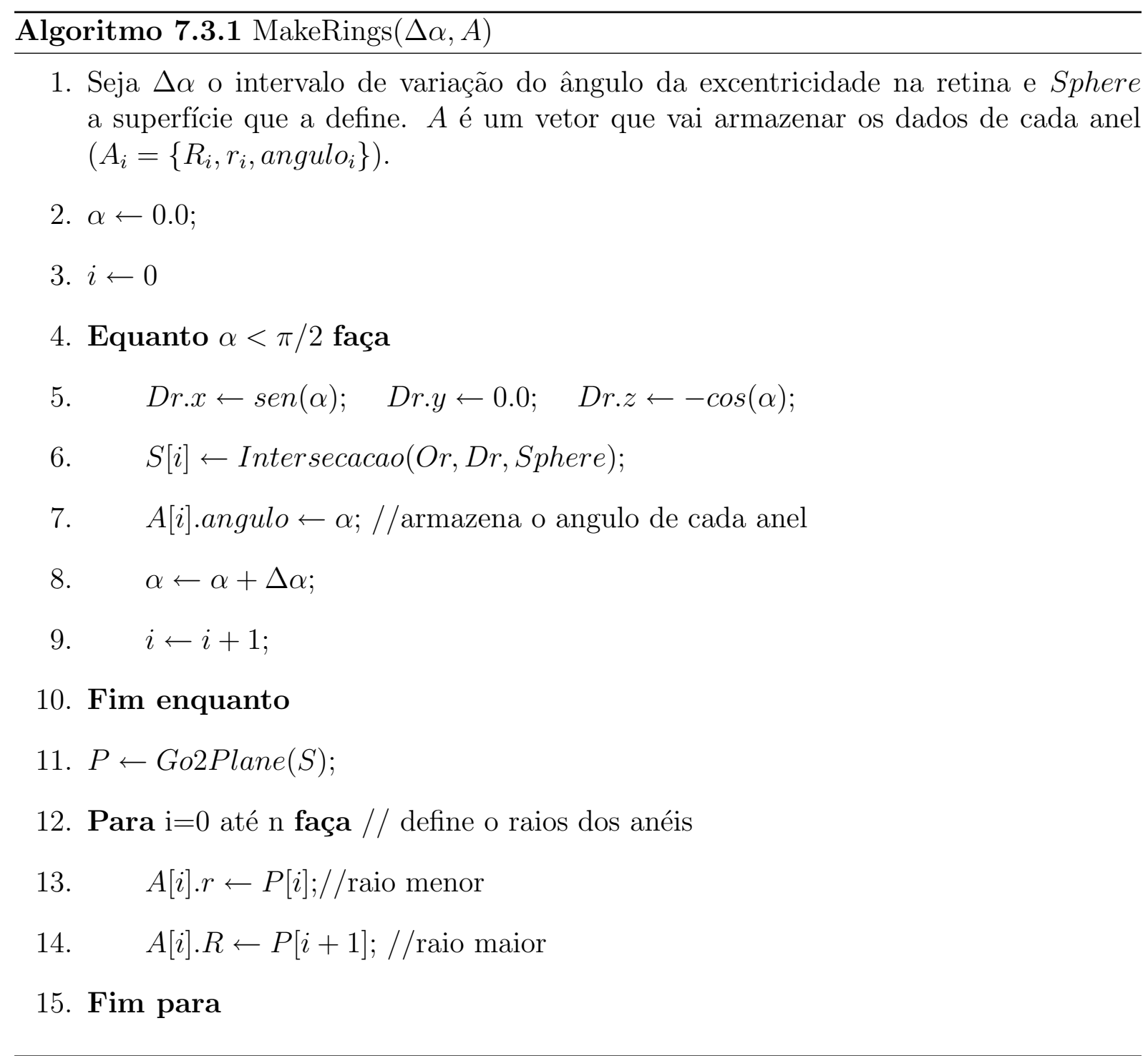

\subsection{Receptores}

A componente dos receptores é responsável em distribuir as células receptoras em cada anel no plano de projeção (imagem $\operatorname{PGM}(\operatorname{mxn})$ ).

O gráfico da Figura 7.5 é uma discretização do gráfico da Figura 3.2 com valores normalizados entre 0 e 1. A densidade é dada em relação ao ângulo com a fóvea (ângulo $\alpha$ da Figura 7.4(a)). 


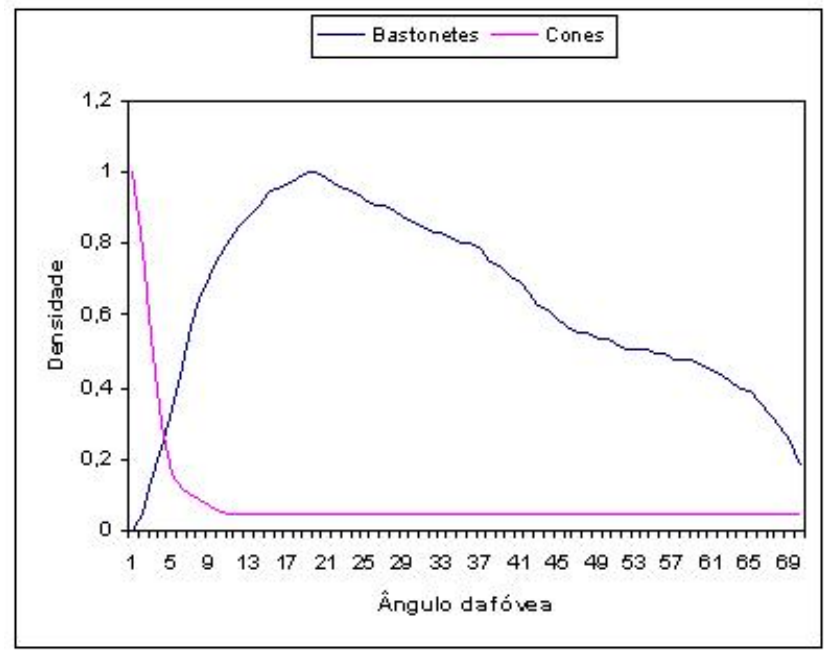

Figura 7.5: Densidade das células receptoras nas excentricidade da retina.

A densidade de células em uma determinada região é dada por:

$$
\text { Densidade }=\frac{\text { Número de células }}{\text { Área da região }}
$$

Assim, o número de células em uma dada região:

$$
\text { Número de células }=\text { Densidade }(\alpha) * \text { Área da região }
$$

Na componente de anéis concêntricos foram definidos os anéis na imagem PGM(mxn), Figura 7.4(a), e armazenados em um vetor $A$ onde cada item define uma tripla $\left(A_{i}=\right.$ $\left\{R_{i}, r_{i}\right.$ angulo $\left._{i}\right\}$ ), raio maior, raio menor e ângulo de excentricidade, respectivamente.

Usando a Equação 7.3, a componente de receptores calcula a quantidade de células em cada anel $A_{i}$. Onde Área da região é a quantidade de pixel dentro do anel $A_{i}$ na

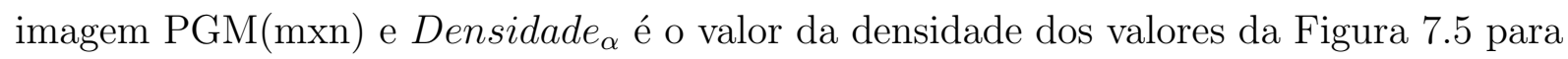
$\alpha=A_{i}$.angulo. Assim, como os valores para densidade estão normalizados entre 0 e 1 , um anel que possuir densidade máxima igual a 1 (na fóvea, em caso de cones), terá o número de células igual a quantidade de pixels. Nesse caso todos os pixels pertencentes ao anel serão selecionados como receptor e não haverá perda de informação nessa região, pois a luz incidente em todos os pixels será detectada (Figura 7.6(a)). Caso a densidade seja abaixo de 1, o número de células será menor do que o total de pixel, ocasionando uma perda de informação, pois parte da luz incidente nessa região não será detectada (região 
cinza da Figura 7.6(b)).

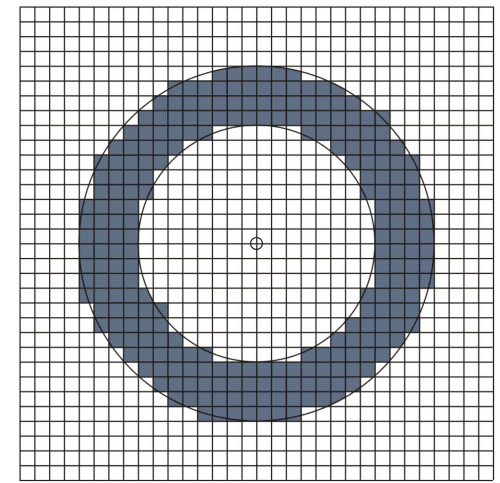

(a)

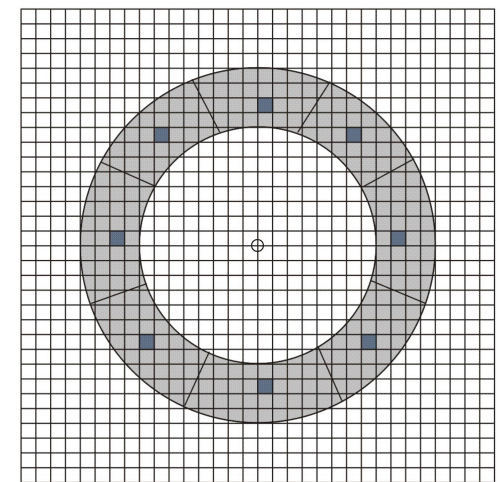

(b)

Figura 7.6: (a) Anel com densidade máxima, toda a luz incidente neste anel será detectada. (b) Anel com densidade baixa, grande parte da luz incidente nesse anel é perdida, pois não há receptores para detectá-la.

O Algoritmo 7.4.1 mostra como esse processo é feito.

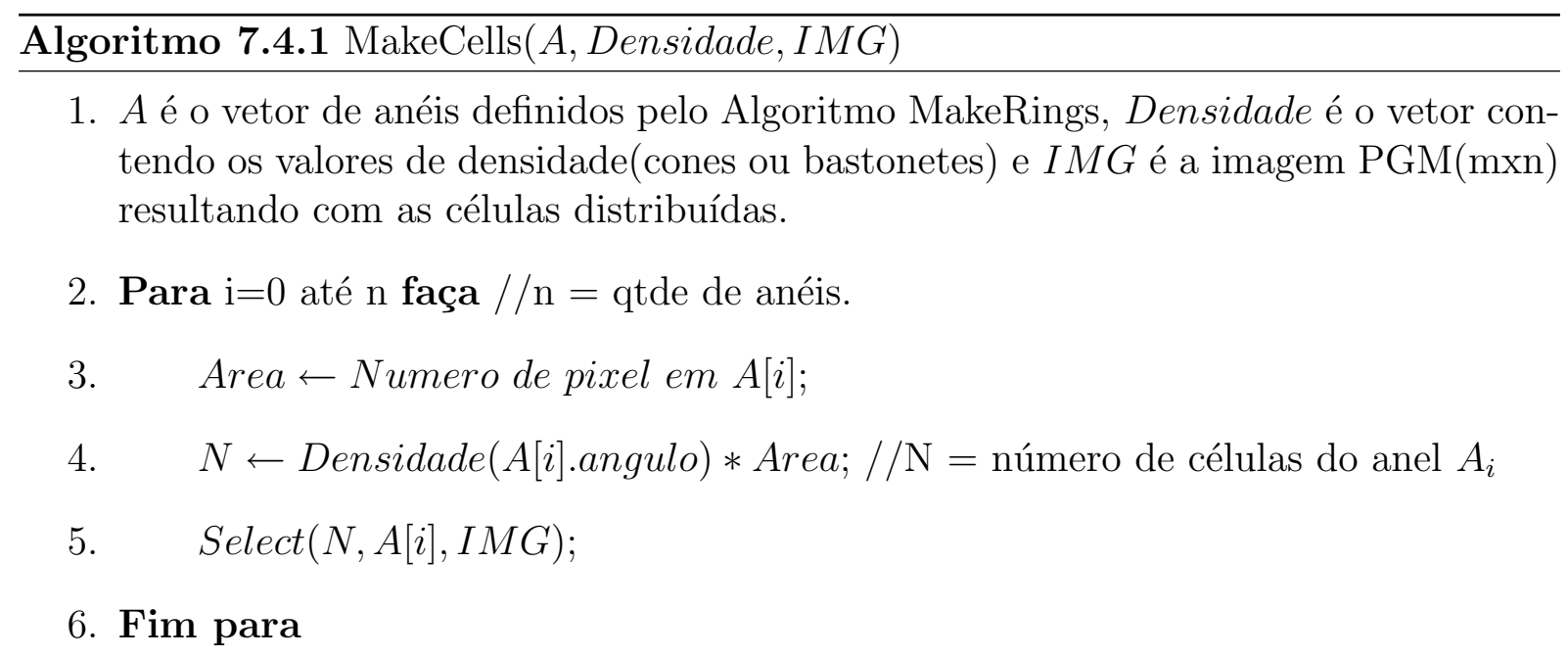

A função $\operatorname{Select}(N, A[i], I M G)$ do Algoritmo 7.4.1 seleciona $N$ pixels pertencentes ao anel $A[i]$ da imagem $I M G$ como células receptoras. Como na Figura 7.6(b) o anel ficará divido em diversas regiões denominadas setores. Cada setor corresponde a uma célula receptora e abrange vários pixels do anel. Assim, $N$ pode ser definido como a resolução do anel dada por $N=\rho * \theta$, onde $\rho$ é a quantidade de circunferências que compõem o anel e $\theta$ é a quantidade de setores alinhados em cada circunferência do anel. Por exemplo, 


\section{Modelagem da retina no Olho Virtual}

no anel da Figura 7.6(b), a resolução é dada por (1x8) pois possui 1 circunferência de 8 setores. A Figura 7.7 ilustra como são definidos $\rho$ e $\theta$ em um anel.

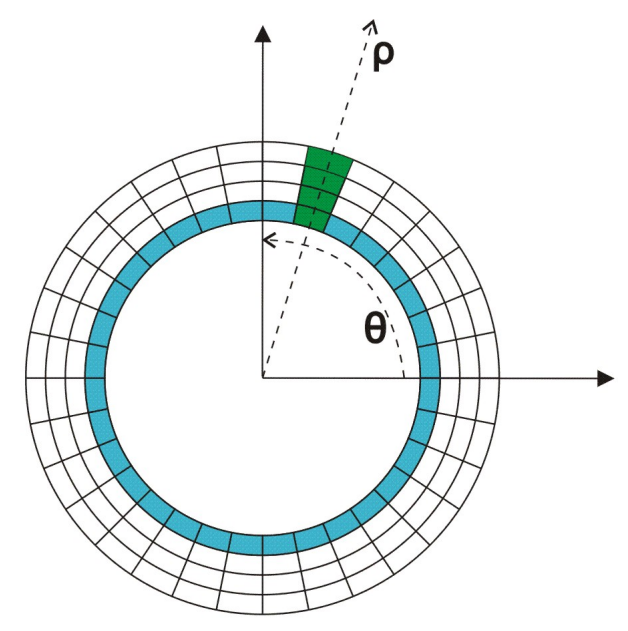

Figura 7.7: Resolução de um anel em $(\rho, \theta))$.

Dados os valores de $\rho$ e $\theta$, as células receptoras são distribuídas, dentro do anel, em $\rho$ circunferências com $\theta$ células cada. A Equação 7.4 é usada para selecionar $\theta$ pontos em uma circunferência:

$$
\begin{aligned}
& y_{i}=\operatorname{sen}\left(\theta_{i}\right) * r+c_{y} \\
& x_{i}=\cos \left(\theta_{i}\right) * r+c_{x}
\end{aligned}
$$

Para $i=1,2,3, \ldots, \theta$, onde $c_{x}$ e $c_{y}$, são as coordenadas do centro da circunferência.

O Algoritmo 7.4.2 mostra em detalhes esse processo.

A Figura 7.8(a) é um exemplo gerado pela componente de receptores para a distribuição de cones de $0^{\circ}$ a $32^{\circ}$ de excentricidade da retina. Cada célula é representada por um ponto preto, assim, na fóvea $\left(0^{\circ}\right)$ compreende uma região central totalmente preta, indicando que a concentração de células é máxima. A quantidade de células diminui rapidamente até $10^{\circ}$, mantendo seu valor constante para regiões de excentricidades superiores.

Na Figura 7.8(b) é mostrado um exemplo para a distribuição de bastonetes, também de $0^{\circ}$ a $32^{\circ}$ de excentricidade da retina. Note que a região central é totalmente desprovida deste tipo de célula (sem nenhum ponto preto), enquanto que na região um pouco mais afastada, de aproximadamente $20^{\circ}$ de excentricidade, a concentração atinge seu valor máximo e a partir de então, para excentricidades maiores de $20^{\circ}$, o número de células 


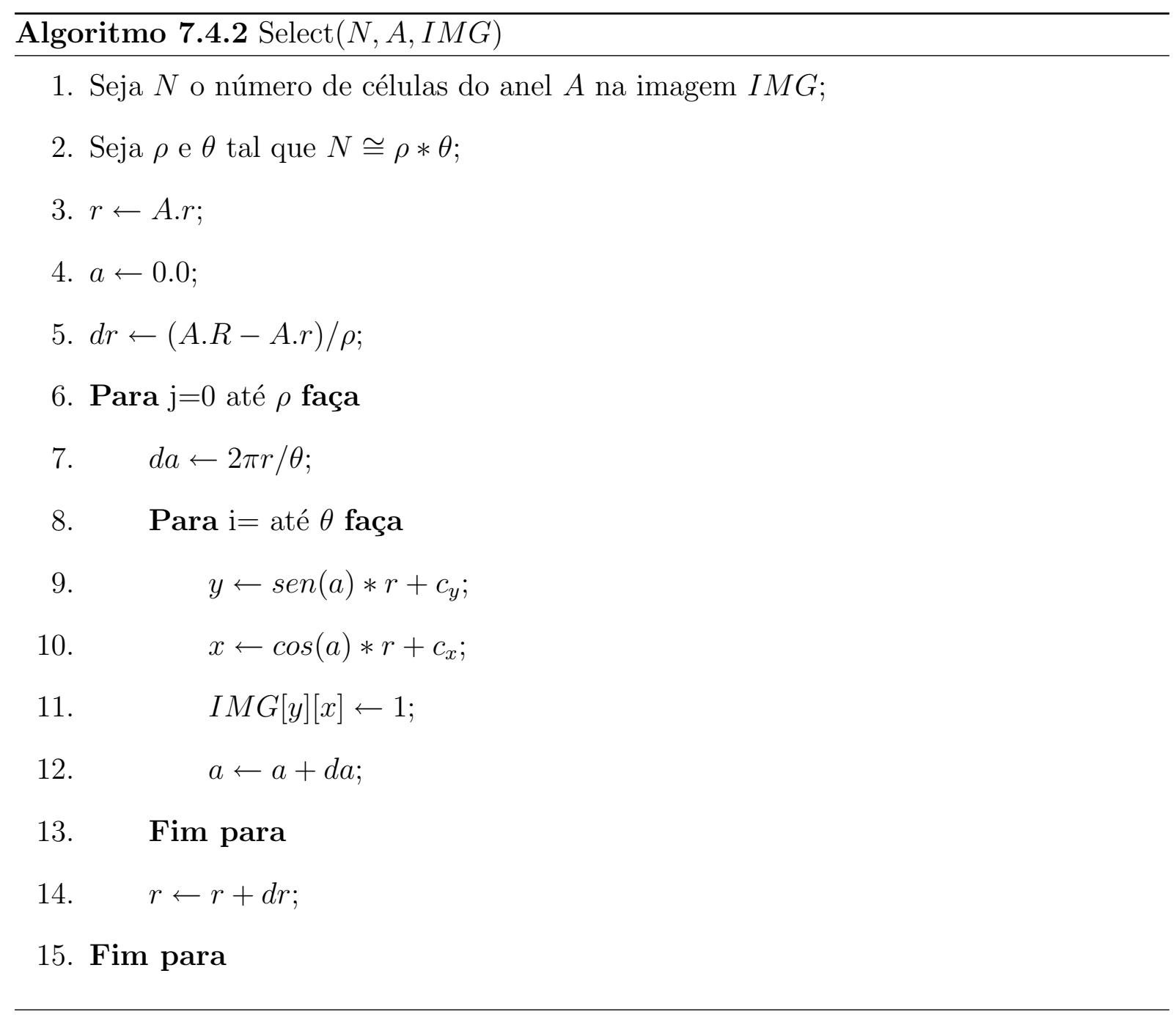

diminui lentamente. Os pixels pretos são células e os brancos significam ausência de célula.

\subsubsection{Relação de aspecto de um setor $(\gamma)$}

A relação de aspecto de um setor é a relação dada entre sua altura e sua largura (VJT08). Considerando o fato de que um setor não possui forma retangular, sua largura não é bem definida. No entanto, o comprimento do arco intermediário do anel que o setor localiza, é escolhido como uma aproximação da largura (Figura 7.9).

Usando regras básicas de geometria, a largura de um setor pertencente a um anel $A(\rho, \theta)=\{R, r$, angulo $\}$ é dado por:

$$
w=\frac{2 \pi}{\theta} \cdot \frac{R+r}{2}
$$




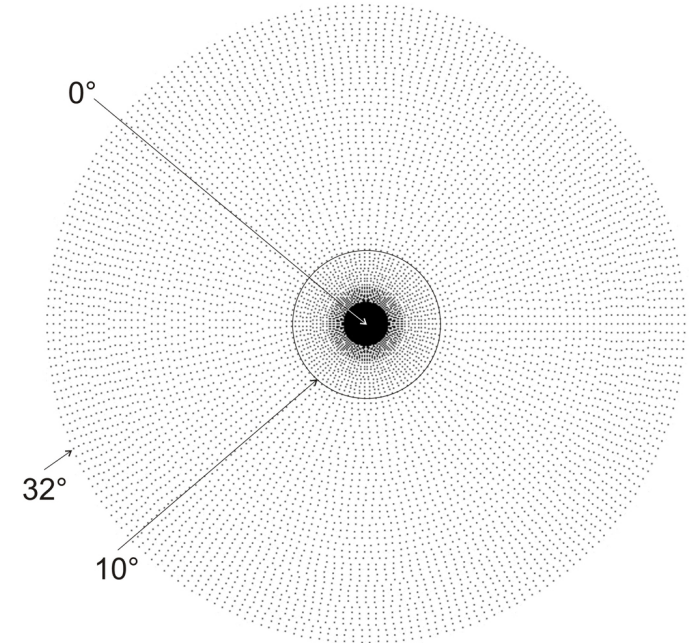

(a)

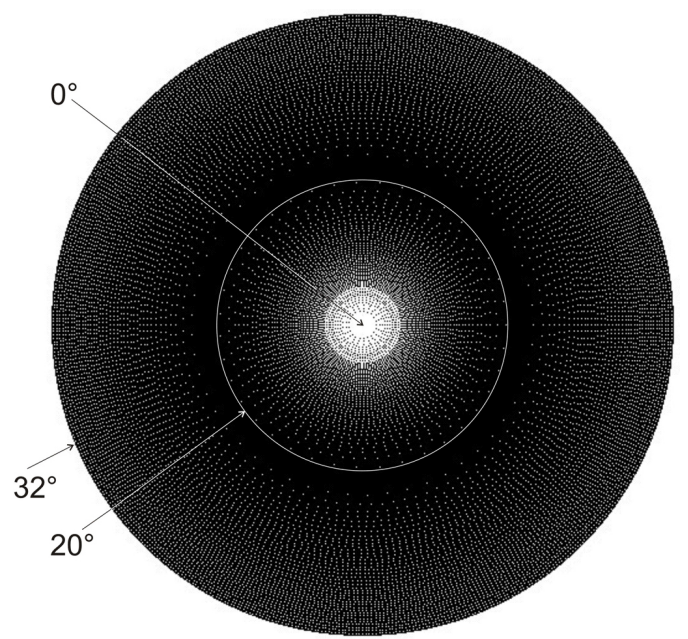

(b)

Figura 7.8: (a) Distribuição das células cones. (b) Distribuição das células bastonetes.

E a altura de um setor é dada como:

$$
h=\frac{R-r}{\rho}
$$

Assim, a relação de aspecto dos setores de um anel $A_{i}$ é dado por:

$$
\gamma=\frac{w}{h}
$$

Para melhores resultado, é desejável que os setores nos anéis tenham formas aproximadas de um quadrado. Para que isso aconteça é necessário $w \cong h$, em outras palavras, quanto mais próximo de 1 for $\gamma$ mais regular será a distribuição das células, formando setores mais parecidos com quadrados. Assim, são escolhidos valores para $(\rho, \theta)$ tal que $\gamma \cong 1$.

\subsubsection{Funcionalidades das células receptoras}

Na Seção 3.4 foi visto que umas das principais diferenças entre células cones e bastonetes é em como esses dois tipos de células respondem ao estimulo de luz. As células cones possuem alta resolução na fóvea, sendo boas em percepção de detalhes em alta luminosidade. As células bastonetes são mais numerosas na periferia e sua atuação está relacionada a informações de baixo contraste. 


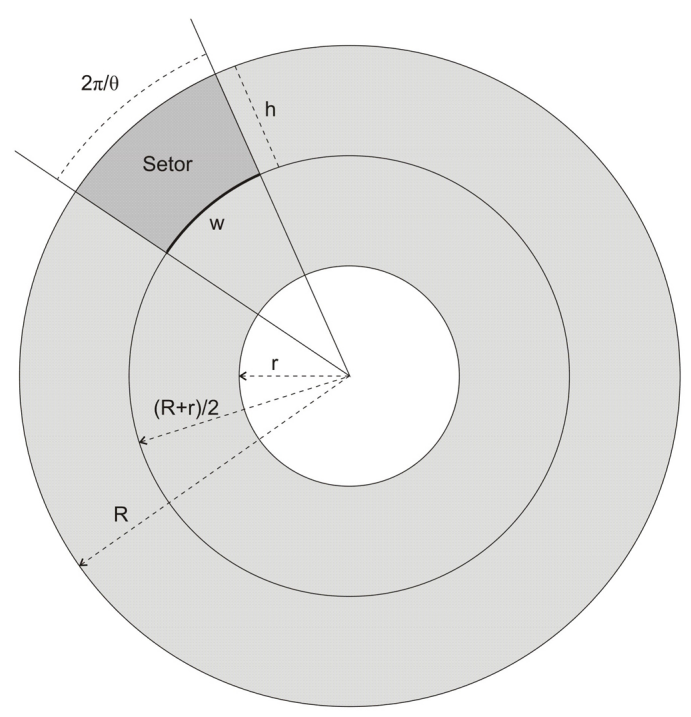

Figura 7.9: Relação de aspecto de um setor.

Para reproduzir tais comportamentos cada célula gerada na distribuição (Figura 7.8) deverá analisar valores das células pertencentes a sua vizinhança. Para os cones, deverá haver uma redução no seu sinal gerado se os valores das redondezas forem de baixo contraste. Enquanto os bastonetes, responderão em alto nível se as redondezas possuírem valores de baixo contrastes.

\subsection{Mapeamento de patologias}

A componente de degenerações é a responsável em fazer o mapeamento de patologias degenerativas da retina a partir de dados reais, obtidos em exames de retinopatia em pacientes portadores da doença. O usuário tem a opção de passar para o programa, um arquivo contendo uma fotografia da retina mapeada com as regiões onde as células possuem sua habilidade de percepção reduzida. Nesta imagem é indicado também, pelo usuário, o pixel correspondente a fóvea e o pixel correspondente ao black spot. Na Seção 7.5.1 é mostrado como o usuário pode mapear tais regiões e na Seção 7.5.2 é apresentado como a retina virtual realiza o mapeamento nas imagens resultantes.

\subsubsection{Mapeando as degenerações}

A ferramenta Degenerações foi desenvolvida para que o usuário possa mapear as regiões danificadas da retina. Neste momento é preciso definir também, em que pixel 


\section{Modelagem da retina no Olho Virtual}

da imagem está localizada a região da fóvea e o black spot 3.5.1 para que o Olho Virtual possa realizar o mapeamento, que será visto na Seção 7.5.2. O software oferece uma interface simples e objetiva ao usuário, provendo ferramentas necessárias para mapear as regiões.

A seguir são mostradas as cinco ferramentas básicas (Figura 7.10) que o programa possui:

- Fóvea: Clicando na ferramenta Fóvea, o usuário pode definir em qual pixel da imagem a fóvea está localizada.

- Black Spot: Clicando na ferramenta Black Spot, o usuário pode definir em qual pixel da imagem o black spot está localizado.

- Caneta: Clicando na ferramenta Caneta, o usuário pode definir quais pixels possuem céluas receptoras com capacidade de percepção reduzida. Assim pode-se formar regiões fechadas indicando que dentro deste local todas as células são danificadas.

- Balde: Clicando na ferramenta Balde, o usuário pode definir regiões com intensidades de cores semelhantes para serem rotuladas como regiões danificadas.

- Nível: Clicando na ferramenta Nível, o usuário define o nível de redução das habilidades das células receptoras, podendo reduzir em 10\%, 20\%, 30\%, 40\%, 50\%, 60\%, $70 \%, 80 \%, 90 \%$ ou $100 \%$.

A Figura 7.10 mostra os pontos mapeados como fóvea e black spot. Observe que a imagem possui várias regiões escuras indicando degeneração celular, nesse exemplo, foram mapeadas algumas dessas regiões ao redor da fóvea, são as regiões mais escuras e mais bem definidas.

Após o usuário definir as regiões, o programa irá salvar a imagem em um arquivo nomeado como nome_do_arquivo $\left[F_{i}, F_{j}, B S_{i}, B S_{j}\right] . p g m$, onde $F_{i}$ e $F_{j}$ são as coordenadas do pixel onde está localizada a fóvea, e $B S_{i}$ e $B S_{j}$ são as coordenadas do pixel onde está localizado o black spot. Este arquivo será então passado como entrada para a retina do Olho Virtual, e a definiremos como imagem degenerada. 


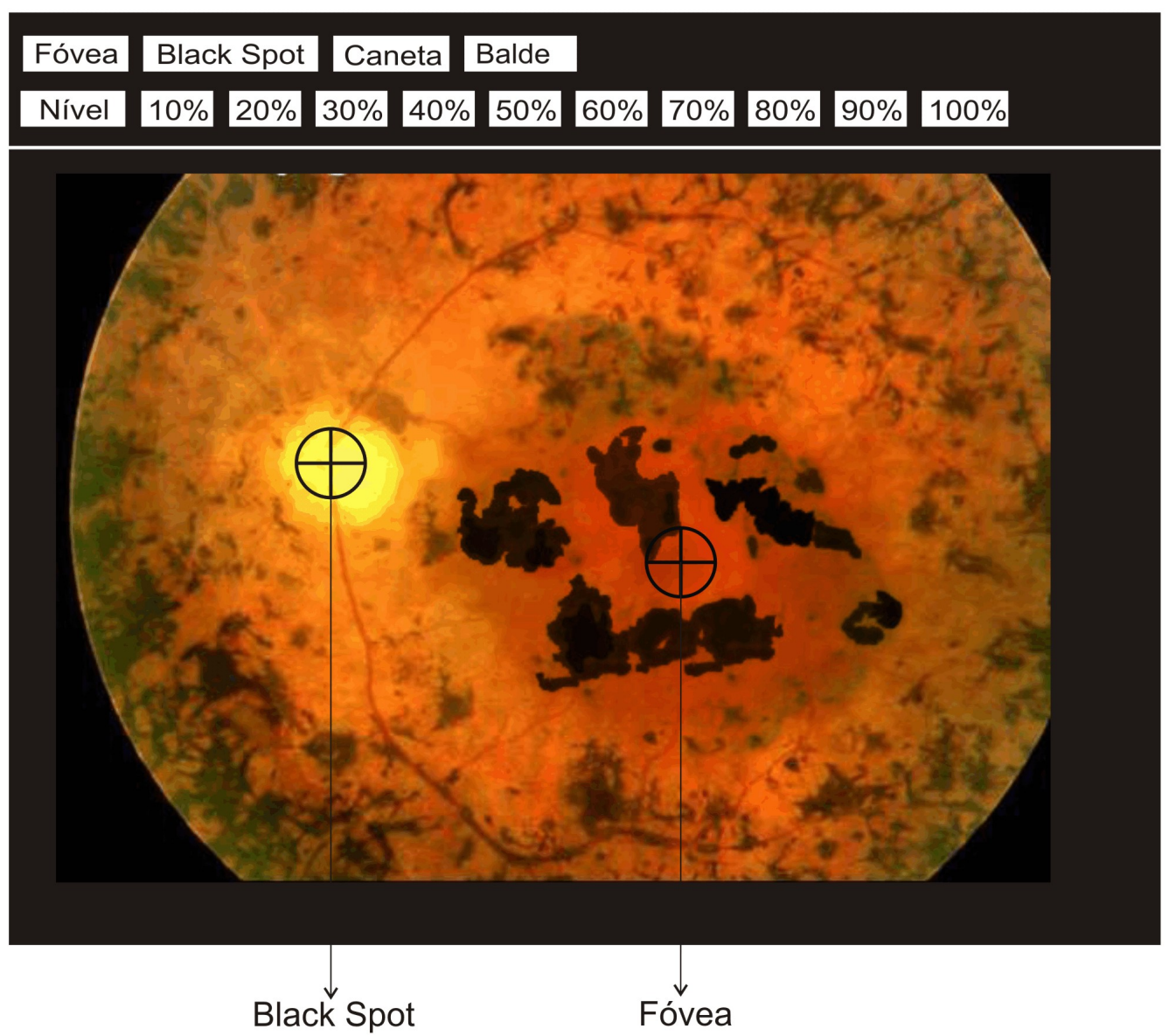

Figura 7.10: Um exemplo da execução do software e suas ferramentas.

\subsubsection{Mapeamento da patologia no VEye}

A imagem resultante do software de degenerações é posta no plano de projeção $\pi$, Figura 7.1 de tal forma que a fóvea da imagem corresponda a fóvea do modelo do olho, por exemplo, se a fóvea do modelo está localizada no ponto $(0,0, z)$ o pixel da imagem que representa o centro da fóvea será $(0,0, z)$. A mesma correspondência deve haver para o black spot da imagem com o do modelo (Figura 7.11).

Dessa forma a imagem degenerada é projetada no fundo da retina. É usada a componente de projeção paralela (Figura 7.3(b)). Em seguida o resultado é novamente projetado e mapeado ao plano de projeção, mas dessa vez é usada projeção perspectiva, para que o resultado fique compatível com as demais projeções (Figura 7.3(a)).

A Figura 7.12 é um exemplo de distribuição da células cones mapeadas com células degeneradas. As regiões em branco indicam que as células neste local não possuem ca- 


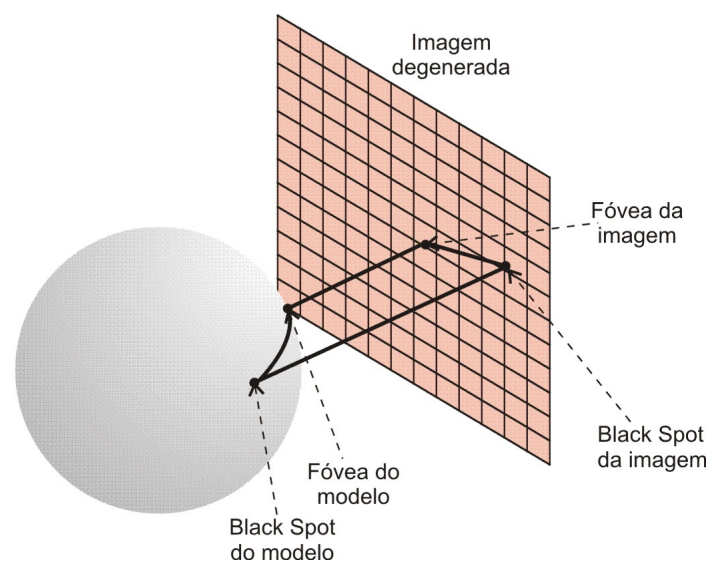

Figura 7.11: Mapeamento da imagem de retina degenerada com a retina no VEye.

pacidade para responder ao estimulo de luz. Este mapeamento foi obtido combinando a distribuição de células gerada na Figura 7.8(a) com a imagem do exemplo 7.10.

Figura 7.12: Mapeamento de células degeneradas na distribuição das células cones

\subsection{Campos receptivos}

Os campos receptivos são processados sobre o resultado gerado pela componente dos receptores. Em outras palavras, o sinal que os receptores produzem é enviado para as células ganglionares, onde estas produzem o sinal de cada campo receptivo. Como visto na Seção 3.7.1, existem células com sinal inibitório no centro e com o sinal inibitório na periferia. 


\section{Modelagem da retina no Olho Virtual}

Um campo receptivo é modelado por uma simplificação do filtro de Marr-Hildreth (Seção 4.5), como uma máscara $C R$ de tamanho $(h x h)$, com número de elemento $N=h * h$, possui um raio menor $(r)$ que define a área central e um raio maior que define a periferia. Assim, a máscara $C R$ é definida pela Equação 7.8 .

$$
C R_{i j}^{+}=\left\{\begin{array}{rll}
+1 / N_{r} & \text { se } & d \leq r \\
-1 / N_{R} & \text { se } & r<d \leq R \\
0 & \text { se } & d>R
\end{array}\right.
$$

Onde $N_{r}$ é a quantidade de elementos dentro da área central e $N_{R}$ é a quantidade de elementos dentro da área periférica e $d$ é dado por:

$$
d=\sqrt{i^{2}+j^{2}}
$$

O campo receptivo da Equação 7.8 define campos On-Center Off-Surround. Para definir campos Off-Center On-Surround basta inverter o sinal:

$$
C R_{i j}^{-}=\left\{\begin{array}{rll}
-1 / N_{r} & \text { se } & d \leq r \\
+1 / N_{R} & \text { se } & r<d \leq R \\
0 & \text { se } & d>R
\end{array}\right.
$$

Se imagem $I(m x n)$ possui uma célula ganglionar no pixel $(k, l)$, a reposta do campo receptivo desta célula será dado pela operação de convolução $I(k, l) \otimes C R$, com o centro da máscara $C R$ no ponto $(k, l)$ de $I$.

A Seção 3.7.2 explica como os campos receptivos atuam como detectores de bordas. De acordo com a teoria, é usado uma combinação dos dois campos receptivos, On-Center e Off-Center. Assim, o operador de gradiente entre os dois campos $C R^{+}$e $C R^{-}$define um detector de bordas $D B$ e é dado pela Equação 7.11 .

$$
D B_{i j}=\sqrt{C R_{i j}^{+2}+C R_{i j}^{-2}}
$$




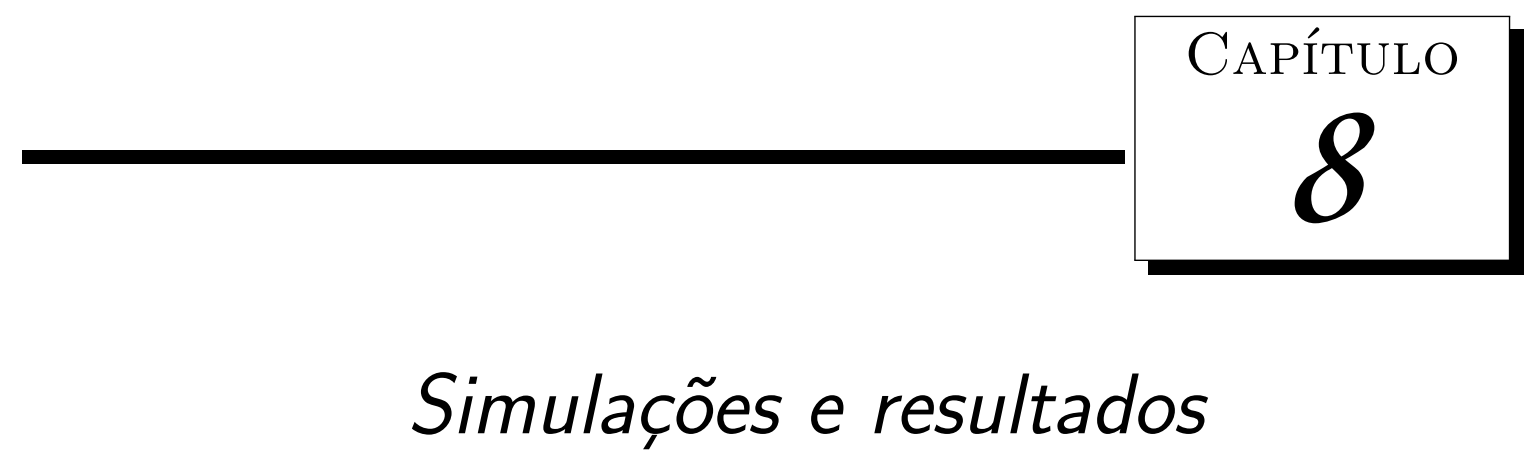

Neste capítulo são apresentados alguns resultados obtidos da retina no Olho Virtual. São elaboradas simulações em dois níveis celulares da retina. O primeiro, em nível de receptores, onde são comparadas as visões sob as perspectivas dos cones e bastonetes e, também, a diferença de resolução na imagem formada em diferentes excentricidades na retina. O segundo nível é em relação aos campos receptivos, onde são analisadas as informações estabelecidas pelas células gânglios nos caminhos parvo e magnocelular.

Os resultados obtidos nas simulações de experimentos psicofísicos são parâmetros eficientes para comprar o comportamento da retina do VEye com uma retina natural descrito na literatura.

Além dessas, também foram desenvolvidas simulações de ametropias, cuja modelagem foi baseada nas propriedades geométricas da retina.

\subsection{Simulação das ametropias}

Foram feitas simulações de ametropias envolvendo os mais comuns tipos de erros refrativos do sistema visual humano. A teoria da Seção 6.2 foi utilizada para induzir tais miopia e hipermetropia no Olho Virtual.

Para simulação de miopia foi usado o modelo de Le Grand no seu estado não acomo- 


\section{Simulações e resultados}

dado. O objeto imagem foi posto à $6.0 \mathrm{~m}$ à frente do olho, com o raio da pupila de 1.0 $\mathrm{mm}$. Sob tais condições, foram simulados diferentes graus de miopia com e sem o uso de lentes corretivas. O resultado é mostrado na Figura 8.1, onde a primeira linha são imagens formadas por olhos míopes sem o uso de lente corretiva para os graus de -1.0, $-2.0,-3.0,-4.0$ e -5.0 nas imagens $(\mathrm{a}),(\mathrm{b}),(\mathrm{c}),(\mathrm{d}),(\mathrm{e})$ respectivamente. Na segunda linha são mostradas as imagens formadas por olhos míopes com o uso de lente corretiva para os graus de -1.0, -2.0, -3.0, -4.0 e -5.0 nas imagens (f), (g), (h), (i) e (j) respectivamente.

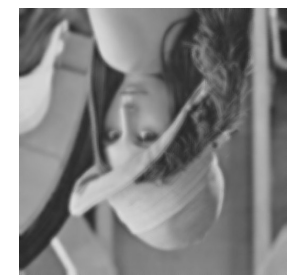

(a) m. -1D

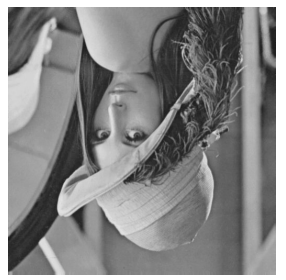

(f) m.l.d -1D

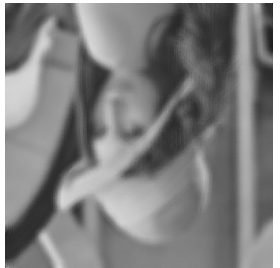

(b) m. $-2 \mathrm{D}$

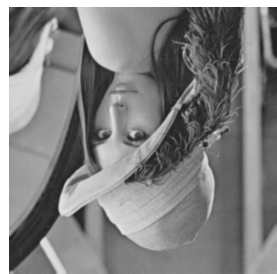

(g) m.l.d -2D

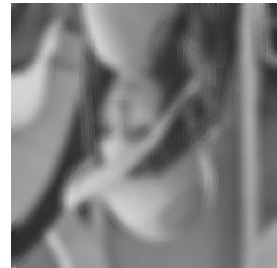

(c) m. $-3 \mathrm{D}$

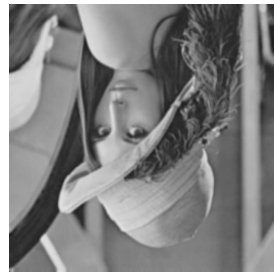

(h) m.l.d -3D

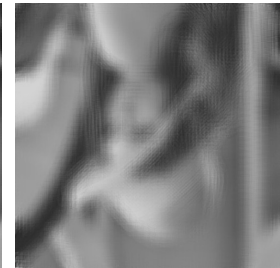

(d) m. $-4 \mathrm{D}$

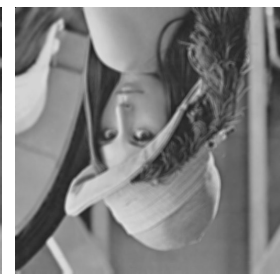

(i) m.l.d $-4 \mathrm{D}$

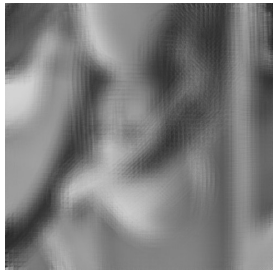

(e) m. $-5 \mathrm{D}$

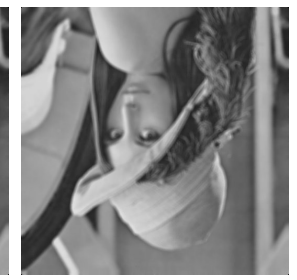

(j) m.l.d -5D

Figura 8.1: Imagens geradas pela simulação de olhos míopes no modelo de $l g r_{u} \cdot \mathrm{m} .=$ miopia, m.l.d = miopia e lente divergente.

É fácil perceber pelos resultados que a nitidez nas imagens diminui enquanto o grau de miopia aumenta. Na simulação em que a lente divergente foi usada, a imagem apresenta ser tão nítida quanto em um olho emétrope.

Para a simulação de hipermetropia, o objeto imagem foi colocado aproximadamente à $14 \mathrm{~cm}$ à frente do olho, modelo de Le Grand acomodado $\left(l g r_{a}\right)$ com raio da pupila de $1.0 \mathrm{~mm}$. A Figura 8.2 mostra os resultados na formação de imagens com e sem o uso de lentes corretivas, neste caso lentes convergentes.

Pode-se notar que quanto maior o grau de hipermetropia presente no olho, maior será o "borrão" gerado na imagem formada na retina. Isto acontece porque os olhos amétropes possuem o ponto de convergência dos raios em um local diferente da retina. Como consequência, há uma área de atividade maior desses raios, mostrado na Figura 


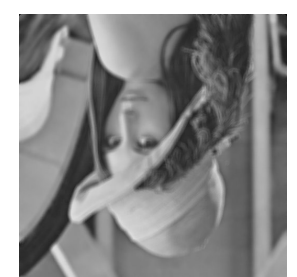

(a) h. $+1 \mathrm{D}$

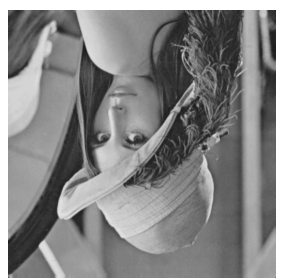

(f) h.l.c $+1 \mathrm{D}$

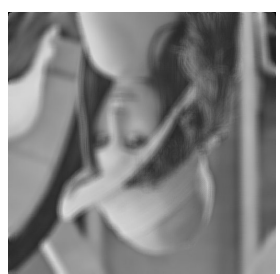

(b) h. $+2 \mathrm{D}$

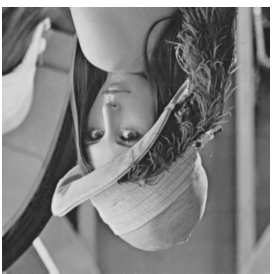

(g) h.l.c $+2 \mathrm{D}$

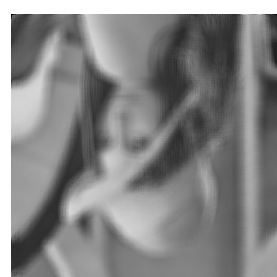

(c) h. $+3 \mathrm{D}$

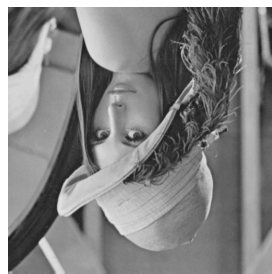

(h) h.l.c $+3 \mathrm{D}$

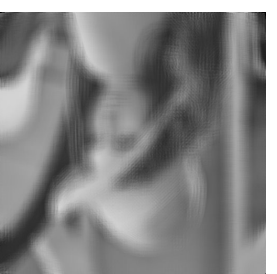

(d) h. $+4 \mathrm{D}$

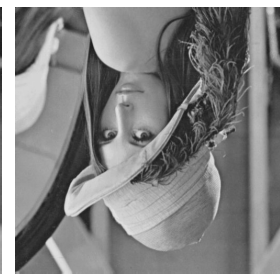

(i) h.l.c $+4 \mathrm{D}$

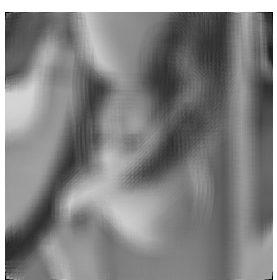

(e) h. $+5 \mathrm{D}$

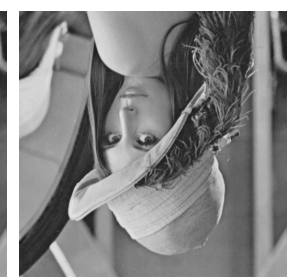

(j) h.l.c $+5 \mathrm{D}$

Figura 8.2: Imagens geradas pela simulação de olhos hipermétropes no modelo de $l g r_{a}$. h. = hipermetropia, h.l.c = hipermetropia e lente convergente.

6.4. Esta área de atividade é chamada círculo de confusão, Definição 5.1. Quanto menor for o círculo de confusão mais nítido será a imagem formada na retina.

Por fim, para uma análise quantitativa dos algoritmos desenvolvidos, foi calculado o raio do círculo de confusão $\rho^{\prime}$ na simulação de miopia e hipermetropia para dez casos diferentes, o resultado pode ser visto nos gráficos da Figura 8.3.

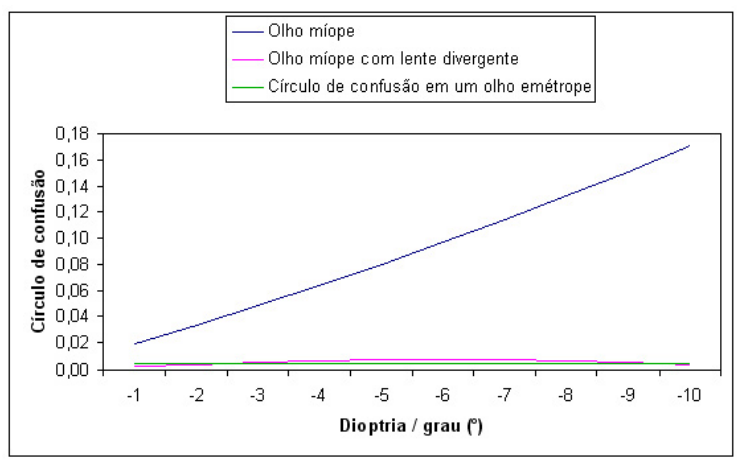

(a)

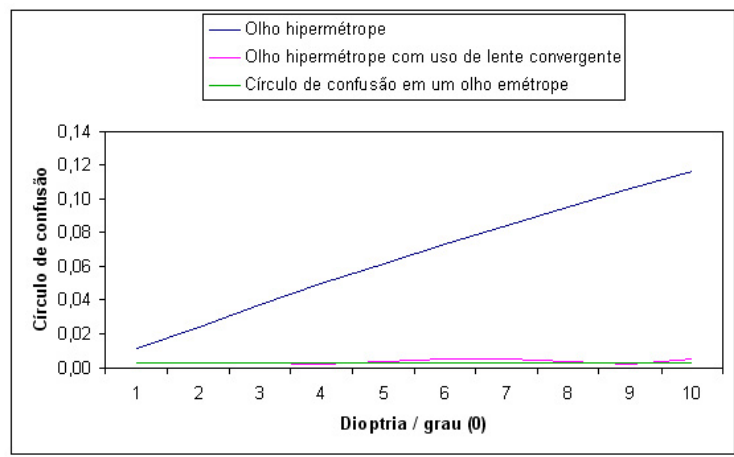

(b)

Figura 8.3: (a)Círculo de confusão em olhos míopes com e sem o uso de lentes divergentes. (b) Círculo de confusão em olhos hipermétropes com e sem o uso de lentes convergentes.

O círculo de confusão cresce juntamente com o grau de ametropia, o que significa uma perda de nitidez nas imagens resultantes. Depois do uso de lentes corretivas, o círculo de confusão volta a ter valores próximos aos de olhos emétropes, resultando em uma imagem 
mais clara e mais parecida com a original.

\subsection{Fóvea versus periferia}

Na Seção 3.5 foi mostrado como as células são distribuídas na retina. De acordo com essa teoria, os cones são as células responsáveis para uma visão mais apurada e estão distribuídos de forma radial, com sua maior concentração no centro. Na Seção 7.4 foi apresentada uma modelagem computacional para essa distribuição celular.

Para ilustrar a diferença de resolução entre imagens formadas nas regiões da fóvea e periferia, foram feitas simulações do processo de formação de imagens nessas duas regiões. A Figura 8.4 contém as distribuições celulares usadas nos exemplos desta seção. Lembrando que, em se tratando de resolução de imagem, só faz sentido comparar os sinais gerados pelas células cones. Os bastonetes desempenham papéis que não pertencem a esse contexto e, além do mais, tais células são ausentes na fóvea da retina.

A Figura 8.4 contém quatro imagens, que são nomeadas da seguinte forma:

- (a) Imagem Original: Espaço reservado para as imagens originais nos exemplos utilizados;

- (b) Distribuição $D_{1}$ : Distribuição dos cones para imagens formadas somente na fóvea. Todos os pixels nessa região são pretos, pois representam células muito próximas umas das outras;

- (c) Distribuição $D_{2}$ : Distribuição dos cones para imagens formadas nas regiões da fóvea e periferia com excentricidades de $0^{\circ}$ a $16^{\circ}$. Isso significa que a imagem possui 16 anéis como os descritos na Figura 7.4(b);

- (d) Distribuição $D_{3}$ : Distribuição dos cones para imagens formadas nas regiões da fóvea e periferia com excentricidades de $0^{\circ}$ a $50^{\circ}$. Isso significa que a imagem possui 50 anéis como os descritos na Figura 7.4(b).

A Figura 8.5 apresenta simulações para as três distribuições $D_{1}, D_{2}$ e $D_{3}$ citadas na Figura 8.4. Outras simulações são apresentadas nas Figuras 8.8, 8.9, 8.10 e 8.11.

Os resultados mostram que a resolução na imagem formada decrementa com a distância em relação ao centro. Alem disso, o tamanho das células na fóvea são menores do que na 


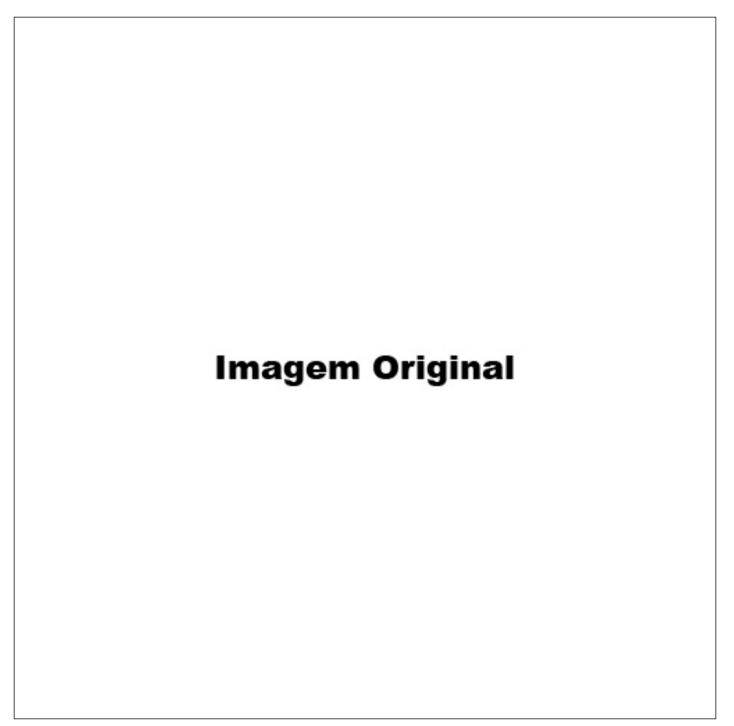

(a)

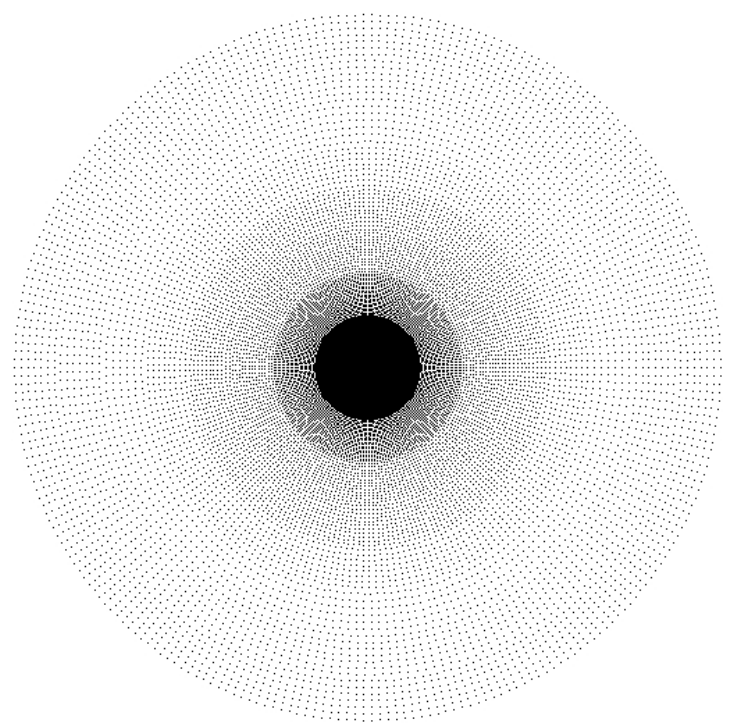

(c)

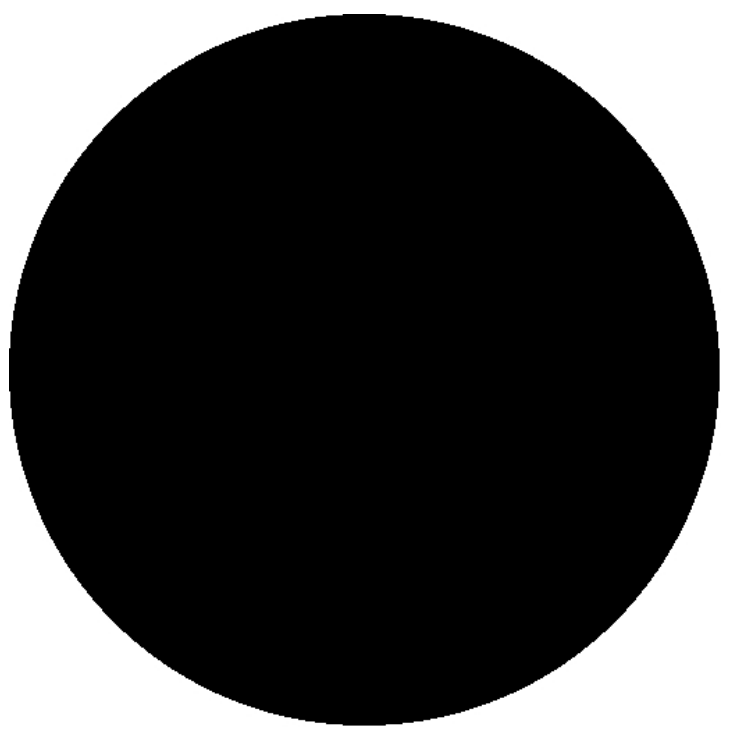

(b)

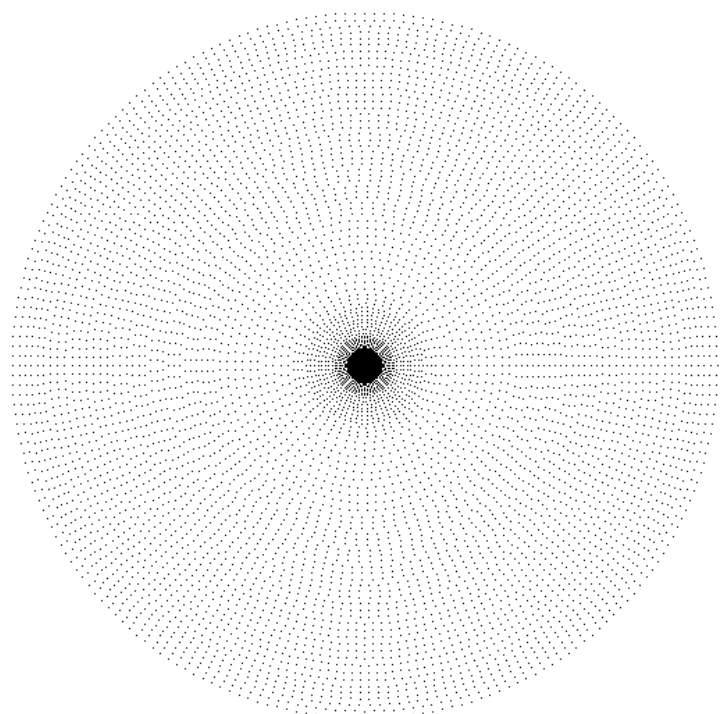

(d)

Figura 8.4: (a) Espaço reservado a imagem original. (b) Distribuição $D_{1}$ dos cones para imagens formadas somente na fóvea. (c) $D_{2}$ Distribuição dos cones para imagens formadas nas regiões da fóvea e periferia com excentricidades de $0^{\circ}$ a $16^{\circ}$. (d) $D_{3}$ Distribuição dos cones para imagens formadas nas regiões da fóvea e periferia com excentricidades de $0^{\circ} \mathrm{a}$ $50^{\circ}$ 


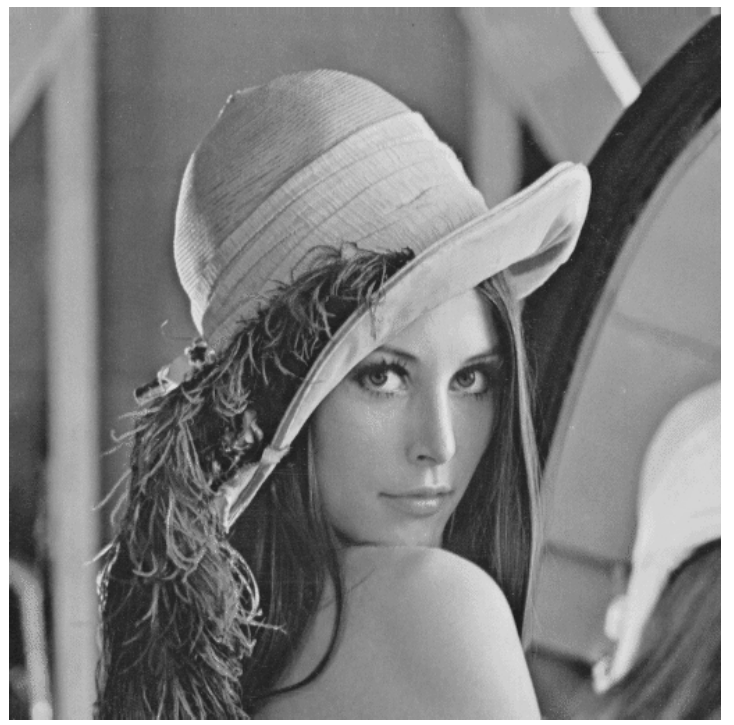

(a)

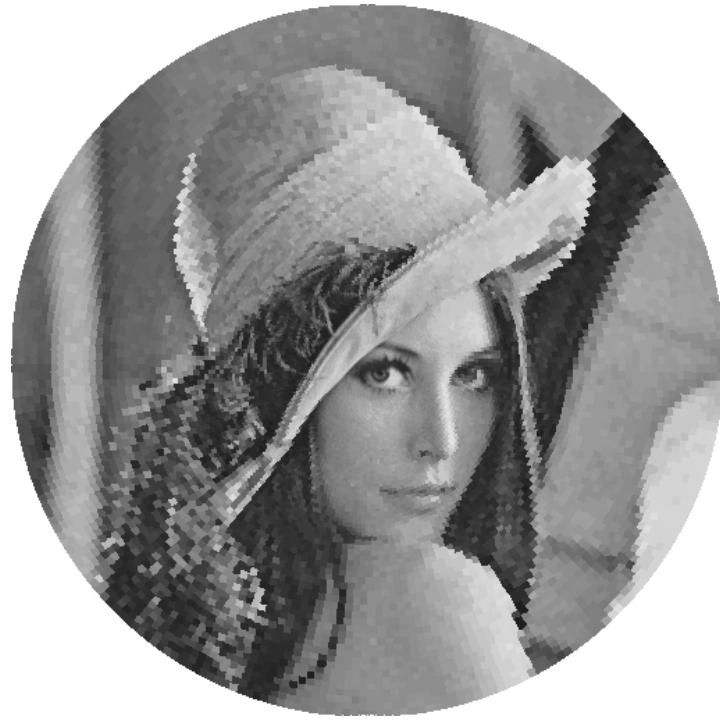

(c)

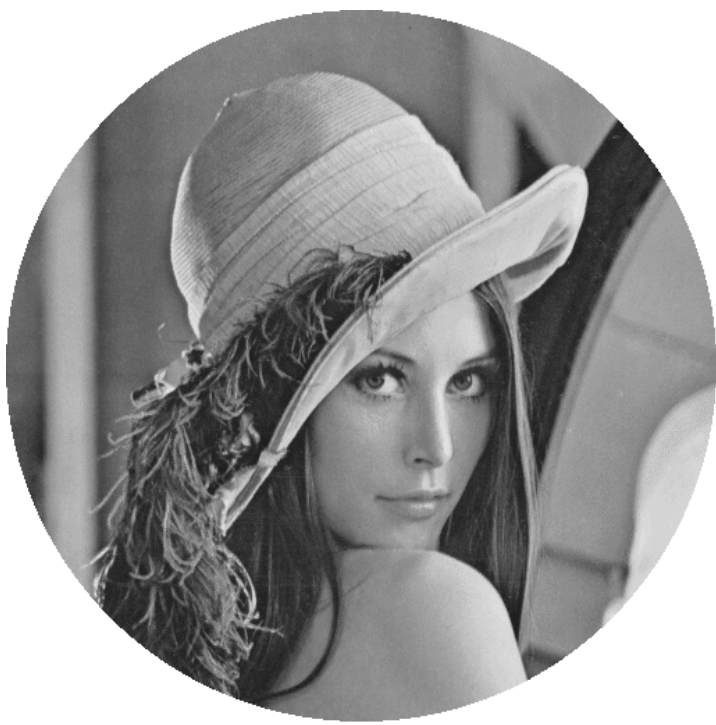

(b)

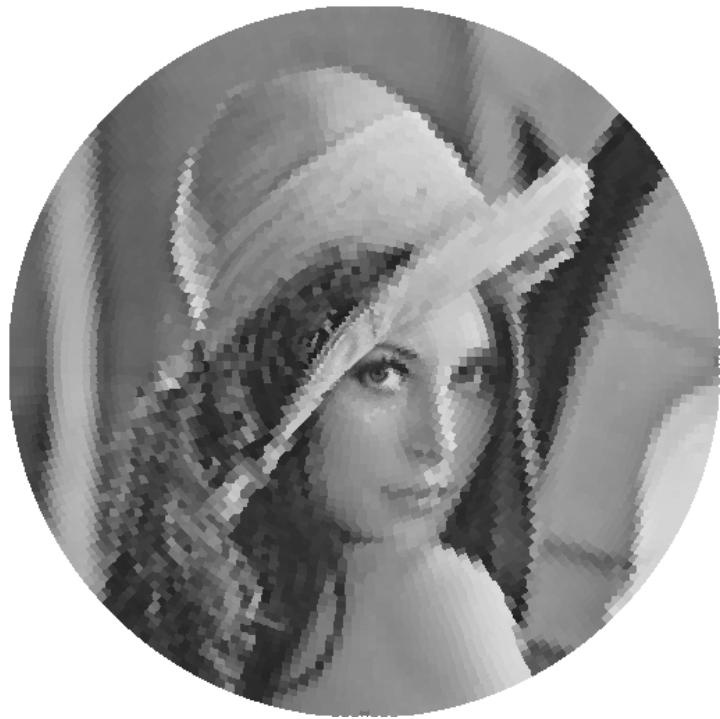

(d)

Figura 8.5: Resultado das simulações de formação de imagem pelas células cones. (a) Imagem original. (b) Imagem formada na fóvea $\left(D_{1}\right)$. (c) Imagem formada na fóvea e periferia $\left(D_{2}\right)$. (d) Imagem formada na fóvea e periferia $\left(D_{3}\right)$. 


\section{Simulações e resultados}

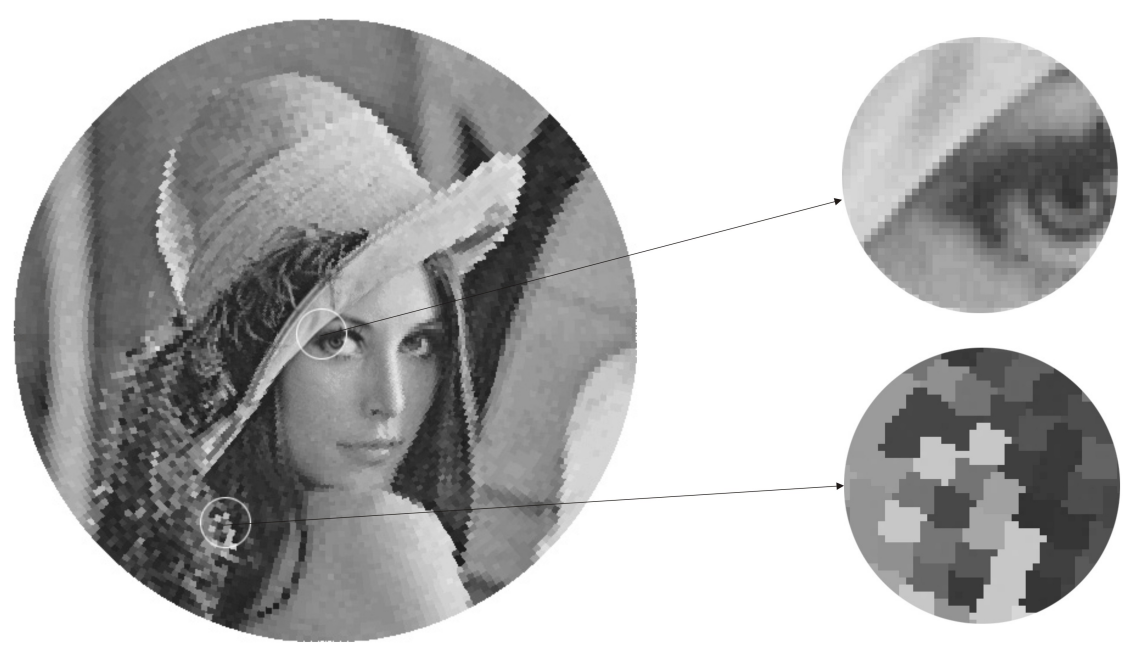

Figura 8.6: Ampliação feita na imagem formada nas regiões de fóvea e periferia.

periferia. Para melhor visualizar tais diferenças, é mostrado na Figura 8.6 uma ampliação nas regiões. Pode-se notar que na fóvea há muito mais células do que na periferia, e que o tamanho das mesmas são menores, proporcionando neste local uma melhor qualidade na visão e boa qualidade na percepção de detalhes.

Os gráficos da Figura 8.7 mostram a densidade de células cones nas excentricidades na distribuição $D_{3}$ dada na Figura 8.4. A densidade é dada por $D=N$.Celulas/Area, onde a área, no gráfico da Figura 8.7(a) é dada em $\mathrm{mm}^{2}$ correspondente a área que o anel ocupa na superfície quádrica da retina (Figura 7.4(a)), e a área no gráfico da Figura 8.7(b) é dada pela quantidade de pixels que o anel ocupa na imagem (Figura 7.4(b)).

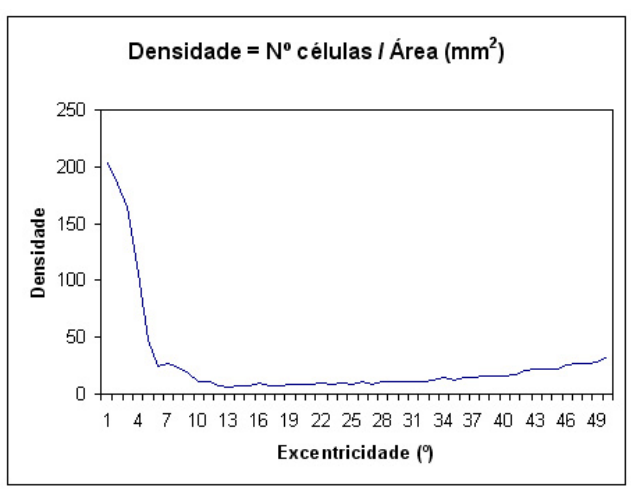

(a)

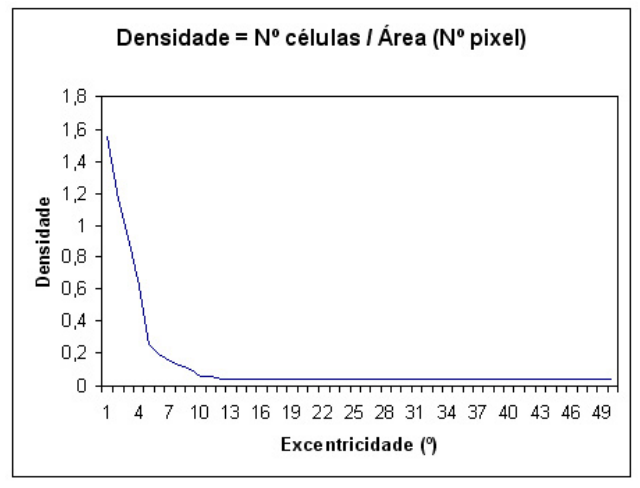

(b)

Figura 8.7: Densidade de cones em $D_{3}$. (a) Área dada em $\mathrm{mm}^{2}$. (b) Área dada em quantidade de pixels. 


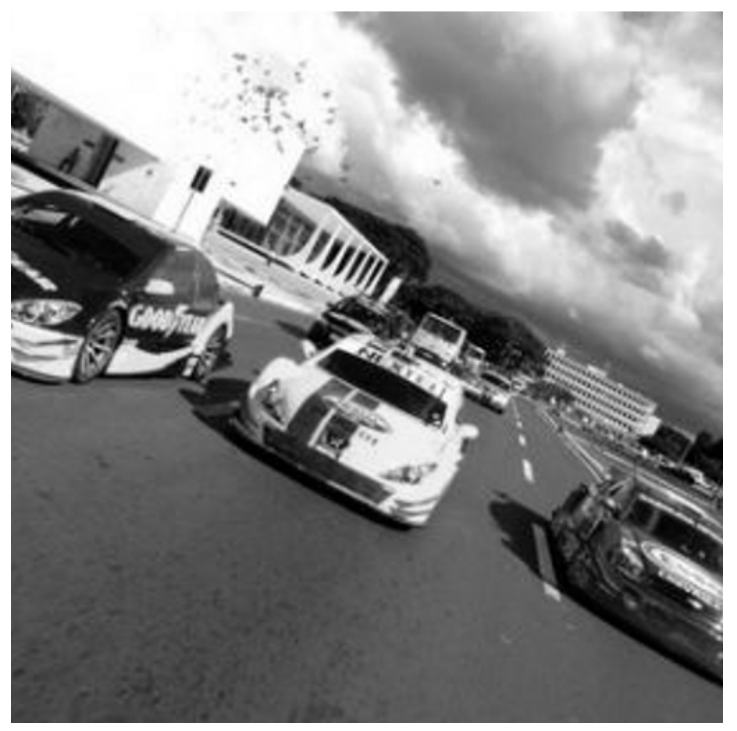

(a)

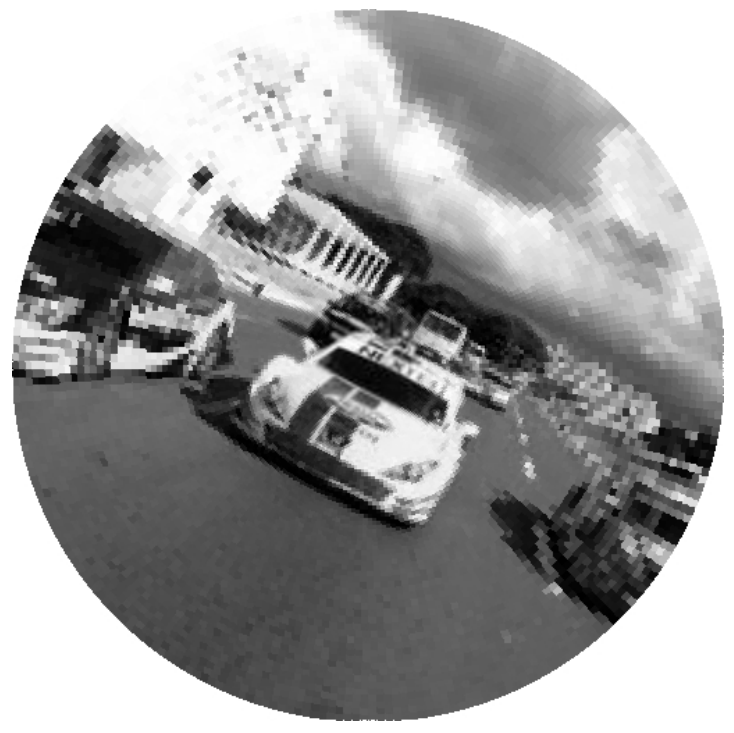

(c)

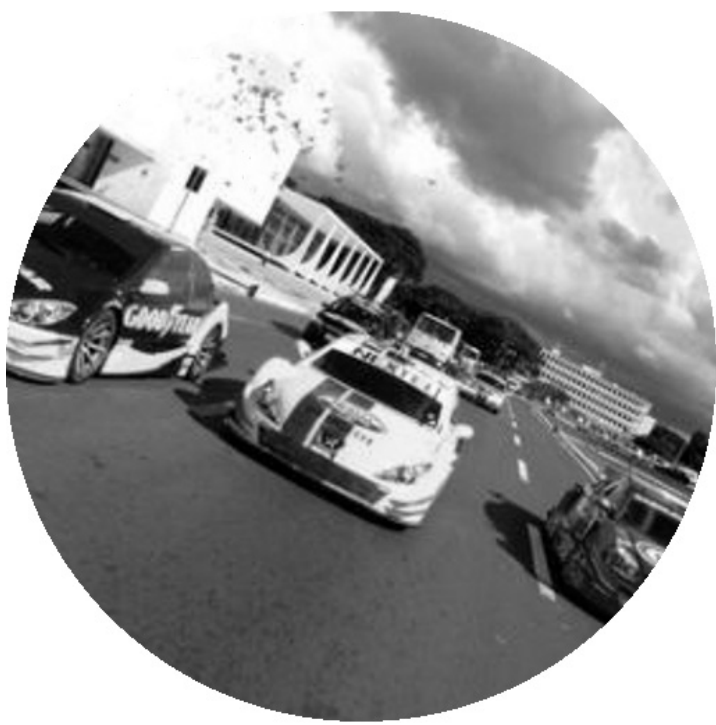

(b)

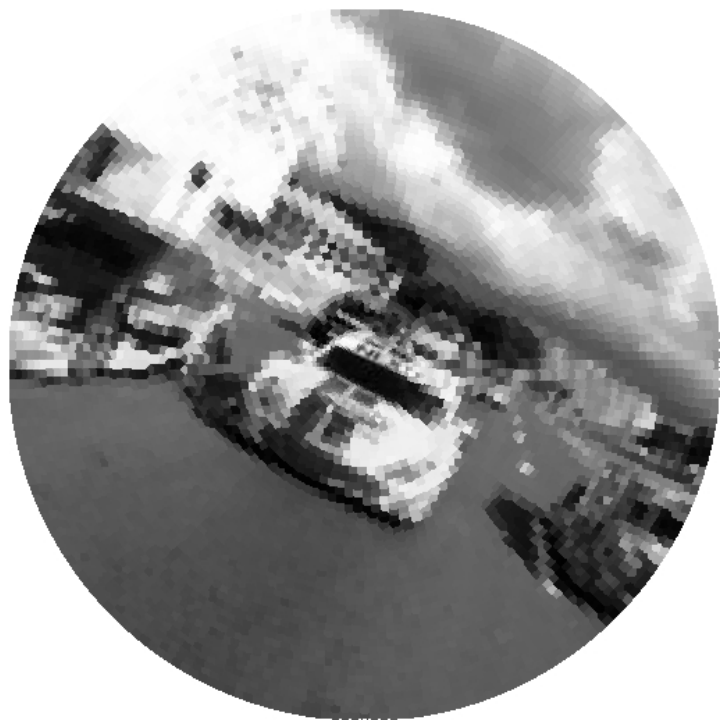

(d)

Figura 8.8: Resultado das simulações de formação de imagem pelas células cones. (a) Imagem original. (b) Imagem formada na fóvea $\left(D_{1}\right)$. (c) Imagem formada na fóvea e periferia $\left(D_{2}\right)$. (d) Imagem formada na fóvea e periferia $\left(D_{3}\right)$. 


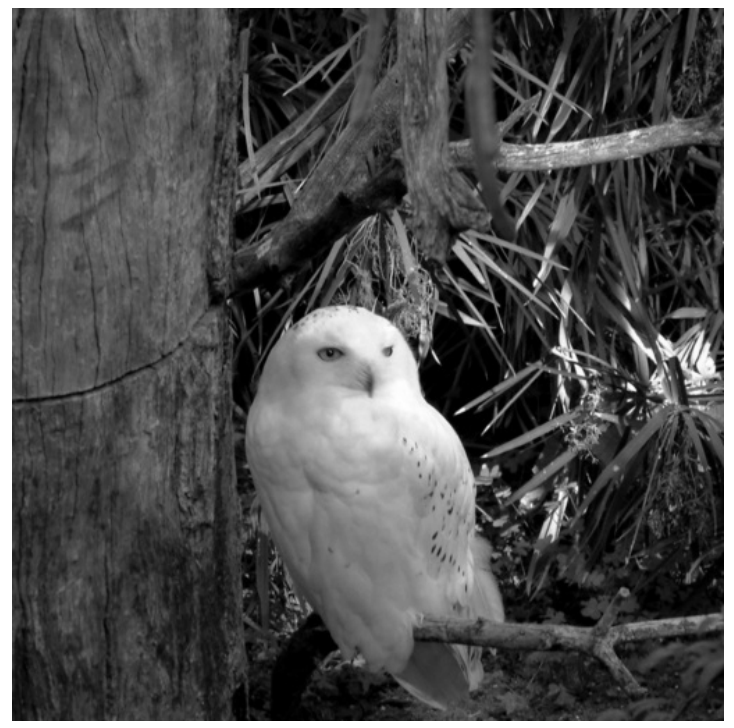

(a)

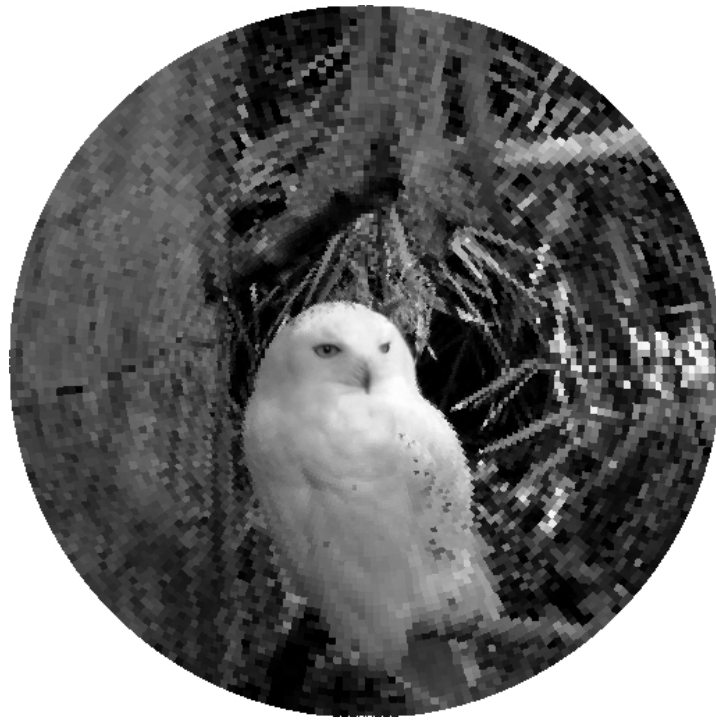

(c)

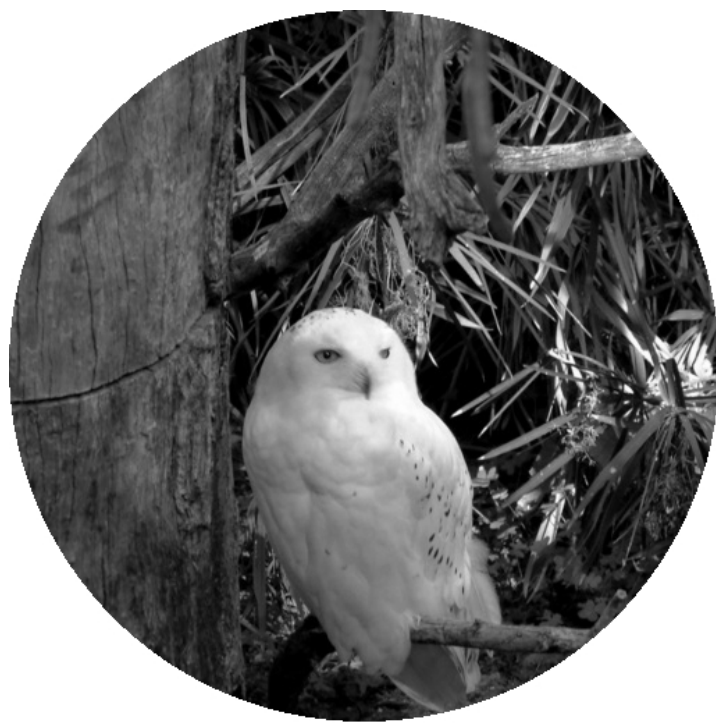

(b)

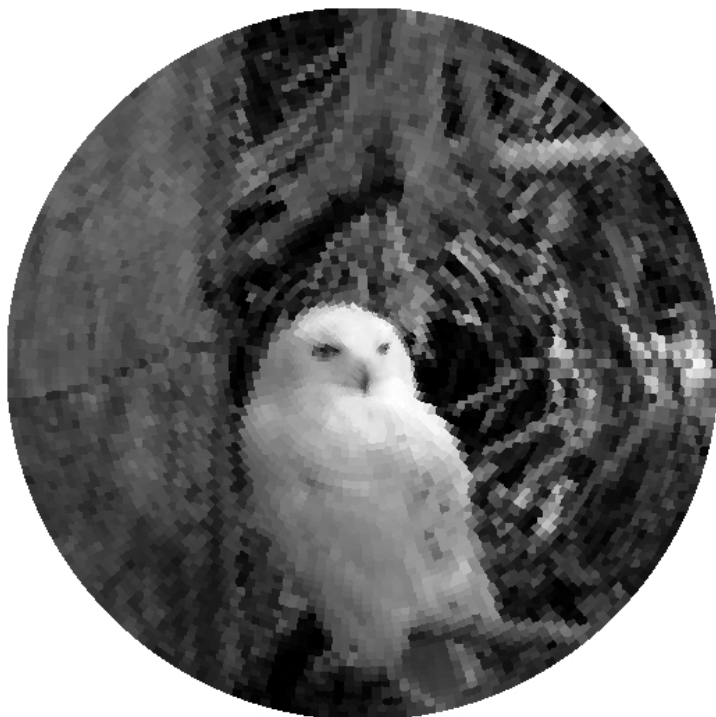

(d)

Figura 8.9: Resultado das simulações de formação de imagem pelas células cones. (a) Imagem original. (b) Imagem formada na fóvea $\left(D_{1}\right)$. (c) Imagem formada na fóvea e periferia $\left(D_{2}\right)$. (d) Imagem formada na fóvea e periferia $\left(D_{3}\right)$. 


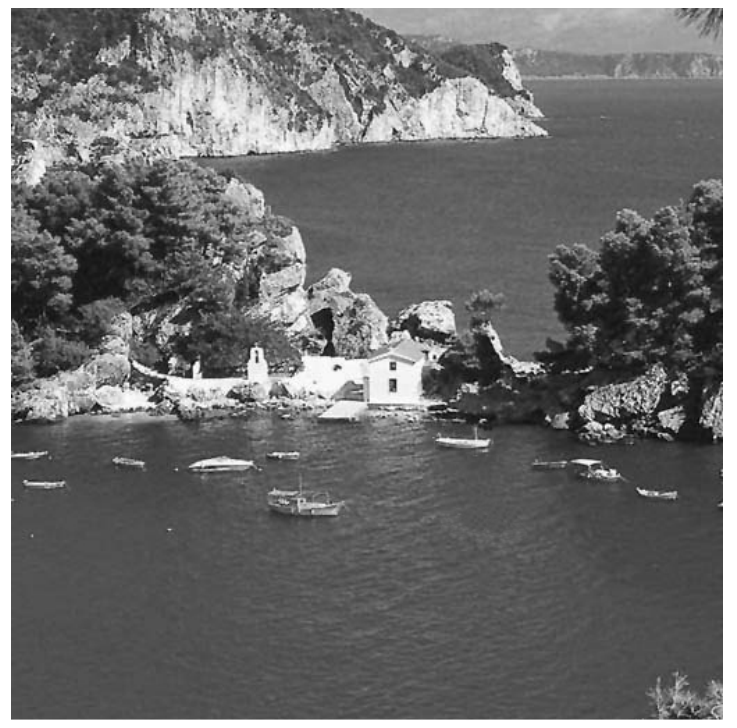

(a)

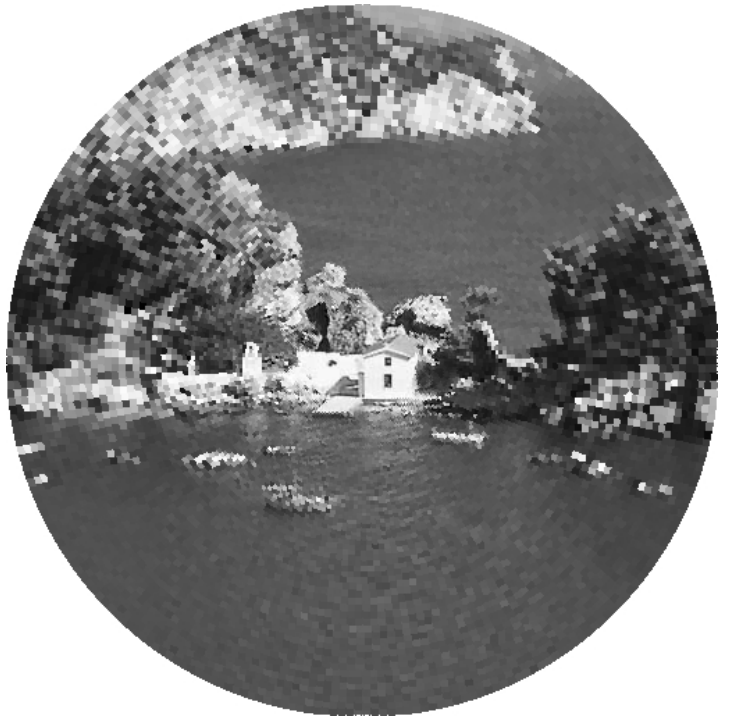

(c)

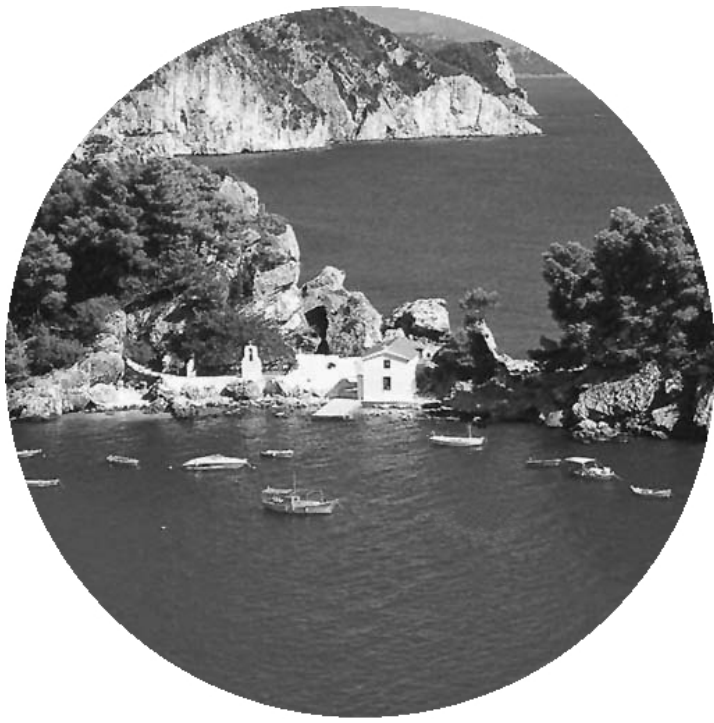

(b)

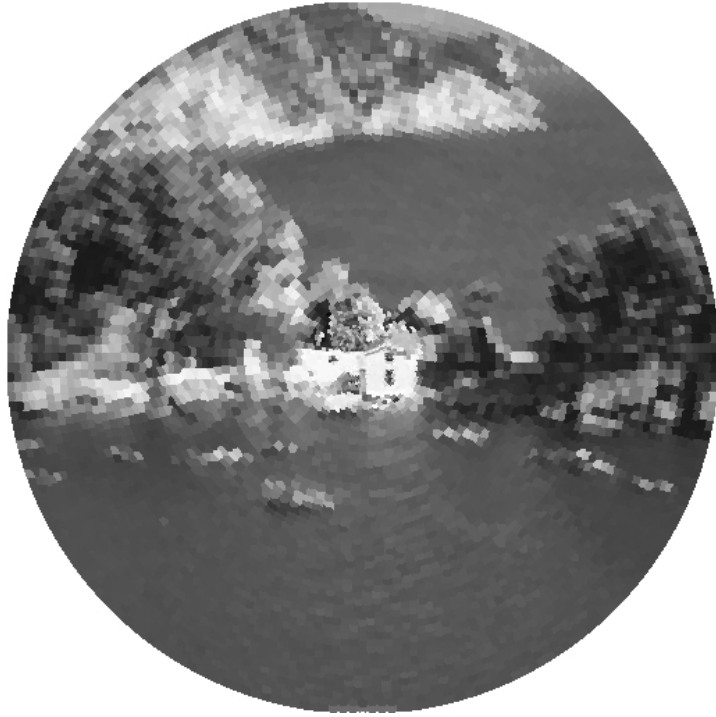

(d)

Figura 8.10: Resultado das simulações de formação de imagem pelas células cones. (a) Imagem original. (b) Imagem formada na fóvea $\left(D_{1}\right)$. (c) Imagem formada na fóvea e periferia $\left(D_{2}\right)$. (d) Imagem formada na fóvea e periferia $\left(D_{3}\right)$. 


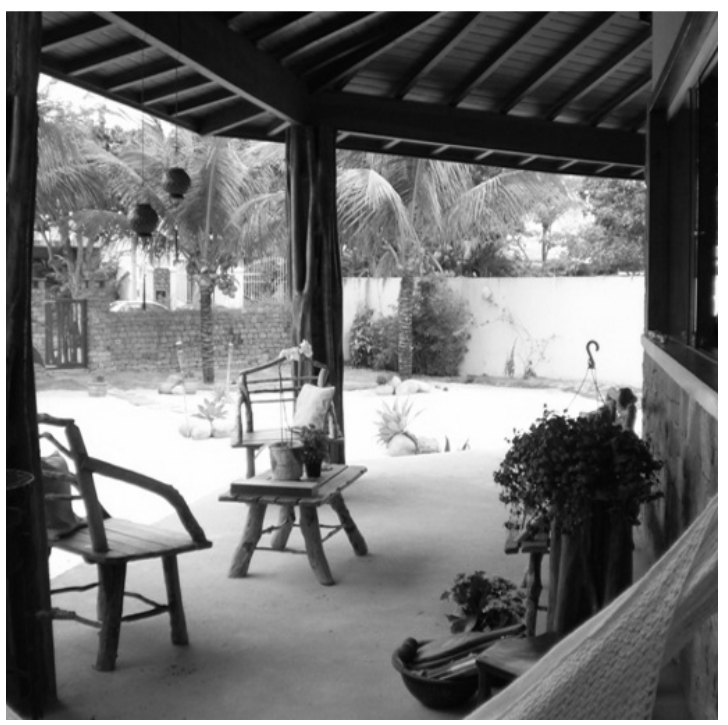

(a)

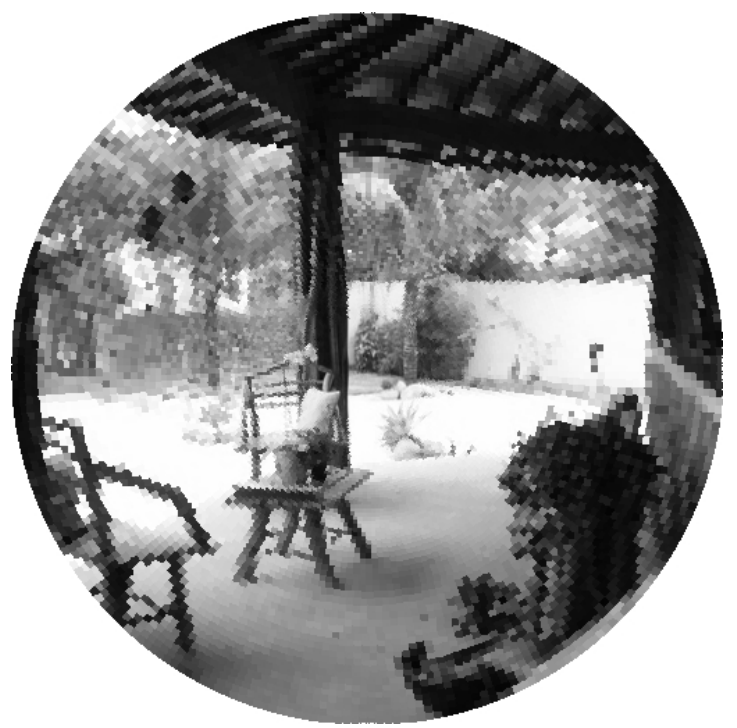

(c)

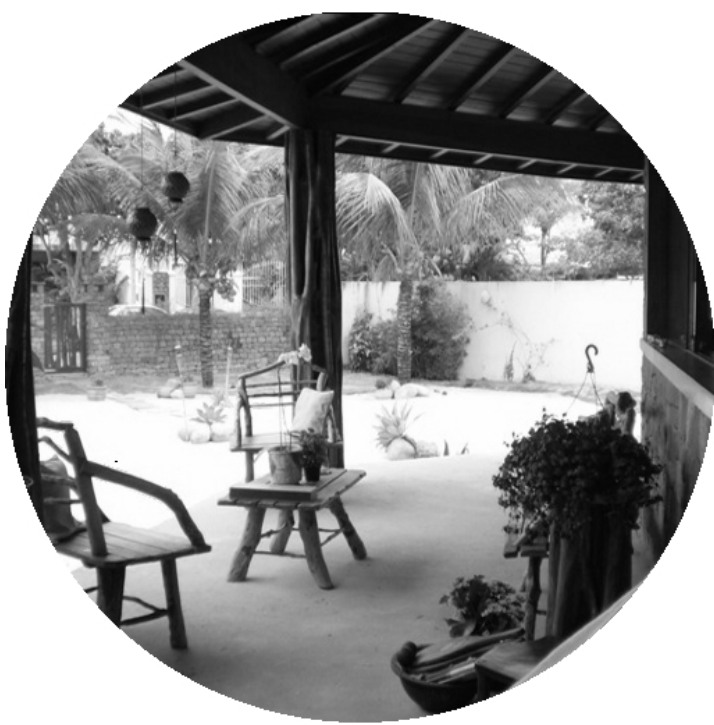

(b)

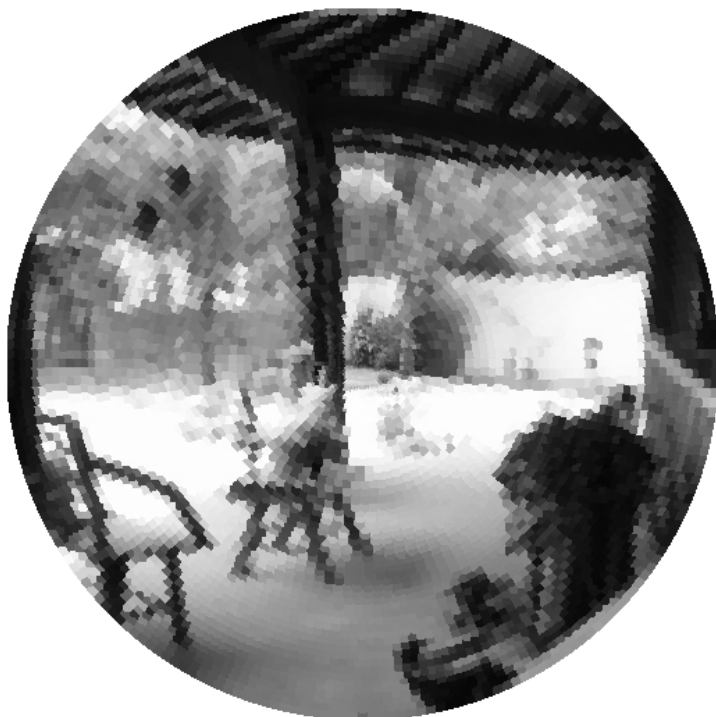

(d)

Figura 8.11: Resultado das simulações de formação de imagem pelas células cones. (a) Imagem original. (b) Imagem formada na fóvea $\left(D_{1}\right)$. (c) Imagem formada na fóvea e periferia $\left(D_{2}\right)$. (d) Imagem formada na fóvea e periferia $\left(D_{3}\right)$. 


\subsection{Cone versus bastonetes}

Na Seção 7.4.2 foi proposto um modelo computacional para reproduzir o comportamento dessas células receptoras. As células cones possuem alta resolução na fóvea, sendo boas percepção de detalhes a alta luminosidade. As células bastonetes são mais numerosas na periferia e sua atuação está relacionada a informações de baixo contraste.

Para averiguar como tais células atuam na retina do Olho Virtual, foram feitas simulações com imagens de alto e baixo contraste. A Figura 8.12(a) mostra um texto com letras pretas sobre um fundo branco (alto contraste) e a Figura 8.12(b) mostra um texto cinza sobre um fundo preto (baixo contraste). O objetivo é verificar como essas duas imagens são vistas sob perspectivas das células cones e bastonetes.

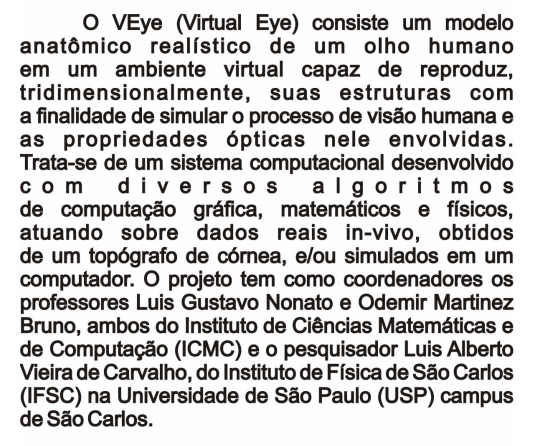

(a)

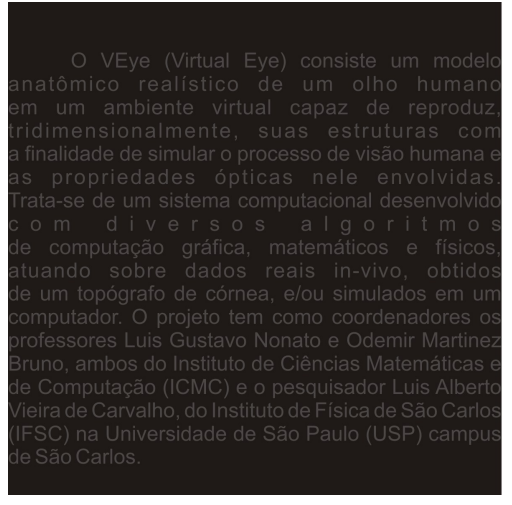

(b)

Figura 8.12: (a) Imagem experimental com alto contraste. (b) Imagem experimental com baixo contraste.

Essas duas imagens foram postas à frente do olho para gerar simulações de formação de imagens para células cones da retina do Olho Virtual. O resultado é observado na Figura 8.13.

A Figura 8.13(a) mostra a imagem formada pelas células cones para a imagem de alto contraste da Figura 8.12(a). Observe que, diante de alta luminosidade, as células cones respondem com alto nível de resolução na fóvea e, até mesmo na periferia, é possível identificar a presença de objetos, porém com baixa nível de resolução. Por outro lado, a resposta gerada pelas células cones, quando estas são estimuladas pela imagem de baixo contraste da Figura 8.12(b), é consideravelmente fraca, sendo incapaz de identificar obje- 


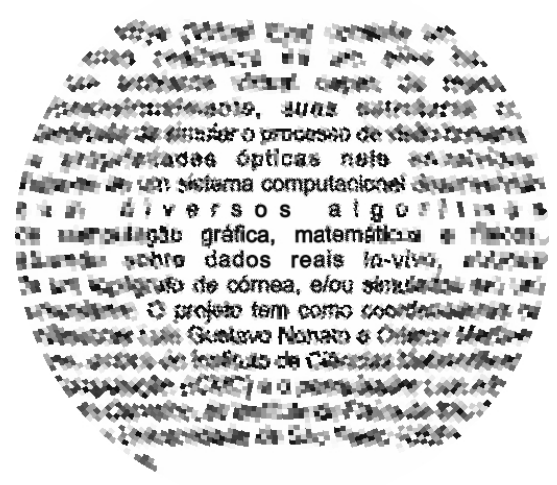

(a)

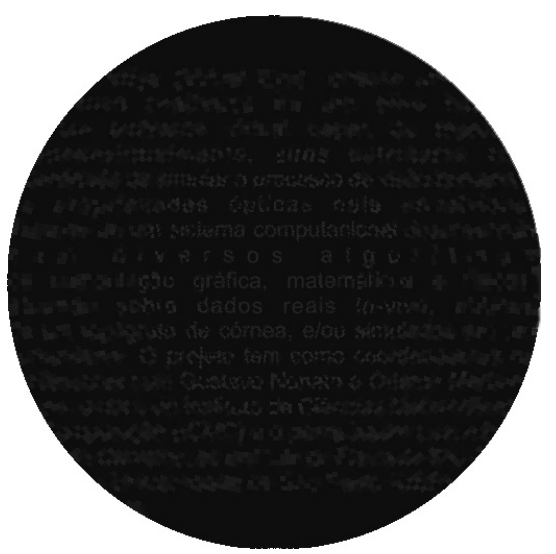

(b)

Figura 8.13: (a) Imagem da Figura 8.12(a) formada pela atuação das células cones. (b) Imagem da Figura 8.12(b) formada pela atuação das células cones.

tos em quaisquer posição da retina.

Neste caso, para poder detectar objetos em baixo contraste são usadas as células bastonetes. O resultado é mostrado na Figura 8.14.

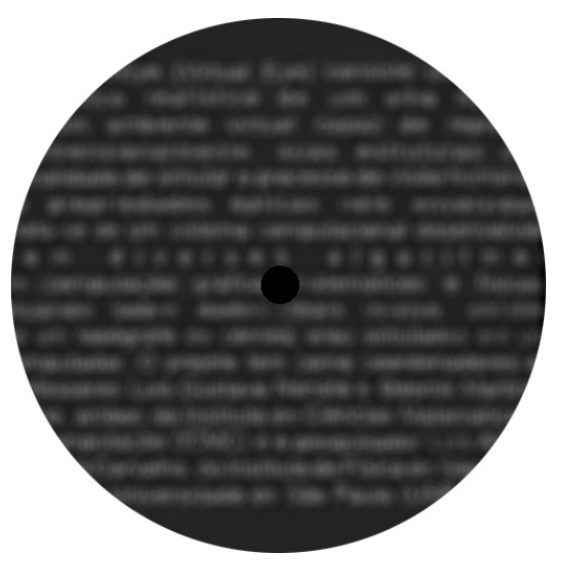

Figura 8.14: Imagem da Figura 8.12(b) formada pela atuação das células bastonetes.

Os objetos em baixo contraste podem ser detectados pelos bastonetes devido ao fato de sua grande quantidade de células ao longo da retina, e além disso, esses neurônios são mais sensíveis a luz do que os cones. No entanto, pode ser observado pelo resultado da Figura 8.14, que a resolução diminui ao ponto que os objetos não possam ser identificados. Isso ocorre porque os bastonetes não enviam suas repostas para o cérebro separadamente, em outras palavras, vários bastonetes próximos (como em campos receptivos) convergem seus sinais em um único gânglio, havendo assim uma perda de informação, causando a 


\section{Simulações e resultados}

queda na resolução da imagem formada.

Uma forma experimental de averiguar como os receptores atuam é se colocando em um ambiante totalmente desprovido de fonte de luz. Nestas condições, tente procurar por algum interruptor na parede, você observará que ao tentar focalizar o interruptor ele desaparece de sua vista e a medida que você olha para outros lados o interruptor aparece.

Para estudar o comportamento das células neste caso, foi feita uma simulação da situação na retina do VEye . O resultado pode ser observado na Figura 8.15

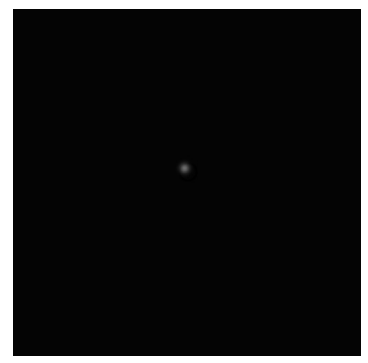

(a)

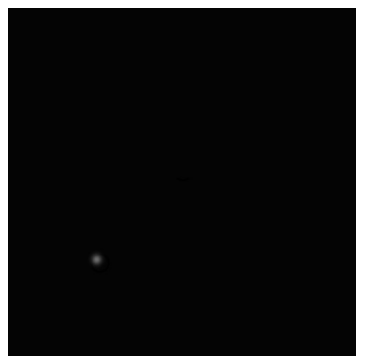

(d)

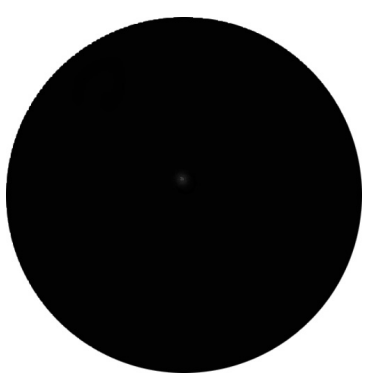

(b)

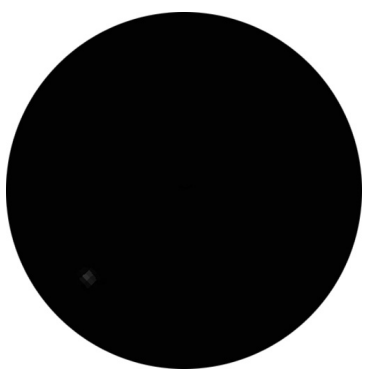

(e)

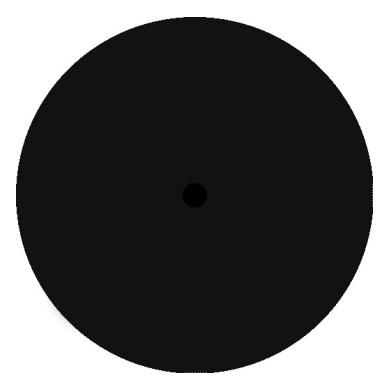

(c)

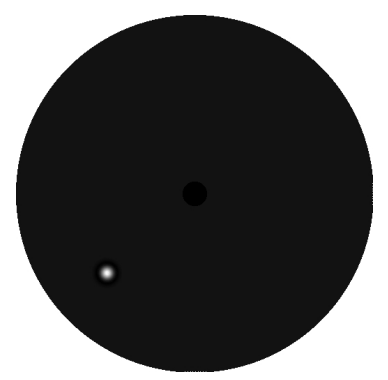

(f)

Figura 8.15: (a) Imagem original com interruptor no foco. (b) Resposta das células cones para imagem (a). (c) Resposta das células bastonetes para imagem (a). (d) Imagem original com interruptor fora do foco. (e) Resposta das células cones para imagem (d). (f) Resposta das células bastonetes para imagem (d)

O resultado da Figura 8.15 mostra mais uma vez que os bastonetes são mais eficientes em baixo contraste do que os cones. Para o interruptor no foco (Figura 8.15(a)) as células cones apresentam uma baixa resposta (Figura 8.15(b)), enquanto as células bastonetes não emitem nenhuma reposta (Figura 8.15(c)), pois esta região central é a fóvea e não existe nenhum bastonete presente. Para o interruptor fora do foco (Figura 8.15(d)), as células cones emitem repostam baixas (Figura 8.15(e)) e os bastonetes respostas altas (Figura 8.15(f)). 


\subsection{Patologias da retina}

O software Degenerações, descrito na Seção 7.5.1, permite que um médico ou estudante de oftalmologia mapeie regiões degenerativas da retina do paciente a partir de uma fotografia obtida em exames de retinopatia. A retina do Olho Virtual utiliza esse mapeamento para formar imagens sob a perspectiva da doença. Dessa forma é possível determinar o que o paciente pode ou não ver de uma determinada cena. Esse recurso pode tornar-se um guia útil em análises e acompanhamento do tratamento da doença.

A Figura 8.16 mostra dois exemplos de mapeamento (nível 100\%) obtido pelo software de Degenerações. Para as Figuras 8.16 (a) e (b) a degeneração está localizada na região da mácula da retina, assim, as células que ali se encontram não terão suas habilidade em responder ao estimulo de luz e uma imagem que se formar ali não será vista pela pessoa cuja a retina possui esse mapeamento. Para as Figuras 8.16 (c) e (d) a degeneração está localizada na região logo após a mácula, danificando quase toda a periferia da retina.

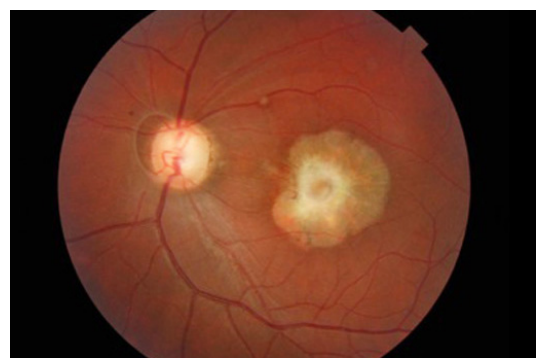

(a)

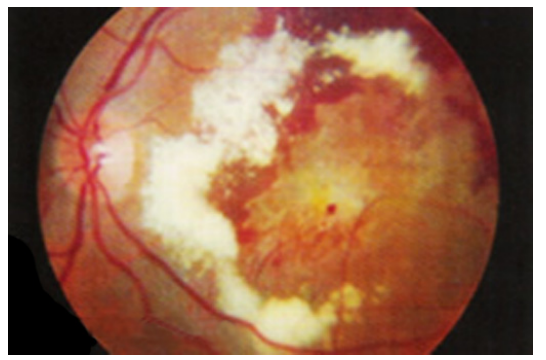

(c)

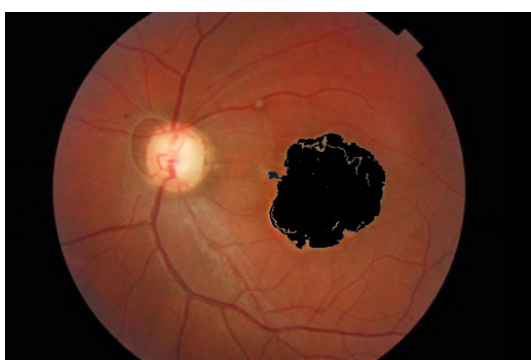

(b)

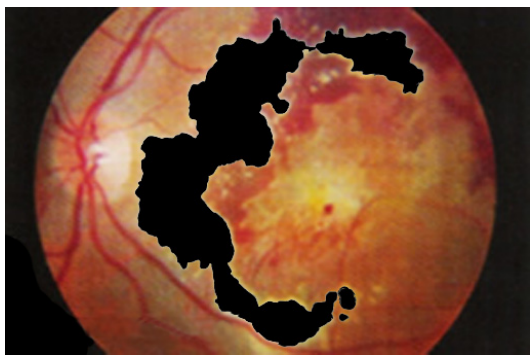

(d)

Figura 8.16: (a) e (c) Imagens originais das retinas com as degenerações. (b) e (d) Mapeamentos feitos no programa de Degenerações.

As Figuras 8.17 contém alguns resultados obtidos na simulação da retina do Olho Virtual com os mapeamentos das Figuras 8.16. 


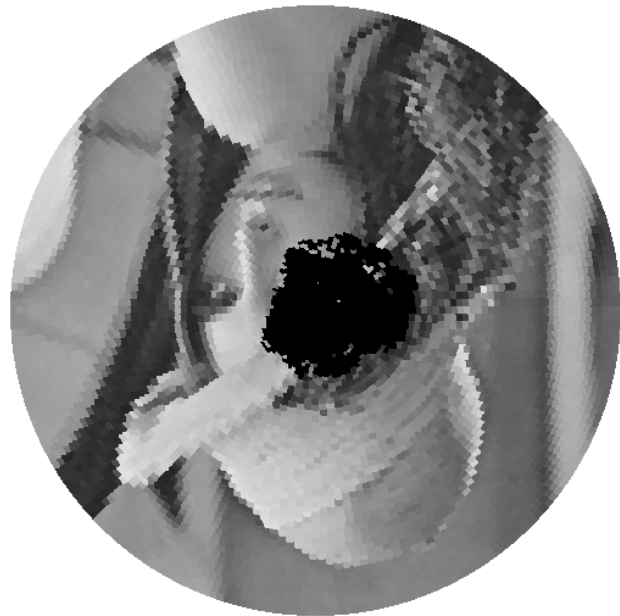

(a)

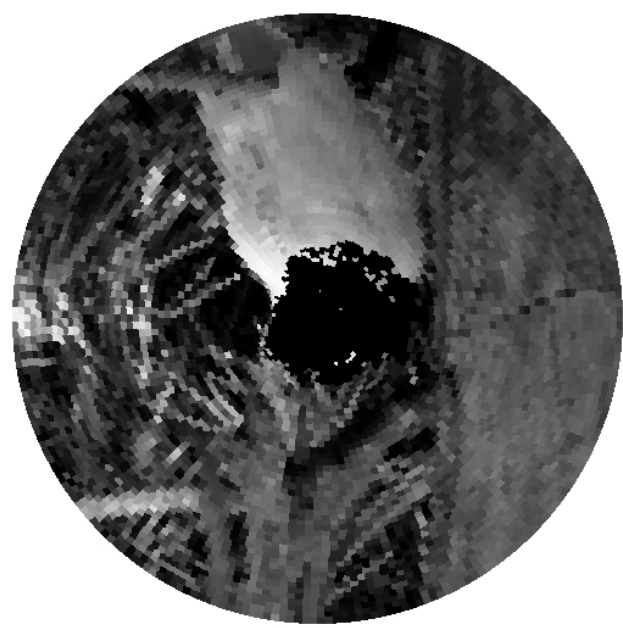

(c)

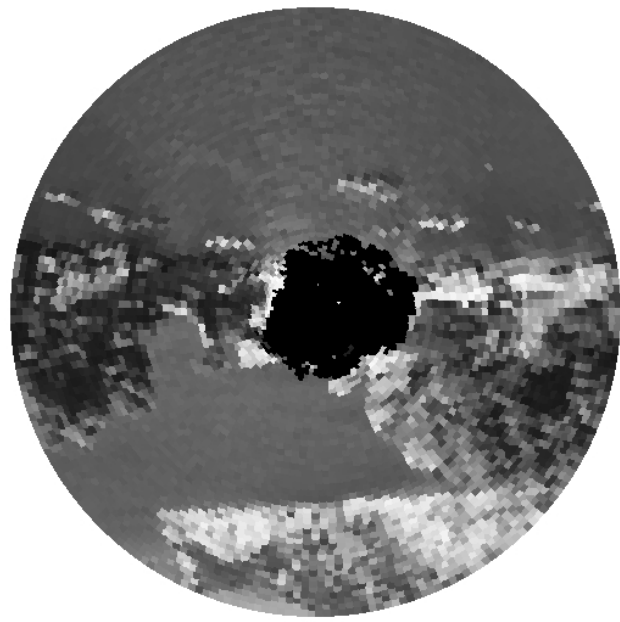

(e)

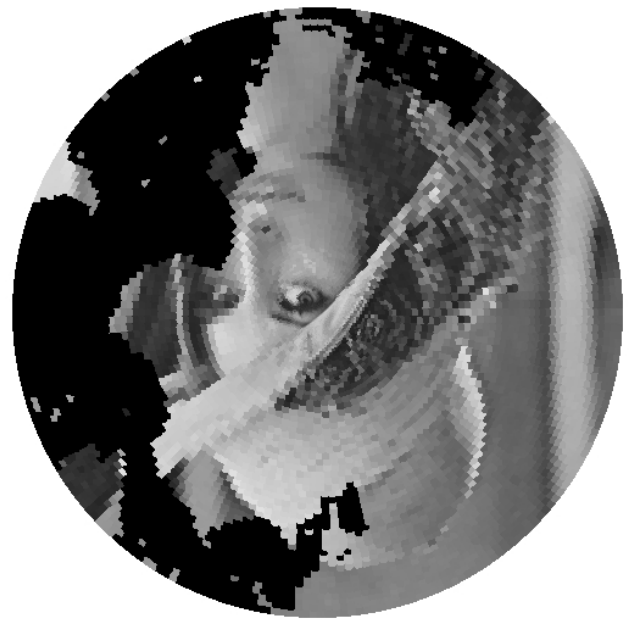

(b)

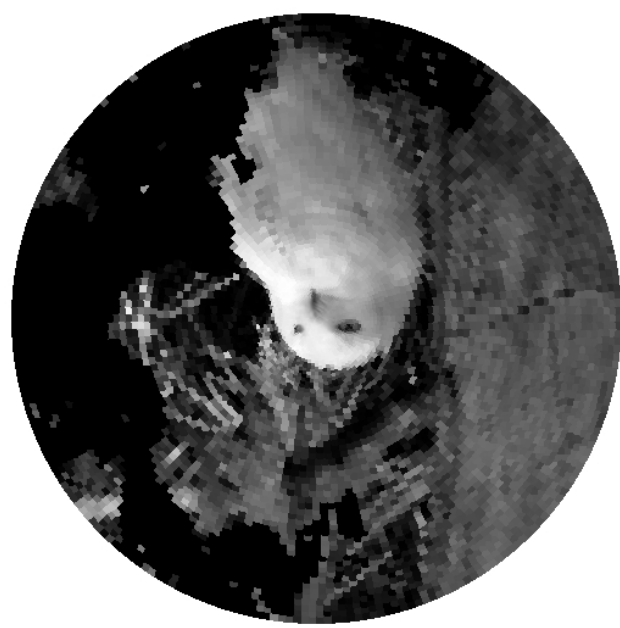

(d)

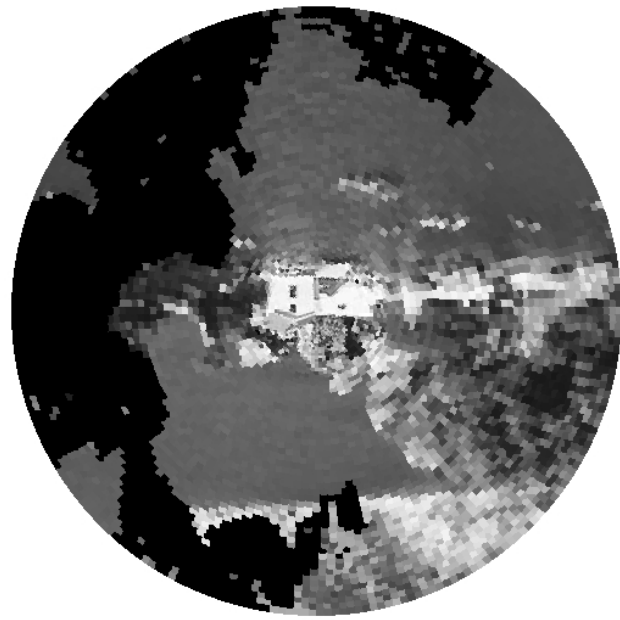

(f)

Figura 8.17: Resultados de simulações de mapeamento de patologias na retina. 


\subsection{Campos receptivos}

Para reproduzir o efeito dos campos receptivos das células ganglionares da retina foi proposto um modelo descrito na Seção 7.6. Com esse modelo é possível simular o processamento de informações gerenciadas por células que constituem o caminho parvo e magnocelular. Além disso, são apresentados os campos On-Center Off-Surround, OffCenter On-Surround e um detector de bordas realizado com a combinação desses dois sinais.

A Figura 8.18 mostra o resultado de uma simulação dos campos receptivos parvos (células cones) para a imagem da Lena formada completamente na fóvea. Os campos nesta região possui tamanho pequeno, permitindo a captação de detalhes na cena. Na Figura 8.18(a) é mostrado o sinal produzidos por campos On-Center Off-Surround, na Figura 8.18 é mostrado o sinal Off-Center On-Surround e na 8.18(c) é mostrado a combinação dos campos para atuar como detector de bordas na retina.

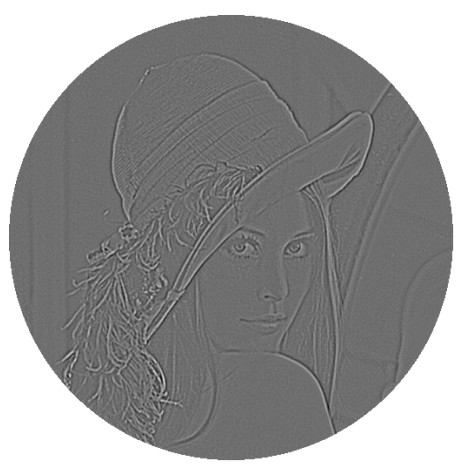

(a)

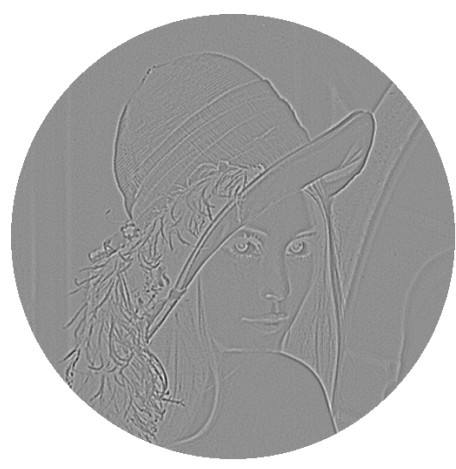

(b)

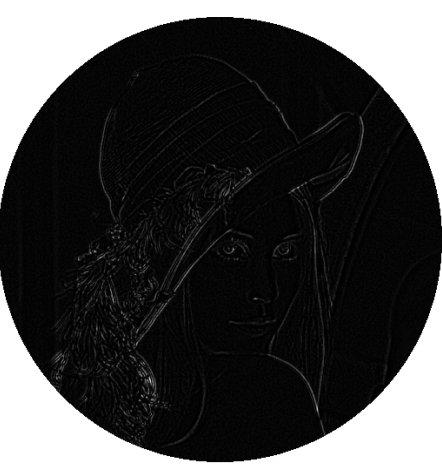

(c)

Figura 8.18: (a) Campos receptivos On-Center Off-Surround. (b) Campos receptivos Off-Center On-Surround. (c) Campos receptivos como detector de bordas.

Na Figura 8.19 é mostrada a imagem da Lena formada em diversas áreas da retina, cobrindo a região da fóvea até aproximadamente $44^{\circ}$ de excentricidade na periferia. Observe que, quanto mais distantes da fóvea, as bordas que surgem na imagem ficam cada vez mais grossas. Isso acorre devido ao fato de que os campos receptivos parvos aumentam seu tamanho quando se localizam na periferia da retina. O gráfico na Figura 3.7 mostra como é o aumento no diâmetro desses campos.

A Figura 8.20 mostra o resultado de uma simulação dos campos receptivos magnos 


\section{Simulações e resultados}

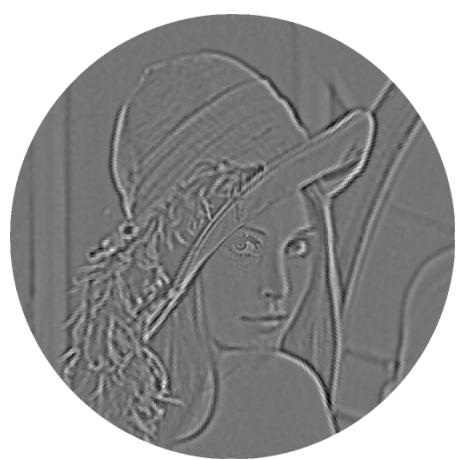

(a)

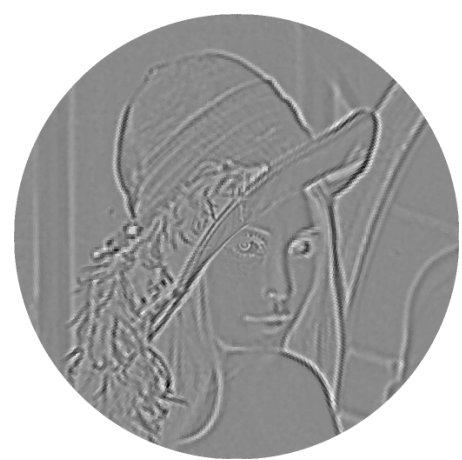

(b)

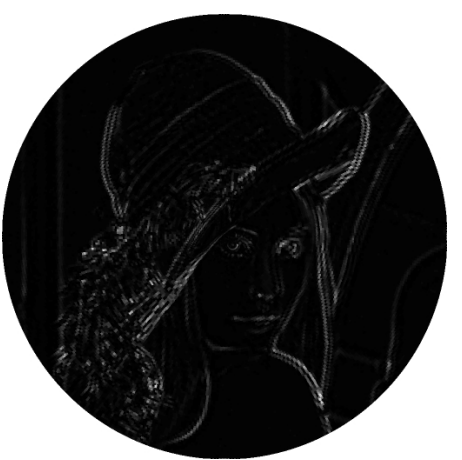

(c)

Figura 8.19: (a) Campos receptivos On-Center Off-Surround. (b) Campos receptivos Off-Center On-Surround. (c) Campos receptivos como detector de bordas.

(células bastonetes) para a imagem da Lena formada na periferia da retina. No centro, não há sinal deste tipo de campo, pois na fóvea não há células bastonetes presentes. Nesta imagem, pode-se notar que as bordas são mais grossas dos que as estabelecidas por campos parvos, pois os campos magnos possuem diâmetro maior do que qualquer campo parvo e em qualquer região da retina.

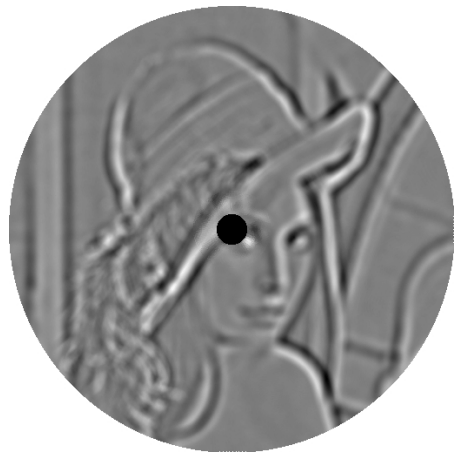

(a)

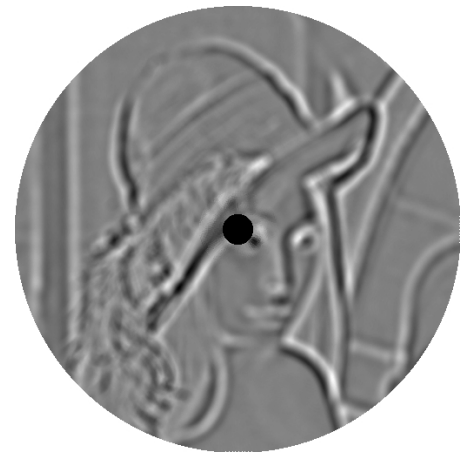

(b)

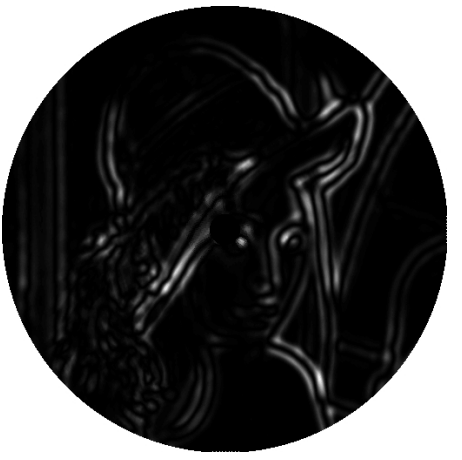

(c)

Figura 8.20: (a) Campos receptivos On-Center Off-Surround. (b) Campos receptivos Off-Center On-Surround. (c) Campos receptivos como detector de bordas.

Apesar de sua grande quantidade, os campos receptivos magnos não geram sinais que permitem o reconhecimento de pequenos detalhes na cena. Isso é consequência do fato destes campos possuírem diâmetros largos. Como demonstrado nas simulações da Seção 8.3, muitas células bastonetes enviam sinais para um único gânglio, ocasionando perdas na informação original. 


\subsection{Experimentos}

Alguns experimentos podem ser feitos com facilidade para explorar os fenômenos psicofísicos ocorrentes na visão humana. Alguns, envolvem a distribuição das células ao longo da retina e outros demonstram o funcionamento dos campos receptivos da mesma. Essa seção é dedicada a simulação de alguns destes experimentos para verificar e comparar a retina artificial desenvolvida neste trabalho com os fenômenos presentes na visão natural.

\subsubsection{Acuidade Visual}

Na Seção 3.5.1 foi mostrado que os receptores estão distribuídos na retina (Figura 3.2) de forma radial e com a máxima concentração de cones no centro. Esta organização celular implica em uma diferença de resolução nas excentricidades da retina, resultando em uma acuidade visual mais apurada na fóvea do que na periferia.

\section{Reconhecendo letras}

É possível demonstrar que a acuidade visual, definida na Seção 2.1.2, é superior na fóvea olhando para o $\mathbf{X}$ no meio da linha da Figura 8.21. Sem mover os olhos, veja quantas letras podem ser identificadas ao lado esquerdo e/ou direito do $\mathbf{X}$. Percebe-se que é possível identificar apenas poucas letras e quanto mais distante, mais difícil tornase para identificá-las. Isto significa que a acuidade visual tende a diminuir a medida em que a imagem projetada se afasta da fóvea, local onde encontra-se a maior concentração de cones.

\section{H C N R LAZ IF X N S M Q P Z K D Y P}

Figura 8.21: Demonstração da acuidade visual. Experimento extraído de (Gol02).

Para este experimento foi usado o modelo de Le Grand acomodado $\left(\lg _{a}\right)$ com o raio da pupila de $1.0 \mathrm{~mm}$. A imagem da Figura 8.21 foi posta a uma distância de 147.747 $m m$ à frente do olho com $22 \mathrm{~cm}$ de diâmetro. O resultado é uma imagem formada nas excentricidades de $0^{\circ}$ (fóvea) à $32^{\circ}$ (periferia). Deve-se lembrar, também, que as células responsáveis em obter boa qualidade em detalhes na visão são os receptores do tipo cone, 


\section{Simulações e resultados}

então neste caso foi usada a distribuição celular mostrada na Figura 8.4(c) e o resultado é mostrado na Figura 8.22.

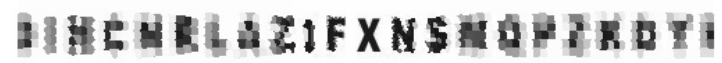

Figura 8.22: Resultado da simulação de acuidade visual na retina do Olho Virtual gerado como resposta das células cones.

O simulação permite verificar que poucas letras próximas do $\mathbf{X}$ são identificáveis. Outro fator que pode ser notado é que até mesmo a habilidade de percepção das cores é reduzida na periferia, chegando ao ponto de não ser identificável nem a forma nem a cor de um objeto.

\section{Anéis de Landolt}

Os anéis de Landolt são frequentemente utilizados para testar e medir acuidade visual. Trata-se de vários círculos incompletos apresentados em várias direções, Figura 8.23. O objetivo é analisar o quão longe dois pontos pretos devem estar para que o espaço entre eles possam ser identificados. O experimento foi executado com uma imagem contendo vários anéis em diferente tamanho em diferentes excentricidades da retina.

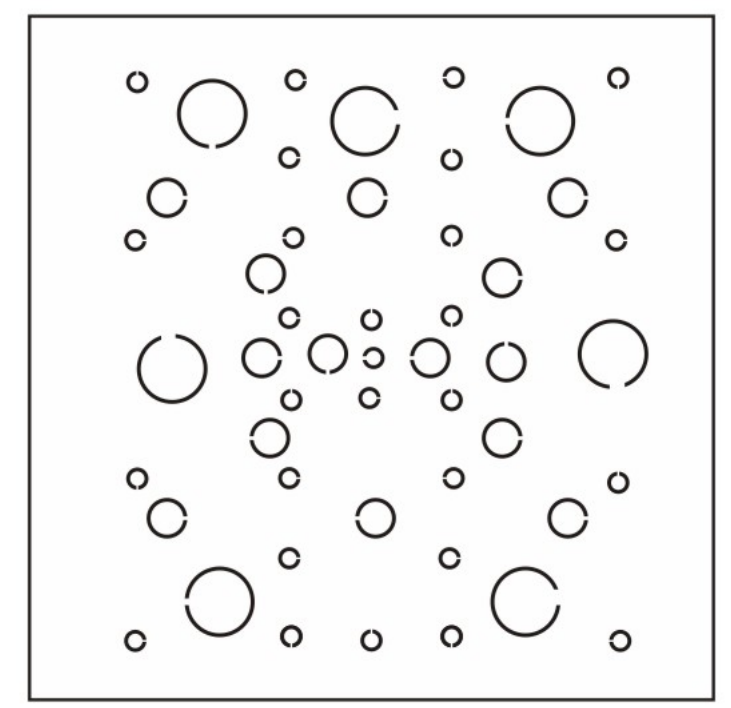

Figura 8.23: Anéis de Landolt, usado em testes de acuidade visual. Experimento extraído de (Gol02).

Para este experimento foi usado o modelo de Le Grand acomodado $\left(\operatorname{lgr}_{a}\right)$ com o raio 


\section{Simulações e resultados}

da pupila de $1.0 \mathrm{~mm}$. A imagem da Figura 8.23 foi posta a uma distância de $147.747 \mathrm{~mm}$ à frente do olho com aproximadamente $16 \mathrm{~cm}$ de diâmetro. O resultado é uma imagem formada nas excentricidades de $0^{\circ}$ (fóvea) à $24^{\circ}$ (periferia) mostrado na Figura 8.24.

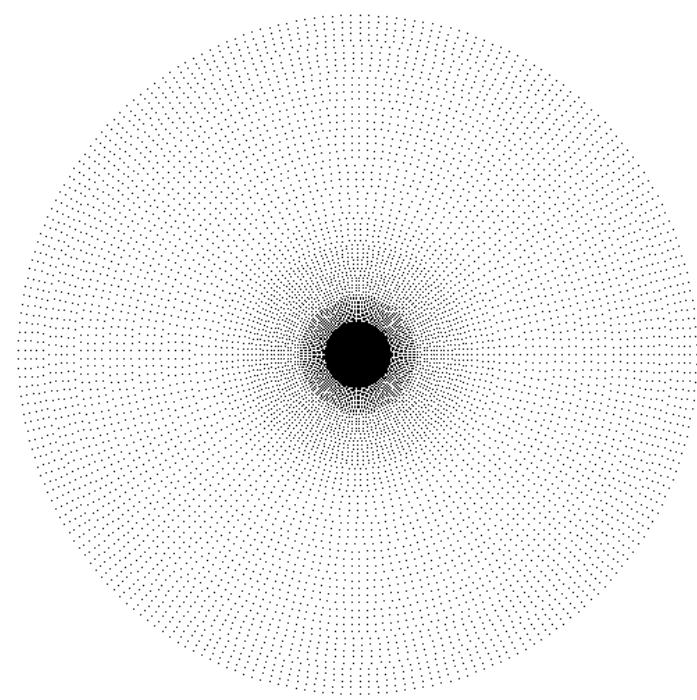

(a)

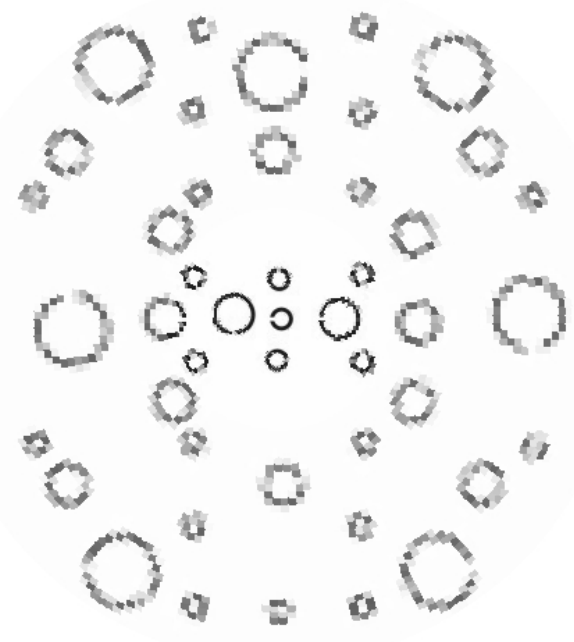

(b)

Figura 8.24: Simulação dos anéis de Landolt na retina do VEye . (a) Distribuição dos cones utilizada. (b) Respostas das células cones diante da imagem dos anéis de Landolt.

A Figura 8.24(a) mostra a distribuição dos cones utilizada na simulação e a Figura 8.24(b) mostra a resposta dada por essas células diante da imagem de Landolt. Note que, para os anéis menores, não é possível identificar a sua direção a não ser que estejam muito próximos à fóvea e que, mesmo os anéis maiores apresenta uma certa dificuldade em identificá-los se o espaço em branco for pequeno.

\section{Stuart Anstis}

Stuart Anstis, um psicólogo na universidade York em Toronto, estava interessado em saber como a habilidade de reconhecer letras varia dependendo de quão longe da fóvea está a imagem. Com um anteparo branco, Anstis posicionava as letras próximas das bordas do anteparo de modo que uma pessoa, à $57 \mathrm{~cm}$, não as identifique. Então, as letras eram trazidas para o centro, no ponto de fixação, até a pessoa conseguir identificálas. Quando isto era feito com letras de vários tamanhos, Anstis, descobriu que letras pequenas precisavam ser trazidas muito mais perto do centro de fixação do que letras grandes. 


\section{Simulações e resultados}

A Figura 8.25 demonstra os resultados de Anstis. Segurando a imagem um pouco menos que a distância do braço à frente do olho e focando o ponto central, todas as letras devem ser igualmente legíveis, pois o tamanho da letra incrementa com o decremento da acuidade visual.

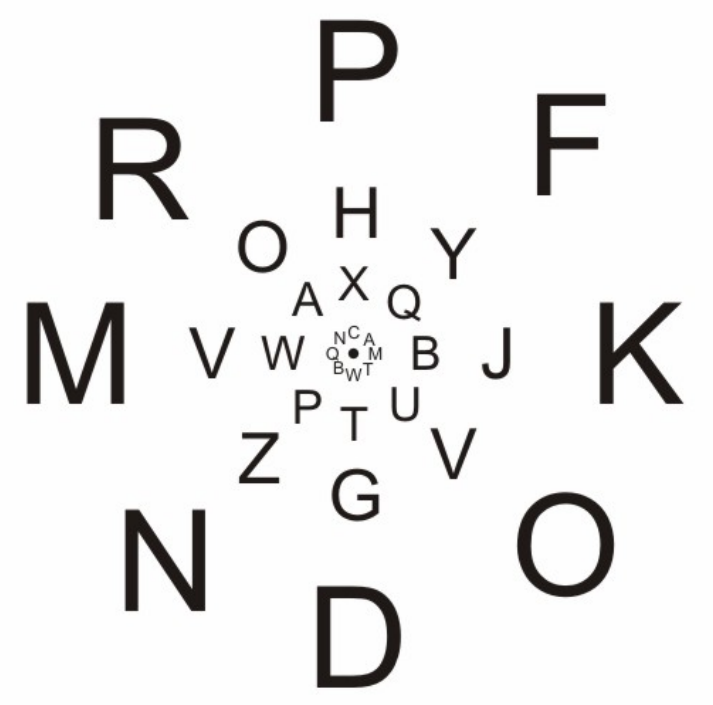

Figura 8.25: Demonstração de Stuart Anstis. Todas as letras neste quadrado devem ser legíveis quando o ponto central é focalizado. Experimento extraído de (SB90).

Para este experimento foi usado o modelo de Le Grand acomodado $\left(\operatorname{lgr}_{a}\right)$ com o raio da pupila de $1.0 \mathrm{~mm}$. A imagem da Figura 8.25 foi posta a uma distância de $147.747 \mathrm{~mm}$ à frente do olho com aproximadamente $16 \mathrm{~cm}$ de diâmetro. O resultado é uma imagem formada nas excentricidades de $0^{\circ}$ (fóvea) à $24^{\circ}$ (periferia).

A Figura 8.26(a) mostra a distribuição dos cones utilizada na simulação e a Figura 8.26(b) mostra a resposta dada por essas células diante da imagem de Stuart. Esse experimento mostra que imagens de objetos relativamente grandes, formada na periferia da retina, podem ser identificadas, porém, para objetos menores há a necessidade de trazê-los para o ponto focal para serem distinguidos.

\subsubsection{Hermann Grid}

Ao olhar para Figura 8.27, é possível perceber manchas ou "fantasmas" escuros em quase todas as intersecções entre as barras brancas. Pode se provar que esses pontos 


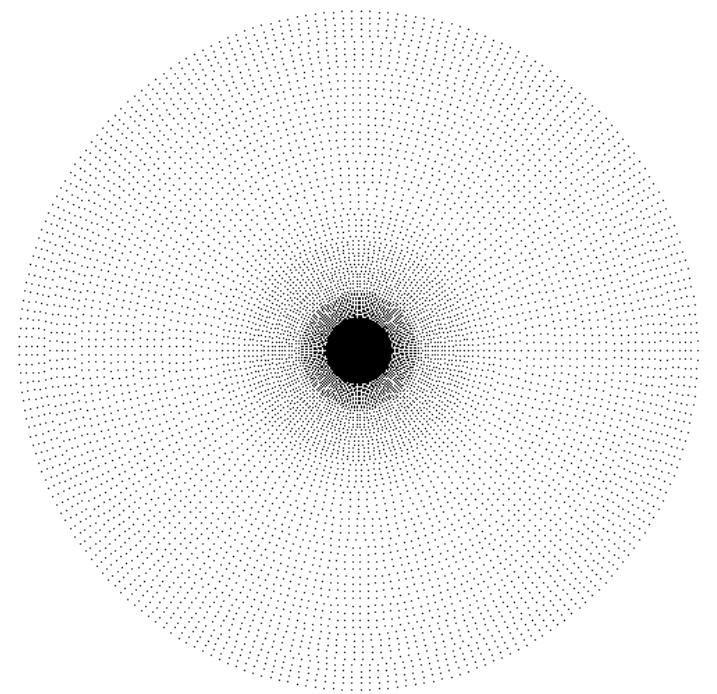

(a)

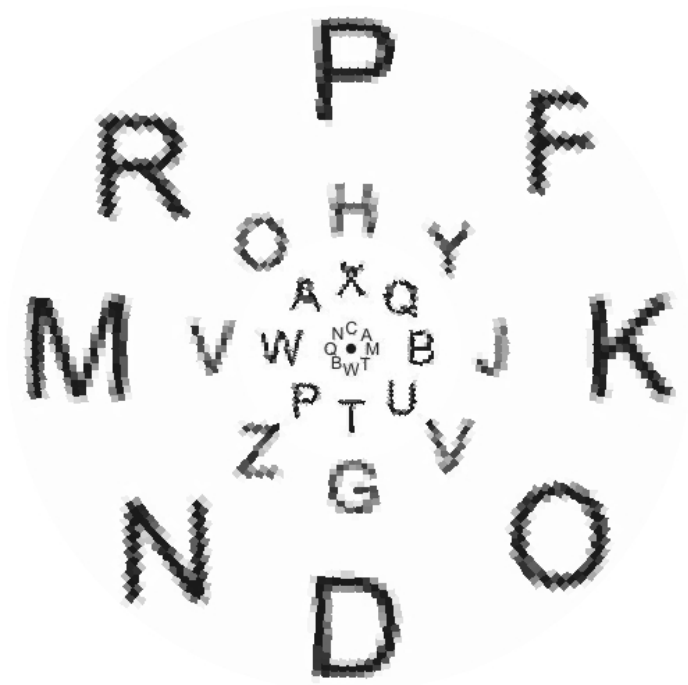

(b)

Figura 8.26: Simulação dos anéis de Landolt na retina do Olho Virtual. (a) Distribuição dos cones utilizada. (b) Respostas das células cones diante da imagem de Stuart.

escuros não estão fisicamente presentes notando que eles desaparecem quando você olha diretamente para um ponto qualquer de cruzamento das barras. Descrito por Ludimar Hermann em 1870, esse fenômeno ocorre devido ao mecanismo neurofisiológico centersurround dos campos receptivos das células ganglionares, Seção 3.7.1, na retina.

Podemos fazer uso dos campos receptivos On-Center Off-Surround para explicar como tais manchas são vistas pelo olho. Duas perguntas devem ser respondidas:

- 1. Porque as manchas aparecem somente nas intersecções das barras brancas?

- 2. Porque as manchas desaparecem quando se olha diretamente para a intersecção?

Para a primeira pergunta, observe que a Figura 8.28 permite comparar como a imagem de Hermann Grid formada na retina afeta dois campos receptivos em diferentes posições: um centrado na intersecção de duas barras e o outro centrado entre duas intersecções. Note que os centros de ambos os campos receptivos recebem a mesma quantidade de luz, mas as periferias recebem quantidade diferentes. Assim, o campo da direita, recebe maiores quantidade de luz em sua parte $\mathrm{OFF}$, o que ocasiona uma redução na sua taxa de resposta. Enquanto o outro campo recebe pouca luz em sua parte OFF, fazendo com que este tenha uma taxa de resposta maior. 


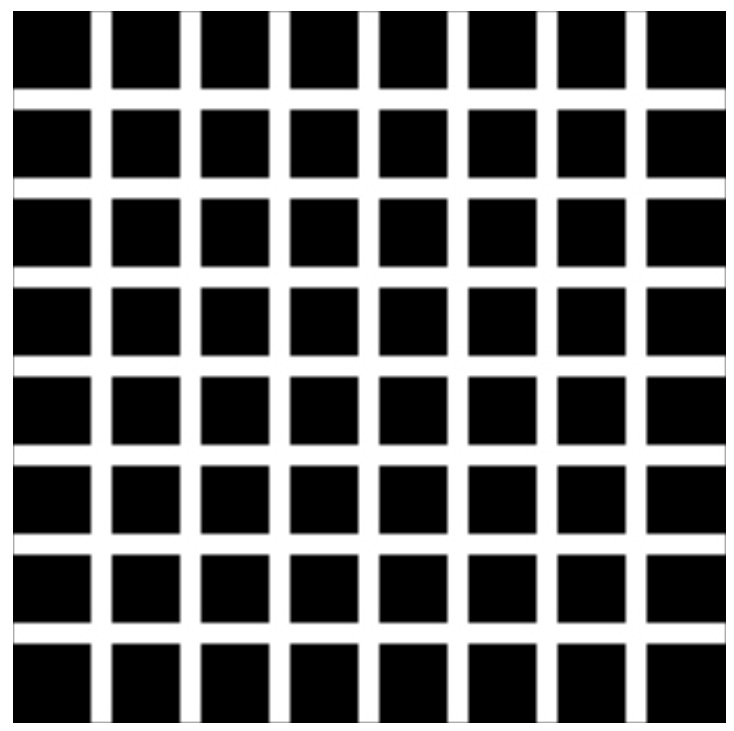

Figura 8.27: Ilusão de Hermann Grid. Manchas escuras aparecem nas intersecções das barras brancas e desaparecem quando se olha fixamente para elas. Experimento extraído de (SB90).

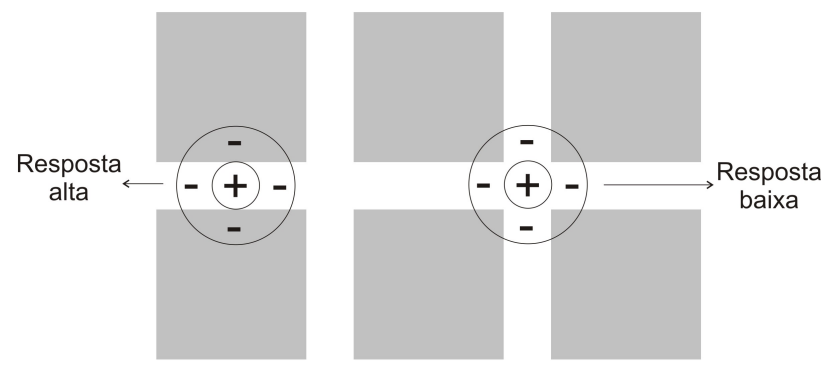

Figura 8.28: Possível explicação para Hermann Grid.

Para responder a segunda pergunta, deve ser levar em consideração o tamanho dos campos receptivos estimulados. De acordo com a Seção 3.7.1, os menores campos receptivos estão presentes na mácula da retina. Ao olhar diretamente para um ponto de intersecção de duas barras, são estimulados os campos receptivos da mácula, cujos centro e periferia são tão pequenos que ambas as regiões são formadas dentro de uma barra branca. Como pode ser visto na Figura 8.29, esses campos receptivos menores recebem a mesma quantidade de luz em toda a sua região, o que gera uma taxa de resposta baixa.

A Figura 8.30(a) mostra uma simulação dos campos receptivos On-Center Off-Surround no ponto de fixação e a Figura 8.30(b) uma simulação na região periférica. Tais resultados demonstram que os campos receptivos da retina do Olho Virtual se comportam de acordo com o modelo sugerido nas Figuras 8.28 e 8.29. 


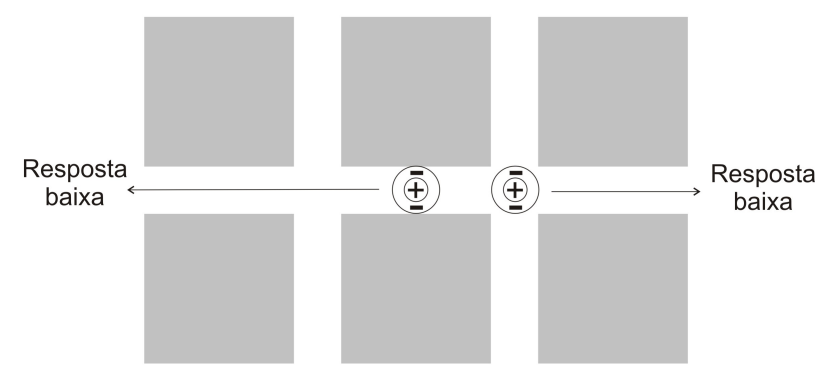

Figura 8.29: Possível explicação para Hermann Grid no ponto de fixação.

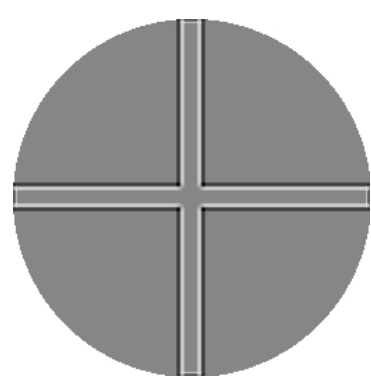

(a)

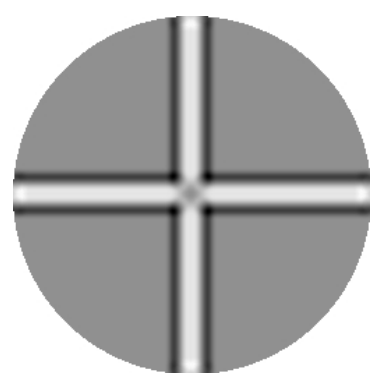

(b)

Figura 8.30: Simulação dos campos receptivos para ilusão de Hermann Grid. (a) Região periférica. (b) Ponto de fixação.

A Figura 8.31 apresenta uma simulação com a imagem de Herman Grid sendo formada em diversas excentricidades na retina. Para este experimento foi usado o modelo de $L e$ Grand acomodado $\left(\lg r_{a}\right)$ com o raio da pupila de $1.0 \mathrm{~mm}$. A imagem foi posta a uma distância de $147.747 \mathrm{~mm}$ à frente do olho com $20 \mathrm{~cm}$ de diâmetro. O resultado é uma imagem formada nas excentricidades de $0^{\circ}$ (fóvea) à $32^{\circ}$ (periferia).

Este experimento permite comparar a diferença de atuação dos campos receptivos em diversas excentricidade da retina. Essa diferença é causada pela variação do diâmetro dos campos, Seção 3.7.1, onde os maiores estão localizados na periferia e os menores no centro.

\subsubsection{Mach Bands}

Em 1880, Ernst Mach descreveu outro fenômeno causado pela arquitetura centersurround dos campos receptivos na retina. O topo da Figura 8.32 mostra um tipo de padrão que Mach desenvolveu e gráfico abaixo especifica a intensidade de luz de cada região do padrão. O eixo horizontal representa a posição no padrão e o eixo vertical a 


\section{Simulações e resultados}

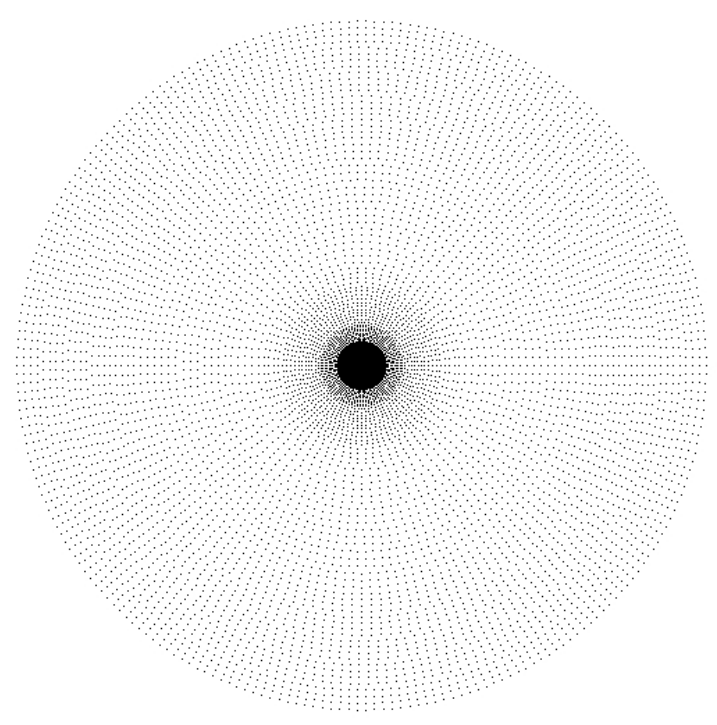

(a)

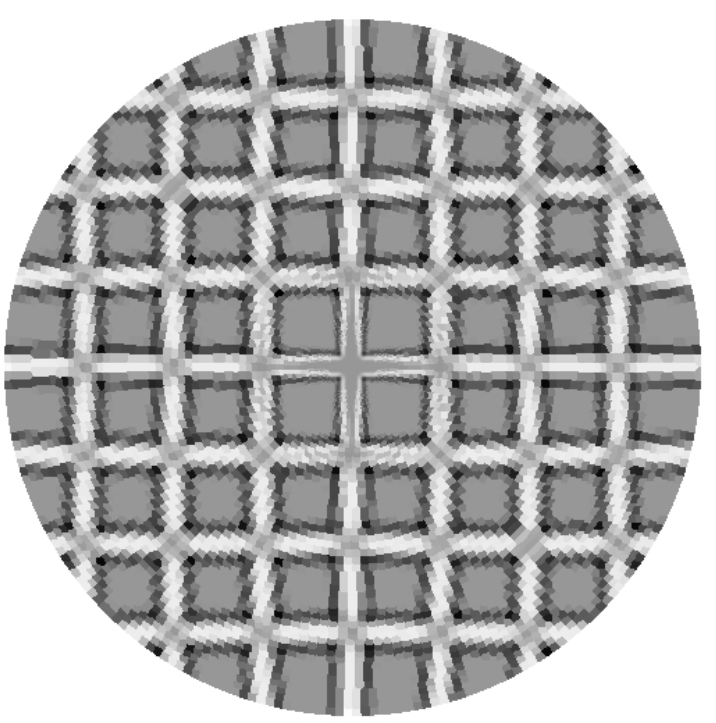

(b)

Figura 8.31: Simulação dos campos receptivos para ilusão de Hermann Grid no ponto de fixação e nas regiões periféricas.

intensidade de luz para aquela posição. O gráfico mostra que a intensidade de luz aumenta dentro do padrão da esquerda para direita e que cada faixa do padrão possui uma única intensidade de luz.

No entanto, ao olhar para o padrão é possível notar uma inconsistência com o gráfico: em particular, cada faixa do padrão não parece uniforme. Observe que, para uma faixa qualquer no meio do padrão, nas proximidades da aresta que a divide com a faixa da direita (mais clara) a tonalidade de luz aparenta ser mais escura, enquanto, nas proximidades da aresta que a divide com a faixa da esquerda (mais escura) a tonalidade de luz aparenta ser mais clara. Em outras palavras, a luminosidade dentro de uma faixa varia mesmo quando a intensidade de luz é constante.

Para entender como esse fenômeno ocorre, vamos considerar como as células ganglionares da retina responde a este padrão. Para simplificar a explicação considere apenas duas faixas do padrão e que quatro campos receptivos On-Center Off-Surround são estimulados, Figura 8.33. Para saber qual resposta cada célula enviará para o cérebro, é necessário ponderar a quantidade de luz incidente nas duas regiões (centro e periferia) do campo receptivo.

Os campos receptivos A e D responderão de forma igual pois são estimulados da mesma 


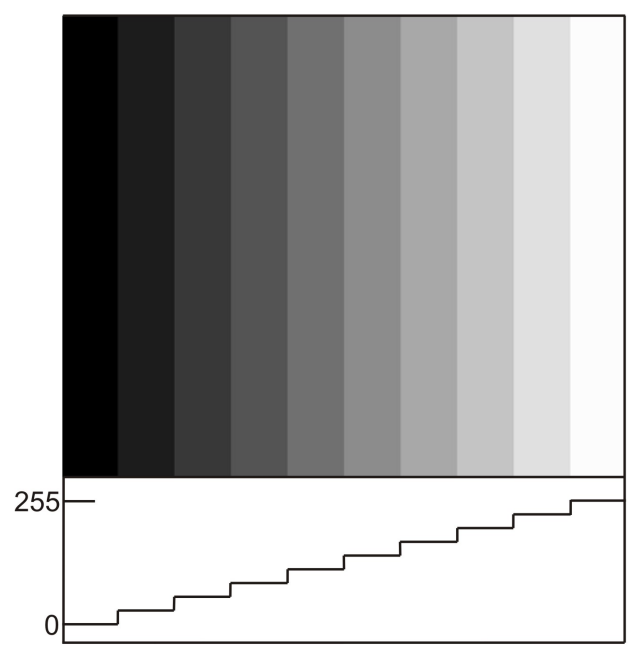

Figura 8.32: A intensidade de luz varia no padrão, mas é constante dentro de cada faixa. Experimento extraído de (SB90).

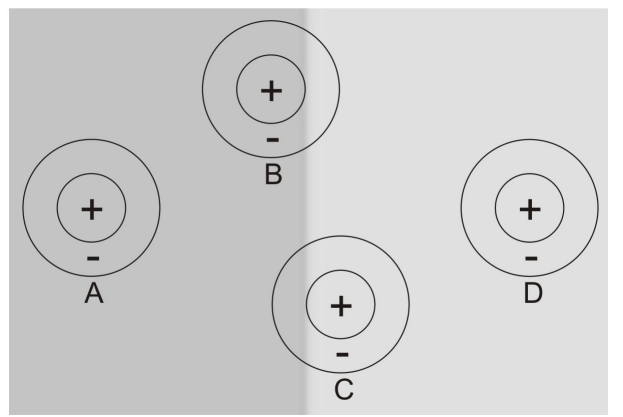

Figura 8.33: Possivel explicação para Mach Bands com campos receptivos On-Center Off-Surround.

forma em toda sua região. O campo receptivo B é mais iluminado na sua periferia do que no centro, gerando uma taxa de resposta baixa, pois B é On-Center Off-Surround. Por outro lado, a iluminação do campo receptivo $\mathrm{C}$ é favorável ao tipo On-Center OffSurround, sendo mais iluminado no centro do que na periferia, o que produz uma taxa de resposta alta.

A simulação deste experimento foi feito usando o modelo de Le Grand acomodado $\left(\lg r_{a}\right)$ com o raio da pupila de $1.0 \mathrm{~mm}$. A imagem de Mach Bands foi posta a uma distância de $147.747 \mathrm{~mm}$ à frente do olho com $12 \mathrm{~mm}$ de diâmetro. O resultado é uma imagem formada inteiramente na fóvea. A Figura 8.34 mostra a resposta gerada pelos campos receptivos On-Center Off-Surround dos gânglios parvos no Olho Virtual.

O resultado obtido mostrou-se condizente com a possível explicação da Figura 8.33. 


\section{Simulações e resultados}

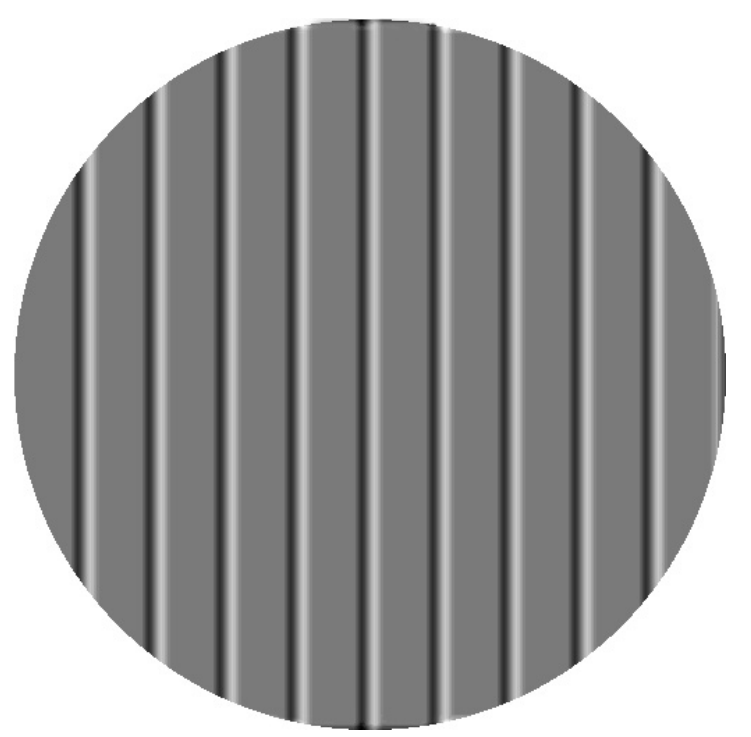

Figura 8.34: Resultado gerado pela simulação dos campos receptivos On-Center OffSurround dos gânglios parvos para imagem de Mach Bands.

Observe que, em todas as faixas, as extremidades mais a esquerda são mais claras do que as extremidades mais a direita. A sensação de que a luminosidade nas faixas do padrão Mach Bands varia, mesmo quando a intensidade de luz incidente não varia, é causada pelo o fato de que a responta da célula não depende apenas da luz incidente sobre ela, mas sim de todas as regiões que a envolve. É por causa desse sinal enviado ao cérebro que a ilusão acontece.

O gráfico da Figura 8.35 mostra com mais clareza a variação do sinal nas regiões de bordas. No interior das faixas, o sinal se mantém constante e nas extremidades há uma variação. A área cinza do gráfico representa uma faixa do padrão.

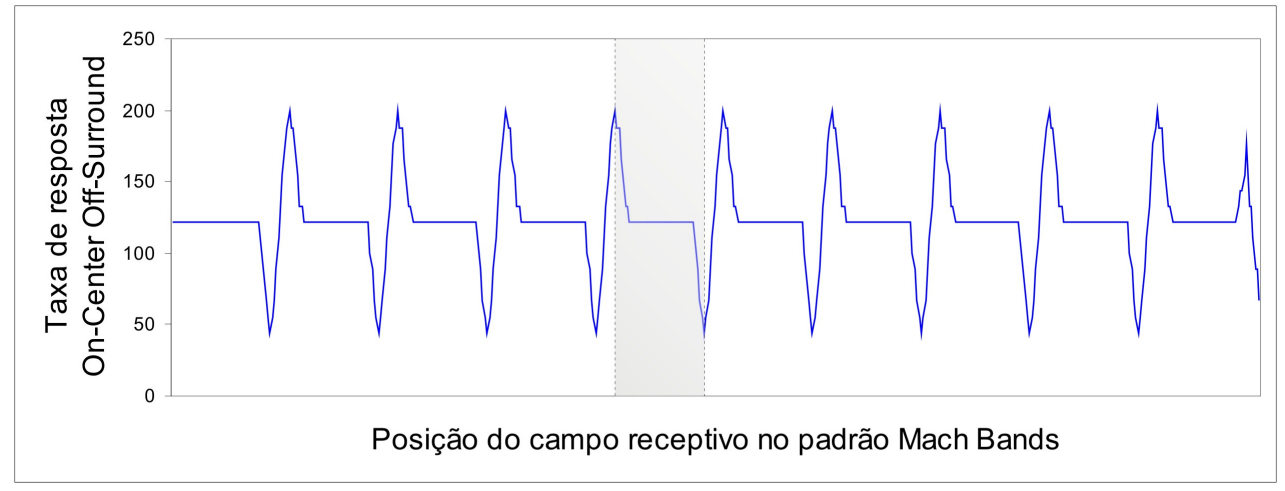

Figura 8.35: Taxa de resposta dos campos receptivos ao longo do padrão Mach Bands. 


\subsubsection{Contraste simultâneo}

Ao olhar para os dois quadrados centrais da Figura 8.36, o quadrado da direita aparenta ser mais claro que o da esquerda. Porém, os dois quadrados possuem a mesma intensidade de cor. Este efeito é chamado de contraste simultâneo.

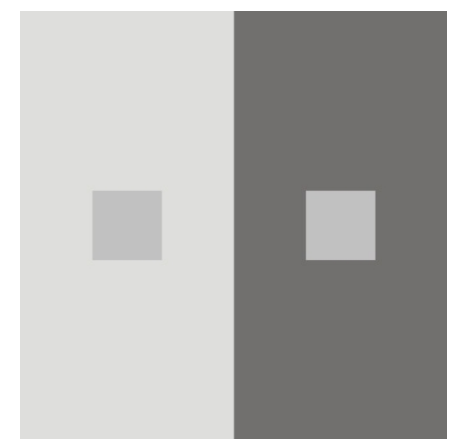

Figura 8.36: Contraste Simultâneo. Os dois quadrados centrais refletem a mesma quantidade de luz, mas parecem diferentes. Experimento extraído de (Gol02).

Podemos dizer que as áreas externas influenciam na percepção das áreas internas. Uma possível explicação para isso acontecer pode ser baseada nos campos receptivos $O n$ Center Off-Surround da retina, cujas as regiões laterais são inibitórias. Na Figura 8.37, a intensidade dos sinais inibitórios enviados para os quadrados centrais é indicado pelo tamanho das setas. Pode-se perceber que as células contidas no quadrado da esquerda recebem mais sinais inibitórios, provocando uma inibição maior na sua taxa de resposta. Enquanto as células do quadrado da direita recebem poucos sinais inibitórios, provocando uma aumento no sinal excitatório.

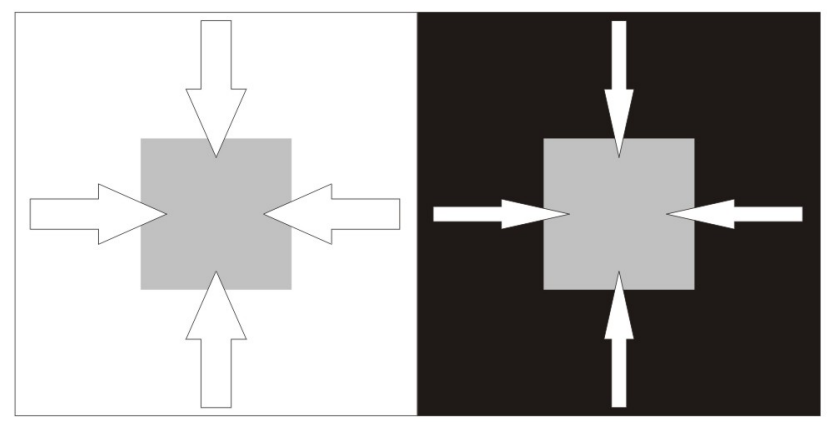

Figura 8.37: Possível explicação para contraste simultâneo usando campos receptivos On-Center Off-Surround.

A simulação deste experimento foi feita usando o modelo de Le Grand acomodado 


\section{Simulações e resultados}

$\left(\operatorname{lgr}_{a}\right)$ com o raio da pupila de $1.0 \mathrm{~mm}$. A imagem da 8.36 foi posta a uma distância de $147.747 \mathrm{~mm}$ à frente do olho com $12 \mathrm{~mm}$ de diâmetro, resultando em uma imagem formada inteiramente na fóvea (Figura 8.38) e posteriormente com $20 \mathrm{~cm}$ resultando em uma imagem formada na fóvea nas regiões periféricas.

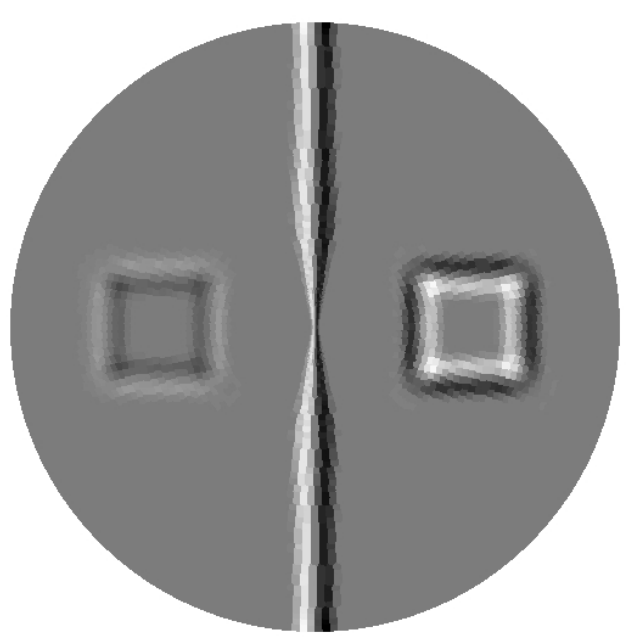

(a)

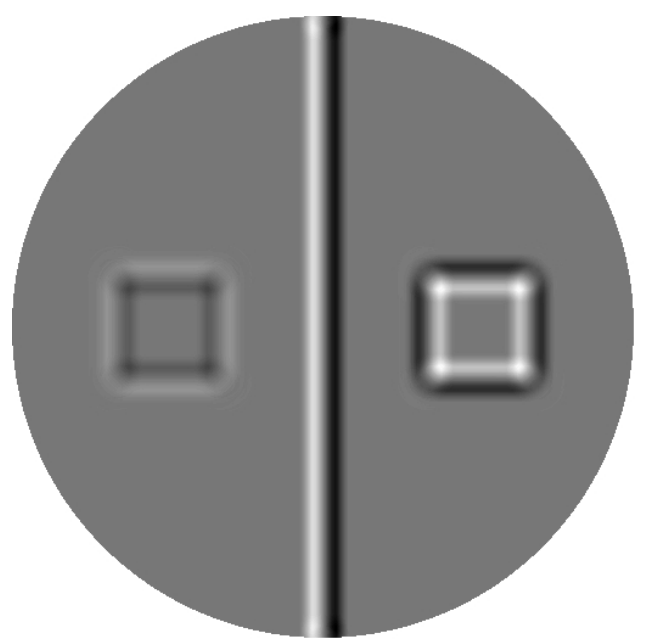

(b)

Figura 8.38:

Pode-se observar, pelo resultado, que os campos receptivos dos quadrados possuem taxas de respostas diferentes. O da direita possui sinais maiores, aparentando ser mais claro, enquanto o da esquerda possui sinais menores, aparentando ser mais escuro. Assim, os resultados apresentam compatibilidade com a explicação sugerida. 


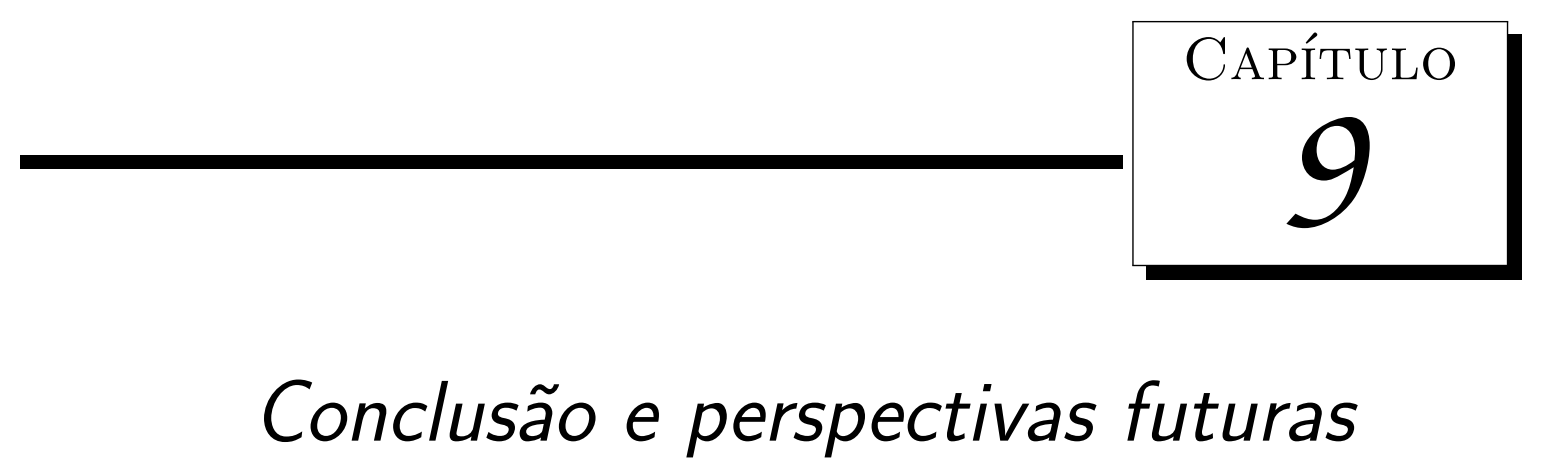

Nesta dissertação foi proposto um modelo computacional capaz de reproduzir algumas das funcionalidades da retina humana. Tal modelo se diferencia dos demais encontrados na literatura por ser o único no qual não possui como dados de entrada imagens convencionais (JPEG, BMP, PGM e etc), mas sim um conjunto de pontos gerado na simulação do processo de visão humana do projeto Olho Virtual, descrito no Capítulo 5. Este fato possibilitou o mapeamento de diversas áreas da retina, fazendo com que cada região da imagem gerada tenha correspondência direta com a superfície geométrica que a reproduz.

O modelo desenvolvido é capaz de gerar representações das imagens, captadas pelos olhos, que são enviadas para o cérebro em dois níveis celulares: receptores e gânglios. As representações referentes aos receptores reproduzem suas atividades e também a distribuição radial estabelecida na retina. Dessa forma, foram elaborados modelos diferentes para cones e bastonetes, permitindo assim, fazer comparações de imagens formadas nas regiões da fóvea e periferia da retina. Além disso, é possível comparar também, imagens formadas sob as perspectivas das células cones e bastonetes que constituem os sistemas parvo e magno respectivamente.

As representações referentes aos gânglios são os resultados gerados pelos campos receptivos destas células. Neste contexto, a retina implementada é capaz de reproduzir os 


\section{Conclusão e perspectivas futuras}

sinais antagônicos provindos das células cones ou bastonetes. Assim, é possível analisar e comparar a atuação de campos receptivos On-Center Off-Surround e Off-Center OnSurround para os caminhos parvo e magnocelular. Além disso, foi mostrado também, como os campos ON e OFF podem ser úteis no processo de detecção de bordas realizado pelo cérebro.

O Mapping Damages foi uma ferramenta de grande utilidade desenvolvida neste trabalho. Com este programa é possível fazer o mapeamento de patologias degenerativas da retina utilizando dados reais obtidos por exames de retinopatia em pacientes portadores da doença. Este recurso pode tornar-se um guia útil em análises e acompanhamento do tratamento da doença.

No Capítulo 8 foram apresentados os resultados de simulações para testar a veracidade do modelo proposto. Na Seção 8.1 foi mostrado como uma imagem é vista por um olho acometido de doenças relacionadas aos erros refrativos, como miopia e hipermetropia. $\mathrm{Na}$ Seção 8.2 foi feita uma comparação entre imagens formadas nas regiões da fóvea e periferia da retina. Na Seção 8.3 foi feita uma comparação entre as imagens vistas pelas células cones e bastonetes. Na Seção 8.4 foram mostrados os resultados do mapeamento de patologias na retina e na Seção 8.5 foram mostrados os resultados referentes aos campos receptivos e detecção de bordas.

Além dessas, foram feitas também, simulações acerca de experimentos psicofísicos relacionados aos fenômenos ocorrentes na retina humana, Seção 8.6. Os resultados das simulações de ilusões de ópticas como Hermann Grid e Mach Bands, mostraram-se condizentes com as possíveis explicações teóricas encontradas na literatura, validando deste modo o sistema artificial.

O processamento de imagens realizado pelo cérebro, no processo de percepção e reconhecimento de objetos e cenas, é um campo de pesquisa em que há muito a se descobrir. Este processamento tem início nas células que constituem a retina e o desenvolvimento deste trabalho permite alavancar estudos referentes ao processo de visão humana do ponto de vista neurológico, auxiliando o entendimento do sistema visual biológico e também a elaboração de sistemas de visão artificial.

Este trabalho permite, ainda, o desenvolvimento de algumas atividades pertinente às 


\section{Conclusão e perspectivas futuras}

células da retina humana. O mapeamento do blind spot (Seção 3.5.1), ou ponto cego, pode ser adicionado ao modelo, permitindo averiguar o processo de formação de imagens neste local. Outra possibilidade, é o desenvolvimento de um modelo sensorial capaz de reproduzir o comportamento das células cones levando em consideração a cor da luz incidente sobre elas. Dessa forma, são necessários três tipos de cones para a captação das três cores primárias azul, verde e vermelho, possibilitando simulações de percepção de coeres e daltonismo.

Em se tratando das células bastonetes, pode-se propor um modelo no qual a distribuição celular seja capaz de responder ao estímulo da luz e aos movimentos desta, fazendo uma comparação entre os sinais gerados por cones e bastonetes diantes desta situação, porém, é necessário fazer adaptações no Olho virtual para que este seja capaz de capturar imagens em movimento. 
Conclusão e perspectivas futuras 


\section{Referências Bibliográficas}

[ALS06] H. Brünner A. Langenbucher, A. Viestenz and B. Seitz. Ray tracing through a schematic eye containing second-order (quadric) surfaces using $4 \mathrm{x} 4$ matrix notation. Ophthal. Physiol. Opt., 26:180-188, 2006.

[AR06] Marcelo Gattass e Waldemar Celes Alberto Raposo, Flavio Szenberg. Visão estereoscópica, realidade virtual,realidade aumentada e colaboração. Technical report, Departamento de Informática, PUC-Rio, 2006.

[AS00] David A. Atchison and George Smith. Optics of the Human Eye. Reed Educational and Professional Publishing Ltd, 2000.

[Bas06] Eduardo Wisnieski Basso. Visão e cognição. Technical report, Universidade Federal do Rio Grande do Sul, 2006.

[BS05] L. S. Balasuriya and J. P. Siebert. An artificial retina with a self-organization retinal receptive field tessellation. Technical report, University of Glasgow, 2005.

[Car06] Raphael Vivacqua Carneiro. Uma modelagem matemático-computacional do sistema biológico de percepção de movimento e velocidade. Master's thesis, Universidade Federal do Espírito Santo, 2006.

[Dur05] Rodrigo Silva Duran. Modelador e visualizador do sistema visual humano. 


\section{Referências Bibliográficas}

Master's thesis, Universidade de São Paulo - Instituto de Ciências Matemáticas e de Computação-ICMC/USP São Carlos, 2005.

[EK00] Thomas Jessell Eric Kandel, James Schwartz. Principles of Neural Science. McGraw Hill, 4th edition, 2000.

[EMS52] H H EMSLEY. Visual Optics. London: Hatton Press ltd, 1952.

[Fer08] Leandro Henrique O. Fernandes. Simulação de fenômenos ópticos e fisiológico do sistema de visão humana. Master's thesis, Universidade de São Paulo - São Carlos, 2008.

[FR97] Eric Dinet Frédérique Robert. An image filtering process based on foveal mechanism simulation. Signals, Systems e Computers, 1997. Conference Record of the Thirty-First Asilomar Conference on, 2:1725-1729, 1997.

[Gas00] Alberto Gaspar. Física 2, ondas, óptica e termodinâmica. Ática, 2000.

[Gol02] E. Bruce Goldstain. Sensation and Perception. Wadsworth, sixth edition, 2002.

[Gul09] A Gullstrand. In the helmholtzs treatise on physiological optics. Hamburg, 1909.

[GW92] Rafael C. Gonzales and Richard E. Woods. Digital Image Processing. AddisonWesley Publishing Company, first edition, 1992.

[HEL09] H. HELMHOLTZ. Physiologic optics. Hamburg, 1909.

[Hos08] Hosp. Hospital de olhos de são paulo. http://www.hospitaldeolhos.net/, 2008. [acesso em 26/02/2008].

[KOO83] A. C KOOIJMAN. Light distribution on the retina of a wide-angle theoretical eye. Opt Soc Amer, 73:1544-1550, 1983.

[LCE64] Howson Lemke C. E. Equilibrium points od bimatrix games. Journals on Applied Mathematics, 12:413-423, 1964. 


\section{Referências Bibliográficas}

[LH97] BRENNAN N. A. LIOU H. Anatomically accurate, finite model eye for optical modeling. Opt. Soc.of Am, A 14:1684-1695, 1997.

[Mar96] David Marr. Vision. Freeman and Company, 1996.

[ME75] Born M. and Wolf E. Principles of optics. Pergamon Press, pages 464-466, 1975.

[MF97] Margaret W. Matlin and Hugh J. Foley. Sensation and Perception. Allyn and Bacon, fourth edition, 1997.

[NC02] Luis Gustavo Nonato and Antônio Castelo. A topological for handling triangle insertion and removal into two-dimensional unstructured meshes. Cadernos de Computação do ICMC-USP/São Carlos, 2(3):221-244, 2002.

[OMB08] Luis Alberto Carvalho Odemir Martinez Bruno. Óptica e Fisiologia da Visão. Roca, 2008.

[Ope08a] OpenGL. Glut and opengl utility libraries. http://www.opengl.org/resources/libraries/, 2008. [acesso em 26/02/2008].

[Ope08b] OpenGL. Open graphics library. http://www.opengl.org, 2008. [acesso em $26 / 02 / 2008]$.

[Pet07] Richard Alan Peters. On the computation of the discrete log-polar transform. Technical report, Vanderbilt University School of Engneering, 2007.

[PP98] Leno S. Pedrotti and Frank L. Pedrotti. Optics and Vision. Prentice-Hall, 1998.

[Rig08] Laboratório Ótico Rigor. O olho humano - anatomia. http://www.laboratoriorigor.com.br/anatomia.html, 2008. [Visitado em: $17 / 01 / 08]$.

[RN83] J. BESCOS R. NAVARRO, J. SANTAMAR. Accommodation-dependent model of the human eye with aspherics. Optical Society of America, A 2:1273$1281,1983$. 


\section{Referências Bibliográficas}

[SB90] Robert Sekuler and Randolph Blake. Perception. McGraw-Hill, second edition, 1990.

[VJT08] Filiberto Pla V. Javier Traver. Log-polar mapping template desing: From tasklevel requirements to geometry parameters. Image and Vision Computing, 26:1354-1370, 2008.

[WG08] Hui Wei and XuDong Guan. The simulation of early vision in biological retina and analysis on its perfomace. In 2008 Congress on Image and Signal Processing. Proceedings of the 2008 IEEE, 2008.

[Woh08] Adrien Wohrer. Model and large-scale simulator of a biological retina, with contrast gain control. PhD in specialized in control, signal and image processing, University of Nice-Sophia Antipolis, 2008.

[WQXz05] Zhang Ke Wang Qi, Li Yan-jun and Xiong Xian-ze. Inverse log polar transformation algorithm based on sub-pixel interpolation. Optoelectronics Letters, 2:1354-1370, 2005.

[YLG80] EL HAGE S.G Y LE GRAND. Physiological optics. Springer-Verlag, 1980.

[Yun04] Hugh D. Yung. Óptica e Fisica Moderna. Addison Weslyy, 2004.

[Zek93] Semir Zeki. A Vision of the Brain. Blackwell Science, 1993. 